University of Louisville

ThinkIR: The University of Louisville's Institutional Repository

$12-2013$

\title{
A multiple objective optimization approach to the decommissioning and dismantling of a nuclear power plant.
}

Sven Sudholt 1974-

University of Louisville

Follow this and additional works at: https://ir.library.louisville.edu/etd

\section{Recommended Citation}

Sudholt, Sven 1974-, "A multiple objective optimization approach to the decommissioning and dismantling of a nuclear power plant." (2013). Electronic Theses and Dissertations. Paper 1401.

https://doi.org/10.18297/etd/1401

This Doctoral Dissertation is brought to you for free and open access by ThinkIR: The University of Louisville's Institutional Repository. It has been accepted for inclusion in Electronic Theses and Dissertations by an authorized administrator of ThinkIR: The University of Louisville's Institutional Repository. This title appears here courtesy of the author, who has retained all other copyrights. For more information, please contact thinkir@louisville.edu. 


\title{
A MULTIPLE OBJECTIVE OPTIMIZATION APPROACH TO THE DECOMMISSIONING AND DISMANTLING OF A NUCLEAR POWER PLANT
}

\author{
By \\ Sven Sudholt \\ MEng. University of Louisville, USA 2010 \\ MSc. University of Weimar, Germany 2005 \\ Dipl.-Ing. (FH) UAS, Oldenburg, Germany 2002
}

\begin{abstract}
A Dissertation
Submitted to the Faculty of the

J.B. Speed School of Engineering of the University of Louisville in Partial Fulfillment of the Requirements for the
\end{abstract}

Doctor of Philosophy

\author{
Department of Industrial Engineering \\ University of Louisville \\ Louisville, Kentucky
}

December 2013 
CCopyright 2013 by Sven Sudholt

All rights Reserved 



\section{A MULTIPLE OBJECTIVE OPTIMIZATION APPROACH TO THE DECOMMISSIONING AND DISMANTLING OF A NUCLEAR POWER PLANT}

By

Sven Sudholt

MEng. University of Louisville, USA 2010

MSc. University of Weimar, Germany 2005

Dipl.-Ing. (FH) UAS, Oldenburg, Germany 2002

A Dissertation Approved on

September 05, 2013

By the following Dissertation Committee:

W. E. Biles, PhD, P.E (Dissertation Director)

Gerald W. Evans, PhD

S. M. Alexander, PhD

W. M. McGinley, PhD 


\section{DEDICATION}

This dissertation is dedicated to my parents Ursula and Theo Sudholt who have given me the vigor and discipline to tackle every task with enthusiasm and determination. Without their encouragement and support this project would not have been made possible. 


\section{ACKNOWLEDGEMENTS}

I would like to express my deep gratitude to Dr. W. E. Biles, my research advisor, for his patient, enthusiastic encouragement and useful critiques of this research work. I would also like to thank the dissertation committee, Dr. Gerald W. Evans, Dr. Suraj M. Alexander and Dr. W. Mark McGinley for their assistance in keeping my progress on schedule.

My grateful thanks go to Ms. Annette Bender (AREVA NP) and Mr. Uwe Kraps (AREVA NP), Dr. Ulrich Rüdt (Siemens AG) and Mr. Dietmar Petersen (Siemens AG) for their everlasting support and help. All of them offered me access to the area of the nuclear technology and provided me very helpful data for my research. This dissertation would not have been possible without you. Many thanks indeed.

I would like to extend my thanks to the support team and hotline of AIMMS 3 (Advanced Integrated Multidimensional Modeling Software), MATLAB, SPSS and the R-statistics blog for their support and helpful training.

Finally, I wish to thank all faculty members of IE department of J.B. Speed School of Engineering - University of Louisville and all participants of the German $\mathrm{PhD}$ program for a lot of inspiring exchanges and discussions. 


\title{
ABSTRACT \\ A MULTIPLE OBJECTIVE OPTIMIZATION APPROACH TO THE DECOMMISSIONING AND DISMANTLING OF A NUCLEAR POWER PLANT
}

\author{
Sven Sudholt
}

September 05, 2013

The complexity, relevance and critical nature of the decommissioning of nuclear power plants (NPP) are of great significance in today's society. Following the catastrophe in Fukushima a shift in the general public's perception of NPP took place throughout the world and in Europe in particular.

In this dissertation interdisciplinary methods will be discussed to identify solutions which take into account the technological complexity and organizational issues involved in the dismantling and decommissioning process of NPP.

Operations research, lean management, simultaneous engineering, cost analysis, multipleobjective optimization, project management, software tools are powerful concepts and methodologies when undertaking the dismantling and decommissioning process of NPP.

Besides the presentation of a wide range of terminological and methodological definitions and technical terms based on the Literature Review, in the dissertation a framework for model development of a Multiple objective optimization problem (MOOP) will discussed focusing on empirical data from a virtual NPP. The theoretical foundation of the framework is at the intersection of two successful approaches used to describe and accomplish similar complex challenges, and the integration of state-of-theart process approaches such as lean management. The procedural conception of the model is mainly leant on the OMEGA model (International Atomic Energy Agency (IAEA) (2008)). Mathematically the model is derived from Jones et. al. (1998). 
Finally the application of the model using different software tools (AIMMS, MATLAB, $\mathrm{R}$ and SPSS) will be presented.

In conclusion the work will be put into a position to venture a critical outlook and discussion for the future of the decommissioning and dismantling processes of NPP.

The main goal of this dissertation is to define the requirements for the optimization of three objectives: Minimizing the total project cost, reducing the safety hazard (risk) and managing project duration. Also a description of how the programming language $\mathrm{R}$ and the AIMMS program interfaces with the OMEGA application and how $\mathrm{R}$ will be used to solve the MOOP will be given. The software Microsoft Project will be leveraged in order to model this objective.

\section{Key words:}

AIMMS - Cost Analysis - Decommissioning of Nuclear Power Plants - Dismantling and Decommissioning process - Lean Management - Math Model - MATLAB - OMEGA Code - MS Project - Multiple Objective Optimization Problem (MOOP) - Project Management - Simultaneous Engineering - SPSS - R the programming language Reactor Internals - Risk management 


\section{TABLE OF CONTENTS}

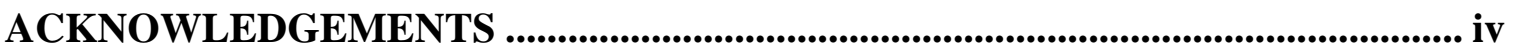

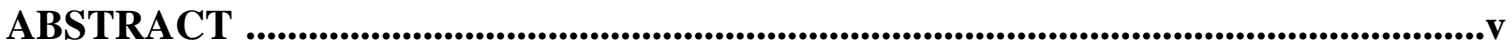

LIST OF TABLES ...................................................................................................... xiv

LIST OF FIGURES .................................................................................................................

1 INTRODUCTION...................................................................................................................1

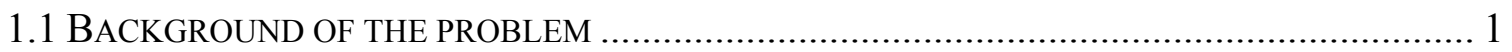

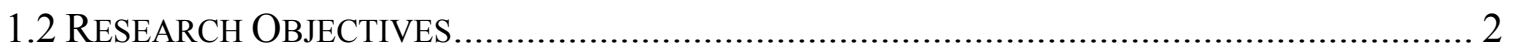

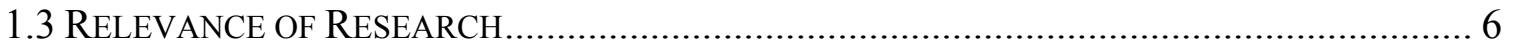

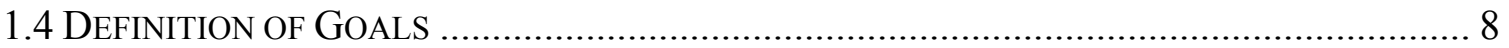

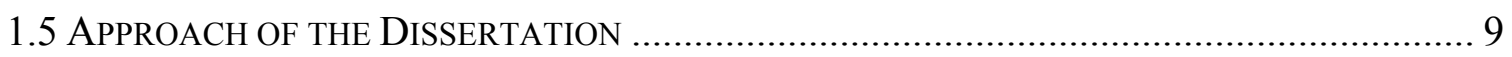

2 LITERATURE REVIEW .................................................................................................10

2.1 Social and Political Perspective...................................................................... 10

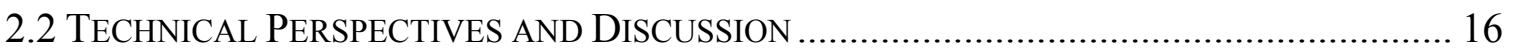

2.2.1 Operational view …….......................................................................... 16

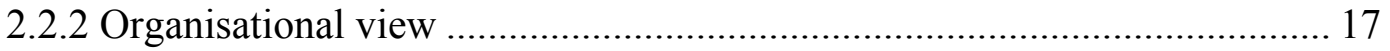

2.2.3 Elements of decommissioning cost estimates ............................................. 18

2.2.4 Approaches for estimating cost.............................................................. 19

2.2.5 Effect of decommissioning strategy on cost .............................................. 19

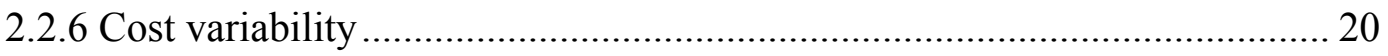

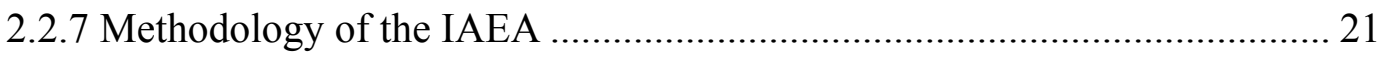

2.2.8 The Principles of decommissioning and cost analysis ................................ 21

2.2.9 'Algorithmization' of the material .............................................................. 22

2.3 Functional AREAS AND ORganizATIONAL STRUCtURES ....................................... 23

2.3.1 Dismantling methods and equipment............................................................. 23

2.3.2 Background / Reasons for selection of applied methods ............................. 24 


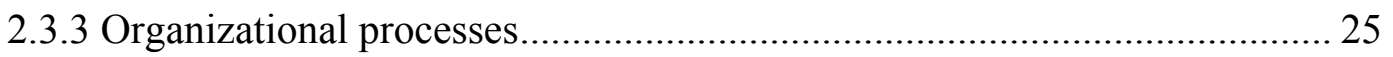

2.4 EConOMIC AND ORgANIZATIONAL PERSPECTIVES .................................................. 27

2.4.1 Planning / Strategy / Organization / Management ........................................ 27

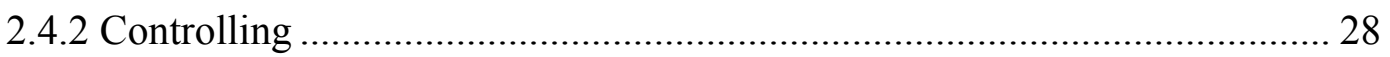

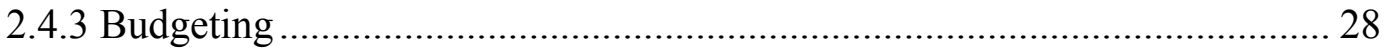

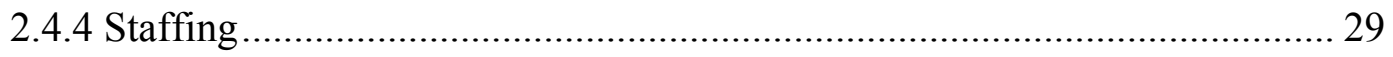

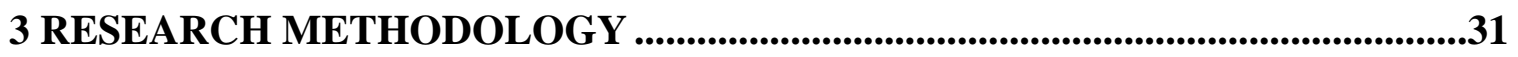

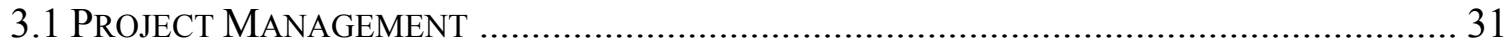

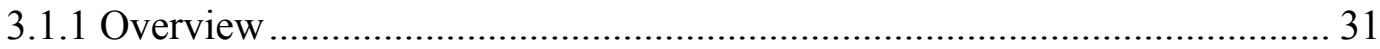

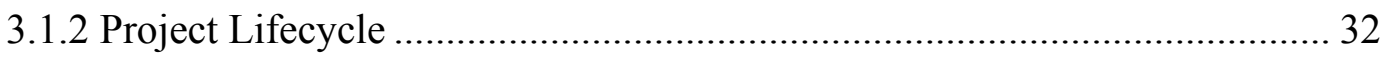

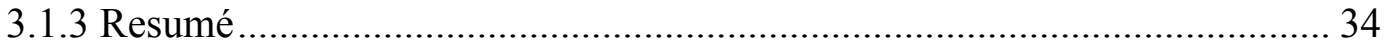

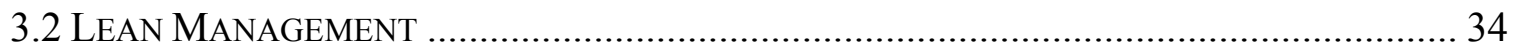

3.2.1 Overview ............................................................................................. 34

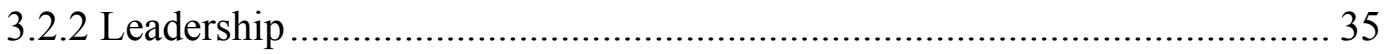

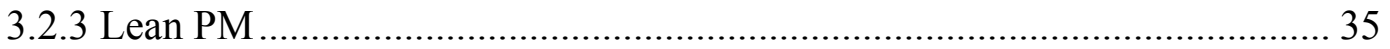

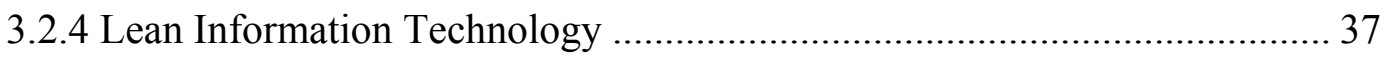

3.2.5 Lean Management Software-Tools .......................................................... 37

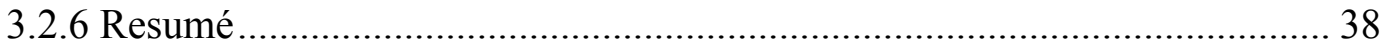

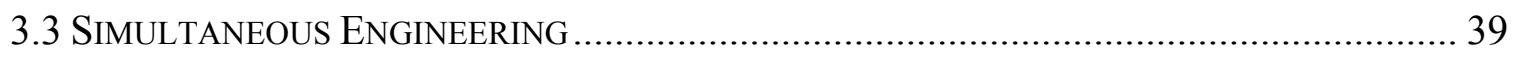

3.3.1 Definition of the term "simultaneous engineering" ........................................ 39

3.3.2 Different approaches to simultaneous engineering ...................................... 39

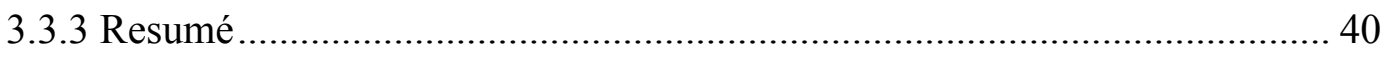

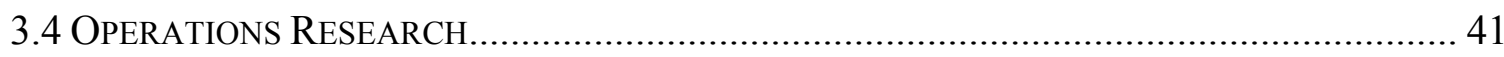

3.4.1 Definitions of the term "OPERATIONS RESEARCH" ............................... 41

3.4.2 Main Characteristics of Operations Research .............................................. 43

3.4.3 Scientific Methodology in OR ................................................................ 45

3.4.4 Features of Operations Research Approach ................................................. 47

3.4.5 Optimization techniques in OR .............................................................. 49

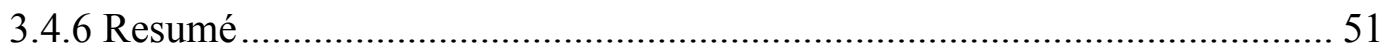

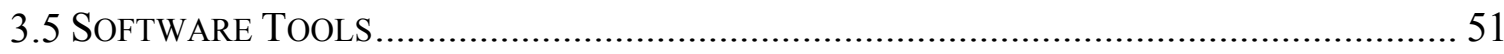

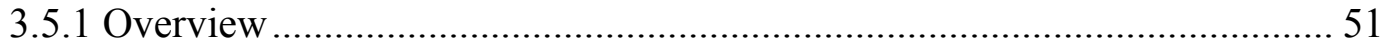


3.5.2 Usage of the Optimization-Tool "AIMMS" ................................................ 52

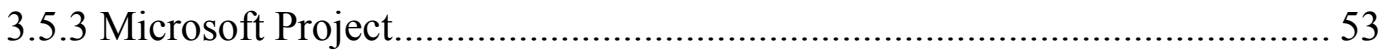

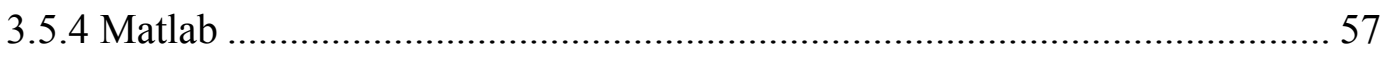

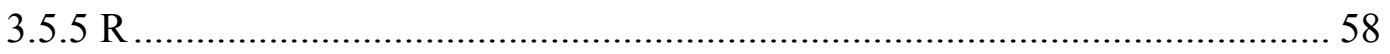

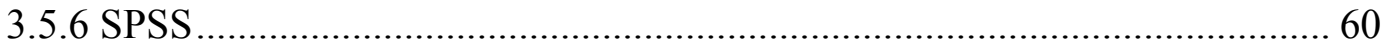

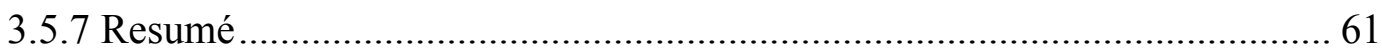

4 FRAMEWORK OF MODEL DEVELOPMENT.......................................................62

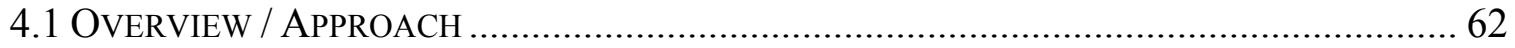

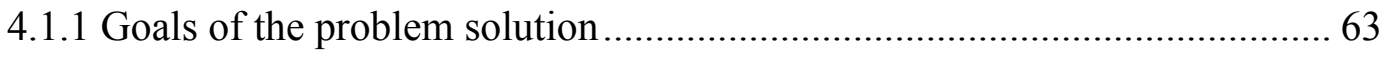

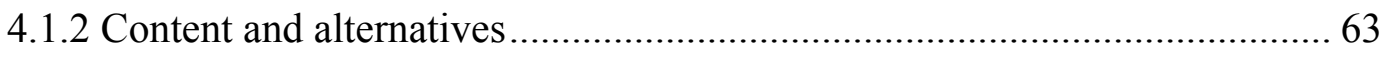

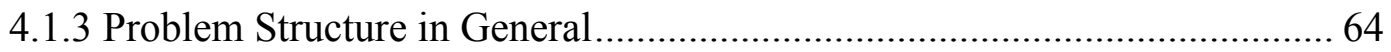

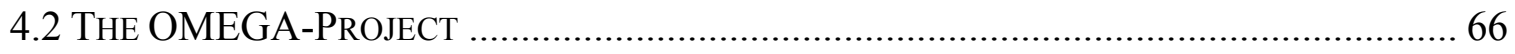

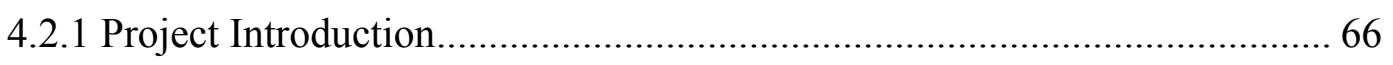

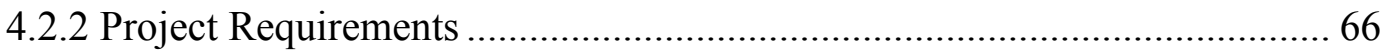

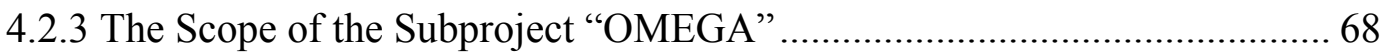

4.2.4 The OMEGA code and its applications …………………………............. 70

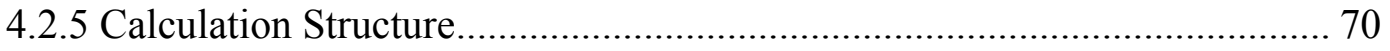

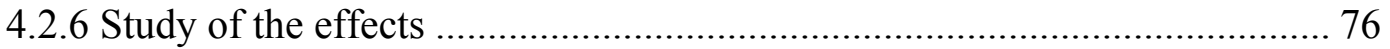

4.2.7 OMEGA model components taken into account ......................................... 76

4.3 DeCOMMISSIONING COST ESTIMATING AND FUNDING APPROACHES ............................. 77

4.3.1 Stages for successive estimates and calculations for decommissioning ...... 78

4.3.2 Cost categories for the decommissioning of NPP ....................................... 79

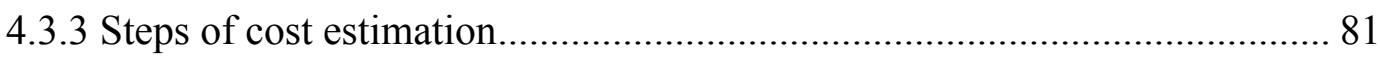

4.3.4 Approach for costing model for research reactors ....................................... 83

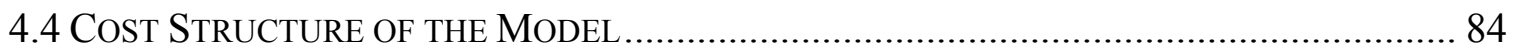

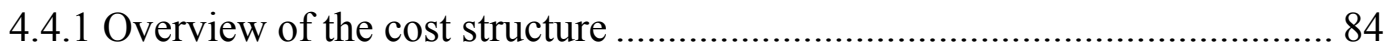

4.4.2 Product function for a particular activity ……………………..................... 87

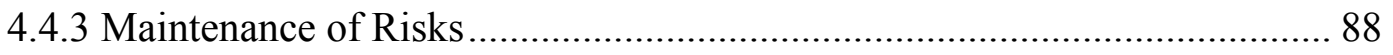

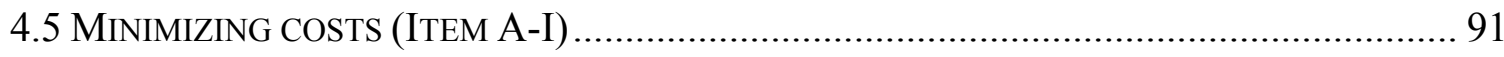

4.6 MiNIMIZING THE CONTINUED RISK OF STORAGE (ITEM A-II) ........................................ 94

4.7 Minimizing Project DuRation (Item A-III) ....................................................... 97 


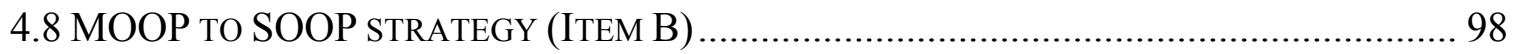

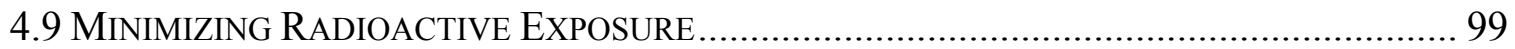

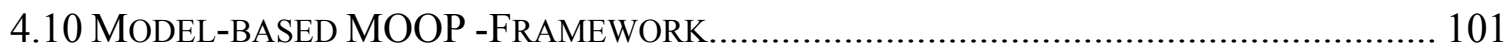

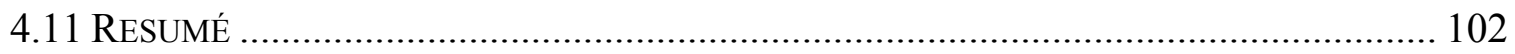

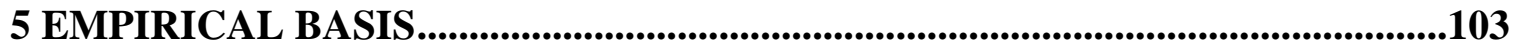

5.1 CASE Study: VirTual OR ReAl NPP (OVERVIEW) .............................................. 103

5.2 PROJECT SCHEDULE OF THE DisMANTLING OF REACTOR INTERNALS -

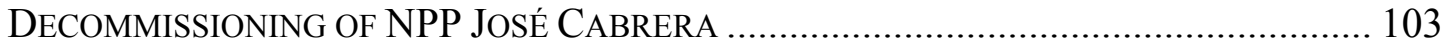

5.3 CENTRAL PROCESSES OF THE REQUIREMENT ANALYSIS............................................. 105

5.4 CUTTING TECHNIQUES AND MATERIALS IN THE PROJECT ........................................... 106

5.5 OVERVIEW OF COMPONENTS AND MASSES TO BE DISMANTLED AND PACKAGED ....... 108

5.5.1 Upper Core Internals, Lower Core Internals, Core Support Structure....... 108

5.5.2 Reactor Opening Deck, Spent Fuel Pool and Reactor Cavity.................... 109

5.5.3 Equipment for Cutting, Disassembly \& Handling of RVI Components.... 111

5.5.4 Packaging of Cut Segments ...................................................................... 113

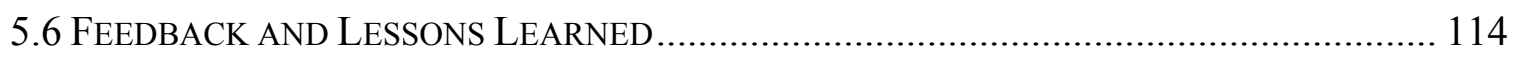

5.7 Preliminary EstimateS For Quantities AND Physical …………………….... 115

6 APPLICATION AND DISCUSSION OF RESULTS.................................................117

6.1 APPlication OF THE MOdel using AIMMS, MATLAB, R, SPSS (OVERVIEW) ...... 117

6.2 APPLICATION OF THE MODEL USING MS PROJECT ................................................... 117

6.3 APPLICATION OF THE MODEL IN AIMMS …………………………………….... 129

6.3.1 Declaration of the model......................................................................... 129

6.3.2 Specification of the Minimization of the risk of storage ………................ 131

6.3.3 Specification of the Constraint for Minimization of the risk of storage .... 133

6.3.4 Attributes of sets, variables, parameters, constraints and mathematical

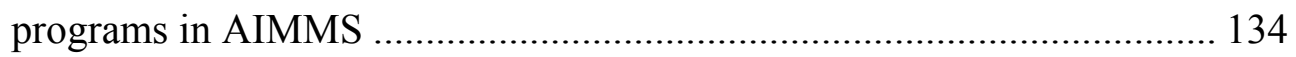

6.3.5 Creating a Database Table ………............................................................ 135

6.3.6 Executing, Initializing, Terminating the Model and AIMMS Math Program

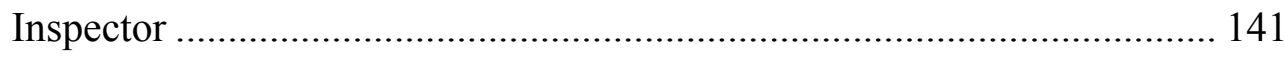

6.3.7 MS-Project - Aided Application of the framework (Item C) .................... 142

6.4 APPLICATION OF THE MODEL IN MATLAB ……………......................................143 
6.5 APPLICATION OF THE MODEL IN R 145

6.5.1 Introduction of the function constrOptim() ......................................... 146

6.5.2 Applying the function constrOptim() to the model............................... 147

6.5.3 Usage of the TunePareto-Package ...................................................... 148

6.5.4 Usage of the optimize()-Function.................................................. 150

6.6 APPLICATION OF THE MODEL IN SPSS ............................................................ 178

7 SUMMARY, CONCLUSIONS AND RECOMMENDATIONS ..........................179

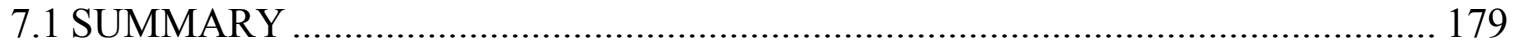

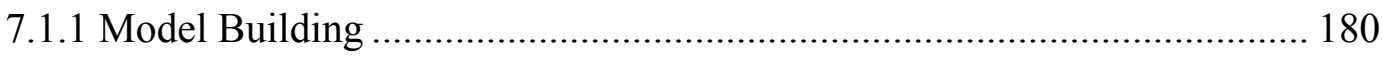

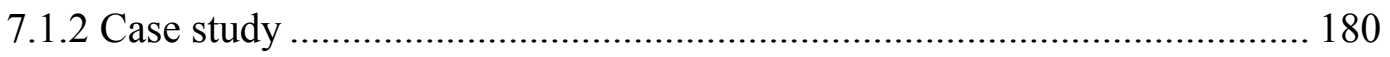

7.1.3 Application of software tools ......................................................... 180

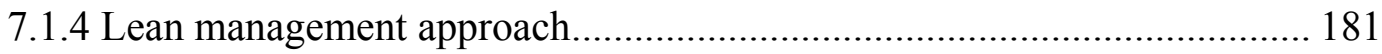

7.1.5 Simultaneous engineering approach .............................................. 182

7.1.6 Application of operations research methods ......................................... 182

7.1.7 Evaluation of the numerical results................................................... 183

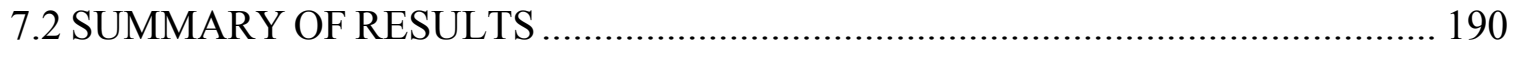

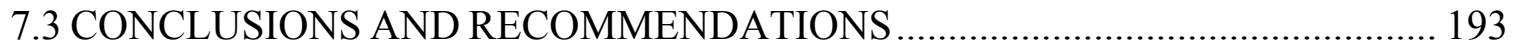

7.3.1 Contribution to the body of knowledge ............................................ 197

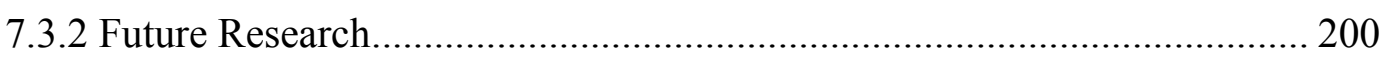

REFERENCES ..............................................................................................................................204

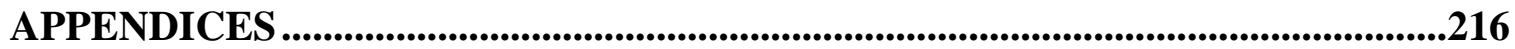

APPENDIX 1 -MS PROJECT RESSOURCE PLAN ........................................ 216

APPENDIX 2 - MS PROJECT CALENDAR VIEW - JANUARY 2014 .............. 217

APPENDIX 2 A - MS PROJECT CALENDAR VIEW - FEBRUARY 2014............ 218

APPENDIX 2 B -MS PROJECT CALENDAR VIEW - MARCH 2014 .................. 219

APPENDIX 2 C - MS PROJECT - CALENDAR VIEW - APRIL 2014 .................. 220

APPENDIX 2 D - MS PROJECT - CALENDAR VIEW - MAY 2014 .................... 221

APPENDIX 2 E - MS PROJECT - CALENDAR VIEW - JUNE 2014.................... 222

APPENDIX $2 \mathrm{~F}$ - MS PROJECT - CALENDAR VIEW - JULY 2014.................... 223

APPENDIX $2 \mathrm{G}$ - MS PROJECT - CALENDAR VIEW - AUGUST 2014 .............. 224

APPENDIX $2 \mathrm{H}$ - MS PROJECT - CALENDAR VIEW - SEPTEMBER 2014 ....... 225 
APPENDIX 2 I - MS PROJECT - CALENDAR VIEW - OCTOBER 2014.............. 226

APPENDIX $2 \mathrm{~J}$ - MS PROJECT - CALENDAR VIEW - NOVEMBER 2014 ......... 227

APPENDIX $2 \mathrm{~K}$ - MS PROJECT - CALENDAR VIEW - DECEMBER 2014........... 228

APPENDIX 2 L - MS PROJECT - CALENDAR VIEW - JANUARY 2015 .............. 229

APPENDIX $2 \mathrm{M}$ - MS PROJECT - CALENDAR VIEW - FEBRUARY 2015 ……... 230

APPENDIX $2 \mathrm{~N}$-MS PROJECT - CALENDAR VIEW - MARCH 2015 ………….... 231

APPENDIX 3 - MS PROJECT - NETWORK DIAGRAM (EXCERPTS) .............. 232

APPENDIX 3 A - MS PROJECT - NETWORK DIAGRAM (EXCERPTS) ............. 233

APPENDIX 3 B - MS PROJECT - NETWORK DIAGRAM (EXCERPTS) ............. 234

APPENDIX $4-$ VERPACKUNGSPLÄNE (PACKAGING PLANS OF CUT

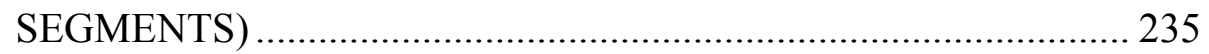

APPENDIX 4 A -PACKAGING PLAN OF CUT SEGMENTS ………………….... 236

APPENDIX 4 B -PACKAGING PLAN OF CUT SEGMENTS …………………..... 237

APPENDIX 4 C -PACKAGING PLAN OF CUT SEGMENTS …………………... 238

APPENDIX 4 D -PACKAGING PLAN OF CUT SEGMENTS ………………….... 239

APPENDIX 4 E -PACKAGING PLAN OF CUT SEGMENTS ………………….... 240

APPENDIX $4 \mathrm{~F}$-PACKAGING PLAN OF CUT SEGMENTS ................................. 241

APPENDIX $4 \mathrm{G}$-PACKAGING PLAN OF CUT SEGMENTS …………………..... 242

APPENDIX $4 \mathrm{H}$-PACKAGING PLAN OF CUT SEGMENTS …………………...... 243

APPENDIX 4 I -PACKAGING PLAN OF CUT SEGMENTS ………………….... 244

APPENDIX 5 -R-CODE-PARETO OPTMIZATION ......................................... 245

APPENDIX 6 -RSTUDIO - WORKSPACE ……………………................... 250

APPENDIX 7 -RSTUDIO-PARETO-OPTIMUM-PLOT .................................... 251

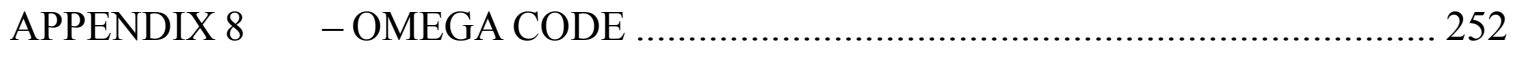

APPENDIX 8 A -PRINCIPAL SCHEME OF DECOMMISSIONING

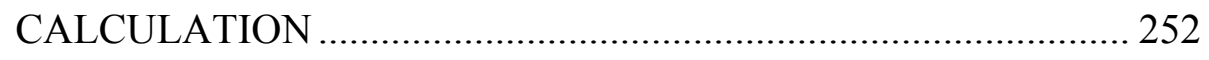

APPENDIX 8 B - GROUPS OF CALC. PARAMETERS ………………………...... 253

APPENDIX 8 C -BASIC GROUPS OF DATA...................................................... 253

APPENDIX 8 D - GENERAL PROCEDURES FOR EVALUATION OF

DECOMMISSIONING PARAMETERS ......................................... 254 


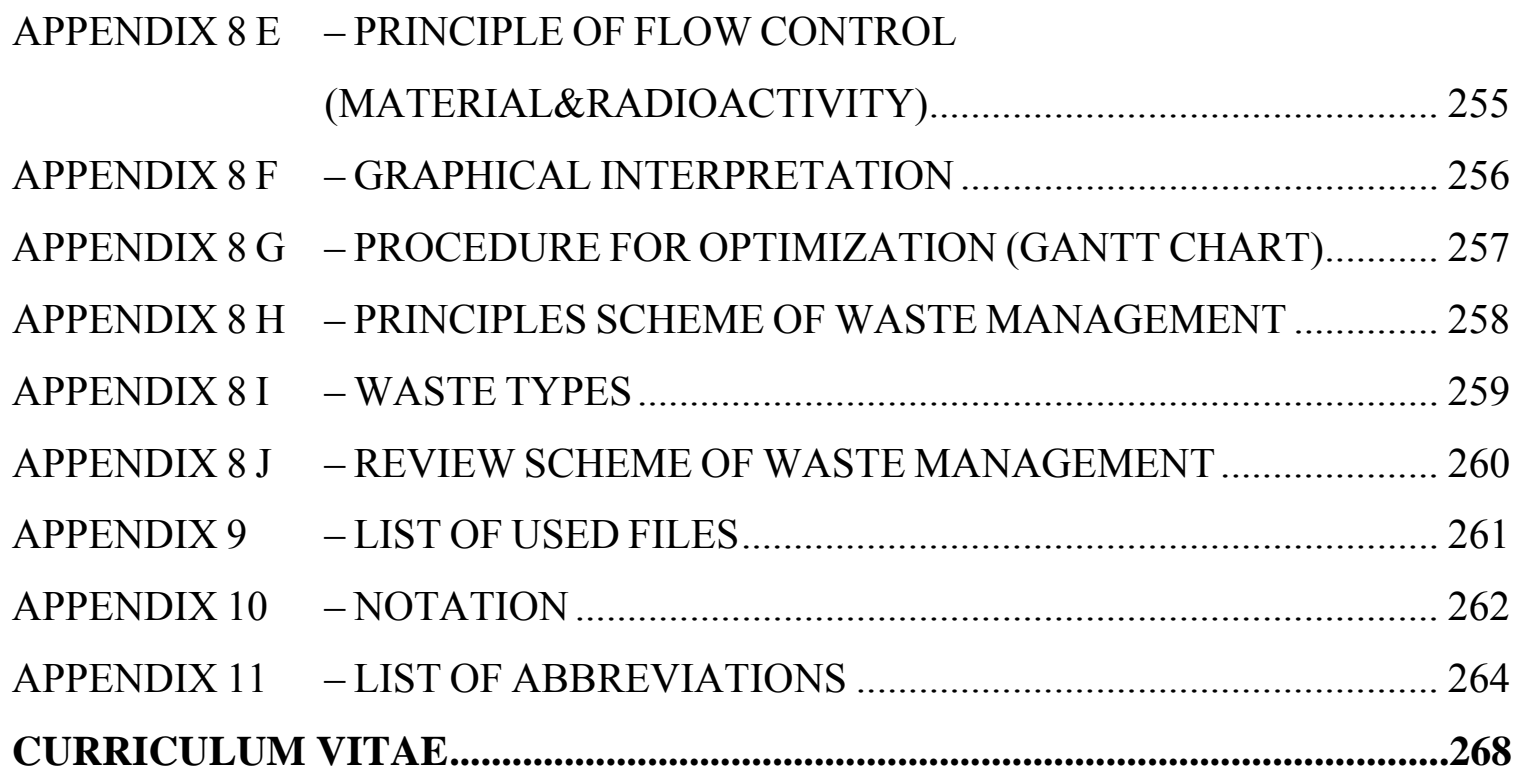




\section{LIST OF TABLES}

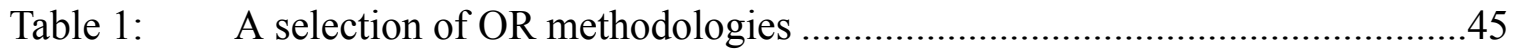

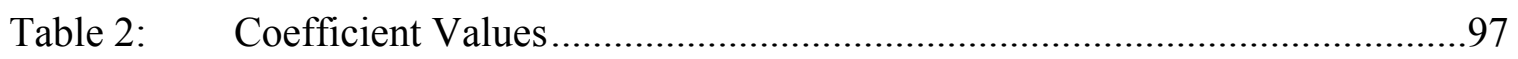

Table 3: Table of estimated personnel requirements..............................................105

Table 4: Characteristics of applicable cutting techniques ....................................106

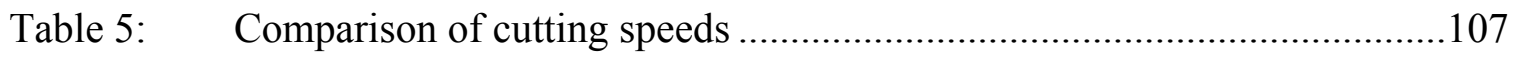

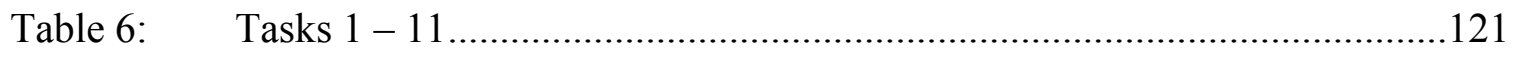

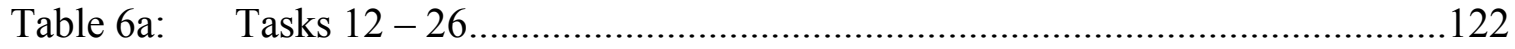

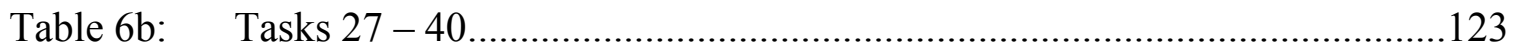

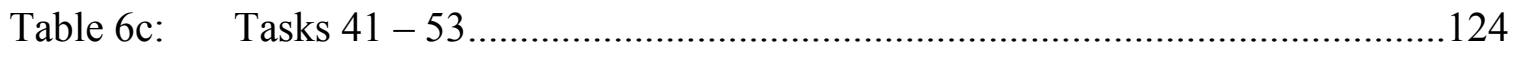

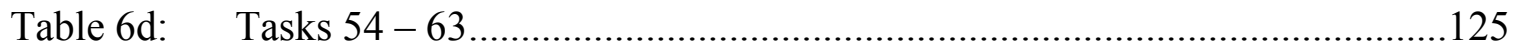

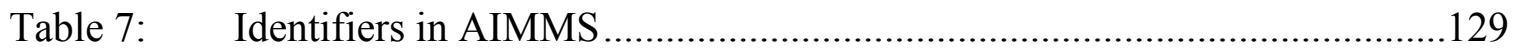

Table 8: $\quad$ Virtual Database Table (Template) I.....................................................137

Table 8a: Virtual Database Table (Template) II ...................................................138

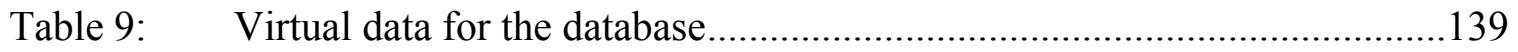

Table 10: $\quad$ List of tasks in AIMMS in MS Project 2013 ........................................142

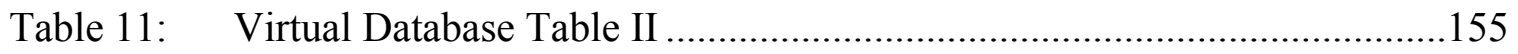

Table 12: Interdependencies between parameters, variables and functions in the

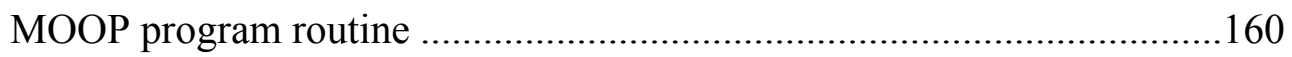

Table 13: Interdependencies between functions and their tasks in the MOOP

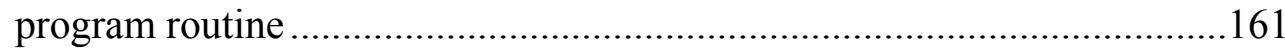

Table 14: Comparing the R-MOOP with worst case and average case scenarios......183

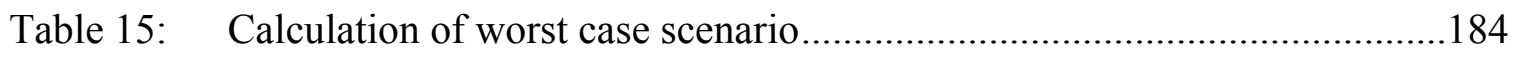

Table 16: Comparing the R-MOOP with the worst case and average case scenarios 188

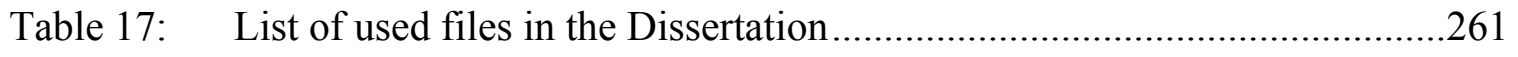




\section{LIST OF FIGURES}

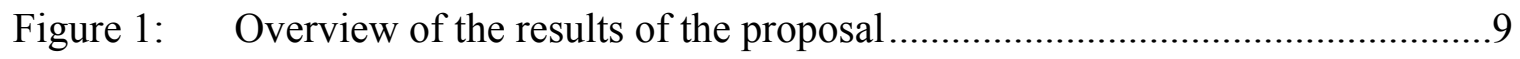

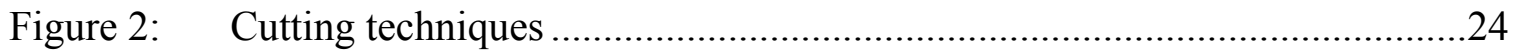

Figure 3: Applicable Cutting Techniques .............................................................25

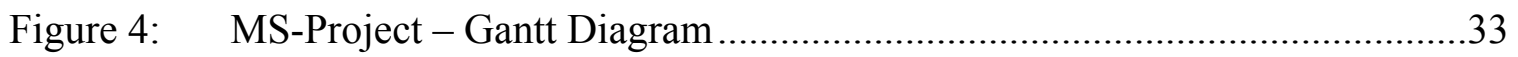

Figure 5: Example of an executive standardized cost calculation structure ................73

Figure 6: Principal phases of development of the inventory database and generating of the calculation structure .................................................... 74

Figure 7: Changes of amounts of waste in the states storage, treatment and disposal.85

Figure 8: Project schedule extract with the ZIRP scope .......................................104

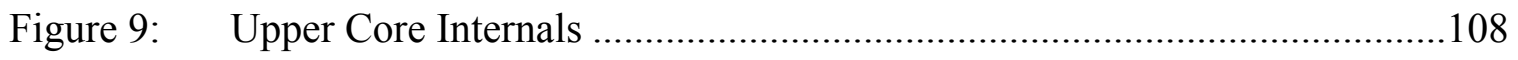

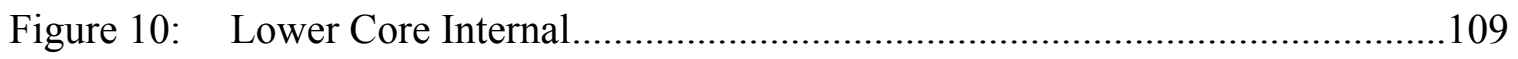

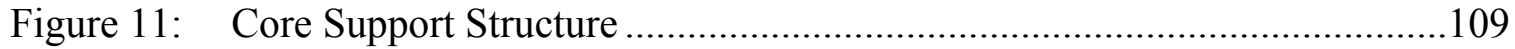

Figure 12: Top View on the Reactor Operating Deck .........................................110

Figure 13: Occupation of the Spent Fuel Pool ..................................................... 110

Figure 14: Occupation of the Reactor Cavity ........................................................111

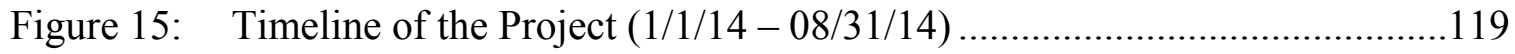

Figure 15a: Timeline of the Project $(9 / 1 / 14-3 / 26 / 15)$...........................................120

Figure 16: MS Project - Phases "Preliminary Analysis" and "Planning and Design" 127

Figure 17: MS Project - Phases "Execution" and "Monitoring and Controlling".......128

Figure 18: Adding the identifiers to the model ...................................................130

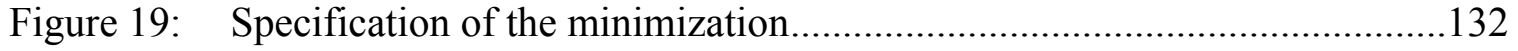

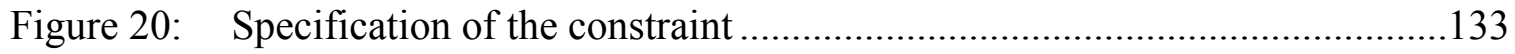

Figure 21: Creating a Database Table in AIMMS .................................................136

Figure 22: AIMMS-Data Management Setup .....................................................139

Figure 23: Write a file min_npp_func.m for the objective function ..........................143

Figure 24: Write a file constraint_npp.m for the constraints ...................................144 
Figure 25: Invoke constrained optimization routine .145

Figure 26: Matrix view of the virtual database table .158

Figure 27: UML-Diagram of the R-MOOP program routine and interactions between functions .162

Figure 28: Generating results in the dissertation 191

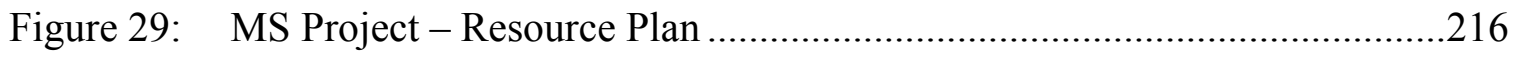

Figure 30: MS Project - Calendar View January 2014 .........................................217

Figure 30a: MS Project - Calendar View February 2014 ......................................218

Figure 30b: MS Project - Calendar View March 2014 ...........................................219

Figure 30c: MS Project - Calendar View April 2014 ............................................220

Figure 30d: $\quad$ MS Project - Calendar View May 2014 ................................................221

Figure 30e: MS Project - Calendar View June 2014 ..............................................222

Figure 30f: MS Project - Calendar View July 2014 ...........................................223

Figure 30g: MS Project - Calendar View August 2014 ...........................................224

Figure 30h: MS Project - Calendar View September 2014 ......................................225

Figure 30i: MS Project - Calendar View October 2014 .......................................226

Figure 30j: MS Project - Calendar View November 2014 .....................................227

Figure 30k: MS Project - Calendar View December 2014 ......................................228

Figure 301: MS Project - Calendar View January 2015 ......................................229

Figure 30m: MS Project - Calendar View February 2015 .....................................230

Figure 30n: MS Project - Calendar View March 2015 ......................................... 231

Figure 31: MS Project - Network Diagrams (Excerpts) ...................................... 232

Figure 31a: MS Project - Network Diagrams (Excerpts) ......................................233

Figure 31b: MS Project - Network Diagrams (Excerpts).......................................234

Figure 32: "Verpackungspläne" (packaging plans of cut seg.)................................. 235

Figure 32a: Verpackungsplan - SA-G-362102 - 0001_D - SSFE Stifte + SSFE

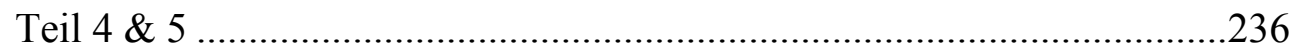

Figure 32b: Verpackungsplan - SA-G-362102 - 0051_A - OKG Mantel Ring 4.......237

Figure 32c: Verpackungsplan - SA-G-362102 - 0056_C - Tragstange Teil 3 ...........238

Figure 32d: Verpackungsplan - SA-G-362102 - 0067_B - Gitterplatte .....................239 
Figure 32e: Verpackungsplan - SA-G-362102 - 0074_B - Gitterplatte

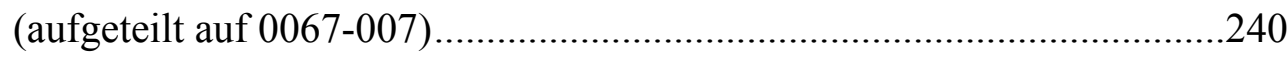

Figure 32f: Verpackungsplan - SA-G-362102 - 0155_A - OKG Mantel Ring 3.......241

Figure 32g: Verpackungsplan - SA-G-362102 - 0161_D - SSFE Teil 3 ....................242

Figure 32h: Verpackungsplan - SA-G-362102 - 0167_C - Tragstangen Teil 2 .........243

Figure 32i: Verpackungsplan - SA-G-362102 - 0183_F - OKG Aufbauten ..............244

Figure 33: R-Code - Pareto-Optimization ......................................................... 249

Figure 34: RStudio - Screenshot of the Workspace …........................................... 250

Figure 35: RStudio-Pareto-Optimum-Plot-DominationGraph.............................. 251

Figure 36: Principal scheme of the decommissioning calculation code OMEGA..... 252

Figure 37: Principle of the material and radioactivity flow control as implemented in OMEGA code............................................................. 255

Figure 38: Graphical interpretation of main steps of the interactive work with OMEGA code..................................................................... 256

Figure 39: Procedure for the optimization of decommissioning options using a

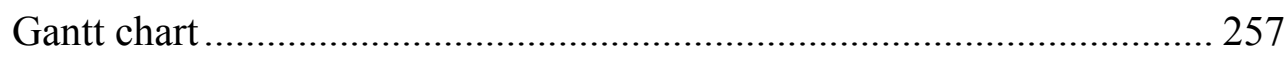

Figure 40: Principle scheme of the waste management in the OMEGA code........... 258

Figure 41: Review scheme of waste management in the OMEGA code .................... 260 


\section{INTRODUCTION}

\subsection{Background of the problem}

The primary goal in the decommissioning of NPP is to reduce the total financial expenditure while at the same time minimizing operational risk. These two factors are evaluated from the point of view of ${ }^{1}$ :

- the government,

- accounting,

- $\quad$ valuation, and

- investment perspectives.

From a governmental perspective, a system of checks and balances is necessary in order to reduce the risk of conflict of interest. Establishing a framework based on the independence of involved parties/stakeholders avoids potential situations in which the operator obtains the power to use monetary funds for alternative/deviant purposes. In order to meet qualitative characteristics of modern accounting and to improve its accountability, the International Financial Reporting Standards (IFRS) must be applied with EU interpretation and guidance. For valuation to be given, a comprehensive risk assessment to allow transparency is indispensable. Establishing guidelines for financial asset management through high investment performance must respect the prudence principle through a guarantee scheme ${ }^{2}$.

According to legislative proposals, the decommissioning funds should not be solely based on the EURATOM Treaty but also on the Treaty of the European Communities, together

\footnotetext{
${ }^{1}$ see Irrek (2007), p. VIIff.

${ }^{2}$ see Irrek (2007), p. VIIIff.
} 
with articles 95 and 175 on environmental grounds. Recommendations are made in this thesis to guarantee the availability of sufficient funds to Member States, as well as further harmonization at the EU level. In order to increase transparency, it is advised that information sharing and reporting be encouraged across the $\mathrm{EU}^{3}$.

A regulator normally undertakes the licensing issue in the process of decommissioning. To achieve good results, it is highly recommended that the regulator work together with the operators. But it is also very important to make a clear distinction between the operators and the decommissioning responsibilities in case a situation arises in which a plant has to be shut down and the operators insist on operation ${ }^{4}$.

Before an active decommissioning can be realized, the safety case has to report on the risks and dangers and therefore a regulator's evaluation is required. Good quality safety management can save time and prevent complications. Immediately after the shutdown, the disposal of spent fuel has to be dealt with in order to reduce risk. However, during the dismantling, decontamination and disposing of waste unexpected risks can appear ${ }^{5}$.

\subsection{Research Objectives}

In order to deal with the inherent complexity associated with the decommissioning of NPP, the objective of this research is to take into account the "hard facts" such as

- Functional,

- Economic,

- Technical / Operations research (OR)-based issues, such as multiple-objective optimization (minimizing total costs, project time and the potential for radiation exposure).

\footnotetext{
${ }^{3}$ see Irrek (2007), p. VIIIff.

${ }^{4}$ see IAEA (2004a), p. 5

5 see IAEA (2004a), p. 5
} 
The tools that will be investigated toward accomplishing these objectives are the following:

- Project management,

- Lean management,

- Simultaneous engineering,

- Mathematics, and

- Applied informatics.

The decommissioning of a NPP is a complicated process, which involves activities like ${ }^{6}$ :

- detailed examination of the decontamination and dismantling of a power plant, equipment and facilities,

- demolition of buildings and structures,

- $\quad$ site remediation, and

- management of residual waste and other materials.

All of these activities help to supply op-statutory provisions and to ensure the health and safety of the operating staff, the public and protect the environment. To guarantee that the decommissioning process is carried out in a secure and cost-efficient manner, careful planning and management is $\mathrm{key}^{7}$. Until the mid 1980s, these types of projects were undertaken infrequently. Meanwhile many documents which delivered guidelines/best practices on technologies, strategy, safety, waste management and regulation were being published by the International Atom Energy Agency (IAEA), US Nuclear Regulatory Commission (NRC), the Department of Energy (DOE), the Organization of Economic Co-operation and Development (OECD), the Nuclear Energy Agency (NEA) and the

\footnotetext{
${ }^{6}$ see IAEA (2004a), p. 1

${ }^{7}$ see IAEA (2004a), p. 1
} 
European Commission. Each year, a large amount of information dealing with decommissioning is circulated and presented by specialists at international conferences ${ }^{8}$.

OMEGA is a program performing decommissioning assessments to reach iteratively a desired level of accuracy ${ }^{9}$, by Daniska et al 2008. OMEGA will be used as a source of knowledge to develop a model and its implementation in this dissertation, as described later.

With a myriad of issues that need to be addressed, it is very important that there be a manager who takes responsibility for and spearheads a suitable decommissioning roadmap. If there is no special manager, it is necessary to engage specialists, consultants, or contractors, e.g. through outsourcing ${ }^{10}$.

Defueling is an ever growing problem due to a lack of storage capacity. Consequently, spent fuel is sometimes stored in potentially unsafe storage units. Waste management is a key factor within the decommissioning roadmap and can reduce dismantling and decontamination activities when there are no adequate precautions. The waste has to be conditioned and stabilized to reduce risks of degradation, dispersion and unauthorized removal ${ }^{11}$.

For a professional dismantling of nuclear installations subsequent work phases must be defined and adhered to including:

- Project preparation (background determination, project development and strategic planning),

- Pre-scheduling, design and approval planning,

- Execution preparation (execution planning, assignment preparation and participation during the assignment),

- Execution (project monitoring),

- Project conclusion (project support and documentation).

${ }^{8}$ see IAEA (2004a), p. 1

9 see IAEA (2008), p. 4

${ }^{10}$ see IAEA (2004a), p. 5

${ }^{11}$ see IAEA $(2004 \mathrm{a})$, p. 5 
Based on these requirements the focus of this dissertation will center on three items $(\mathrm{A}-\mathrm{C})$ :

A) The scope is limited to three objectives:

1. Minimizing total project cost $f_{1}(X)$,

2. Minimizing safety hazard (risk) $\mathrm{f}_{2}(\mathrm{X})$, and

3. Minimizing project duration $\mathrm{f}_{3}(\mathrm{X})$.

A multiple-objective optimization problem (MOOP) is created by these goals. In this dissertation it will be stated, how each objective is quantified, identifying the variables affecting each objective function and the ranges for those variables, or $a_{i} \leq x_{i} \leq c_{i}, I=1, \ldots, n$ and the form of the function $f_{j}$ $(\mathrm{X}), \mathrm{j}=1, \ldots, \mathrm{m}$.

B) Using the MOOP to single-objective optimization problem (SOOP) strategy, one of the above objective functions $\mathrm{f}_{\mathrm{j}}(\mathrm{X})$ will be minimized while holding the other two variables under a bounding value $d_{b}$. This MOOP to SOOP process will be repeated over several iterations in an attempt to identify a convergent solution.

C) A description of how the AIMMS program interfaces with the OMEGA application, and how AIMMS will be used to solve the MOOP will be provided. Microsoft Project will be leveraged, in order to model this item.

The modeling and implementation of these items and objectives is detailed described in chapter 4. The MOOP created by the three objectives (A-I, A-II and A-III) is based on the model by Jones et.al 1998 which is mathematically derived in chapter 4, 4.2. The three objectives are formulated in chapter 4, 4.5 (A-I), 4.6 (A-II) and 4.7 (A-III). According to item $B$ the minimization of $f_{2}(X)$ is formulated using the MOOP to SOOP strategy in chapter 4, 4.8. The description of how the AIMMS program interfaces with the model leant on Jones et. al 1998 and the OMEGA model is presented in chapter 6, 6.3 (see item C). Microsoft Project is used in order to model the third item (see C) and also to fulfill 
the main goal of professionally solving the work phases of the dismantling of nuclear installations (see chapter 6, 6.2 and 6.3.7).

\subsection{Relevance of Research}

The relevance of this study is pertinent in the current economy when we consider that the organisation of the energy supply and the optimization of the industry's cost management and project management are the foundations for high productivity and efficiency.

More than half of the reactors in Germany are 20 years old or older ${ }^{12}$.

Over the course of the next 20 years these reactors will reach the end of their technical and economic life span. Most of the older nuclear reactors were built with an average life expectancy of 40 years.

Interwoven within this process is the enormously complicated situation of technically and financially closing down a NPP, given that most of the buildings and tools are radioactively contaminated. The necessary shut down and disassembly of the plants are only made possible when extensive precautionary measures are taken. One of the most important questions faced is what to do with the radioactively contaminated material. Infested building blocks and the nuclear fuel system are hard to handle. Due to their permanent nuclear contamination, they are a serious threat to mankind and the environment. These parts have to be isolated from the biosphere until radioactivity reaches a harmless level. An important question is, who will finance this process? In Germany alone, the total cost of shut down and waste disposal is estimated at 30 billion Euros. This is the amount of financial reserves for shut down and waste disposal by German power plant operators ${ }^{13}$.

The European Commission foresees a total of 36 billion $€$, with $45 \%$ reserved for shutdown and $55 \%$ for waste disposal. These reserves have been integrated into the electricity price. According to RWE AG the margin of waste-costs are 0.27 Cent per

\footnotetext{
12 see Bachelorarbeit (2010), Kosten-Nutzenanalyse der Nutzung von Atomenergie, p. 15; compare with Weßelmann (2007)

${ }^{13}$ see annual reports of E.ON AG (2006); RWE AG annual report 2006, EnBW annual report (2006), Vattenfall Europe annual report (2006)
} 
kWH. The Verband der Elektrizitätswirtschaft (VDEW) states that the price for shut down and waste-costs is 0.65 Cent per $\mathrm{kWH}^{14}$.

The average cost for nuclear waste disposal is 1.2 billion Euro per NPP for final storage methods and 3.4 billion Euro for reprocessing methods ${ }^{15}$.

For shut down of the Stade NPP, the following costs were estimated: 500 million Euros for demolition of the building, 750 million Euros for the disposal of the boiling water reactor and 630 million Euros for the pressurized water reactor ${ }^{16}$.

The price for the disposal of the boiling water reactor is higher because it has higher contamination levels than the pressurized water reactor. Not only is the question of cost important, but the question of timing is likewise pivotal because a shut-down of the majority of NPP and a final sealing of radioactive waste will likely take up to 70-80 years. This calculation is relevant only if no other NPP are being built ${ }^{17}$.

In order to give an objective, correct and dispassionate overview of the relevancy of the areas of the decommissioning and dismantling of NPP, in the following chapters the relevancy will be examined further from numerous perspectives, such as the societal and political perspective. After all, it seems to be highly valuable to use an interdisciplinary thought process, combining many approaches such as lean management and simultaneous engineering, the use of expert knowledge of project management, operations research techniques, applied informatics etc.

The complexity of this topic is likewise enormous because risk factors must be conceptualized and handled from the aforementioned interdisciplinary perspective. There is a great need for a systematic approach based on multidisciplinary conditions. For this reason the broad spectrum of these objectives will be focused upon in chapter 2 (Literature Review) and chapter 3 (Research Methodology).

\footnotetext{
${ }^{14}$ see Bachelorarbeit (2010), Kosten-Nutzenanalyse der Nutzung von Atomenergie, p. 16; compare with Richmann (1997)

${ }^{15}$ see Bachelorarbeit (2010), Kosten-Nutzenanalyse der Nutzung von Atomenergie, p. 16; compare with Hennicke et al (2000)

${ }^{16}$ see Bachelorarbeit (2010), Kosten-Nutzenanalyse der Nutzung von Atomenergie, p. 16; compare with Hennicke et al. (2000)

${ }^{17}$ see BFS (2007)
} 


\subsection{Definition of Goals}

The subsequent activities defined in this dissertation are as follows:

(1) Research of up-to-date empirical data for designing a virtual NPP,

(2) Description of empirical data within the framed model,

(3) Formulation of a procedure model, based on the given NPP,

(4) Capturing the project structure, processes and project time management assisted by project management tools (e. g. MS Project),

(5) Integration of the data basis and the process structure with the programming language $\mathrm{R}$ and with the operations research tool AIMMS,

(6) Application of state-of-the-art optimization techniques (MOOP) to the given empirical data,

(7) Assessment and evaluation of results and discussion.

The goal of this dissertation is to elaborate the aforementioned next steps. In the proposal, concepts, methods and tools were presented that were deemed helpful in completing the project's goals.

The goal is to select the most significant concepts, methods and tools. Following an indepth evaluation, the selected concepts, methods and tools will be integrated in a new model. This model aims to be a unique framework in order to reduce the gap between market needs and a state-of-the-art academic approach (see chapter 4). 


\subsection{Approach of the Dissertation}

The next figure gives an overview of each step defined in this proposal (see Figure 1).

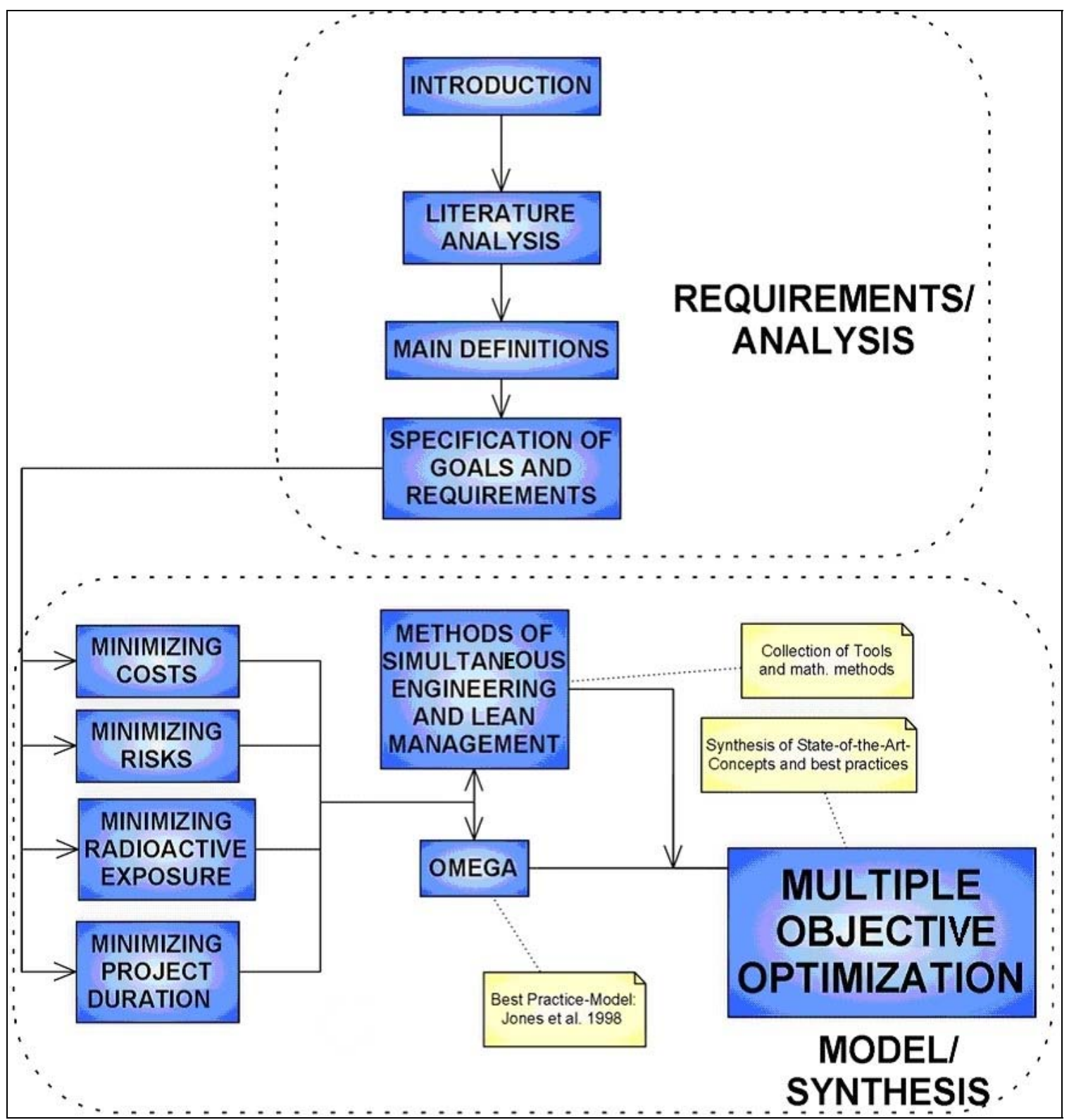

Figure 1: Overview of the results of the proposal 


\section{LITERATURE REVIEW}

\subsection{Social and Political Perspective}

In the area of decommissioning Bayliss/Langley (2003) consider waste management and environmental remediation. Bonavigo et al. (2010) examine the contamination spread during decommissioning of a NPP. Bochud et al. (2009) use Monte Carlo Simulation of a Clearance Box Monitor for NPP Decommissioning. Bushart et al. (2010) investigate the program change management during NPP decommissioning. Higashi et al. (2010) consider the dose assessment for setting of Emergency Planning Zone (EPZ) in an emergency plan for decommissioning of NPP. Iguchi/Masami (2010) use a risk-informed approach for the regulation of the decommissioning of nuclear facilities. The IAEA (2004) presents results about the planning, management and organization of the decommissioning of nuclear facilities and lessons learned. Irrek (2007) from the Wuppertal Institute for Climate, Environment and Energy, makes a comparison among different decommissioning funds' methodologies for nuclear installations. The Nuclear Decommissioning Authority (2011) presents a nuclear decommissioning authority business plan for 2011-2014. Takashima (2010) explores the construction, decommissioning, and replacement of NPP under uncertainty. Tromans (2010) inspects nuclear law, the law applying to nuclear installation and radioactive substances in its historical context ${ }^{18} 19202122232425262728$.

\footnotetext{
${ }^{18}$ see Bayliss/Langley (2003)

${ }^{19}$ see Bonavigo et al. (2010)

${ }^{20}$ see Bochud et al. (2009)

${ }^{21}$ see Bushart et al. (2010)

${ }^{22}$ see Higashi et al. (2010)

${ }^{23}$ see Iguchi/Masami (2010)

${ }^{24}$ see IAEA (2004a)

${ }^{25}$ see Irrek (2007)

${ }^{26}$ see Nuclear Decommissioning Authority (2011)

${ }^{27}$ see Takashima (2010)

${ }^{28}$ see Tromans (2010)
} 
K. Yoshino (2010) writes in his text 'Decommissioning Project: The first challenge in Japan' about the oldest magnox nuclear reactor in Japan named Tokai-1. It began operation in 1966 and was used in the establishment and introductory stages regarding the advancement of NPP technologies. After 32 years Tokai-1 ceased operation and began the steps needed to decommission the plant which forecasted to be a 20 year process. The technology and documentation of the experiences and procedures used in this process will be highly valuable information pertaining to the removal and sterilization of reactors and contaminated areas in the near future ${ }^{29}$.

When a NPP is shut down, it leaves behind many types of extremely harmful and dangerous radioactive waste. This hazardous waste must be removed and the plant decommissioned as soon as possible. This procedure is what the General Accounting Office (GAO) (2003) strives to accomplish. The text 'Nuclear regulation NRC needs more effective analysis to ensure accumulation of sufficient funds to decommission power plants was intended to review the 1999 study done by GAO which found that owners decommissioning funds were in fact not adequate to guarantee the completion of the process. With the information gained in their recent findings, GAO is certain that $\mathrm{NRC}$ must create a much more effective and thorough analysis process, evaluating the owners' decommissioning funds and guaranteeing that they are progressing at a healthy and steady rate ${ }^{30}$.

D.W. Reisenweaver (2004) writes in his text 'Status of the decommissioning of nuclear facilities around the world, International Atomic Energy Agency' of the current position we are in across the globe regarding the decommissioning processes throughout the many types of facilities that become affected, due to the handling of radioactivity. It provides an in-depth analysis of the processes concerning these environmentally harmful materials in past ventures, our current processes and those that we will undertake in the near future. The overall objective of the text is to educate its audience as to the fact that the current

\footnotetext{
${ }^{29}$ see K. Yoshino (2010)

${ }^{30}$ see GAO (2003)
} 
level of resources may be insufficient to have our present and future NPP successfully decommissioned ${ }^{31}$.

The report created by Masuda et al. (2010) revolves around revising and reviewing decommissioning processes. There are currently 4 NPP undergoing decommissioning and the number is estimated to increase in the near future. After some deliberation, a new safety regulation system commenced within the industry in 2005 that consists of a structure based on a review and independent approval process. This text places its focus on the substantial results that will be produced through the reviewing of the method of decommissioning of power reactors and nuclear fuel cycle facilities, the ceasing of licenses and a more detailed management of decommissioning waste ${ }^{32}$.

In the work of Bylkin et al. (2011) a number of areas relating to the decommissioning of NPP were examined. There are certain methods and practical approaches involved in analyzing and evaluating decommissioning which are highlighted. Furthermore Bylkin, et al., go on to analyze the significance of establishing prerequisites to facilitate the development of decommissioning simulation models in the real world ${ }^{33}$.

In his work, Irvine (2011) discusses the potential of nuclear power in a world that has its concerns. Though the need for alternative energy sources is required due to carbon emissions and an increase in the cost of fossil fuels, nuclear power is an energy source that causes some debate. Irvine creates awareness of the plausibility of nuclear power and the benefits of nuclear fusion and attempts to diminish common public concern by addressing such factors as nuclear safety, costs of development and waste disposal ${ }^{34}$.

In their work, Masuda et al. (2010), Kato provides an in-depth discussion of four nuclear power stations in Japan and the decommissioning processes involved in each of them. The authors go on to highlight four major areas of research. These include the review process of a decommissioning plan of power reactors, the review process of a decommissioning plan of nuclear fuel cycle facilities, the termination of a license at the end of decommissioning and the management of decommissioning waste. The idea

\footnotetext{
${ }^{31}$ see D.W. Reisenweaver (2004)

32 see Masuda et al. (2010)

${ }^{33}$ see Bylkin et al. (2011)

${ }^{34}$ see Irvine (2011)
} 
behind the research is to establish a comprehensive and standardized approach to decommissioning a NPP and the varying relaying factors involved in this process ${ }^{35}$.

Bonavigo et al. (2010) discuss the detrimental effects caused by the decommissioning and dismantling of the E. Fermi NPP in Italy. By analyzing a specific power plant they are able to go into great detail concerning the cause and effect of the decommissioning. During the decommissioning process, radioactive materials are released from NPP causing harmful effects. In their work, Bonavigo, et al., suggest the majority of the radioactivity inside NPP is caused by neutron activation. Apart from this they also propose contamination of materials and systems that have come in contact with the main coolant or other contaminated fluids/gases as partially contributing to the production of radioactivity. With a focus on the E. Fermi NPP, Bonavigo, et al. (2010) in particular, examine the cutting of contaminated metal components in the dismantling process. It is worth noting that this cutting is said to cause production of aerosol components and dust. This is because metal dusts and aerosols can cause harmful effects on both the environment and human health. Furthermore, Bonavigo, et al., highlight two methods of assessment of the amount of radioactivity produced from the cutting of the contaminated metal components. Their work also puts forth ideas of individual protection from radioactive devices in order to prevent/cope with the issues of inhalation and contamination $^{36}$.

Within their work Bond, Palerm and Haigh (2004) analyze a variety of case studies describing the decommissioning of NPP. Information for each of the case studies was developed from reviews of the Environmental Statement, interviews with key personnel identified by the study team as well as site visits. It is evident that in the near future a vast number of NPP will be decommissioned with the decommissioning proposals subjected to the Environmental Impact Assessment (EIA). Currently there are only a few NPP that have undergone decommissioning. Three different EU countries (Germany, Spain and the UK) have experienced the decommissioning of power plants. Detailed reviews of these activities were carried out in order to identify best practices for future decommissioning.

\footnotetext{
35 see Masuda et al. (2010)

${ }^{36}$ see Bonavigo et al. (2010)
} 
Using the information gained from the case studies, Bond, et al., pointed to five 'success factors' used to summarize the main aspects of recommended best practices in decommissioning. They pinpointed these best practices as follows ${ }^{37}$ :

- acceptance by governing authorities of the value of participation,

- integration of all participation activities under the EIA,

- carrying out participation activities before final strategies are adopted,

- keeping the decision-making process transparent and finally

- providing sufficient information to the public to facilitate participation.

Regarding lean management Gentes/Freund (2009) explore the implementation of lean Management in the decommissioning of nuclear facilities. Anderson et al. (2008) examine Computer-Aided Lean Management for the Energy Industry. Balle/Balle (2009) discuss the "Lean Manager" in this context. Emiliani (2007) defines a "Real Lean"approach for a better understanding of the lean management system. Hunger (2007) shows new ways for lean Management as a principle agent model with respect to human capital. Huntzinger (2007) thematize lean cost management and the accounting for lean by establishing flow. Kerber/Dreckshage (2011) focus on lean supply chain management essentials and develop a framework for materials managers. Miller (2010) addresses lean team management and shows how to create lean management \& lean organization. Petschnig (2009) surveys the effects of lean management on company value. Plenert (2007) talks about reinventing "Lean" and introduces lean management into the supply chain. Plenert et al. (2009) define lean management principles for information technology. Sabri/Shaikh (2009) describe lean and agile value chain management and offer a guide to the next level of improvement. Shinkle et al. (2004) develop a transforming strategy on how to implement a lean management system 3839404142434445 4647484950

\footnotetext{
${ }^{37}$ see Bond, Palerm and Haigh (2004)

38 see Gentes/Freund (2009)

${ }^{39}$ see Anderson et al. (2008)

${ }^{40}$ see Balle/Balle (2009)

${ }^{41}$ see Emiliani (2007)
} 
Concerning simultaneous engineering, Bylkin et al. (2011) presented a composition and structure of simulation models for evaluating decommissioning costs for NPP units ${ }^{51}$.

Unsure future employment of an operator is a general problem as a result of final shut down decisions for political, environmental, and economic reasons. As the operator's primary objective and duty is to achieve effective operation and maintenance, he can no longer follow through when another power intervenes. Furthermore, a lack of experience especially in the field of planning and managing the decommissioning causes low working morale, needless delays and increased costs ${ }^{52}$.

Besides these concerns, the most immediate issues are those of staff and public relations, particularly when abrupt final shut down decisions are made. Regulating authorities want to know how to calm and ensure public safety. In this case, management has to deal with the struggle to hold on to the working morale of the staff too. When the plant shutdown takes place some years before the decommissioning, it may be very difficult to manage this problem due to a lack of expert knowledge and because of plant disassembly ${ }^{53}$.

The European Commission estimates that by 2025 one third of the 145 NPP now operating in the European Union will have to be shut down. This decommissioning process involves the need for the demolition of nuclear facilities, as well as the disposal of nuclear waste and spent fuel. Adequate and accessible funding is a crucial factor and must be estimated during the years of operation so as to ensure the safety of EU citizens $^{54}$.

\footnotetext{
42 see Hunger (2007)

${ }^{43}$ see Huntzinger (2007)

${ }^{44}$ see Kerber/Dreckshage (2011)

${ }^{45}$ see Miller (2010)

${ }^{46}$ see Petschnig (2009)

${ }^{47}$ see Plenert (2007)

${ }^{48}$ see Plenert et al. (2009)

${ }^{49}$ see Sabri/Shaikh (2009)

${ }^{50}$ see Shinkle et al. (2004)

${ }^{51}$ see Bylkin et al. (2011)

${ }^{52}$ see IAEA (2004a), p. 3

${ }^{53}$ see IAEA (2004a), p. 4

${ }^{54}$ see Irrek (2007), p. VII
} 
Irrek report evaluates the Member States in their particular regimes for decommissioning costs, since there are existing differences among the Member States in ${ }^{55}$ :

- operation,

- governance,

- investment, and

- accessibility of funds.

The granting of operating licenses must be based on the polluter pays principle. High cost facilities should not be ignored in the financial plan, given that such reprocessing plants or facilities have experienced accidents. Cost estimates fluctuate in numerous countries due to ${ }^{56}$ :

- varying reduction mechanisms,

- timing of dismantlement,

- external management, and

- decreased access to funds resulting in an increased probability for risk and uncertainty.

Additionally the issues of communication, the role of the media and public relations should be considered although these issues are not the focus of this work.

\subsection{Technical Perspectives and Discussion}

\subsubsection{Operational view}

The issues of the operational view are as follows:

- varying reduction mechanisms,

- timing of dismantlement,

${ }^{55}$ see Irrek (2007), p. VII

${ }^{56}$ see Irrek (2007), p. VII 
- detailed examinations of the decontamination and dismantling of a power plant, equipment and facilities,

- the demolition of buildings and structures,

- site remediation and

- management of residual waste and other materials,

- disassembling and disintegration,

- decontamination and conditioning,

- clearing out and evacuation of the materials or decentralized intermediate storage.

\subsubsection{Organisational view}

The organisational view encompasses

- governance,

- investment,

- accessibility of funds throughout the EU,

- external management.

- increased restriction of funds,

- accounting,

- valuation, and

- investment perspectives. 


\subsubsection{Elements of decommissioning cost estimates}

Comparing cost estimates between organizations, should be done with care as costs are often specific to the conditions and requirements of a single plant. Due to the lack of an agreed upon structure for making cost comparisons between organisations, a joint publication was produced to outline definitions of cost groups and items. These include ${ }^{57}$ :

- Pre-decommissioning actions,

- Facility shut down activities,

- Procedure of general equipment and material,

- Dismantling activities, waste treatment and disposal,

- Security, surveillance and maintenance,

- Site cleanup and landscaping,

- Project management,

- Engineering and site support,

- Research and development, and

- Fuel and other costs.

Cost groups based on overall activities that cannot be categorized in a specific time period and activities carried out with a similar emphasis were identified, including ${ }^{58}$ :

- Labour costs,

- Capital, equipment and material costs,

- Expenses, and

- Contingency.

\footnotetext{
57 see Nuclear Energy Agency (2003), p. 46, 47

58 see Nuclear Energy Agency (2003), p. 46, 47
} 


\subsubsection{Approaches for estimating cost}

Approaches for estimating cost elements in the decommissioning process should be based on a model of the decommissioning process time schedule and planned decommissioning activities. The most accurate cost estimates are based on activity-based models of the actual site being decommissioned. An engineer's expert judgement is needed for specific plant designs so that general assumptions can be adapted to the specific case of a given plant $^{59}$.

The approaches can be based on assumptions, past experience and the extrapolation of cost elements within each site. Elements such as labour costs from sites of different sizes can be used as a basis and scaled up or down based on the decommissioning of other nuclear installations. Where a history of contamination exists, engineering judgement is necessary ${ }^{60}$.

As a basis for initial estimates, decommissioning cost estimates from other countries can be used when national case studies do not exist. The elements from cost estimates carried out in another country can be adjusted to reflect national practices. The cost elements may require adaptation in this case in order to reflect local, specific-case aspects ${ }^{61}$.

\subsubsection{Effect of decommissioning strategy on cost}

Decommissioning strategies for cost estimate purposes depend on immediate and deferred decommissioning options, which may be influenced by the resources/knowledge base or lack thereof of waste disposal facilities. The total duration of decommissioning including deferral and dismantling time is 40 years for all types of water reactors ${ }^{62}$.

The overnight decommissioning cost estimates provided show no great impact on the cost for regardless of the type or size of a reactor. This may be because the same volume of work must be performed regardless of reactor type or size. If the timing of when the work

\footnotetext{
${ }^{59}$ see Nuclear Energy Agency (2003), p. 48

${ }^{60}$ see Nuclear Energy Agency (2003), p. 48

${ }^{61}$ see Nuclear Energy Agency (2003), p. 48

62 see Nuclear Energy Agency (2003), p. 78
} 
will be carried out changes, it will have limited effects on the overnight costs. However, maintenance and care costs will be higher during dormancy in the deferral period ${ }^{63}$.

In terms of deferring decommission, some variations may appear as a result of facility maintenance over extended periods, depending on the type of safe-store strategy used. The costs of surveillance depend on the characteristics and status of the site. A shut down unit on the site may become a significant component of the total decommissioning cost. Whichever option is assumed, it does not affect the discounted cost of decommissioning because of the time value of money ${ }^{64}$.

\subsubsection{Cost variability}

By analysing the data supplied within the present study, it is observed that cost comparisons (national and international) are useful for both the government and industry in their decision making process. The estimation and analysis of decommissioning costs are well accepted by governments and the industry and understood by stakeholders for their intended purposes ${ }^{65}$.

Cost estimates are based on a series of hypotheses reflecting industrial strategy choices or assumptions, national regulations and policy, and economic and social situations which are specific to the power plant concerned. All cost estimates provided for the study were based on a strategy, including final deposit of all radioactive waste ${ }^{66}$.

Other factors considered under decommissioning strategies include radiation protection and industrial safety, radioactive waste management and disposable options available, technical complexity, regulations, political factors and social acceptance ${ }^{67}$.

The type of reactor does not seem to affect decommissioning costs significantly on a unit cost per kWe basis. This appears to be fairly dependant on the reactor type, which may be due to the fact that dismantling techniques are somewhat common and applicable across reactor types. The total volume of work needed is also common to all large metal and

\footnotetext{
63 see Nuclear Energy Agency (2003), p. 78

${ }^{64}$ see Nuclear Energy Agency (2003), p. 78

65 see Nuclear Energy Agency (2003), p. 76

${ }^{66}$ see Nuclear Energy Agency (2003), p. 76

${ }^{67}$ see Nuclear Energy Agency (2003), p. 76
} 
concrete nuclear facilities. Thus differences in labour costs, plant operating histories, waste conditioning requirements and waste disposal costs explain most of the spread in reported costs ${ }^{68}$.

\subsubsection{Methodology of the IAEA}

The developed methodology of the IAEA allows for several decommissioning options in order to evaluate and select the optimal option with a multi attribute analysis. A sensitivity analysis is possible, enabling margins of decommissioning costs and other parameters to be revealed. After being developed between 1999 and 2003, the code was tested and upgraded between 2004 and 2005. An overview of the OMEGA code is presented here ${ }^{69}$.

Model calculations were undertaken during development of the OMEGA code to develop new modules for waste management scenarios and the management of uncertainties in decommissioning cost analysis. The code was previously used for evaluation and optimization of various projects including NPP's in Slovakia (A1 NPP, V1 NPP, V2 NPP, EMO 1, 2, EMO 3, 4), the safety related parameters for normal planned decommissioning activities within the IAEA project DeSa (see Graham et al. 2006), in model calculation for the Swedish Nuclear Inspectorate, for model calculation within this CRP, and for improvement of the decommissioning plan for Paks NPP in Hungary ${ }^{70}$.

\subsubsection{The Principles of decommissioning and cost analysis}

The principles of decommissioning costs implemented within the OMEGA code are as follows:

The management of the standardized calculation structure involves the template of a standardized structure to configure the activities of a decommissioning option in a standardized format, corresponding to the facility structure of buildings-floors-items in rooms $^{71}$.

\footnotetext{
${ }^{68}$ see Nuclear Energy Agency (2003), p. 76, 77

${ }^{69}$ see IAEA (2008), p. 220

${ }^{70}$ see IAEA (2008), p. 221

${ }^{71}$ see IAEA (2008), p. 221
} 
- How to do it: This covers the conditions of calculation in order to select manual/remote operations, relevant protection of personnel, production of relevant calculation data and the factors of correction for manpower calculation. Management of calculation structure and conditions of calculation can be identified in each decommissioning costing methodology $\mathrm{y}^{72}$.

- The sequence of management of material and radioactivity flow within the code produces a calculation of final waste disposal and material release and waste matter into the environment. This is done by applying the concept of material and radioactivity flow modelling in decommissioning, which corresponds to primary and secondary waste generation and flow in waste generation and management of decommissioning activities ${ }^{73}$.

- The time management of decommissioning includes a time structure used for the re-calculation of costs and other parameters to evaluate the effect of time on decommissioning. The WBS and its link to grouped or non grouped items in the calculation structure, is included in the concept on online optimization of decommissioning schedules. Time management and sequence of management represent new items in decommissioning costing methodology ${ }^{74}$.

\subsection{9 ‘Algorithmization' of the material}

The compact standardized calculation structure within the code, which includes all decommissioning option activities and the resulting waste (see Wickham et al. 2007) also includes the transition period after the shutdown and the activities involved in spent fuel management ${ }^{75}$.

The question of radioactivity heavily influences the choice of decommissioning activities and various parameters, as well as special cases of a facility with a non-standardised radiological situation ${ }^{76}$.

\footnotetext{
72 see IAEA (2008), p. 221

${ }^{73}$ see IAEA (2008), p. 221

${ }^{74}$ see IAEA (2008), p. 221

75 see Wickham et al. (2007)

${ }^{76}$ see IAEA (2008), p. 222
} 
These aspects within the development of standardized decommissioning costs refer to issues of 'Algorithmization' of the material flow through calculation modelling and of radiological issues. This helps to optimize the decommissioning process and waste management, and to manage the effect of time on material flow and decommissioning by identifying the location of radioactivity ${ }^{77}$. Principles of accuracy related to material flow, optimization of waste management, and performance of sensitivity analysis occur through a calculation run on costs and decommissioning parameters for a given decommissioning scenario. This is enabled by the code's capacity for compact, internal linking of the standardized calculation structure and correct sequencing of the calculation process. The calculations and options of exposure of personnel and manual/remote operation within waste management are analysed through a concept of nuclide vectors. The vectors are stored with the date of their definition. Prior to calculation, nuclide compositions are used in a nuclide-resolved calculation process. The deferring of decommissioning activities is analysed through this concept ${ }^{78}$.

\subsection{Functional Areas and Organizational Structures}

\subsubsection{Dismantling methods and equipment}

The wall thickness needs to be taken into account when dismantling components of nuclear facilities, by cutting the existing components into convenient pieces. Relevant dismantling techniques, such as thermal, mechanical, hydraulic, as well as blasting or cutting techniques are used. It has to be decided whether existing techniques can be used or if purpose built techniques, such as with the "Versuchsatomkraftwerk (VAK)", need to be applied. This experimental power plant was dismantled successfully with the water abrasive jetting technique for the first time. The criteria for the selection of appropriate cutting techniques include ${ }^{79}$

- Components to be cut,

- Size of the cutting devices,

\footnotetext{
${ }^{77}$ see IAEA (2008), p. 222

${ }_{78}$ see IAEA (2008), p. 222

${ }^{79}$ see AREVA NP GmbH (2011), p. 147
} 
- Efficiency of the cutting technique,

- Reliability of the technology,

- Generation of secondary waste (filters for water purification etc.),

- Generation of aerosols and hydrosols,

- Decontamination properties of the devices,

- Performance time,

- Local dose rate, and

- Costs

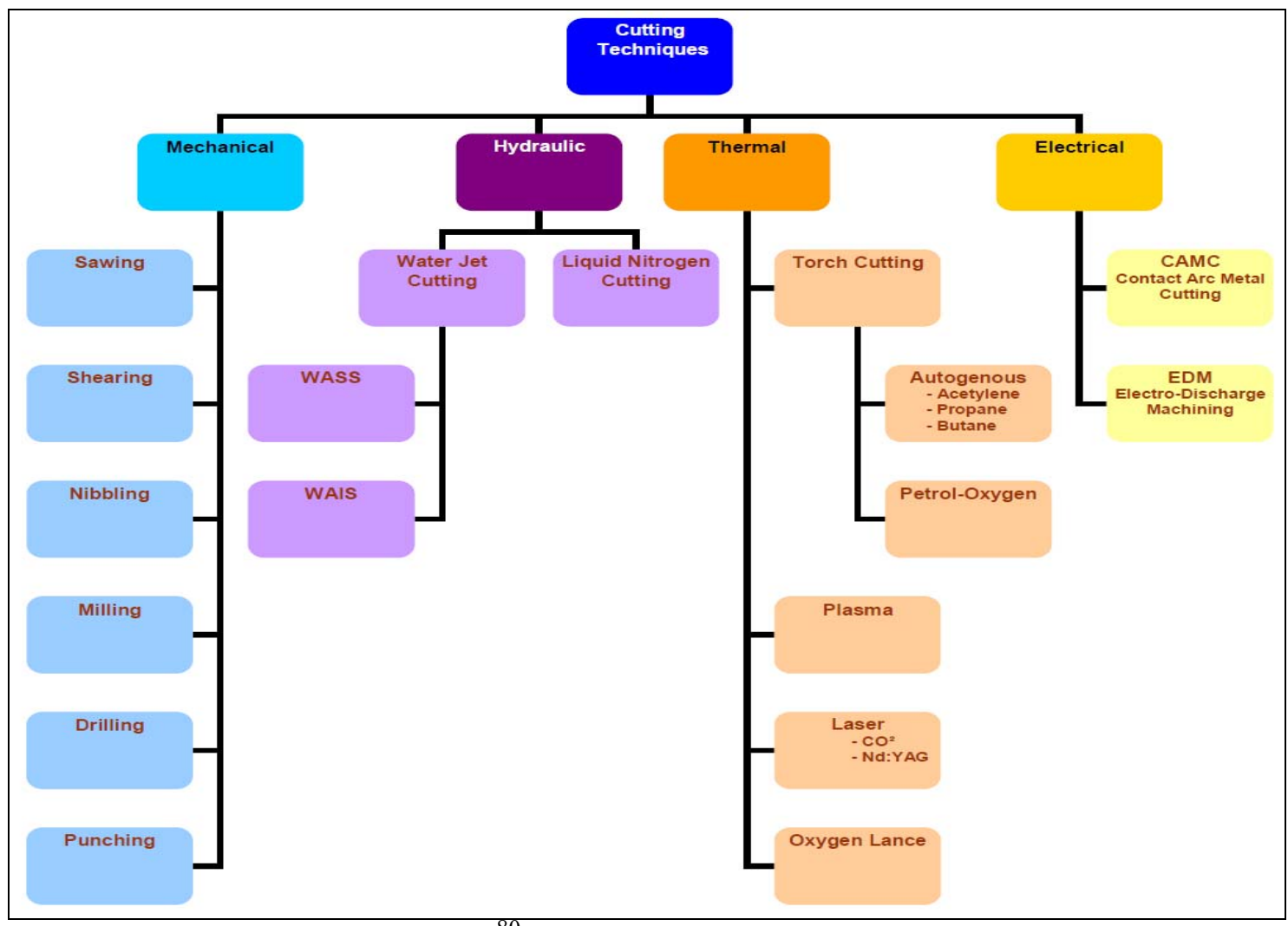

Figure 2: $\quad$ Cutting techniques $^{80}$

\subsubsection{Background / Reasons for selection of applied methods}

Germany has gained experience with decontamination and dismantling techniques as well as radiation and waste management. The general cutting techniques are shown in figures

\footnotetext{
${ }^{80}$ see AREVA NP GmbH (2011), p. 148
} 
Figure 2 and Figure $3^{81}$. Selecting an applicable cutting technique depends on the geometry of the components, cutting speeds and health aspects. Under water cutting technologies are shown below.

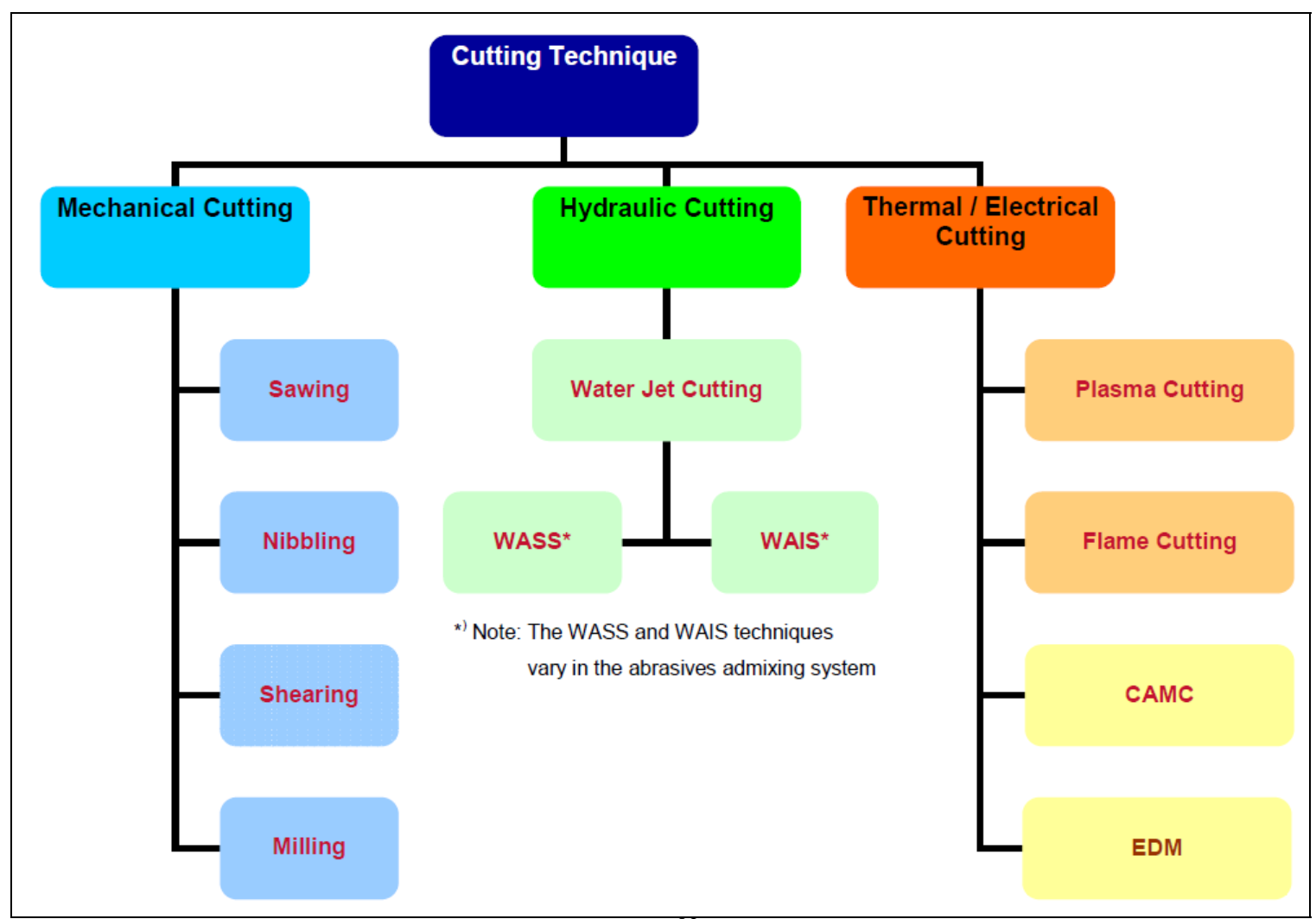

Figure 3: $\quad$ Applicable Cutting Techniques ${ }^{82}$

\subsubsection{Organizational processes}

The Organization of Economic Co-operation and Development (OECD) and the Nuclear Energy Agency (NEA) (2003) provide relevant information on regulations and policies regarding decommissioning along with the corresponding decommissioning expenses and approaches. An in-depth evaluation of costs is presented in this study and offers valuable information on the expenses involved in the entire decommissioning process. The cost estimates look closely at the specific characteristics of particular plants and specific variables such as reactor types and size. In summary, with the report being crafted by a

\footnotetext{
${ }^{81}$ see AREVA NP GmbH (2011), p. 148

${ }^{82}$ see AREVA NP GmbH (2011), p. 149
} 
range of experts and a wealth of knowledge on the issue available, the report offers a professional opinion on the current situation and provides us with an objective perspective $^{83}$.

The National Research Council (2001) conducted this study in an attempt to research the issue of decommissioning NPP and to improve upon productivity and the time it takes to sanitize a site. Their aim was to look for current and more innovative processes to more efficiently clean the contaminated areas. After an in-depth analysis and study of the circumstances, Environmental Management believes that costs can be reduced by around $\$ 15$ billion with the use of these new technologies. The report also stresses the difference between the deactivation of a site (safely shutting down a site) and decommissioning a site (which involves decontamination or dismantling) ${ }^{84}$.

The International Energy Agency (IEA) created a small book filled with valuable information called Key World Energy Statistics. The IEA was founded in 1974 and has progressively earned a reputation as a respected, reliable and professional source of energy related statistics. The information is highly valued by all those concerned with any type of energy. The result is a small book filled with fundamental energy information. This book is a fantastic resource for any student, scholar, or business. There is further evidence of these 'success factors' in a review of public participation experiences in the literature which covers 13 projects.

For further organizational issues such as planning, strategy and management from the economic point of view see chapter 2.4.2. Functional and technical interfaces according to the mentioned issues will be presented in different parts of the work, mainly in chapters 3,4 and 5 .

\footnotetext{
${ }^{83}$ see Nuclear Energy Agency (NEA) (2003)

${ }^{84}$ see Nation Research Council (2001)
} 


\subsection{Economic and Organizational Perspectives}

\subsubsection{Planning / Strategy / Organization / Management}

In Germany the financial planning of a shutdown and the disposal of waste is based on solutions within the company. The focus here is only on shutdown and waste disposal in the field of commercial nuclear energy use. NPP are managed by federal or state governments. The managing organizations of NPP are generally responsible for balancesheet calculations relating to shut down and waste disposal situations. In their trade and tax balance reserves they already calculate what these costs will be. In 2006 a total of 437 NPP covered $6.5 \%$ of the global primary energy need ${ }^{85}$.

S. Tromans (2010) work on 'Nuclear Law' is a useful and informative text on the UK, EC and international laws which surround the dealings with and uses of nuclear energy and other radioactive hazardous wastes. The text was originally published in 1997 but due to increased public interest and on-going debates surrounding the issue it has been revised and reissued and currently provides a far more thorough explanation of all relevant information. Troman focuses strongly on the development processes of nuclear legislation. The discussion on decommissioning within the text is an extremely important read and provides very relevant and in-depth insights on the topic ${ }^{86}$.

In the journal 'Construction, Decommissioning and Replacement of NPP under Uncertainty' written by R. Takashima (2010), the main focus is on the deregulation of electricity markets. The author writes that there are 54 commercial NPP in Japan at the moment and that the Tokai NPP of the Japan Atomic Power Company and the Hamaoka NPP of the Chubu Electric Power Company are presently being decommissioned. This is in turn being deregulated to the electricity markets, affecting countries such as the United States, the United Kingdom and Japan ${ }^{87}$.

Methods, techniques and tools which aid in directing and managing issues will be presented in the chapters 3,4 and 5 .

\footnotetext{
${ }^{85}$ see Bachelorarbeit (2010), Kosten-Nutzenanalyse der Nutzung von Atomenergie, p. 15; compare with Hoppenbrock (2008)

${ }^{86}$ see S. Tromans (2010)

${ }^{87}$ see R. Takashima (2010)
} 


\subsubsection{Controlling}

Controlling the processes requires observing and determining variables. Identified variances are helpful for the evaluation. Learning from errors is central. Last Planner Meetings contain resources demand, flow creation, waste minimization, knowledge transfer, experience use, create value, weekly work, and future work planning. The next Meeting engagements define execution activities, coordination of all involved participants, work flow definition and joint optimization. Work planning for the next two weeks approaches missing prerequisites identification, work/activities execution preparation, and joint optimization. The research project goals are the minimization of iteration steps and the optimization of involved participants' coordination in order to create trustworthy engagements, increase transparency across the entire process, and furnish an integer process perspective for continuous optimization ${ }^{88}$.

Further methods and tools for the controlling of projects will be presented in chapter 3 , 3.5.3.

\subsubsection{Budgeting}

In her work, Burger (2011) discusses the role of various stakeholders in energy-related issues. She underlines the need for the commitment and participation of these stakeholders in order to prevent and solve environmental and other energy-related problems. Burger goes on to describe in detail the successful and unsuccessful decisionmaking process of stakeholders in environmental management. However the focus of her work is on how science and stakeholders interact to solve potentially difficult and contentious issues pertaining to energy and the environment ${ }^{89}$.

\footnotetext{
${ }^{88}$ see Gentes/Freund (2009)

${ }^{89}$ see Burger (2011)
} 


\subsubsection{Staffing}

The staff description of individual departments depends on the differences between technologies and staffing requirements. Standard positions within nuclear safety operations and maintenance teams include ${ }^{90}$ :

- Operations Manager,

- Engineering Manager,

- Maintenance Manager,

- Mods and Support Manager,

- Outage and Planning Manager,

- Training Manager

- Radiation Protection and Chemistry Manager,

- Organizational Effectiveness Manager,

- Licensing Supervisor.

The operations department staff who tend to the day to day operations of the plant include those working on both off and on-shift components. On-shift staff has a control room person and a support person for non-licensed operators and off-shift staff support the overall plant. Also aspects such as staff vacation time, illness or dependent care leave etc. need to be taken into account in order to manage minimum staff levels. Licensed reactor operators take the place of the non-licensed personnel and become part of the control room on a rotational basis in to accommodate staff leave ${ }^{92}$.

Systems engineering maintains system reliability, including single-unit greenfield deployment and any additional units on existing sites. Staffing depends on the number

\footnotetext{
${ }^{90}$ see United States Department of Energy (2004), p. 98

${ }^{91}$ see United States Department of Energy (2004), p. 98

${ }^{92}$ see United States Department of Energy (2004), p. 99
} 
and complexity of the units and the existing staff for the engineering of common site support systems ${ }^{93}$.

Staff efficiency is important within the maintenance team which is responsible for troubleshooting and periodic loop and systems calibration. In order to mainly acquire non-stock components and services, at least one individual is added to the staff for each additional unit at an existing site, in order to maintain it $^{94}$.

A five shift rotation system is used - in this case - within the Radiation Protection Department with two shifts that cover the added day shift workload due to the fact that on-shift staffing cannot be shared with existing units. One Radiation Protection supervisor per shift, three technicians (plus two technicians on day shift for sampling and operational duties), chemistry technicians and supporting decontamination technicians are required $^{95}$.

A new unit requires some special staff training. The program and certifications for operations training is plant specific and requires requalification and initial training for the extra plant and instructors specifically for operations. Existing unit engineering training will be used and some specialized instruction will be required for maintenance training for specific parts of the new unit. Supplementary instructors are included to perform the maintenance training of the staff in these areas ${ }^{96}$.

\footnotetext{
93 see United States Department of Energy (2004), p. 101

${ }^{94}$ see United States Department of Energy (2004), p. $101 \mathrm{ff}$.

${ }^{95}$ see United States Department of Energy (2004), p. 102

${ }^{96}$ see United States Department of Energy (2004), p. 102
} 


\section{RESEARCH METHODOLOGY}

\subsection{Project Management}

\subsubsection{Overview}

Project participants include ${ }^{97}$ :

- regulatory authorities,

- engineering firms,

- contractors,

- agencies, and

- evaluation / auditing experts.

The projects are notably complex, demanding a large amount of project management and execution.

Experts need long periods to elaborate the final reports. The existing silo-structures obstruct the good coordination and cooperation between all those participants ${ }^{98}$.

Approaches of implementation convey that only a conceptualized design is possible to apply for a license, and all additional reviewing information is to be submitted across the licensing process. The whole process must be extremely transparent. The coordination of the ongoing activities must be optimized continuously, exploiting optimization potential, while using cooperative project management methods to implement the Last Planner

${ }^{97}$ see Gentes/Freund (2009)

${ }^{98}$ see Gentes/Freund (2009) 
Systems, and maximize the potential in the function of optimization. The Last Planner System improves coordination and cooperation between all participants ${ }^{99}$.

\subsubsection{Project Lifecycle}

Bushart et al. (2010) describe certain milestones in their work that need to be met in order to decommission a NPP. They focus on change management as a result of the decommissioning of the power plants. The milestones ensure that change management is a smoother process. Planning is also considered a key area by Bushart, et al. A constructive decommissioning plan can lead to considerable project savings. Three major power plants are highlighted in their work including; Maine Yankee Atomic Power Plant, Yankee Nuclear Power Station, and the Haddam Neck Plant. They stress the importance of using and learning from information gained from previously decommissioned plants when undertaking a new decommissioning project ${ }^{100}$.

The processing of calculated data, generation of output data formats, and the decommissioning schedule of the option are in the form of Gantt charts in MS Project ${ }^{101}$ (see Figure 4).

The Gantt chart illustrates a project schedule with the start and finish dates of adjacent elements and their phases in a project. The Gantt chart helps to visualize the work breakdown structure of the project. Also it is possible to show the dependency and relationships between phases and activity-levels. The current status and the degree of completion are also shown. In the above chart the following milestones

- Analysis of project,

- Initial Design,

- Prototyping and formative testing,

- Summative Testing,

- Documentation

\footnotetext{
${ }^{99}$ see Gentes/Freund (2009)

${ }^{100}$ see Bushart et al. (2010)

${ }^{101}$ see IAEA (2008), p. 222
} 


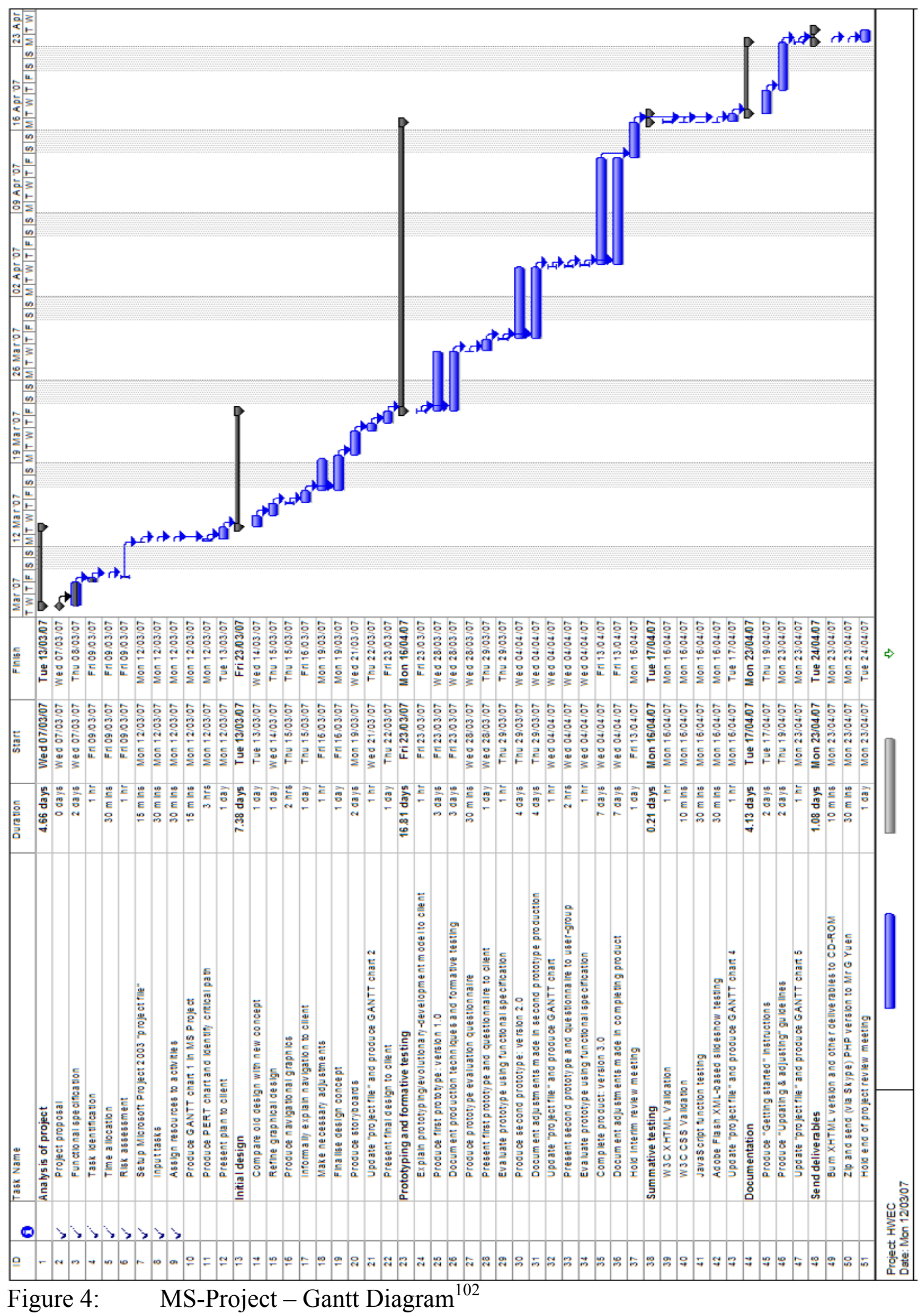

${ }^{102}$ see REMZA (2012) 
are modelled. This approach is a common way to implement the model and its chronological development. The application of Gantt charts is essential for the representation of the model. In chapter 3, 3.5.2 another tool (AIMMS) is presented to monitor the project performance in a given phase and the constellation of input data. Further project management techniques include

- Project analysis,

- Project goals definition,

- Project organization, and

- Project implementation.

The application of these methods and techniques will be carried out by using MS Project 2013 in chapter 6.2 .

\subsubsection{Resumé}

The applicability of these methods and concepts of project management will be shown in detail in the chapters 3.5.3 and 6.2. In order to achieve an higher degree of theoretical knowledge further research on issues as system theory, cybernetics, scientific management, computational complexity theory, agile management, lean management and simultaneous engineering must be elaborated.

\subsection{Lean Management}

\subsubsection{Overview}

This text 'Reinventing Lean: Introducing Lean Management into the Supply Chain' written by author G.J. Plenert (2007), is essentially focused on supply chain management and distinguishes itself from other texts on the topic because of its in-depth insight into management tools to better implement the lean ideals and also provide an analysis of the various aspects directly related to the supply chain management system. It precisely explains the capacity that a Lean SCM system has to offer and describes how to take full advantage of this particular method. This text provides a comprehensive explanation of 
specific areas of the supply chain management field that other books on the issue do not offer $^{103}$.

Within his work, Hunger (2007) shows different approaches to the concept of lean management. Hunger is not satisfied with the generic approach, since the problems are associated with the loss of human capital. Hunger's work therefore goes deeper into other areas such as the iteration model and the concept of holism, incorporating them with Lean management principles in order to create a broader and more successful approach to management. His work is generally for ambitious decision makers and students aiming to improve their knowledge of Lean management in an ever-changing environment ${ }^{104}$.

\subsubsection{Leadership}

Emiliani (2007) directs his work towards busy corporate executives. The idea behind his approach is to promote lean management in an exciting and engaging style in an attempt to attract managers from their normal management practices. In a practical manner, Emiliani discusses the purposes, advantages and myths surrounding lean management. The focus of his work is on two principles ${ }^{105}$ :

(1) Continuous improvement and

(2) Respect for people.

Emiliani shows how these two areas of management coincide to create a successful working environment.

\subsubsection{Lean PM}

'Transforming Strategy into Success: How to implement a Lean Management System' by Smith, Gooding and Shinkle, was nominated as a contender for "The Year's Best Reference and Reading Material" in 2004. It dissects the lean management system drawing on its strengths and weaknesses and provides a very clear explanation of the issue and helpful advice on how to approach implementing and maintaining the system to

\footnotetext{
103 see G.J. Plenert (2007)

${ }^{104}$ see Hunger (2007)

105 see Emiliani (2007)
} 
the nth degree. The text focuses on team building, strategic management and leadership to deliver sound and professionally recognized opinions. Fundamental knowledge and experience is provided in this book and should be studied by any organization aspiring to successfully implement and maintain a Lean Management System ${ }^{106}$.

'End to End Lean Management: A Guide to Complete Supply Chain Improvement' written by R.J. Trent (2008) is a study specifically designed to help readers by providing a comprehensive explanation of Supply Chain methods. This text sets itself apart from its competitors because it addresses the more in-depth ideologies that many others do not. It delivers vital information on not just the core issues but across all various yet interwoven and important aspects of the methodology. This book will provide the competitive edge within the market for all managerial types across the industry. It is an essential read ${ }^{107}$.

The work of Kerber and Dreckshage (2011) demonstrates how traditional approaches to management are no longer effective enough, spurring a need to incorporate lean supply chain management into enterprise practices. Their work goes into intense detail on the various aspects of Lean, such as leveling, the value stream, hijunka scheduling, standard work and the concept of intervals. Kerber and Dreckshage do not focus solely on Lean management properties, but also combine them with traditional management concepts to ensure understandability and to avoid the loss of successful and conventional aspects from previous management approaches. They state that continuous improvement can be made by balancing demand and capacity rather than completely focusing on balancing supply and demand ${ }^{108}$.

'Lean and Agile Value Chain Management: A Guide to the Next Level of Improvement' written by Shaikh/Sabri (2009), provides a wide variety of in-depth knowledge on the ideal of a lean and agile value chain. Moreover this text thoroughly explains how to develop such methods and utilize them to their maximum potential. Proving explanations on many basic and 'need to know' ideas such as vastly reducing costs, minimizing leadtimes, creating a better standard of flexibility and promoting the future growth of

\footnotetext{
${ }^{106}$ see Shinkle et al. (2004)

107 see R.J. Trent (2008)

${ }^{108}$ see Kerber and Dreckshage (2011)
} 
individual shares within the market. This text is vital reading for any enthusiast who aims to develop the 'lean and agile value chain' methodologies ${ }^{109}$.

\subsubsection{Lean Information Technology}

Plenert (2009) shows a useful tool to improve and rethink your company's IT department. A staggering statistic tells us that somewhere between $50-60 \%$ of a company's information technology department can be deemed ineffective and wasted. With this statistic it is clear that there are many common holes and grey areas within numerous companies that need to be addressed. This text provides the information needed to fully explain the Lean Management principles for a company's IT department and provide effective and efficient techniques on educating your employees and thus improving productivity. It provides unique and extremely valuable ideas on the implementation of these ideals ${ }^{110}$.

\subsubsection{Lean Management Software-Tools}

Miller's work is designed for organizations to utilize the tools of lean management, whereas many other resources do provide information on the topic, they fail to supply such insight. The author believes that 'behavior' is the most important aspect within our current social system. And to have the best possible outcome, one must be aware of its importance and use lean management as a guiding hand, providing heightened levels of organization. This particular text guides the reader through the various levels of organizing procedures and improvements to meet customer demand. In their work, Balle/Balle (2009) discuss the benefits of a lean approach to management. They discuss the narrow minded approach of some managers, relying on business knowledge and technical abilities and ignoring the changing environment around them that demands a change. Displaying several examples of human moments in which lean management has proven successful, Freddy and Michael engage with the readers of their work on another

\footnotetext{
${ }^{109}$ see Sabri/Shaikh (2009)

${ }^{110}$ see Plenert (2009)
} 
level. The focus of their work revolves around five disciplines; go and see, kaizen, clear direction, teamwork and mutual trust ${ }^{111}$.

\subsubsection{Resumé}

Lean management is focused on a well-organized supply chain management system with the ability to continuously improve and emphasizes respect for people. This issue is reflected by effective methods of team building, strategic management and leadership techniques. Since traditional approaches to management are no longer effective, the main focus of performance management is to ensure understandability. This is only possible with the continuous improvement of suitable underlying methods, techniques and tools. The continuous upgrading of IT structures and departments is one aspect of this goal. The utilization of lean management tools and the associated education of employees ensure improvement in productivity. New methods of simultaneous engineering (or concurrent engineering) (see chapter 3.3) are helpful. Here, as a sign of the times, sequential development has been more and more replaced by iterative development.

The tools and methods chosen in this dissertation are in line with the aforementioned issues. A modern project management tool such as MS Project 2013 is a good instrument to use in an attempt to take into consideration the complexity of the required know how and team building capabilities for the best specification and termination of tasks (see chapter 3, 3.5).

During the definition and selection of qualified methods, tools and techniques of lean management issues must be evaluated within the scope of a given project (see chapter 6.2, p.121-123, tasks 5-15 and 34-40).

${ }^{111}$ see Balle/Balle (2009) 


\subsection{Simultaneous Engineering}

\subsubsection{Definition of the term "simultaneous engineering"}

The definition of the simultaneous or concurrent engineering approach is based on five key elements according to the European Space Agency (ESA) ${ }^{112}$ :

- a process,

- a multidisciplinary team,

- an integrated design model,

- a facility, and

- a software infrastructure.

\subsubsection{Different approaches to simultaneous engineering}

The study 'Quality Control System Design Based on Simultaneous Engineering Applied Mechanics and Material' by Y.Y. Yang, and Z.Q. Xu (2010) is a thesis which is written about a plant designated to create car engines. It aims to critically analyze the 'JIT Quality Control' system and evaluate its impact. The thesis focuses strongly on the comparison between the 'Simultaneous Engineering Method' and the standard 'JIT Quality Control' procedures. The resulting findings from the research prove that the 'Simultaneous Engineering Method' significantly reduces the material waste ratio and thus provides a clear and logical choice for future implementation of either method ${ }^{113}$.

Roy et al. (1999) discuss the progression of improvements made within contemporary engineering in their text 'Simultaneous Engineering: Methodologies and Applications'. They also speak to current concerns regarding the advances and execution of these newly implicated systems. This text is directly concerned with the progressive research and newly acquired information on the topics of problem solving architectures, administrative issues and different methods of simultaneous engineering; with topics such as design methods, artificial intelligence and numeric tools also discussed and analyzed. These

\footnotetext{
112 see ESA (2013)

${ }^{113}$ see Y.Y. Yang, and Z.Q. Xu (2010)
} 
issues all concern the implementation of effective systems and the problems that may arise when operating within such systems ${ }^{114}$.

The text 'Simultaneous Engineering for New Product Development: Manufacturing Application' written by J. Ribbens (2000) stresses the importance of simultaneous engineering in relation to new product development (NPD). A large percentage of the important and correlating management positions have little to no time to work on new product development as their time is quite often taken up by more managerial tasks, and for this reason, simultaneous engineering is able to provide a helping hand. It has been proven that simultaneous engineering can act as a catalyst for the whole of development and manufacturing procedures. Overall this text provides solutions to the very current issue of lacking new product development by the implementation of simultaneous engineering $^{115}$.

\subsubsection{Resumé}

Several options of qualified design methods, artificial intelligence techniques and numeric tools are part of the functionality of the tools considered in the next chapters. Regarding the mathematical design of the model, the specifications are elaborated in detail in chapter 4. Regarding the design of the procedure model, MS Project is used and all of the required tasks and phases are modeled with this tool. The issues must be evaluated within the project execution (see chapter 6.2, p. 121-123, tasks 5-15 and 34-40).

\footnotetext{
114 see Roy et al. (1999)

${ }^{115}$ see J. Ribbens (2000)
} 


\subsection{Operations Research}

\subsubsection{Definitions of the term "OPERATIONS RESEARCH”}

A definition of the term OR is difficult, as it provides concepts and methods for a wide range of applications. Traditional definitions of operations research are as follows (Sharma 2006, p. 10):

- "Operations research is the application of the methods of science to complex problems in the direction and management of large systems of men, machines, materials and money in industry, business, government and defense. The distinctive approach is to develop a scientific model of the system incorporating measurements of factors such as chance and risk with which to predict and compare the outcomes of alternative decisions, strategies or controls. The purpose is to help management in determining its policy and actions scientifically."116

- "Operations research is concerned with scientifically deciding how to best design and operate man-machine systems usually requiring the allocation of scarce resources." 117

- "Operations research is the systematic application of quantitative methods, techniques and tools to the analysis of problems involving the operation of systems." 118

- "Operations research is essentially a collection of mathematical techniques and tools which in conjunction with a systems approach, are applied to solve practical decision problems of an economic or engineering nature." 119

- "Operations research utilizes the planned approach (updated scientific method) and an interdisciplinary team in order to represent complex functional relationships as mathematical models for the purpose of providing a quantitative

\footnotetext{
${ }^{116}$ see Operational Research Society, U.K. in Sharma (2006), p. 10

117 see Operations Research Society, America in Sharma (2006), p. 10

${ }^{118}$ see Daellenbach and George, 1978 in Sharma (2006), p. 10

${ }^{119}$ see Daellenbach and George, 1978 in Sharma (2006), p. 10
} 
basis for decision-making and uncovering new problems for quantitative analysis. $" 120$

- "This new decision-making field has been characterized by the use of scientific knowledge through interdisciplinary team effort for the purpose of determining the best utilization of limited resources."121

- "Operations research, in the most general sense, can be characterized as the application of scientific methods, techniques and tools, to problems involving the operations of a system so as to provide those in control of the operations with optimum solutions to the problem."122

- "Operations research is the art of winning wars without actually fighting them. (...) This definition refers to the military origin of the subject where a team of experts were not actually participating in military operations for winning the war but providing advisory and intellectual support for initiating strategic military actions." 123

- "Operations research is the art of finding bad answers to problems to which otherwise worse answers are given." 124

- "Operations research has been described as a method, an approach, a set of techniques, a team activity, a combination of many disciplines, an extension of particular disciplines (mathematics, engineering, and economics), a new discipline, a vocation, even a religion. It is perhaps some of all these things."

- "Operations research may be described as a scientific approach to decisionmaking that involves the operations of an organizational system.", 126

- "Operations research is a scientific method of providing executive departments with a quantitative basis for decisions under their control."127

${ }^{120}$ see Thierauf and Klekant (1975) in Sharma (2006), p. $10 \mathrm{ff}$.

${ }^{121}$ see Taha (1976) in Sharma (2006), p. 11

${ }^{122}$ see Churchman, Ackoffand Arnoff (1957) in Sharma (2006), p. 11

${ }^{123}$ see Sharma (2006), p. 11

${ }^{124}$ see TL. Saaty, (1958) in Sharma (2006), p. 11

${ }^{125}$ see Cook, (1977) in Sharma (2006), p. 11

${ }^{126}$ see Hiller and Lieberman (1980) in Sharma (2006), p. 11 


\subsubsection{Main Characteristics of Operations Research}

The term Operations Research (OR) originated during WWII, when it was used to deal with certain tactical problems. After the war OR techniques where applied to a wide set of problems. In OR, mathematical techniques and algorithms are applied to solve problems and help coordinate large-scale projects. Most large institutions, especially those within the service sector, make use of this technique ${ }^{128}$. OR deals with challenges on a holistic level. It analyses all possible factors, any of which could be the cause of the problem. Looking only at the immediate problem may fail to yield satisfying results. A mathematical model of the organization is essential. The mathematical model is analyzed by scientists from di erent fields. Industries, especially the service industry, rely on OR to solve all kinds of problems ${ }^{129}$.

\subsubsection{Phases of OR}

Once the problem is formulated, a mathematical model is constructed. Depending on the structure, various methods may be applied in order to find a solution. These models are free from any human factors, which may influence decision-making ${ }^{130}$.

\subsubsection{Scope of OR}

OR techniques may analyze problems involving:

- Finance and accounting,

- Marketing,

- Purchasing and procurement,

- Production, and/or

- Management $^{131}$.

${ }^{127}$ see Morse and G.E. Kimball in Sharma (2006), p. 11

${ }^{128}$ see lyer (2008), p.1

${ }^{129}$ see lyer (2008), p. lff.

${ }^{130}$ see lyer (2008), p. 2

${ }^{131}$ see lyer (2008), p. 2 


\subsubsection{Drawbacks and Difficulties of OR}

Improper definition and formulation of the problem may create problems, as data collection, which may be financially draining and time consuming. OR analysis is based on past observations and doesn't guarantee what will happen in the future. OR is only useful if OR experts translate the ideas into an easily comprehensive language and it is properly implemented ${ }^{132}$.

Examining complex problems and calculating the best way to achieve certain objectives can be done through OR, as stated by the Australian Society for OR (ASOR). OR came into use when the british military needed to find the best way to dispense their material and manpower during World War II. Later the United States needed OR to develop management techniques for allocating insufficient resources and to succeed with their militaristic and industrial goals ${ }^{133}$. Many academic societies were born in Britain and the U.S. in the 1950 s contributing to the development of OR, and the field continues to grow today. OR's influence was broadened from military, statistics, mathematics and engineering to include the domains of industry, transportation, business, health and crime.

\footnotetext{
132 see lyer (2008), p. 2

133 see Carter/Price, (2001) in Heyer (2004), p. 1-2
} 


\subsubsection{Scientific Methodology in OR}

The scientific methods on which operations research is based are as follows (see table 1):

Table 1: A selection of OR methodologies ${ }^{134}$

\begin{tabular}{|l|l|}
\hline $\begin{array}{l}\text { Linear } \\
\text { Programming }\end{array}$ & $\begin{array}{l}\text { A fixed amount of resources are accredited to meet a number of } \\
\text { demands in a way that a given objective/some objectives are } \\
\text { optimized and other defined conditions are also met. }\end{array}$ \\
\hline Queuing Theory & $\begin{array}{l}\text { In situations where there is a queue with a minimum investment } \\
\text { cost, this theory can determine the expected number of people in a } \\
\text { queue, anticipated waiting time, anticipated idle time etc. }\end{array}$ \\
\hline Game Theory & $\begin{array}{l}\text { Resolves conflicting game situations, assuming all players want to } \\
\text { maximise profits and minimize losses. }\end{array}$ \\
\hline Simulation & $\begin{array}{l}\text { Learning about a situation by setting up a model of it along with } \\
\text { performing experiments. }\end{array}$ \\
\hline Markov Process & $\begin{array}{l}\text { Used to calculate the probability of being in a particular state. The } \\
\text { technique is based on situations where various states are defined } \\
\text { and the system moves from one state to another through } \\
\text { probability. }\end{array}$ \\
\hline
\end{tabular}

Operations Research is comprised of a number of steps ${ }^{135}$ :

1. The operations researcher gathers information to find solutions in order to formulate the problem.

2. A model is developed of the systems, processes and environments using equations, relationships or a formula.

3. The operations manager has to select and collect data input by making sure enough data exists to use and test the model.

4. A solution to the model is found through much updating and modification.

\footnotetext{
${ }^{134}$ adapted from Carter \& Price (2001) in Heyer (2004), p. 1-2

${ }^{135}$ see Carter \& Price (2001) in Heyer (2004), p. 1-2
} 
5. The model must be verified to make sure it provides a valid prediction of how the system runs and if it can reliably handle past, present and future aspects of the problem.

6. The operations researcher works closely with management to implement the solution $^{136}$.

OR enables a better systems control, decision making and better organizations. However, traditional OR techniques cannot always be used to model intricate problems. The chasm between the operations researcher and management creates a limitation, as well as their lack of understanding of the entanglement of human relations and behaviour required to carry out implementation $^{137}$.

\subsubsection{Research Phases of OR}

This is the most complex phase, because it encompasses:

(i) Observation and data collection,

(ii) Defining the model,

(iii) Experimentation to test the hypothesis,

(iv) Analysis,

(v) Results prediction,

(vi) Generalization ${ }^{138}$.

\subsubsection{Action Phase}

A recommendation, which deals with the whole process of creating the model, shall be drafted and implemented ${ }^{139}$.

\footnotetext{
${ }^{136}$ see Carter \& Price (2001) in Heyer, R. (2004), p. 1-2

137 see Heyer, R. (2004), p. 1-2

${ }^{138}$ see Sharma, p. 12

139 see Sharma, p. 12
} 


\subsubsection{Judgement Phase}

(i) Identification of the problem,

(ii) Selection of the objective and values,

(iii) Application of the scale of measurement,

(iv) Formulation of the problem, so that a solution can be obtained ${ }^{140}$.

\subsubsection{Features of Operations Research Approach}

\subsubsection{Methodological Approach}

Once a hypothesis is drafted, it has to be tested and the results need to be analyzed. An alternative hypothesis has to be drafted, if the current one is insufficient ${ }^{141}$.

\subsubsection{Objectivistic Approach}

Alternative courses of action are compared, in order to acquire an optimal solution of the problem under analysis ${ }^{142}$.

\subsubsection{Interdisciplinary Approach}

One person may not be able to tackle the whole scope of the problem. Hence, various experts may have to cooperate to yield the desired outcome ${ }^{143}$.

\subsubsection{Wholistic Approach}

The wholistic approach involves the examination of all conflicting objectives and claims $^{144}$.

\footnotetext{
${ }^{140}$ see Sharma, p. 13

${ }^{141}$ see Sharma, p. 13

${ }^{142}$ see Sharma, p. 13

${ }^{143}$ see Sharma, p. 13,14

${ }^{144}$ compare with Sharma, p. 14
} 


\subsubsection{Scope of Operations Research}

Industrial management supplies us with a large array of problems. It is therefore essential to have an overall view of how to optimize profit. Alternative methods have to be drafted, and possible changes must be identified.

Operations research is widely applied in modern warfare. Submarine activities of, for example, the navy, have to be coordinated in order to achieve an optimal strategy and consistent goal.

In developing economies, where hunger has to be combated, planning in operations research is important. Income growth per capita has to be maximized whilst considering national resource limitations and political and social goals. Optimal distribution of water and farmland has to be carried out, whilst guaranteeing minimum cost and maximum benefit. Operations research can be applied to business and society to help combat economical and industrial problems ${ }^{145}$. Further application areas of OR are:

- Environment, Energy, and Sustainability,

- Financial Engineering,

- Manufacturing, Service, and Supply Chain Operation,

- Operations and Supply Chains,

- Optimization - This issue will be deepened in the chapters 4.5 to 4.10 and 6 and is the emphasis of this dissertation.

${ }^{145}$ see Sharma, p. 14,15 


\subsubsection{Optimization techniques in OR}

The main optimization techniques in OR are as follows ${ }^{146}$ :

o Stochastic - very general, but inefficient (e.g. random walk, simulated annealing, Monte Carlo \& tabu),

o Linear Programming - fast, but restricted to linear situations only,

o Gradient Based/Hill Climbing - nonlinear, applicable to smooth (differentiable) functions,

o Simplex Based - nonlinear for discontinuous functions,

o Sequential Optimization - ranks objectives by preference and optimizes them in order (lexicographic),

o Weighting Objectives - creating a single scalar vector function to optimize, multiple runs needed,

o Constraint - optimizes preferred objective with others treated as constraints,

o Global Criterion - minimizes the distance to an ideal vector,

o Goal Programming - minimizes deviation from target constraints,

o Game Theory - searches for Nash equilibrium,

o Multiattribute Utility Theory - maximizes preferences or fitness,

o Surrogate Worth Trade-Off - quantifies and minimizes compromises,

o Q-Analysis - uses topology maths, multicriteria polyhedral dynamics,

o Dynamic Compromise Programming - uses state transition functions, parameters change over time.

\footnotetext{
${ }^{146}$ see Lucas (2006)
} 


\subsubsection{Practical Multiobjective Optimization}

The evolutionary Multiobjective optimization (EMOO) technique has a multi parameter and multi objective nature. It is possible to use EMOO to figure out Multiobjective Optimization Problems (MOP) or Multiobjective Combinatorial Optimization (MOCO) problems. This is done by using types of genetic algorithms, namely Multiobjective Evolutionary Algorithms (MOEA). This paper looks into easier and more practical ways of utilizing this tool within our daily lives, without computer assistance. It is recommended to reference a glossary or introduction to aid in the understanding of technical terms within this paper ${ }^{147}$.

As opposed to an ideal 'answer' for such problems, there is instead a large family of alternative solutions. The number of solutions means we must make our decisions depending upon the full dynamic of the situation, meaning complex systems, choices and implications. The creation of a maximum efficiency in a wider global context is formed by the competition of these objectives. The result shows a multi-level form of selection applied to individuals and populations and that multiple values allow real world ecologies and societies $^{148}$.

Compromises between cost and performance have to be made in terms of optimizing for all objectives. In the case of a decision where a compromise is hard to come to, other factors or contexts are taken into account i.e. our wider lifestyle or worldview ${ }^{149}$.

In a case where a set of solutions contains some solutions which are weaker than others, the stronger solutions are often perceived as 'dominating' the others, while the weaker ones are discarded. This is called the 'Pareto-optimal set' (of resultant fitness) or 'Pareto Front' (of objective vectors). Next, criteria or preferences need to be created within a full contextual situation to form a 'Decision Maker'. This can be done before optimization (giving a scalar fitness function), after optimization (choosing from the full Paretooptimal set), or interactively (an acceptable solution moderately accumulated). Appropriate given static (hard) preferences and changing objectives is first, the second

\footnotetext{
147 see Lucas (2006)

148 see Lucas (2006)

${ }^{149}$ see Lucas (2006)
} 
for static objectives and changing (soft) preferences, and the third where both are dynamically changing (co-evolution) ${ }^{150}$.

\subsubsection{Resumé}

Optimization techniques in OR are used for solving problems from different traditional areas of work. The application of these operations research (OR) techniques is helpful in analysis and iterative development, testing, evaluation and controlling of the project's needs. In this thesis an MOOP / SOOP approach to a decommissioning and dismantling project will be developed and implemented by software tools. In chapter 4 the mathematical design, strategy and technique of the OR problem is presented in detail.

\subsection{Software Tools}

\subsubsection{Overview}

In this section of the study the focus will be on tools, which are of potential use in meeting the goals of the model specified in chapter 4 .

AIMMS is an optimization technology that must be thoroughly evaluated, since it is the preferable tool to be integrated in the model (see chapter 3.5.2).

MS Project is the project management tool, which is used in executing the model (see chapter 3.5.3).

MATLAB, SPSS and R are alternative proprietary and open source tools, which would potentially prove helpful in solving the mathematical requirements of the model. These alternative tools will be discussed in order to have a comparison of the estimated performance amongst both proprietary and open source tools. In doing so we are able to evaluate the functionality, compatibility, reliability, user friendliness, degree of standardization etc. between all potential tools.

${ }^{150}$ see Lucas (2006) 


\subsubsection{Usage of the Optimization-Tool “AIMMS”}

\subsubsection{Introduction}

"AIMMS is an optimization technology that enables you to make complex decisions faster, more accurately, and more consistently by suggesting \& comparing optimal solutions. Our optimization technology can retrieve the most value out of your assets. It is used by leading companies to support and improve decision making in a wide range of industries."

In order to solve the problem framed in chapter 4, with the goal of minimizing costs, radiation exposure and project duration, monitoring tools are necessary to get the highest achievable control of the model and its components. AIMMS (Advanced Interactive Multidimensional Modeling System) supports this goal attainment with common methods and functions (e.g. Lean Management and Simultaneous Engineering techniques, simulations, forecasts, risk assessments), in order to make the model and its degree of efficiency as visible as possible.

\subsubsection{Application of AIMMS on the model}

The specification of the model and its minimization functions will be shown in the next chapter. AIMMS offers so called linear optimization tricks, useful for models with linear and nonlinear structures. In the specified model the minimizing functions are of the following structure:

Minimize: $\quad \sum_{j \in J} c_{j} x_{j}$

Subject to:

$$
\begin{array}{r}
\sum_{j \in J} a_{i j} x_{j} \gtrless b_{i} \quad \forall i \in I \\
x_{j} \geq 0 \quad \forall j \in J
\end{array}
$$

${ }^{151}$ see AIMMS (2012a); "AIMMS is developed and brought to the market by Paragon Decision Technology. The company also provides application development consultancy, and support to its customers and works in close co-operation with selected service partners." 
AIMMS offers several state-of-the-art-techniques and optimization functions, explained in the "AIMMS-Optimization Modeling-Manual" 152 with detailed information for application and implementation.

\subsubsection{Algebraic Representation of Models}

The method of translating an explicit format to an AIMMS format is explained in the AIMMS Modeling Guide. The explicit form is the algebraic notation. Differences between several representations of the same model are illustrated by the potato chips model. The model should have comments where numbers are given to provide for quick understanding and a descriptive symbol for each number or group of numbers. A more efficient and structured approach for model building can be created. The motivation is then drawn for symbolic model formulation ${ }^{153}$.

In chapter 6.3 the function for the constrained minimization problem will be specified in AIMMS.

\subsubsection{Microsoft Project}

\subsubsection{Overview}

Microsoft Project is one of the dominant PC-based project management software tools on the market. The goal of MS Project is it to support project manager in

- formulating a project plan,

- allocating resources to tasks,

- pursuing progress,

- controlling the budget and

- monitoring workloads.

${ }^{152}$ see AIMMS (2012b), p. 63ff.

${ }^{153}$ see AIMMS (2012b), p. $32 \mathrm{ff}$. 


\subsubsection{The Project Map: Your road map to project management}

The Project Map assists in project management through the three phases of the project life cycle, including building a plan, tracking and managing a project, and concluding the $\operatorname{project}^{154}$.

\section{Build a Plan}

A plan is necessary before starting a project in order to define what will be explored, the scope of the project, and its desired outcome. When building a plan, several goals also need to be planned for. The project should be initiated by defining aims, expectations, and limitations. A project plan can then be started, involving a project file where preliminary project data and planning documents are attached. The outcomes should be defined including the actual product or service that is required ${ }^{155}$.

\section{Plan project activities}

It is very important to plan for the full scope of the project and the major activities involved in creating the project. The work involved can be organized into milestones, phases and tasks and then entered into the project plan, and the tasks can be further structured through the customized work breakdown structure (WBS) codes or outline codes. Often times, based on the task durations entered, Project 2007 can calculate a realistic schedule and then schedule specific tasks for specific dates. Relationships can be created between projects by creating task dependencies, for the purpose of evaluating the effects of activities of one project on another project ${ }^{156}$.

\section{Plan for and procure resources}

Using the information already collected, preliminary estimates can be made, requirements can be identified and staffing and processes to acquire the resources needed, can be initiated. After the resource information is identified, approved and procured, it can be

\footnotetext{
${ }^{154}$ see Microsoft Office (2013)

155 see Microsoft Office (2013)

${ }^{156}$ see Microsoft Office (2013)
} 
entered in the project plan. These resources can be shared across multiple projects. Resources can also be assigned to specific tasks set up as part of the project ${ }^{157}$.

\section{Plan project costs}

The costs of the project are the resources, people involved, equipment used and materials consumed. The costs of the resources and tasks must first be estimated and can be saved as a budget before the plan is tracked and managed. Important notes about the budget can be attached and the information can be transferred to other file formats. Preparations to stay within the budget should be made. You can specify a start date for the financial year, control the calculation options, and determine when the costs are payable ${ }^{158}$.

\section{Plan for quality and risks}

The project should be planned for unexpected outcomes by identifying quality standards to achieve project objectives. Identifying risks and planning for them helps keep the project on schedule and on budget ${ }^{159}$.

\section{Plan communication and security}

Methods for effective communication should be established to keep the project current, and the security features of Project 2007 should be used to prevent unauthorized access to project information ${ }^{160}$.

\section{Optimize a project plan}

After beginning the project, the project plan should be optimized to meet the finish date, reviewing the distribution of resources, and meeting the budget ${ }^{161}$.

\section{Print and distribute project information}

After arranging the project, it is important to keep project members up-to-date by providing printed and online project information and reports ${ }^{162}$.

\footnotetext{
${ }^{157}$ see Microsoft Office (2013)

${ }^{158}$ see Microsoft Office (2013)

${ }^{159}$ see Microsoft Office (2013)

${ }^{160}$ see Microsoft Office (2013)

${ }^{161}$ see Microsoft Office (2013)

${ }^{162}$ see Microsoft Office (2013)
} 


\section{Track and Manage a Project and Track progress}

To track the progress of the project, you have to select the items you want to track along with the tracking method. The progress can be recorded and updates can be replied to ${ }^{163}$.

\section{Manage a schedule}

Your schedule can be reviewed to identify problems with it and a variety of strategies exist to manage your project schedule. The progress can be reported to team members and stakeholders ${ }^{164}$.

\section{Manage resources}

Resources should be managed by balancing their workloads and tracking the progress on tasks. In order to check that the resources are ideally assigned to tasks to produce the required result, review the resource information such as assignments, resource costs, and variances between planned and actual work. Over allocation or under allocation information shows where workload needs to be managed to get the best results from resources. The shared resource information after adding enterprise resources needs to be managed to ensure it is cost effective and flexible ${ }^{165}$.

\section{Manage costs}

The costs of the project need to be kept within budget by reviewing the basic cost information and performing a more detailed analysis of the cost information. Project 2007 can fix the budget problem and re-optimize the schedule for $\operatorname{cost}^{166}$.

\section{Manage risks}

New project aims can be found when the risks of the project are identified, moderated and controlled. You may need to respond to risk events to control the effect on the $\operatorname{project}^{167}$.

\footnotetext{
${ }^{163}$ see Microsoft Office (2013)

${ }^{164}$ see Microsoft Office (2013)

165 see Microsoft Office (2013)

166 see Microsoft Office (2013)

${ }^{167}$ see Microsoft Office (2013)
} 


\section{Close a Project and review final project information}

To close a project, the team members and stakeholders should analyze the project by summarizing project information, project effectiveness and archiving project data in order to produce the final view or report ${ }^{168}$.

In several chapters MS Project is used as a tool to organize the processes developed in this dissertation (s. chapter 6.3.7).

\subsubsection{Matlab}

\subsubsection{Overview}

MATLAB $^{\circledR}$ is a solution to spreadsheets and traditional programming languages, used for numerical computation, visualization and programming. The user can analyze data, develop algorithms, and create models and applications. It can be used for a variety of applications, making it useable for over a million engineers and scientists in industry and academia. Signal processing and communications, image and video processing, control systems, test and measurement, computational finance, and computational biology can be achieved with MATLAB ${ }^{169}$.

MATLAB was developed to perform numerical calculations on vectors and matrices. It can do fairly sophisticated graphics on two and three dimensions and has a high level programming language (a "baby C") that makes it easy to code complicated algorithms involving vectors and matrices. It can solve nonlinear initial-value and linear boundaryvalue differential equations ${ }^{170}$.

\footnotetext{
${ }^{168}$ see Microsoft Office (2013)

${ }^{169}$ see MATLAB (2012)

${ }^{170}$ see Overman (2012), p. 3
} 


\subsubsection{Available Functions}

There are several MATLAB-functions which are helpful in solving the constrained minimization problems discussed in this work ${ }^{171}$ :

- fminbnd Find minimum of single-variable function on fixed interval

- fmincon Find minimum of constrained nonlinear multivariable function

- fseminf Find minimum of semi-infinitely constrained multivariable nonlinear function

In chapter 6.4 the function for the constrained minimization problem will be specified in MATLAB.

\subsubsection{R}

$\mathrm{R}$ - the programming language - is also a tool to solve the mathematical requirements.

\subsubsection{Introduction to $\mathbf{R}$}

$\mathrm{R}$ can be defined as a language and environment for running code for statistical computing and graphics. It is a GNU ("GNU-is-not-UNIX") project and has similarities to the $\mathrm{S}$ language. The $\mathrm{S}$ language tends to be used for research into statistical methodology, whereas the $\mathrm{R}$ language is the Open Source pathway into statistical methodology. It allows a number of statistical and graphical techniques. The user of the R language has full control over design choices in graphics and it is very easy to produce well-designed publication-quality plots, which is considered one of its strengths. $\mathrm{R}$ can be used on a range of UNIX platforms and equivalent systems along with Windows, MacOS, FreeBSD (Berkeley Software Distribution) and Linux and it is accessible as Free Software through the Free Software Foundation's GNU General Public License in code source form ${ }^{172}$.

\footnotetext{
${ }^{171}$ see Mathworks (2013)

${ }^{172}$ see R-Project (2013)
} 


\subsubsection{The $R$ environment}

$\mathrm{R}$ includes a data handling and storage facility, a suite of operators for calculations on arrays in particular matrices, an accumulation of intermediate tools for data analysis, graphical facilities for data analysis which display either on-screen or on hardcopy, and a programming language which includes conditionals, loops, user-defined recursive functions and input and output facilities ${ }^{173}$.

The R “environment” describes a comprehensive system where statistical techniques are carried out, and allows users to define new functions. Users can easily follow algorithmic choices made because of the R systems similarity to S. C, C++ and Fortran code can be linked and called at run time for computer-comprehensive tasks, and C code can be written to manipulate $\mathrm{R}$ objects. $\mathrm{R}$ can be broadened through packages of which eight are supplied and more packages are available on the Internet through the CRAN family of sites which have a variety of modern statistics. Hardcopy and online diverse documentation is provided $^{174}$.

\subsubsection{Optimization routines available as an $\mathbf{R}$ Package}

The Numerical Algorithms Group's Fortran Library has over 1,700 algorithms and has given out a new and trial version of some optimization routines as an $\mathrm{R}$ Package. This release includes over 100 new user-callable routines and widened operability integrated into Library chapters on statistics, optimization, wavelet transforms, nonlinear equations, ordinary differential equations, interpolation, surface fitting, matrix operations, linear algebra, and special functions ${ }^{175}$.

Distinctly, the optimization chapters have been widened with new methods. New base generators amplify the large amount of subsisting random number generators and the interpolation chapter now has routines for four- and five-dimensional data. The statistical programming, $\mathrm{R}$, is now accessible through an accompanying trial version of the Optimization Chapters on Minimizing or Maximizing a Function. The code for NAGFWrappers R Package is coming out as open source and is available as a source

\footnotetext{
${ }^{173}$ see R-Project (2013)

174 see R-Project (2013)

175 see Armstrong (2009)
} 
package and a binary package for Windows 32 on the Numerical Algorithms Group (NAG) website. NAG routines from $\mathrm{R}$ can be found with NAG Library Callback Functions in $\mathrm{R}^{176}$.

In chapter 6.5 the function for the constrained minimization problem will be specified in $\mathrm{R}$.

\subsubsection{SPSS}

\subsubsection{Introduction to SPSS}

SPSS (Statistical Package for the Social Sciences) analyzes data through a set of software tools to generate tabulated reports, charts and plots of distributions and trends, descriptive statistics and complex statistical analyses. There are a number of windows available upon selection ${ }^{177}$.

SPSS accommodates the statistical analysis of data including thorough data access and readiness, analytical reporting, graphics and modeling. It can be used for survey authoring and categorization (IBM SPSS Data Collection), data mining (IBM SPSS Modeler), text analytics, statistical analysis, and collaboration and deployment (batch and automated scoring services). More possibilities are available with add-ons.

\subsubsection{Available SPSS Modules}

The available modules accredited are: SPSS Regression - Logistic regression, ordinal regression, multinomial logistic regression, and mixed models. SPSS Correlation Partial correlation, bivariate correlation SPSS Decision Trees. Recognizing groups and anticipating behavior can be done with classification and decision trees. SPSS Forecasting - ANOVA (Analysis of Variance) and ANCOVA (Analysis of Covariance). A correlation analysis and regression equations will be produced from highlighted versions of the mentioned software and analysis of wastage in terms of the case history below will be performed for methods of concreting. This is done by regression and correlation methods and the result is compared with the SPSS software analysis.

\footnotetext{
${ }^{176}$ see Armstrong (2009)

${ }^{177}$ see Jaggi, S., Batra, P. K. (2012), p. 67
} 
In chapter 6.6 the function for the constrained minimization problem will be specified in SPSS.

\subsubsection{Resumé}

In a trial period the applicability of each software tool will be tested. After evaluation of the feasibility a linear programming model will be applied in $\mathrm{R}$ (see chapter 6.5), AIMMS (see chapter 6.3), MATLAB (see chapter 6.4) and SPSS (see chapter 6.6) to solve a MOOP / SOOP. Also a simplified simulation approach will be used in order to generate data for the virtual database discussed in chapter 6.3.5. 


\section{FRAMEWORK OF MODEL DEVELOPMENT}

\subsection{Overview / Approach}

Two main goals were defined (see chapter 1.2). Firstly, the project management issues of a professional dismantling of nuclear installations, such as project preparation, prescheduling, design and approval planning, execution preparation, execution and project conclusion were focused upon, secondly the working out of the three items (A-C)

A) (I) minimizing total project $\operatorname{cost} \mathrm{f}_{1}(\mathrm{X})$

(II) minimizing safety hazard (risk) $\mathrm{f}_{2}(\mathrm{X})$ and

(III) minimizing project duration $\mathrm{f}_{3}(\mathrm{X})$

A MOOP (Multiple Objective Optimization Problem) was created by these goals. It was stated, how each objective is quantified, the variables affecting each objective function were identified and the ranges for those variables, or $a_{i} \leq x_{i} \leq c_{i}, I=1, \ldots, n$ and the form of the function $f_{j}(X), j=1, \ldots, m$.

B) Using the MOOP to single-objective optimization problem (SOOP) strategy, one of the above objective functions $\mathrm{f}_{\mathrm{j}}(\mathrm{X})$ was minimized while holding the other two under a bounding value $\mathrm{d}_{\mathrm{b}}$ and repeating this MOOP to SOOP process through several iterations, trying to identify a convergent solution.

C) A description of how the AIMMS program interfaces with the OMEGA application, and how AIMMS will be used to solve the MOOP was given, too. The description of how the AIMMS program interfaces with the OMEGA model is presented in chapter 6.3 (see item C). 
The traditional approaches are shown in chapter 3, 3.1, 3.2 and 3.3. The project management, lean management and simultaneous approaches are used to achieve the multiple objective optimization problem.

\subsubsection{Goals of the problem solution}

As specified above, the goal is to

- minimize total project costs,

- minimize safety hazard (risk),

- minimize project duration,

- by using meta-modelling techniques.

The dismantling planning or process planning plays the central role. All the process steps for the scheduling of a project or any details and optimization are defined and understood under the term planning. All planning is structured in three planning steps (pre-phase, gross-phase and a detailed planning). If necessary, all operation alternatives will be examined and audited.

\subsubsection{Content and alternatives}

The Content and alternatives of this planning are:

- Disassembling and disintegration

- Decontamination and conditioning

- Clearance and evacuation of the materials or decentralized intermediate storage

- Final centralized storage of radioactive materials

The complexity and expenditure to demonstrate the feasibility of all minimizing goals mentioned above is too high, hence, in this dissertation we focus only on minimizing the continued risk of storage. 


\subsubsection{Problem Structure in General}

Most problems including the stakeholders, solutions, sources of risk and relevant performance measures cannot be determined with classic decision analysis techniques. Determining the elements of a problem can be called problem structuring ${ }^{178}$.

Experts in the simulation community have noted that core processes should be understood before input modeling, specifically the fitting of distributions to data. Moreover, the quality of that process maybe poor due to the use of large amounts of data in problem structuring and solving. This relates to the Limited Information Collection Principal, believing that a purpose should always exist for collecting data before the process to avoid one having no understanding of the data they are collecting ${ }^{179}$.

Completeness means that all aspects of a problem are addressed by its set of features. Operability refers to the possibility of computing values for attributes as a function of possible alternatives. These attributes should also be understandable to those involved in decision making. Decomposability is the idea that the decision maker can decompose the assessment of the preference structure of a problem with a larger set of attributes. Nonredundancy means that there is no commonality between attributes. The number of attributes should be as small as possible. This is difficult to maintain as the decision making process is more accurate with a larger number of attributes; however there is more effort involved. In this case a different alternative could be considered ${ }^{180}$.

The definitions of a problem by Evans (1991), suggests the idea of a gap between a current and a desired situation or the 'state of affairs'. This gap can be positive, negative or unknown ${ }^{181}$, negative, when a drop in performance occurs. A positive gap exists when an opportunity is seen, and unknown when a significant change in the state of affairs has occurred $^{182}$.

Simon (1960) recognized well-structured, semi-structured, and ill-structured problems. Well-structured problems have complete information. They typically have a routine, clear

\footnotetext{
${ }^{178}$ see Evans (2012), p. 1

${ }^{179}$ see Evans (2012), p. $13 \mathrm{ff}$.

${ }^{180}$ see Evans (2012), p. $42 \mathrm{ff}$.

${ }^{181}$ see Basadur, Ellspermann, and Evans (1994)

182 see Evans (2012), p. $1 \mathrm{ff}$.
} 
objectives and obvious solutions. Ackoff (1979) noted however that most problems encountered in real-life do not have a structure and are "messes, where the appropriate decision makers and potential alternative solutions may not be apparent". The data required to model the problem is usually not readily available. Ackoff (1979) termed this type of problem a "mess", that is a dynamic situation consisting of complex systems of changing problems that interact with each other. Rittel and Webber (1973) called these situations "wicked" (as opposed to tame) problems; Schon (1987) called these types of problems "swamps" or "swampy situations" 183 . All these problem structuring concepts will be considered in designing the problem solution approach in the dissertation.

The goal of this chapter is it to discuss the main issues investigated in this dissertation. The classification of the problem structure considered here can be specified as follows:

Risk management issues are addressed in chapters 4.4.3, 4.6 and 4.9.

Decision analysis and support is promoted by the application of special methods (project management (see chapter 3.1), lean management (see chapter 3.2), simultaneous engineering (see chapter 3.3), operations research (see chapter 3.4) and software tools (see chapter 3.5), the leveraging of different approaches within the model-based framework (see chapter 4), taking empirical data as a basis (see chapter 5) and the bundled implementation and application of all of these approaches.

Simulation is used in a simplified manner in order to derive virtual data for use in the virtual database (see chapter 6.3.5) based on the presented empirical data (see chapter 5).

The completeness of the data is deemed average, since relevant data is scarce due to difficulties in obtaining real world data because of national security issues.

Also the operability of the problem solution is deemed average because of the lack of empirical studies using a combination of the presented approaches. Also the operability is limited due to a high degree of virtual or inferred data.

Therefore we must view the problem-structure as semi-structured.

${ }^{183}$ see Evans (2012), p. $2 \mathrm{ff}$. 


\subsection{The OMEGA-Project}

\subsubsection{Project Introduction}

The planned overall objectives of the coordinated research project, the spectrum of possible procedures in the process of selecting scenarios and technologies for the decommissioning of the nuclear facilities are presented in several IAEA Publications (see Arnold 1997), (see Cross et al. (2005) in IAEA-TECDOC-1602. The most important parameters, which are cost and safety, are presented in IAEA publication (see Chard 1999). The safety parameters in the selection of the optimal decommissioning scenario are discussed and presented in the recent IAEA project DeSa (see Graham et al. 2006). The process becomes more objective mainly because the calculated data is specific to the evaluated facility ${ }^{184185186187188}$.

The new computer tool OMEGA, is a code that assists in the evaluation and optimization of the selection of better decommissioning technologies and scenarios. The code uses one compact calculation structure, including the inherent system for flow control of materials and radioactivity, directly linked to the facility inventory, enabling matrices of data which can be used for multi-attribute analysis of decommissioning scenarios. The facility inventory database is also updated in relation to the decommissioning activities, allowing the real radiological situation of the facility to correspond to the calculated data ${ }^{189}$.

\subsubsection{Project Requirements}

Selecting the optimal decommissioning technologies of dismantling and waste management, and the implementation of remote controlled techniques largely effect the decommissioning parameters including cost, manpower and dose ${ }^{190}$.

\footnotetext{
${ }^{184}$ see Arnold (1997)

185 see Cross et al. (2005)

186 see Chard (1999)

187 see Graham et al. (2006)

188 see IAEA (2008), p. 217

${ }^{189}$ see IAEA (2008), p. 218

190 see IAEA (2008), p. 218
} 
Safety in performing the decommissioning activities should be demonstrated, mainly involving the parameter of the annual dose limit for an individual member of the staff and the methodology for evaluating this ${ }^{191}$.

Relating to waste management issues in the decommissioning process, the representative scenarios of waste management available for the decommissioning project are found through the process of using direct data links to the inventory facility database. The International Atomic Energy Agency presents the methodology for evaluating the impact of conditional release of materials from decommissioning as a special case of the waste management scenario ${ }^{192}$.

The additional goal of presenting methodology for harmonizing the structure of decommissioning costs as they are, is presented in the common document of the IAEA, OECD/NEA and the European Commission (see Wickham et al. 2007) - a cost structure, which will improve understanding of individual cost items involved in the decision making process ${ }^{193} 194$.

\footnotetext{
${ }^{191}$ see IAEA (2008), p. 218

192 see IAEA (2008), p. 218

${ }^{193}$ see Wickham et al. (2007)

${ }^{194}$ see IAEA (2008), p. 218
} 


\subsubsection{The Scope of the Subproject "OMEGA"}

The scope of the sub-project aims to present the possibilities introduced in decommissioning costing and planning by the decommissioning code OMEGA. The decommissioning code OMEGA is a new tool for general application in decision making processes and for planning in decommissioning. It implements the internationally accepted standardized structure of items for decommissioning costing.

The following aspects are presented by the International Atomic Energy Agency ${ }^{195}$ :

- The selection of the optimal decommissioning option by evaluation of the decommissioning options

- The application of remote dismantling techniques through modelling techniques

- Safety evaluation in decommissioning,

- Evaluation of conditional release of metallic materials through the analytical approach and waste management scenarios.

The above listed approaches were supported by model calculations using two model databases $^{196}$.

OMEGA is a project for the support of the decision making process in order to select scenarios and technologies for the decommissioning and dismantling of nuclear facilities, modelled in a multi-parametrical process. "The OMEGA code is used for ${ }^{197}$

- generation,

- calculation, and

- optimisation

of individual options of decommissioning in the decision making and planning phases." $" 198$

195 see IAEA (2008), p. 219

196 see IAEA (2008), p. 219

197 see IAEA (2008), p. 217

198 see IAEA (2008), p. 217 
The underlying main parameters are ${ }^{199}$

- "cost",

- "exposure",

- “manpower",

- "personnel",

- "material",

- "radioactivity data"

- and "the decommissioning schedule in the form of the Gantt chart".

The OMEGA tool provides $\mathrm{a}^{200}$

- "standardised structure of items for costing purposes and

- The system for on-line management of material and radioactivity flow in decommissioning process."

Methods for the evaluation and optimisation of decommissioning options and for the modelling of dismantling techniques, such as remote dismantling techniques are the main functions of the OMEGA tool. Additionally methods for the evaluation of safety in the decommissioning planning phase and analytical methods for the optimisation of waste management scenarios, such as the approach for evaluation of conditional release of metals are parts of the OMEGA concept ${ }^{201}$.

${ }^{199}$ see IAEA (2008), p. 217

${ }^{200}$ see IAEA (2008), p. 217

${ }^{201}$ see IAEA (2008), p. 217 


\subsubsection{The OMEGA code and its applications}

Taking into account that the cost structure of most current methodologies is different for various projects; the costs are less, if at all, able to be compared. OMEGA is based on calculation modelling of the complete decommissioning process including waste management, unlike current methodologies, enabling the improvement of current limitations of traditional costing methodologies ${ }^{202}$.

The features of the code are included in the IAEA-TECDOC- $1602^{203}$.

\subsubsection{Calculation Structure}

The calculation structure and process uses the actual material and radiological data. It has the ability to sequentially simulate the real decommissioning process flow and relevant material/radioactivity flow. The calculation items are linked to the material and radiological data of the inventory database and to the database of interim material/ radiological items generated during calculation ${ }^{204}$. In 1999 the OECD/NEA, IAEA and EU published the document "A Proposed Standardized List of Costs Items for Decommissioning Purposes" (PSL) (see OECD/NEA/ EC/ IAEA 1999). This paper offers a definition of the structure of decommissioning activities, presenting the corresponding costs, facilitating and harmonizing the decommission process. In doing so the editing organizations responded to incongruities between the presented costs of various decommissioning projects, which were caused by different activity dimensions, by technical, local and financial factors, by waste management systems etc. The standardized cost structure basically depicts the system of decommissioning with the following activities ${ }^{205}$ :

a) Pre-decommissioning actions.

b) Facility shutdown activities.

c) Procurement of general equipment and material.

202 see IAEA (2008), p. 219

${ }^{203}$ see IAEA (2008), p. 219

${ }^{204}$ see IAEA (2008), p. 220

${ }^{205}$ see Vasko (2012) p. 46 
d) Dismantling activities.

e) Waste processing and disposal.

f) Site security, surveillance and maintenance.

g) Site restoration, cleanup and landscaping.

h) Project management, engineering and site support.

i) Research and development.

j) Fuel and nuclear material.

k) Other costs.

In the framework of the standardized structure are named following cost groups ${ }^{206}$ :

12.0100 Labour costs.

12.0200 Capital, equipment and material costs.

12.0300 Expenses.

12.0400 Contingency.

Although the principle objective was to provide a structure for presenting the costs for decommissioning, the structure is also applicable for other decommissioning parameters, as well as it can serve as the base for the calculation structure of costs. Particular issues of the specific decommissioning projects, such as the project's work breakdown structure, can be composed through the use of the standardized calculation structure ${ }^{207}$.

\subsubsection{Methods of Implementation of Standardized Cost Structure}

The calculation structure in order to calculate costs and further decommissioning parameters results from the interaction of the inventory database and the list of decommissioning activities. During this interaction sets of room-oriented decommissioning activities are repeated considering the structure building object - floor - room and for each inventory item inside the room are generated sets of decommissioning activities. This structure is repeated in various areas of the entire calculation structure for typical decommissioning activities like dismantling,

\footnotetext{
${ }^{206}$ see Vasko (2012) p. 46

${ }^{207}$ see Vasko (2012) p. $46 \mathrm{f}$.
} 
decontamination of building surfaces etc., while other areas don't depend on the inventory database but rely on their own conditions for generation of calculation items ${ }^{208}$.

The implementation of Proposed Standard List (PSL) structure of decommissioning activities is what characterizes the standardized calculation structure for calculating of the decommissioning parameters. Besides, in relevant sections (e.g. dismantling) it refers on the decommissioning inventory database to generate the individual calculation items. Hence the structure of the decommissioning inventory should comprise the necessary data for the generation of the standardized calculation structure. Furthermore it should facilitate the generation of a standardized calculation structure for special features distributed in more independent sections.

\subsubsection{Implementation of Standardized Cost Structure in OMEGA Code}

The implementation of the standardized structure of decommissioning activities takes place in three basic steps ${ }^{209}$ :

- Elaboration of the detailed standardized structure of activities with levels distinguished in numbers.

- Elaboration of the decommissioning database with data elements making possible the generation of the standardized calculation structure.

- Generation of the standardized calculation structure and its management

An example for the simplified proceeding for the implementation of the standardized structure of decommissioning activities is given in Figure 5 which depicts a case of generated standardized cost calculation is depicted:

\footnotetext{
${ }^{208}$ see Vasko (2012) p. 47

${ }^{209}$ see Vasko (2012) p. 47
} 


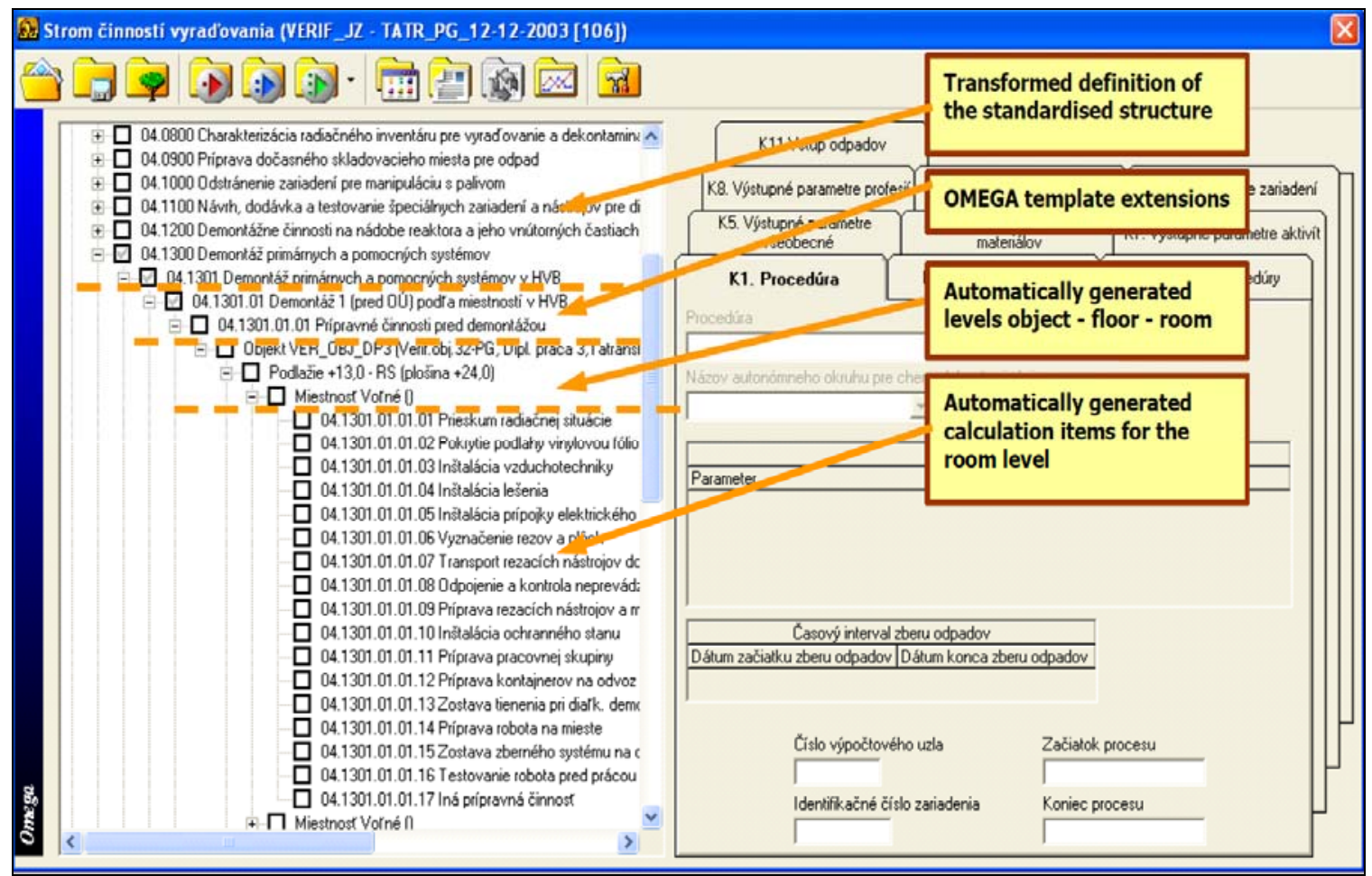

Figure 5: $\quad$ Example of an executive standardized cost calculation structure ${ }^{210}$

This three-step style of the work facilitates flexibility in developing the standardized calculation structures for each nuclear facility. The inventory database for the nuclear facility, providing relevant structure and data which are needed for implementation of standardized structure, acts as precondition ${ }^{211}$.

\subsubsection{Executive Calculation Structure of FA Facility}

The executive calculation structure for the FA Facility has been elaborated basing on the procedure described in the previous chapter. The calculation structure was based on the elaborated inventory database of the FA Facility and a standardized template developed from the principal template of the standardized decommissioning structure created for OMEGA code. Before the production of the standardized calculation structure for the FA Facility, the elaborated inventory database is completed for data necessary for generation

\footnotetext{
${ }^{210}$ see Vasko (2012) p. 49
}

${ }^{211}$ see Vasko (2012) p. 49 
of the calculation structure. The whole process from constructing the inventory database to the generating of the executive calculation structure is depicted in Figure $6^{212}$.

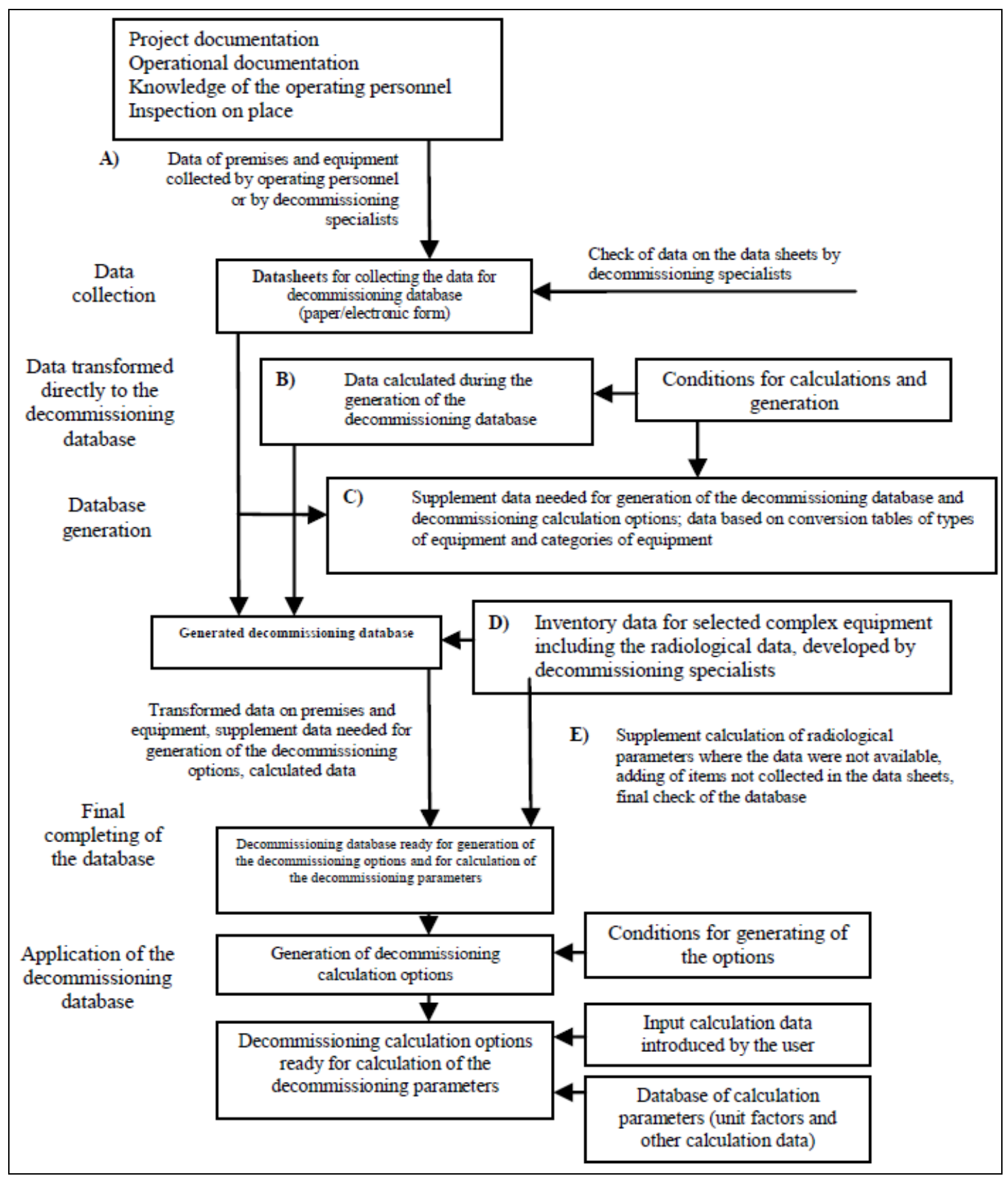

Figure 6: $\quad$ Principal phases of development of the inventory database and generating of the calculation structure ${ }^{213}$

212 see Vasko (2012) p. $49 \mathrm{f}$

${ }^{213}$ see Vasko (2012) p. 50 
- Data of "A" type constitute the primary data to be collected from facility technical documentation. They are based on physical inspection in individual areas of the object $^{214}$.

- Data of "B" type are the secondary data deduced from the primary data by decommissioning experts' calculations ${ }^{215}$.

- Data of "C" type are the data applied in the creation of the calculation database and in the creation (or definition) of the decommissioning calculation options ${ }^{216}$.

- Data of " $D$ " type represent the complement inventory data for complex reactor structures, elaborated in different tasks. For the preparation of such data supplementary complex calculations such as neutron flux calculations, calculation of activation of reactor construction of materials and the elaboration of a hierarchical inventory database structure which correspond to intended dismantling procedure are needed. Other complex equipments like steam generators, volume compensators, primary piping are based on analogous approaches. This type of data should be collected by decommissioning specialists. For the FA Facility this is not the normal case. The refueling machine is the only equipment, for which the described procedure could be exercised in the frame of upgrading of the inventory database $\mathrm{e}^{217}$.

- Data of "E" type consist in general of the radiological data, that is, the contamination levels and the nuclide composition of contamination or dose rate. The corpus of radiological parameters is supposed to be collected in the frame of the primary data collection by the operational personnel. In case they are not disposable as the primary data, the contamination data then can be calculated basing on calculation models of equipment categories. For his part, the nuclide composition can be deduced from radiological analysis of decisive samples ${ }^{218}$.

\footnotetext{
${ }^{214}$ see Vasko( 2012) p. 50

${ }^{215}$ see Vasko (2012) p. 50

${ }^{216}$ see Vasko (2012) p. 50

${ }^{217}$ see Vasko (2012) p. $50 \mathrm{f}$.

${ }^{218}$ see Vasko (2012) p. 50f.
} 


\subsubsection{Study of the effects}

The study of the effects of time in the case of deferred decommissioning is possible through this calculation process, which is nuclide-specific and respects the radioactive decay of individual radionuclides, addressing various nuclide-specific limits for decommissioning activities within the material flow. The decommissioning infrastructure is replicated by various scenarios for waste management from decommissioning activities linked with dismantling, up to the disposal of conditioned radioactive waste or release of materials $^{219}$.

In order to define separate calculation cases, the decommissioning Work Breakdown Structure (WBS) of individual cases is linked to a standardized calculation structure.

After optimization in MS Project software, the decommissioning parameters are automatically recalculated according to the optimized start dates of individual decommissioning activities ${ }^{220}$.

\subsubsection{OMEGA model components taken into account}

In appendix 8 the following issues and components of the OMEGA model are shown in detail:

- Principal scheme of the decommissioning calculation code OMEGA

- OMEGA generates the following groups of calculated parameters

- Three basic groups of data used by OMEGA

- General procedure for the evaluation of decommissioning parameters

- Principle of the material and radioactivity flow control as implemented in the OMEGA code

- The procedure for optimization of decommissioning options using the Gantt chart

\footnotetext{
${ }^{219}$ see IAEA (2008), p. 220

${ }^{220}$ see IAEA (2008), p. 220
} 
- A graphical interpretation of main steps of the interactive work with the OMEGA code

- Principle scheme of the waste management in the OMEGA code

- Waste Types in OMEGA

All of these model components are taken into account during the implementation of the framework (see chapter 6).

\subsection{Decommissioning cost estimating and funding approaches}

Estimating the cost of decommissioning requires a specific approach to be customized to fulfil the purpose for which it is being leveraged. Cost estimates are generally undertaken for purposes such as informing the government and guiding their funding policy, financial requirements, and financial liabilities, as a basis for industrial strategy and for decommissioning activity planning and management. A strategic plan further assists cost and schedule management during operations, contracting, and solicitation of tender offers $^{221}$.

The present study focuses on cost estimates that represent the financial responsibilities of NPP operators. The funding aspect raises the issue of discounting those costs, recognizing that decommissioning expenses will occur in the future and that the value of money is important. Uncertainties can become apparent while estimating and presenting costs, arising due to questions of national policy and regulations, future economic conditions, and various aspects of decommissioning strategy planning. Such uncertainties are generally addressed by contingencies reflected in the projected range of each cost group and element ${ }^{222}$. As next cost estimation methods underlying the framework developed in this dissertation will be compared with traditional cost calculation methods for the decommissioning of NPP.

\footnotetext{
221 see Nuclear Energy Agency (2003), p. 45

222 see Nuclear Energy Agency (2003), p. 45
} 


\subsubsection{Stages for successive estimates and calculations for decommissioning}

There are many sources dealing with cost calculation methods specific to decommissioning. In this context Huebner (1982) emphasizes that the most significant cost factor is the method applied for the commissioning. The methodology, in turn, depends on the radiological condition. According to Taboas et. al. (2004) there are three stages for successive estimates and calculations for decommissioning ${ }^{223}$ :

1. Order-of-magnitude estimate: For this kind of estimate there are used scale-up or scale-down factors and approximate ratios, there is no need of detailed engineering data. The exactitude of the estimates is expected to lie between $-30 \%$ to $+50 \%$.

2. Budgetary estimate: Such an estimate bases on a general concept of which methods and what kind of equipment is going to be used, likewise depending on results of some previous radiological survey. Neither at this stage detailed engineering data is required. The exactitude of the estimates is expected to lie between $-15 \%$ to $+30 \%$.

3. Definite estimate: All details of the project including engineering data have been fixed. The exactitude of the estimates is expected to lie between $-5 \%$ to $+15 \%$.

Regarding this viewpoint the cost estimation method applied in the framework presented in this dissertation is an order-of-magnitude method, since detailed data is not given I the required amount. Only the yearly costs - leant on Jones et al. 1998 (see chapter 4.4ff.) and the values of the presented package plans give an orientation (see chapter 6.3.5 / appendix 4) in the development of the framework.

Alike Taboas et. al. (2004) identify different techniques for estimation applied at different stages, such as the bottom-up technique, specific analogue technique, parametric technique, cost review and update technique, expert opinion technique etc. Depending on the disposable background material (amongst others radiological surveying, technological selection and stage of technical planning) the uncertainty of a cost calculation can highly

${ }^{223}$ see Sjöblom/Lindskog (2004), p. 18 
vary. Because of this the state of development, the methodology and the estimated uncertainty have to be clearly determined ${ }^{224}$.

The uncertainty of the cost estimation in the framework presented in this dissertation is high. The focus is not on exactitude (regarding the materials and their properties), but on the design of the model and its implementation using state-of-the-art-methods and tools.

\subsubsection{Cost categories for the decommissioning of NPP}

Costs can be classified into four categories, depending on the nature of decommissioning activities, methods of cost calculation and types of main input variables ${ }^{225}$ :

a) Activity-dependent costs are related to the intensity of "hands-on" work used for decommissioning, including such activities as decontamination and disposal of wastes, etc. Costs are produced amongst others by labour, energy and equipment but depend mainly on the facility inventory data, specific work factors depending on systems and structures and at least on probably aggravating local working conditions.

b) Period-dependent costs find themselves in correlation to the duration of an entire project or individual activities as well as to the working group configuration and their labour cost unit factors. These costs are mainly independent of the exact level of the hands-on activities.

c) Collateral costs and costs for special items are generated through purchase or rent of equipments for the support of many different activities. Main input variables determining the cost are the equipment elements to be procured as well as the list of payments.

d) Contingency is the special cost item added to cost elements taken into account in order to leave financial scope for unforeseeable cost factors. The consideration of contingency is particularly important where previous experience has shown that unforeseeable events could occur, augmenting the costs.

\footnotetext{
${ }^{224}$ see Sjöblom/Lindskog (2004), p. 19

225 see Daniska/Laraia (2009), p. 4f.
} 
The categories considered in the framework developed in this dissertation belong to activity-dependent costs - regarding the values of radio activity extracted from the package plans (see appendix 4) - and period-dependent cost, based on the data presented by Jones et al. 1998 (see chapter 4.4ff.).

The decommissioning plan should be based on a list of basic activities, for which unit factors (manpower, costs, etc.) are to be defined (see chapter 6.2), as well as on a plant buildings and equipment inventory. The ladder should include all elements of systems and structures and serves for the definition of each type of activity. Through the interaction of the inventory with the activities list the calculation is given a structure. A detailed facility inventory database is fundamental for this approach. The items included in the plant inventory and in the list of activities of the project determine the unit factors, with the goal to develop the basic unit factors (manpower, costs, etc.) for optimum conditions. Furthermore considered are various increase factors such as working height, need for protective equipment, work breaks and other productivity losses. Not least the material and equipment costs in relation to the extent of work determine the final value of a unit factors. The calculation of the duration of individual work phases in a decommissioning project relies on the plant inventory and the list of activities, as well as on the unit factors approach. Those activities defined to be on a critical path - that is, if important phases of the project depend on completion of this activity - affect the whole projects` duration. These costs neither depend on the activities, nor on the duration of the project. Rather they can be calculated considering distinct lists of payment, including periodical payments like taxes, permanent payments during the project such as maintenance, surveillance etc. and specific non periodical payments like permits, licences, consultancies etc. The total cost estimate is finally a result from a threefold cost estimate - activity-dependent costs, period-dependent costs and waste management costs - complemented by the calculation of contingent costs. Special items that constitute a risk for cost escalation can be identified in the standardized cost structure in order of a selected calculation. One of the key steps in costing is the allocation of reasoned contingency to single calculation elements or groups of items. Considering these factors, 
the contingency can vary from $15 \%$ for the disposal of non contaminated equipment outside from the project area up to $75 \%$ for dismantling reactors ${ }^{226}$.

In the framework developed in this dissertation the main focus is on waste management costs (see chapter 4.4ff.). The management of waste is as exemplarily shown based on an inventory database, its preparation for the decommissioning, the development of calculation options and optimization techniques as - also exemplarily shown - based on the R-MOOP routine (see chapter 6.5.4.2).

\subsubsection{Steps of cost estimation}

Considering the described costing methodology and cost estimation, practical procedure in decommissioning costing involves - also based on Daniska/Laraia 2009 - these steps $^{227}$ :

- Preparation of Inventory Database: The database consists first of the systems and structures inventory which is aimed at the identification of the inventory item in the frame of the project building, equipment structure and further parameters like surfaces, volume etc. Secondly the database bases on radiological parameters, which target contamination, radioactivity and dose rates inside and outside of systems - if possible, all of them nuclide ${ }^{228}$.

- Preparation of the Database of Unit Factors: Unit factors serve as items for the database, as well as other data in relation to the foreseen individual decommissioning activities, like manpower unit factors, secondary waste production unit factors, structure of the working time, radio-nuclide parameters, parameters of waste management, correction factors, and other technicaleconomical parameters. In general the data preparation relies on information gained from completed decommissioning projects, as well as on published data or such data lend from nun-nuclear industry ${ }^{229}$.

\footnotetext{
${ }^{226}$ see Daniska/Laraia (2009), p. $5 f$.

227 see Daniska/Laraia (2009), p. 5 f.

${ }^{228}$ see Daniska/Laraia (2009), p. 6

229 see Daniska/Laraia (2009), p. 6
} 
- Generation of Calculation Options: The calculation options are based on existing or planned decommissioning infrastructure and selected decommissioning strategy. Furthermore they are related to the activities from the decommissioning plan. The extent of these options is supposed to take into account all decisive possibilities. The options' creation is based on facility inventory database and the frame of decommissioning activities foreseen in the calculation option ${ }^{230}$.

\section{- Calculation and Optimization of Options and Selection of Optimal Option:}

Each of these options is to calculate and to optimize individually. In the multilevel optimization process are included various steps, such as the adjustment of parameters, timing of schedule, durations etc. The finality of this end phase of decommissioning costing is the choice of the optimal calculation option from the set of options calculated and optimized for the projects facility. In this context an expert group from the IAEA recommends for choice the multi attribute analysis (see IAEA 2005b). This analysis gains his input data from calculated data from each option on the one hand and from subjective data given by the evaluators on the other hand. The option with the best characteristics is finally chosen for the planning of the future decommissioning project ${ }^{231}$.

As discussed in the following parts of the dissertation, only selected parts of these steps will be performed based on the framework developed in the dissertation, regarding the given limited resources.

${ }_{231}^{230}$ see Daniska/Laraia (2009), p. $6 \mathrm{f}$

${ }^{231}$ see Daniska/Laraia (2009), p. 7 


\subsubsection{Approach for costing model for research reactors}

In consideration of the above discussed aspects, the proposed parametric cost estimation system should consist of the following elements ${ }^{232}$ :

a) Implementation of bottom up principle (see IAEA 2005a), meaning the calculation of cost and further parameters decisive for decommissioning.

b) Flexible calculation structure, able to consider or exclude individual elementary decommissioning activities.

c) Standardized calculation structure, meaning the involvement of decommissioning activities as defined by IAEA/OECD/NEA/European Commission (1999) with the aim to harmonize the costing.

d) Calculation structure corresponding with the decommissioning plan, meaning that calculated data is supposed to be generated for every decommissioning activity defined in the plan of the decommission project.

e) Implementation of costing procedure based on international experience.

f) Organization of input data in a well-defined format to make possible the parameterization of the calculation model. Likewise the data has to be adaptable to the circumstances in that the object which is to decommission is embedded.

g) The formats of calculated data should comply with the condition for harmonization in costing.

h) Multi option approach in order to facilitate the decision process should be operable.

Items a) to c) target the main requisitions for the calculation arrangement. These requisitions are to ensure the calculation of data at the lowest elementary section, as well as the flexibility and standardization of the arrangement. Item d) defines the relation of the standardized calculation arrangement to the structure of the decommissioning work breakdown structure (WBS) of the individual decommissioning case. Item e) means that international experience in decommissioning costing has to be considered. Item f) belongs to the key challenges for the costing scheme with the aim to gain the features of the parametric costing model. The key input data are gained from the group of inventory

${ }^{232}$ see Daniska/Laraia (2009), p. 6 
data, unit factors data, personnel data and other input data characteristic for the complex. Item $g$ ) is linked to formats of calculated data, important for the harmonization in costing. These standardized formats can be elaborated either in a data reshuffle or through the direct data presentation in a standardized structure. Item $\mathrm{h}$ ) stands for the multi option approach (see IAEA 2005b) which can be implemented easily when having access to parameterized calculation arrangement in combination with data links to common modules with the key input data decisive for all calculation cases to be analyzed for the individual decommissioning case $^{233}$.

\subsection{Cost Structure of the Model}

\subsubsection{Overview of the cost structure}

Each element of the cost analysis performed is a cost to the manager. These elements are the basis of the costs, and are described by product function equations. Analysis elements can include waste transfer to storage, into treatment, and then to disposal. The equation involves quantities of input and output that are included in producing it.

Each activity within the model is structured as a production process. With knowledge of a production function, knowing which units of input it requires, we are given knowledge of a cost function $^{234}$.

\footnotetext{
${ }^{233}$ see Daniska/Laraia (2009), p. 7 f.

${ }^{234}$ see Jones et al. (1998), p. 9
} 


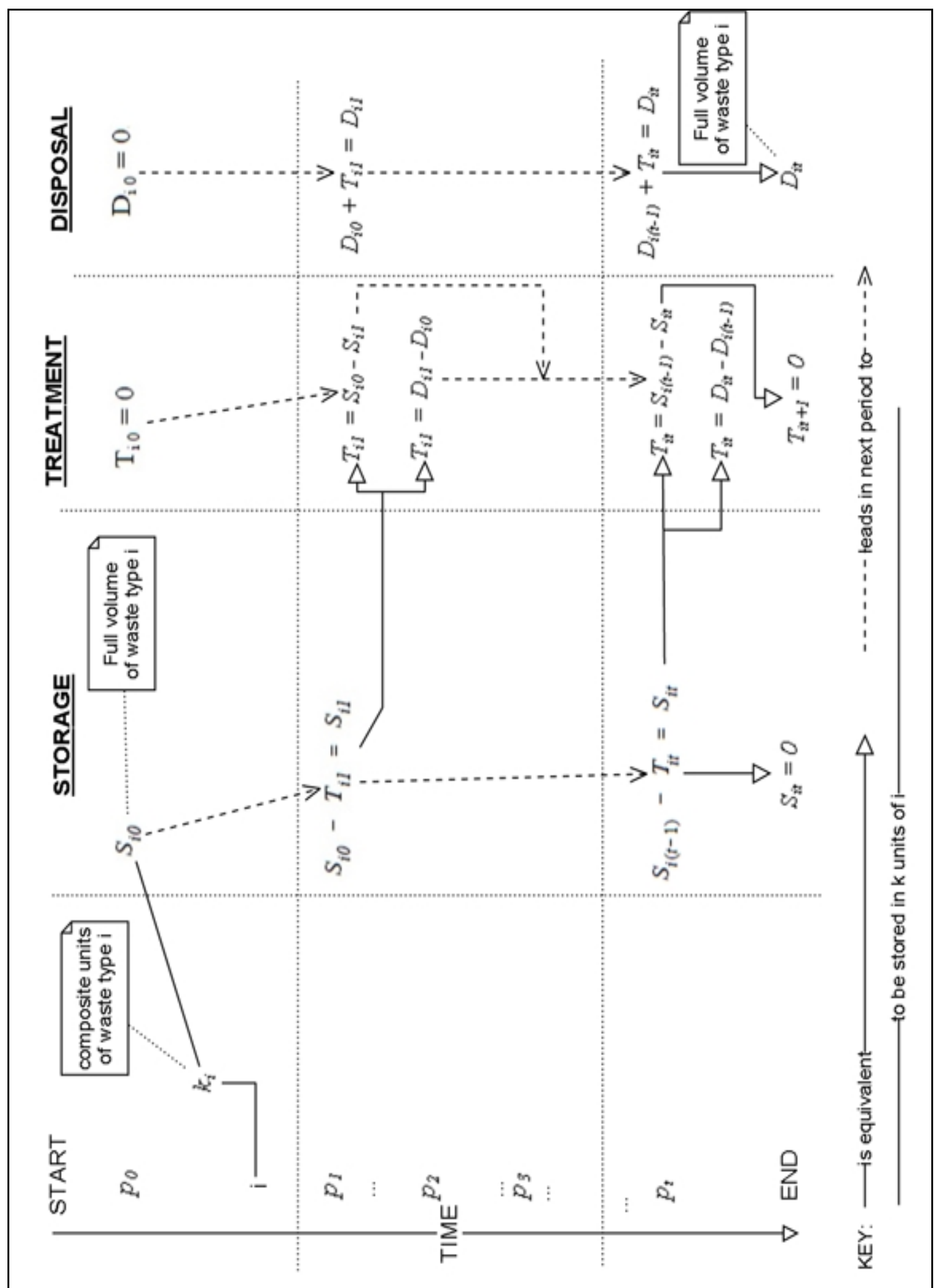

Figure 7: Changes of amounts of waste in the states storage, treatment and disposal 
Figure 7 shows the changes of amounts of waste in the states storage, treatment and disposal in the periods $\mathrm{p}_{0}$ to $\mathrm{p}_{\mathrm{t}}$. The amount of the variable input $\mathrm{k}$ required to store $\mathrm{a}$ volume of waste type $i$ is the first magnitude given. In the first period $\mathrm{p}_{0}$ the amount of $\mathrm{S}_{\mathrm{i} 0}$ represents the amount of the full volume of waste type $i$. The amount of waste in the states $T_{i 0}$ and $D_{i 0}$ in the first period $p_{0}$ is 0 , because the treatment process has not started yet and for this reason no waste is in disposal. In period $p_{1}$ the amount of waste type $i$ in storage is $S_{i 1}$ which is equal to $S_{i 0}-T_{i 1}$. Simultaneously the amount of waste in treatment increases in period 1 from $T_{i 0}$ to $T_{i 1}$ which equals $S_{i 0}-S_{i 1}$ and $D_{i 0}-D_{i 1}$. After this treatment the given amount of waste type $\mathrm{i}$ in period 1 the treated waste passes over to the state of disposal. The amount of waste type $\mathrm{i}$ in disposal is at the end of period $1 \mathrm{D}_{\mathrm{i} 1}$ which equals $D_{i 0}+T_{i 1}$.

In the next periods $p_{t}$ the amount of storage $S_{i 1}$ decreases to $S_{i t}$ which equals $S_{i(t-1)}-T_{t}$. $\mathrm{S}_{\mathrm{i}(\mathrm{t}-1)}$ is the amount of waste type $\mathrm{i}$ in storage in the period before $\mathrm{S}_{\mathrm{it}}$. Simultaneously the amount of waste in treatment increases from $T_{i 1}$ to $T_{i t}$ which equals $S_{i(t-1)}-S_{i t}$ and $D_{i t}-$ $\mathrm{D}_{(\mathrm{t}-1)}$. After this treatment in $\mathrm{p}_{\mathrm{t}}$ of the given amount of waste type $\mathrm{i}$ the treated waste passes over to the state of disposal. The amount of waste type $\mathrm{i}$ in disposal is at the end of period t $D_{i t}$ which equals $D_{i(t-1)}-T_{i t}$.

In the last period the full volume of waste type $\mathrm{i}$ is in disposal and the amounts of waste in storage and treatment zero.

Jones et al. 1998 presume that the lowest risk from waste originate from the states storage and disposal. The risk in the state treatment is especially so high because labor and human contact with waste is at a maximum level. In order to optimize the implementation of the R-MOOP, it is necessary to integrate this fact to the weighting of the risk in the three states additionally. At the end of the ten year period $90.4 \%$ of waste of type TRU, $76.7 \%$ of type MLLW and $66.7 \%$ of the type LLW was treated and relocated to the state disposal because the highest risk is originating from the type TRU. Hence Jones et al. prioritized the type TRU to be processed first and as much as possible, followed by the types MLLW and LLW. This is also a rule that can be expressed in the implementation of the algorithms in the R-MOOP program routine in order to optimize 
the functionality and the degree of the suitability in a real scenario. In analogy the regarded waste types $i$ can be categorized by their risk levels (see table 2).

\subsubsection{Product function for a particular activity}

The product function for a particular activity, describes the amount of the variable, composite input $\mathrm{k}$ that is required to sustain a given volume of a particular waste group in any particular state. The three states are: storage (S), treatment (T), and disposal (D).

The production function for the volume of waste, type (i), stored in time ( $\mathrm{t}$ ) is given $\mathrm{by}^{235}$ :

$S_{i t}=A_{i S} k_{i t S}^{\alpha_{i s}}$

The amount of the variable input $k$ required to store that volume of waste type (i), in time (t), is calculated by inversion of the previous equation ${ }^{236}$ :

$k_{i t S}=\left(S_{i t} / A_{i S}\right)^{1 / \alpha_{i S}}$

The formulation of the amount of waste devoted to treatment also includes retrieval of waste. Similar to the quantity of the input k needed for storage, this quantity for treatment can be found by inverting the production function ${ }^{237}$.

$T_{i t}=A_{i T} k_{i t T}^{\alpha_{i T}} S_{i(t-1)}^{\beta_{i T}}$

When the former equation is inverted, the number of units $\mathrm{k}$ devoted to the volume of waste disposal, can be solved for ${ }^{238}$ :

$D_{i T}=A_{i D} k_{i t D}^{\alpha_{i D}}$

\footnotetext{
${ }^{235}$ see Jones et. al. (1998), p. 9

${ }^{236}$ see Jones et. al. (1998), p. 9

${ }^{237}$ see Jones et. al. (1998), p. 10

238 see Jones et. al. (1998), p. 10
} 


\subsubsection{Maintenance of Risks}

The maintenance of risks associated with a waste type in a particular state requires the use of the composite input $\mathrm{k}$. In order to contain the risk involved, more units of $\mathrm{k}$ are required for a particular volume of waste, and particularly when this volume increases, it becomes more difficult to maintain the risk per unit volume at a given level (as shown with the negative exponent $\alpha$ on the $\mathrm{k}$, where more units of $\mathrm{k}$ reduces risk per unit volume).

"The equation used for risk per unit of waste has an exponent of $\beta$ on the volume variable $(\mathrm{S}, \mathrm{T}$ or $\mathrm{D})$ and the equation for the total risk has an exponent of $\beta+1$. The risk per unit volume is $\mathrm{R}$ on the left-hand side, divided by total volume and both multiplied by volume to eliminate it from the left, thus adding 1 to the exponent of the volume variable on the right" ${ }^{239}$ :

$$
R_{i t S}=A_{i R S} k_{i t R S}^{-\alpha_{i R S}} S_{i t}^{\beta_{i R S}+1}
$$

Total risk of putting a part of the stored waste through treatment is shown by ${ }^{240}$ :

$$
R_{i t T}=A_{i R T} k_{i t R T}^{-\alpha_{i R T}} S_{i t}^{\beta_{i R T}+1}
$$

The risk of treated waste kept in disposal is ${ }^{241}$ :

$$
R_{i t D}=A_{i R D} k_{i t R D}^{-\alpha_{i R D}} S_{i t}^{\beta_{i R D}+1}
$$

In each case it can be seen that the choice of $\mathrm{k}$ controls the total level of risk and risk per unit volume. The total risk of waste in all states is affected by the volumes in each state and the risk choices that are made for each state ${ }^{242}$.

\footnotetext{
${ }^{239}$ see Jones et al. (1998), p. 11

${ }^{240}$ see Jones et al. (1998), p. 11

${ }^{241}$ see Jones et al. (1998), p. 11

${ }^{242}$ see Jones et al. (1998), p. 11
} 
In a period one of ten years, a particular type of waste of type (i) is removed from storage and put into disposal, as shown in the equation below ${ }^{243}$.

$S_{i 0}$ is the setting for the volume of waste in each type of storage,

$T_{i 0}=0$ for volumes of waste going through treatment,

$D_{i 0}=0$ for volumes of waste going through disposal,

$S_{i 0}-T_{i l}=S_{i l}$

and

$D_{i 0}+T_{i l}=D_{i l}$

The choice of the volume of waste type (i) to be treated in the time (t) determines the amount remaining in storage and the amount in disposal. For every time period $(\mathrm{t})$, these relations are generally ${ }^{244}$ :

$S_{i(t-1)}-T_{t}=S_{i t}$

$D_{i(t-1)}-T_{i t}=D_{i t}$

The activity-cost relations and relationships between states shown, build towards optimizing goals, controlling constraints and minimizing terminal period risk ${ }^{245}$.

The plan involving moving waste out of its current state into another one makes sense because of the fact that treatment costs per unit volume for each waste type are greater than either storage or disposal costs. Disposal costs are likewise lower than storage costs. The unit cost of disposal is lower than the unit cost of storage, demonstrated by the fact

${ }^{243}$ see Jones et al. (1998), p. 11

244 see Jones et al. (1998), p. 12

245 see Jones et al. (1998), p. 11 
that the unit risk posed by untreated waste is greater than that of treated and disposed waste $^{246}$.

The relative total costs of volume and risk management were specified as a $90 \%-10 \%$ split, enabling back-calculation of the values for the previous coefficients for all the productions functions (without the allocation of the composite labour inputs into the two types of activity). For the volume production functions, the coefficient values were found by calculating the values of the constant terms using a hypothetical $10 \%$ of the initial stock in storage as a typical throughput in any period. For the risk production functions, engineering judgement was used on relative risks per unit of each waste type. The risk production functions were parameterized on the basis of risk per unit volume of waste in each state ${ }^{247}$.

${ }^{246}$ see Jones et al. (1998), p. 16

${ }^{247}$ see Jones et al. (1998), p. 17 


\subsection{Minimizing costs (Item A-I)}

In general the following costs exist:

- Investment Costs

- Market Interest Rate

- Lifetime (Costs)

- Fuel Costs

- External Costs

- Risk Analysis (Costs)

- Decommissioning Costs

We focus only on a few of these costs, otherwise the complexity and requirements would be too high to be fully accounted for in this work.

A material basis is built by case studies, for example Bond et al. (2004) published the public participation in EIT of NPP Decommissioning Project, a case study analysis for an environmental impact assessment review. Masuda et al. (2010) discussed the status of the support researches for the regulation of nuclear facilities decommissioning in Japan. Kim et al. (2010) studied the preliminary estimation of radioactive waste volume from the decommissioning of Korean Power Plant. IEA (2007) delivered key world energy statistics. Yoshino (2010) presented data about a decommissioning Project in Japan. Luyben (2011) described principles and case studies on Simultaneous Design in this

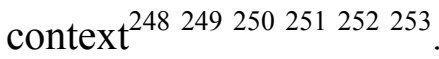

The 'Nuclear Decommissioning Authority' (2011) Business Plan is a written objective of NDA's future plans. They aim to successfully decommission the 19 public nuclear sites

\footnotetext{
248 see Bond et al. (2004)

249 see Masuda et al. (2010)

${ }^{250}$ see Kim et al. (2010)

${ }^{251}$ see IEA (2007)

${ }^{252}$ see Yoshino (2010)

${ }^{253}$ see Luyben (2011)
} 
and leave the area completely clean and refined. Their ongoing development is constantly observed by a range of organizations with invested interest in the successful decommission of these plants. That specific monitoring comes from The Shareholder Executive, which is made up of both the UK and Scottish Government. The progress of the decommissioning of these nuclear sites will also be documented and clearly recorded in the annual business reports so that all information and development can easily be observed by those interested ${ }^{254}$.

Wincel (2003) differentiates itself from many similar texts on Lean Supply Chain Management, by addressing the company's 'business condition' as an attribute of the business in the development stages of its strategy. By providing specific explanations of techniques used within the organization rather than a broad overview of the many aspects of the system, it is a valuable resource. Lean Supply Chain Management alludes to ideas and concepts that can easily change their procedures from cost effective techniques to profit generating concepts. This is an extremely useful insight on the topic of lean supply management with beneficial recommendations ${ }^{255}$.

In conjunction with the Wuppertal Institute for Climate, Environment and Energy, Irrek (2007) analyzes the financial aspects of different decommissioning projects in the European Union and uses this to stress the need for adequate funding for nuclear decommissioning and waste management from Member States and at the European level. He indicates the high rate of nuclear decommissioning that will occur in the near future and the necessary steps that will need to be in place to avoid financial and social loss. Irrek sums his work up with financial recommendations made out to the Member States and actions that should be enforced on a European level ${ }^{256}$.

In his work Huntzinger (2007), highlights the link between physical Lean enterprise and accounting. He makes it evident that this relationship is vital for business success and discusses various principles, philosophies and technical attributes to back this up. Huntzinger references both previous and current data to highlight the failure of traditional

\footnotetext{
254 see Nuclear Decommissioning Authority (2011)

255 see Wincel (2003)

${ }^{256}$ see Irrek (2007)
} 
cost and managerial accounting methods. His main focus is based on accounting information for internal purposes ${ }^{257}$.

Within his work Luyben (2011) goes into comprehensive detail about economic design. He discusses the engineering of economics, ethical economics and product design. General process design principles are outlined with detailed, quantitative and in-depth case studies to add validity to these principles. Luyben satisfies economic criterion such as minimizing total annual cost of both capital and energy by using economic steady-state designs. Overall his work is user friendly, allowing a variety of readers from engineers to students, to make use of it when developing their own work ${ }^{258}$.

Petschnig (2009) strongly focuses on enhancing the potential of companies by using operating cash flow to measure their value. Many financial models have been rethought after the financial crisis hit, and Petschnig believes operating cash flow is still a useful measure as other methods have too many levers to influence the result. Therefore areas such as costs of employed capital are not considered as they are not related to operating cash flow. Petschnig goes on to describe different practical tools of lean management in order to understand the methodology of the work. With references to various specialists, consultants and researchers, Petschnig shows in-depth knowledge in this work ${ }^{259}$.

The work of Anderson et al. (2008) demonstrates how energy business capabilities can be transformed to meet a growing and competitive global economy. They suggest the use of CALM (Computer-Aided Lean Management) to cope with this ever-changing urban environment. CALM has recently been introduced to China, India and Russia due to the developing nature of these countries. Anderson, et al., explore the usefulness of CALM to these countries. The basic aim of the research conducted by Anderson, et al., is to promote CALM as a method to improve business efficiency ${ }^{260}$.

\footnotetext{
257 see Huntzinger (2007)

258 see Luyben (2011)

259 see Petschnig (2009)

260 see Anderson et al. (2008)
} 
The mathematical function of the goal of minimizing the costs $\mathbf{C}$ for a long period $(=10)$ is shown with this objective function ${ }^{261}$ :

$\operatorname{Minimize}_{\left\{T_{i j t}\right\}} \overline{C_{10}}=\sum_{i} \sum_{j \neq S, D} C_{i j 10}$

The minimization is conditional on restrictions on the maximum allowable cost $\mathbf{C}$ per unit volume for each waste type ${ }^{262}$ :

$\lambda_{i j t}\left(C_{i S 0} / S_{i 0}\right) \geq(C / V)_{i j t}, \quad \forall i, j, t$

$\mathrm{V}_{\mathrm{j}}$ is the volume in the particular state $\mathrm{j}$. The allowable cost per unit for each waste type must not be greater than $\lambda$ multiplied by the level of unit cost in storage in the initial period. The values of $\lambda$ can represent a combination of legal constraints and/or environmental management policy decisions. The constraint with the production equation for the unit cost in each waste type calculates the number of units of $\mathrm{k}$ needed to maintain a required unit cost level in each period.

\subsection{Minimizing the continued risk of storage (Item A-II)}

The mathematical statement of the goal of minimizing the continued risk of storage that has remained in disposal for a long period is shown with the objective function ${ }^{263}$ :

$\operatorname{Minimize}_{\left\{T_{i j t}\right\}} \overline{R_{10}}=\sum_{i} \sum_{j \neq S, D} R_{i j 10}$

\footnotetext{
${ }^{261}$ see Jones et al. (1998), p. 12

262 see Jones et al. (1998), p. 12

263 see Jones et al. (1998), p. 14
} 
The minimization is conditional on restrictions on the maximum allowable risk per unit volume for each waste type ${ }^{264}$ :

$\lambda_{i j t}\left(R_{i S 0} / S_{i 0}\right) \geq(R / V)_{i j t,} \quad \forall i, j, t$

The allowable risk per unit for each waste type must not be greater than $\lambda$ multiplied by the level of unit risk in storage in the initial period. The values of $\lambda$ can represent a combination of legal constraints and/or environmental management policy decisions. The constraint with the production equation for the unit risk in each waste type calculates the number of units of $\mathrm{k}$ needed to maintain a required unit risk level in each period. The constraints allow units of $\mathrm{k}$ to be allocated to risk other than in storage, disposal and in period 10 . This and the possible change of the values of $\lambda$, allows the continuity of improvement of safety.

The minimization of waste volumes in storage and disposal is subject to a budget constraint in each period $B_{t}$, created by buying, renting, leasing etc. of the units of $\mathrm{k}$ to manage risk, treat and store waste ${ }^{265}$ :

$B_{t} \geq \sum_{i} \sum_{j \neq S, T, D} \sum_{a=V, R} p_{k} k_{i j a t}, \quad \forall t$

The index "a" represents the sum of the expenditures and must stay within the budget for each period ${ }^{266}$.

Another objective function includes the goal to minimize all risks in all periods. In every period, a requirement of a small volume of each waste type must be treated and a small portion of the budget spent ${ }^{267}$;

\footnotetext{
${ }^{264}$ see Jones et al. (1998), p. 12

265 see Jones et al. (1998), p. 13

${ }^{266}$ see Jones et al. (1998), p. 13

${ }^{267}$ see Jones et al. (1998), p. 14
} 
$\operatorname{Minimize}_{\left\{x_{i j a t}\right\}} \bar{R}=\sum_{t} \min \left(\sum_{i} \sum_{j} \sum_{a} R_{i j a t}\right)$

The minimization of mortgage costs involves finding a treatment plan that will maximize the difference between the costs of holding treated waste in disposal and holding untreated waste in storage over a ten year period. The treatment of disposed waste reduces the future cost of holding it in storage instead - the discounted cost (e. g. the cost in the final period of the ten year activity period, over a future period to recover the treatment costs). $C_{i j a t}$ specifies the costs of storage, disposal and treatment. $C_{i j a t}, t>10$, represents administrative and operational costs ${ }^{268}$ :

Minimize $\left\{x_{i j a t}\right\}=\sum_{t=1}^{10} \sum_{i} \sum_{j} \sum_{a} C_{i j a t}+\sum_{t=11}^{n} \sum_{i} \sum_{j} \sum_{a=S, D} C_{i j a 10}\left(1+i^{t}\right)^{-1}$

Constraints on unit risk levels are necessary to get any units of $\mathrm{k}$ applied to risk containment, since no direct risk objectives exist in the goal. Costs have not been discounted over the ten year operational period in order to compare them to DOE or budget plans and congressional authorizations ${ }^{269}$.

In the above formula, the production (cost) parameters, from economic theory within the mathematical functions, require numerical estimates in the form of the constant terms, the $A_{i j}$, the output elasticities, and the $\alpha_{i j}$ and $\beta_{i j}$ coefficients. The considerable differences in the order of magnitude between composite labour variables, risk variables and waste volume variables are scaled by the A coefficients. The $\alpha$ and $\beta$ coefficients identify percentage changes induced on a variable on either side of the equation. They show cost information through their sum - the sum, being either greater than, less than or exactly 1.0 implies the returns to scale. The sums of the output elasticities were chosen to

\footnotetext{
${ }^{268}$ see Jones et al. (1998), p. 14

${ }^{269}$ see Jones et al. (1998), p. 14
} 
characterize the degree of returns to scale that characterized the activities. The value of each output's elasticity is close to the associated input's share in the cost of elasticity ${ }^{270}$.

The $\lambda$ coefficient values used in the risk constraints show the maximum risk level allowed in each state, 1.00 (for storage), 2.00 (for treatment) and 3.00 (for disposal). The unit material had to remain at $30 \%$ of its initial unit level storage as the unit risk of each type of waste could rise to double its value in storage during treatment, showing the greater exposure of workers to the material and more active handling ${ }^{271}$ (see Table 2).

Table 2: Coefficient Values ${ }^{272}$

\begin{tabular}{|c|c|c|c|c|c|c|}
\hline \multirow{2}{*}{ Parameter } & \multicolumn{2}{|c|}{ Storage } & \multicolumn{2}{c|}{ Treatment } & \multicolumn{2}{c|}{ Disposal } \\
\cline { 2 - 8 } & $\begin{array}{c}\text { volume } \\
\text { mgmt }\end{array}$ & $\begin{array}{c}\text { risk } \\
\text { mgmt }\end{array}$ & $\begin{array}{c}\text { volume } \\
\text { mgmt }\end{array}$ & $\begin{array}{c}\text { risk } \\
\text { mgmt }\end{array}$ & $\begin{array}{c}\text { volume } \\
\text { mgmt }\end{array}$ & $\begin{array}{c}\text { risk } \\
\text { mgmt }\end{array}$ \\
\hline $\mathrm{A}_{\mathrm{TRU} \text {, state, activity }}$ & $2.00 \mathrm{E}+7$ & $7.33 \mathrm{E}-4$ & $5.88 \mathrm{E}-2$ & $7.27 \mathrm{E}-3$ & $4.80 \mathrm{E}+5$ & $1.08 \mathrm{E}-3$ \\
\hline $\mathrm{A}_{\mathrm{LLW}, \text { state, activity }}$ & $6.07 \mathrm{E}+10$ & $8.08 \mathrm{E}-8$ & $1.05 \mathrm{E}-1$ & $1.05 \mathrm{E}-6$ & $4.82 \mathrm{E}+8$ & $2.10 \mathrm{E}-7$ \\
\hline $\mathrm{A}_{\mathrm{MLLW} \text {, state, activity }}$ & $1.80 \mathrm{E}+8$ & $2.02 \mathrm{E}-5$ & $2.05 \mathrm{E}-1$ & $8.60 \mathrm{E}-5$ & $2.30 \mathrm{E}+8$ & $2.32 \mathrm{E}-5$ \\
\hline$\alpha_{\text {state, activity }}$ & 0.115 & 0.100 & 0.400 & 0.500 & 0.990 & 0.250 \\
\hline$\beta_{\text {state, activity }}$ & n.a. & 0.100 & 0.900 & 0.075 & n.a. & 0.030 \\
\hline
\end{tabular}

\subsection{Minimizing Project Duration (Item A-III)}

The mathematical function of the goal of minimizing the duration of a variable period $(=t)$ is shown with this objective function:

$\operatorname{Minimize}_{\left\{T_{i j t}\right\}} \overline{C_{t}} * \overline{R_{t}}$

The minimization is conditional on restrictions on the maximum allowable cost $\boldsymbol{C}$ and $\boldsymbol{R}$ per unit volume for each waste type ${ }^{273}$ :

\footnotetext{
${ }^{270}$ see Jones et al. (1998), p. 15

271 see Jones et al. (1998), p. 17

272 see Jones et al. (1998), p. 18

${ }^{273}$ see Jones et al. (1998), p. 12
} 


$$
\begin{aligned}
& \lambda_{i j t}\left(C_{i S 0} / S_{i 0}\right) \geq(C / V)_{i j t}, \quad \forall i, j, t \\
& \lambda_{i j t}\left(R_{i S 0} / S_{i 0}\right) \geq(R / V)_{i j t}, \quad \forall i, j, t
\end{aligned}
$$

\subsection{MOOP to SOOP strategy (Item B)}

Taking the MOOP to SOOP strategy as a basis, the safety hazard (risk) functions $\mathrm{f}_{2}(\mathrm{X})$ will be minimized while holding $f_{1}(X)$ and $f_{3}(X)$ under a bounding value $d_{b}$ and this MOOP to SOOP process will be repeated over several iterations while trying to identify a convergent solution.

The mathematical notation of this goal is as follows ${ }^{274}$ :

$\operatorname{Minimize}_{\left\{T_{i j t}\right\}} \overline{R_{10}}=\sum_{i} \sum_{j \neq S, D} R_{i j 10}$

The constraints for this function are as follows ${ }^{275} 276$ :

$\lambda_{i j t}\left(R_{i S 0} / S_{i 0}\right) \geq(R / V)_{i j t,} \quad \forall i, j, t$

$\overline{C_{10}} \leq d_{b}$

$\overline{C_{10}} * \overline{R_{t}} \leq d_{b}$

The minimization function (4.14) and the constraints $(4.15)-(4.20)$ will be used in chapter 6 and applied.

\footnotetext{
${ }^{274}$ see Jones et al. (1998), p. 12

275 see Jones et al. (1998), p. 12

${ }^{276}$ see Miettinen (1999), p. 5ff. / Hwang; Masud (1979) / Wikipedia (2013)
} 


\subsection{Minimizing Radioactive Exposure}

Bayliss and Langley (2003) discuss the variety of approaches in the handling of nuclear facilities and radioactive waste management in order to enhance the conservation of the environment. In addition to this, they also describe methods in the dismantling of nuclear facilities. The majority of their work focuses on the decommissioning of nuclear facilities, highlighting the fact that this is a somewhat new phenomenon that has emerged in the last ten years. The harmful and hazardous effects of nuclear facilities and radioactive waste are made evident, stressing the importance of disposing and storing the facility's waste in a safe and stable manner. Bayliss and Langley consider the different groups and areas that could be detrimentally impacted by these harmful effects. These included the nuclear workers, society in general and also the environment. They also make reference to the research conducted by the United Kingdom Atomic Energy Authority (UKAEA), a non departmental public body responsible for managing the UK fusion research program. They use information gained from the UKAEA to show the decommissioning experience over the past 15 years. After radioactive waste is correctly stored and nuclear facilities dismantled, their work then goes on to discuss the restoration of these nuclear licensed facilities into usable environments. Bayliss and Langley's work is user friendly and includes precise information for personnel that may be new to decommissioning and waste management ${ }^{277}$.

In their work, Higashi et al. (2010) discuss the importance of an EPZ (Emergency Planning Zone) in the event of an outpouring of radioactive material into the environment. An EPZ is set in place to minimize the environmental impact of the radioactivity and defines a specific area/boundary, outside of which radioactivity levels are deemed acceptable. Higashi, et al, go on to indicate the scenarios in which decommissioning of a NPP can lead to a further release of radioactive material, even after the plant is closed. If an EPZ is in place prior to 'spent fuel storage phase' and the 'safe maintenance and dismantling phase' there is no need for an offsite emergence plan ${ }^{278}$.

\footnotetext{
277 see Bayliss and Langley (2003)

278 see Higashi et al. (2010)
} 
Iguchi and Masami (2010) highlight the importance of safe dismantlement of a NPP within their work, stressing the long-term hazardous effects from the plant after the spent fuel is removed. They analyze risk factors involved in the dismantling of typical reactor facilities and nuclear fuel facilities. Iguchi and Masami also discuss four different approaches including; the risk-informed approach, the graded approach, the phased approach and the layered approach, all derived to enhance safety when decommissioning a NPP 279 .

In report the IAEA (1998) discusses the value in characterizing radioactive materials prior to decommissioning a NPP. It is made evident that encompassing a radioactive inventory detailing necessary data can improve the planning and strategies involved in a decommissioning process. Included in the report are such relevant areas as health and safety considerations, the characterization process, methods and techniques for characterization and the radiological inventory itself. The report also discusses previous problems experienced during characterization ${ }^{280}$.

In this report, the IAEA (2004a) stresses the importance of planning, managing and organizing the decommissioning process of a NPP in an attempt to prevent similar downfalls in the process conducted in previous projects. Whilst certain decommissioning projects may have produced more detrimental effects due to time and cost factors, this report suggests that with the correct management and organization, many of these effects could have been diminished. Much of the report focuses on lessons learned in decommissioning from a lack of experience and planning ${ }^{281}$.

Within their work, Greenberg, West and Lowrie (2009) cover a number of nuclear issues such as health effects, safety and engineering, nuclear medicine, food irradiation, transporting nuclear materials, spent fuel, nuclear weapons and global warming. They also make reference to the cases of Three Mile Island and Chernobyl. The aim of their research is not to change the public's opinions about nuclear energy but rather to create a greater awareness and understanding of it. With plenty of scientists, engineers and

\footnotetext{
${ }^{279}$ see Iguchi and Masami (2010)

${ }^{280}$ see IAEA (1998)

281 see IAEA (2004a)
} 
administrators (all experts in their respective fields) referenced within their work, Greenberg, et al, deliver relevant and valid information ${ }^{282}$.

\subsection{Model-based MOOP -Framework}

In general a MOOP is characterized by the following main structure ${ }^{283}$

$$
\min \left(f_{1}(x), f_{2}(x), \ldots, f_{k}(x)\right)^{T}
$$

s.t. $x \in X$,

These three functions $f_{1}, f_{2}$ and $f_{3}$ are the three items (see chapters 4.5, 4.6 and 4.7 formulas 4.12, 4.14 and 4.19) stated previously.

$x \in X$

is representing the constraints of $f_{1}, f_{2}$ and $f_{3}$ depicted in formulas 4.13, 4.15, 4.20 and 4.21 .

The application and performance evaluation of MOOP is researched by Mariano/Morales (2000) based on reinforcement learning. MOOP is also considered as a dominated or Pareto optimal solution ${ }^{284}$. Watanabe/Sakakibara (2005) describe MOOP also as a Pareto optimal solution, for example for small calculation $\operatorname{costs}^{285}$. And also Marler/Arora (2002) discuss Pareto optimality regarding MOOP ${ }^{286}$.

The implementation of this MOOP will be demonstrated in R (see chapter 6.5).

The Pareto-optimum problem is covered in $\mathrm{R}$ by the TunePareto-Package, which is applied in this dissertation to the virtual database table (see chapter 6.5).

\footnotetext{
282 see Greenberg, West and Lowrie (2009)

${ }^{283}$ see Miettinen (1999), p. 5ff. / Hwang; Masud (1979) / Wikipedia (2013)

${ }^{284}$ see Mariano/Morales (2000), p. 1

${ }^{285}$ see Watanabe/Sakakibara (2005), p. 1

${ }^{286}$ see Marler/Arora (2002), p. $371 \mathrm{ff}$.
} 


\subsection{Resumé}

The model by Jones et al. 1998 is highly useful as a foundation for the minimization of costs (see chapter 4.5), storage risk (see chapter 4.6) and project duration (see chapter 4.7). The model by IAEA 2008/Daniska et al 2008 is highly useful for a better understanding of the underlying business processes and management issues. Therefore a combination of both of these models' specifications is used in order to implement the application of the framework (see chapter 6).

Before an exemplary implementation of the model is performed more information concerning the underlying empirical data is required. The case studies in the following chapter provide a helpful foundation. 


\section{EMPIRICAL BASIS}

\subsection{Case Study: Virtual or Real NPP (Overview)}

Since the domain of dismantling and decommissioning is an area where secrecy, confidentiality, sensitivity is of utmost importance, it was not easy to find a NPP willing to provide enough data to build a solid empirical basis for a case study in order to apply the given model. Therefore the presented data here constitutes an assortment of data from different real sources in order to have a good idea of what requirements are needed. On this basis, a virtual database can be created in order to use as a source of data for the AIMMS implementation (see chapter 6.3).

\subsection{Project Schedule of the Dismantling of Reactor internals - Decommissioning of NPP José Cabrera}

A good example of a dismantling and decommissioning of a reactor is given in the next figure (see Figure 8). The project schedule is separated in 8 phases - generalized and shortened $^{287}$ :

- Visual inspection

- Positioning equipment for measurements

- Removals

- Advanced measurements

- Extraction of bolts

- Positioning of equipment for the extraction of samples

- Identification, marking and cutting of components

- Transfer

${ }^{287}$ see JCP (2009), p. 200 


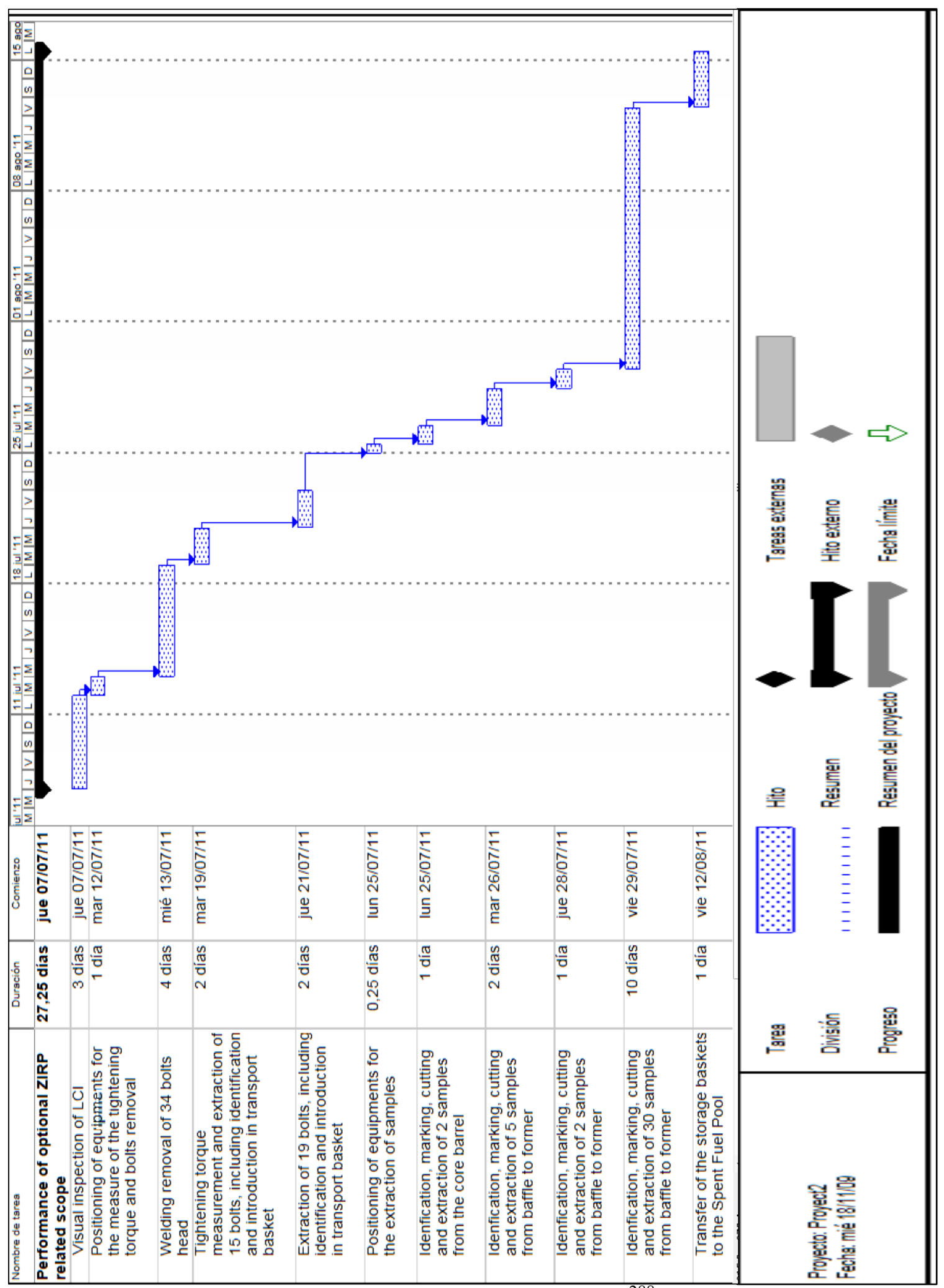

Figure 8: $\quad$ Project schedule extract with the ZIRP scope ${ }^{288}$

${ }^{288}$ see JCP (2009), p. 200 
The table of estimated personnel requirements is also given below (see Table 3).

Table 3: Table of estimated personnel requirements ${ }^{289}$

\begin{tabular}{|l|l|l||}
\hline Project Phase & $\begin{array}{l}\text { On-site } \\
\text { Personnel }\end{array}$ & $\begin{array}{l}\text { Off-site } \\
\text { Personnel }\end{array}$ \\
\hline Phase 2: Final Segmentation and Packaging Plan & 0 & 24 \\
\hline $\begin{array}{l}\text { Phase 3: Mockup Tests and Process Qualifica- } \\
\text { tion }\end{array}$ & 7 & 24 \\
\hline Phase 4: Performance of Plant Modifications & 13 & 8 \\
\hline $\begin{array}{l}\text { Phase 5: Supply, Installation and Pre- operational } \\
\text { Tests of Contractors Equipment }\end{array}$ & 13 & 8 \\
\hline Phase 6: RVI Segmentation and Packaging & 14 & 8 \\
\hline $\begin{array}{l}\text { Phase 7: Final Demobilization, Clean-up and De- } \\
\text { contamination }\end{array}$ & 13 & 6 \\
\hline Phase 8: Final Report & 0 & 10 \\
\hline \hline
\end{tabular}

\subsection{Central processes of the requirement analysis}

The central processes of the requirement analysis and questions regarding the dismantling and decommissioning of the José Cabrera Plant contain the following issues ${ }^{290}$ :

- Components to be cut

- Size of the cutting devices

- Efficiency of the cutting technique

- Reliability of the technology

- Generation of secondary waste (filters for water purification etc.)

- Generation of aerosols and hydrosols

- Decontamination properties of the devices

- Performance time

${ }^{289}$ see JCP (2009), p. 172

${ }^{290}$ see AREVA NP GmbH (2011), p. 147 
- Local dose rate

- Costs

\subsection{Cutting techniques and materials in the project}

Based on the conceivable and applicable cutting techniques - also shown in 2.3.2 - it is possible to extract helpful information for the implementation of the database. The following tables shows the characteristics of those techniques (see Table 4 and Table 5):

Table 4: Characteristics of applicable cutting techniques ${ }^{291}$

\begin{tabular}{|c|c|c|c|}
\hline Technique & Applicability & Process parameter & Process characteristics \\
\hline Sawing & $\begin{array}{l}\text { - thick-walled components } \\
\text { - compound structures free of } \\
\text { stress } \\
\text { - tubes and supported tube bun- } \\
\text { dles }\end{array}$ & $\begin{array}{l}\text { - high cutting performance } \\
\text { - big place requirement } \\
\text { - vacuuming of cutting chips } \\
\text { required }\end{array}$ & $\begin{array}{l}\text { - neither aerosol nor hydrosol genera- } \\
\text { tion } \\
\text { - low amount of secondary waste } \\
\text { - no manipulator qualification } \\
\text { - seizing of saw blade when cutting of } \\
\text { stress-bearing compounds }\end{array}$ \\
\hline WASS & $\begin{array}{l}\text { - concrete and steel structures up } \\
\text { to } 200 \mathrm{~mm} \text { thickness } \\
\text { - compound structures } \\
\text { - precise cutting }\end{array}$ & $\begin{array}{l}\text { - high cutting performance } \\
\text { - low restoring forces } \\
\text { - medium place requirement } \\
\text { - small cutting kerfs of } 1 \mathrm{~mm} \\
\text { - medium cutting speed }\end{array}$ & $\begin{array}{l}\text { - neither aerosol nor hydrosol genera- } \\
\text { tion } \\
\text { - high amount of secondary waste } \\
\text { - manipulator qualification } \\
\text { - no seizing of milling tool when cutting } \\
\text { of stress-bearing compounds }\end{array}$ \\
\hline Shearing & $\begin{array}{l}\text { - thin-walled steel structures up to } \\
200 \mathrm{~mm} \text { thickness } \\
\text { - compound structures } \\
\text { - tubes and supported tube bun- } \\
\text { dles }\end{array}$ & $\begin{array}{l}\text { - low to mean cutting perform- } \\
\text { ance } \\
\text { - medium restoring forces } \\
\text { - little place requirement }\end{array}$ & $\begin{array}{l}\text { - neither aerosol nor hydrosol genera- } \\
\text { tion } \\
\text { - no secondary waste } \\
\text { - manipulator qualification }\end{array}$ \\
\hline Milling & $\begin{array}{l}\text { - thick-walled components } \\
\text { - compound structures free of } \\
\text { stress } \\
\text { - tubes and supported tube bun- } \\
\text { dles } \\
\text { - applicable up to a water depth } \\
\text { of } 6 \mathrm{~m} \text { only }\end{array}$ & $\begin{array}{l}\text { - mean cutting performance } \\
\text { - big restoring forces } \\
\text { - big place requirement } \\
\text { - low cutting speed } \\
\text { - water purification and aerosol } \\
\text { exhaust required }\end{array}$ & $\begin{array}{l}\text { - neither aerosol nor hydrosol genera- } \\
\text { tion } \\
\text { - low amount of secondary waste } \\
\text { - limited manipulator qualification } \\
\text { - seizing of milling tool when cutting of } \\
\text { stress-bearing compounds }\end{array}$ \\
\hline Plasma & $\begin{array}{l}\text { - steel structures up to } \\
130 \text { mm thickness } \\
\text { - compound structures } \\
\text { - tubes and supported tube bun- } \\
\text { dles }\end{array}$ & $\begin{array}{l}\text { - high cutting performance } \\
\text { - no restoring forces } \\
\text { - little place requirement }\end{array}$ & $\begin{array}{l}\text { - low aerosol generation } \\
\text { - medium amount of secondary waste } \\
\text { - manipulator qualification } \\
\text { - no seizing of milling tool when cutting } \\
\text { of stress-bearing compounds }\end{array}$ \\
\hline CAMC & $\begin{array}{l}\text { - steel structures of great thick- } \\
\text { ness up to } 500 \mathrm{~mm} \\
\text { - compound structures } \\
\text { - tubes and supported tube bun- } \\
\text { dles } \\
\text { - applicable to all metals }\end{array}$ & $\begin{array}{l}\text { - high cutting performance } \\
\text { - no restoring forces } \\
\text { - little place requirement } \\
\text { - } \text { high flexibility } \\
\text { - very high cutting speed } \\
\text { - water purification required }\end{array}$ & $\begin{array}{l}\text { - low aerosol generation } \\
\text { - medium amount of secondary waste } \\
\text { - manipulator qualification } \\
\text { - no seizing of milling tool when cutting } \\
\text { of stress-bearing compounds } \\
\text { - perfect for intervention purposes }\end{array}$ \\
\hline EDM & $\begin{array}{l}\text { - ripping of weld seams } \\
\text { - removal of bolts }\end{array}$ & $\begin{array}{l}\text { - } \text { no restoring forces } \\
\text { - little place requirement } \\
\text { - } \text { high flexibility }\end{array}$ & $\begin{array}{l}\text { - low aerosol generation } \\
\text { - very low amount of secondary waste } \\
\text { - manipulator qualification }\end{array}$ \\
\hline
\end{tabular}


Table 5: $\quad$ Comparison of cutting speeds ${ }^{292}$

\begin{tabular}{|c|c|c|c|c|c|}
\hline Cuttin & echnique & Material & Cutting & Set-up time & Remarks \\
\hline Mechanical & & & & & \\
\hline & compass saw & $\max .80 \mathrm{~mm}$ & very low & $\begin{array}{l}\text { first install: } 4 \mathrm{~h} \text {, } \\
\text { positioning } \\
1 \mathrm{~h} / \text { application }\end{array}$ & $\begin{array}{c}\text { for } \\
\text { special applications }\end{array}$ \\
\hline & $\begin{array}{l}\text { mast band saw } \\
\text { (RPV internals ) } \\
\text { (KKS) }\end{array}$ & $40-80 \mathrm{~mm}$ & $5-10 \mathrm{~mm} / \mathrm{min}$. & $50 \%$ & \\
\hline & $\begin{array}{l}\text { band saw for } \\
\text { core shroud } \\
\text { (KWW) }\end{array}$ & $50 \mathrm{~mm}$ & $8-10 \mathrm{~mm} / \mathrm{min}$ & $50 \%$ & $\begin{array}{c}\text { double cut with one } \\
\text { saw band }\end{array}$ \\
\hline & $\begin{array}{l}\text { band saw for } \\
\text { RPV flange } \\
\text { (KWW) }\end{array}$ & $450 \mathrm{~mm}$ & $10 \mathrm{~mm} / \mathrm{min}$ & $\begin{array}{l}\text { first install: } 2 \mathrm{~d}, \\
30 \% \text { / application }\end{array}$ & \\
\hline Hydraulic & & & & & \\
\hline & $\begin{array}{l}\text { WASS for } \\
\text { RPV cyl. part } \\
\text { (in air) }\end{array}$ & $137 \mathrm{~mm}$ & $15-20 \mathrm{~mm} / \mathrm{min}$ & $\begin{array}{l}\text { depending on } \\
\text { application }\end{array}$ & \\
\hline & $\begin{array}{l}\text { WASS for } \\
\text { RPV internals } \\
\text { (under water) }\end{array}$ & $\begin{array}{l}\text { varying, max. } \\
\quad 80 \mathrm{~mm}\end{array}$ & $\begin{array}{c}30- \\
100 \mathrm{~mm} / \mathrm{min}\end{array}$ & $\begin{array}{l}25-50 \% \text {, de- } \\
\text { pending on } \\
\text { cut length and } \\
\text { geometry }\end{array}$ & $\begin{array}{l}\text { max. } 200 \mathrm{~mm} \text { with } \\
\text { present configura- } \\
\text { tion }\end{array}$ \\
\hline Thermal & & & & & \\
\hline & $\begin{array}{l}\text { plasma under } \\
\text { water }\end{array}$ & $\max .250 \mathrm{~mm}$ & $50 \mathrm{~mm} / \mathrm{min}$ & $\begin{array}{l}25-50 \% \text {, de- } \\
\text { pending on } \\
\text { cut length and } \\
\text { geometry }\end{array}$ & \\
\hline & oxygen lance & any & $\begin{array}{l}\text { flame boring: } \\
\qquad 1 \mathrm{~m} / \mathrm{h}\end{array}$ & $\begin{array}{l}\text { no set-up time } \\
\text { because of } \\
\text { manual } \\
\text { operation }\end{array}$ & \\
\hline Fis & petrol-oxygen & $\begin{array}{c}250 \mathrm{~mm} \\
\text { carbon steel }\end{array}$ & & $\begin{array}{l}\text { no set-up time } \\
\text { because of } \\
\text { manual } \\
\text { operation }\end{array}$ & $\begin{array}{l}\text { tests at plated steel } \\
\text { plates with good } \\
\text { prospects }\end{array}$ \\
\hline Electrical & & & & & \\
\hline & EDM & $\max .20 \mathrm{~mm}$ & $5 \mathrm{~mm} / \mathrm{h}$ & $\begin{array}{l}\text { first install: 4h, } \\
\text { positioning } \\
\text { 1h/application }\end{array}$ & \\
\hline$y=$ & CAMC & $\max .800 \mathrm{~mm}$ & $100 \mathrm{~mm} / \mathrm{h}$ & $\begin{array}{l}\text { depending on } \\
\text { application }\end{array}$ & $\begin{array}{c}\text { for interventions } \\
\text { and } \\
\text { special applications }\end{array}$ \\
\hline
\end{tabular}

${ }^{292}$ see AREVA NP GmbH (2011), p. 151 


\subsection{Overview of Components and Masses to be dismantled and packaged}

The overview of components and masses is very helpful in the conception of a virtual database to be used in AIMMS, too. The NPP in Stade was finally shut down in 2015. In 2005 the decommissioning of the unit began.

\subsubsection{Upper Core Internals, Lower Core Internals, Core Support Structure}

In 2007 the dismantling and packing of the Core Internals consisted of ${ }^{293}$ :

- Upper Core Internals (UCI) (see Figure 9)

- Lower Core Internals (LCI) (see Figure 10)

- Core Support Structure (see Figure 11)

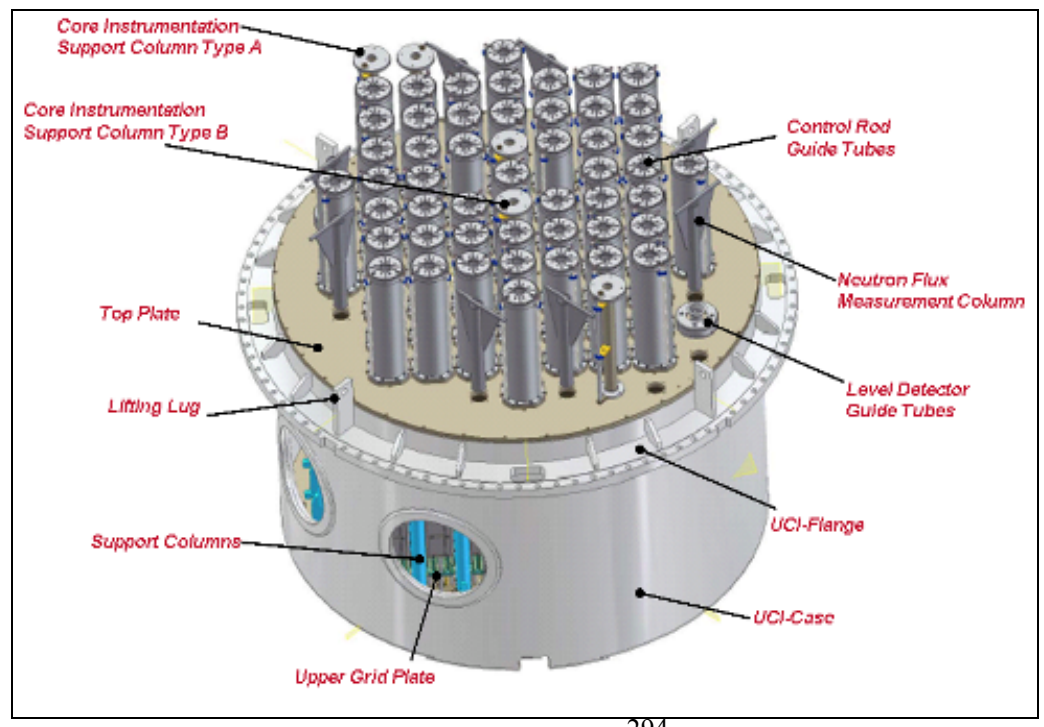

Figure 9: $\quad$ Upper Core Internals ${ }^{294}$

${ }^{293}$ see JCP (2009), p. 13

${ }^{294}$ see JCP (2009), p. 13 


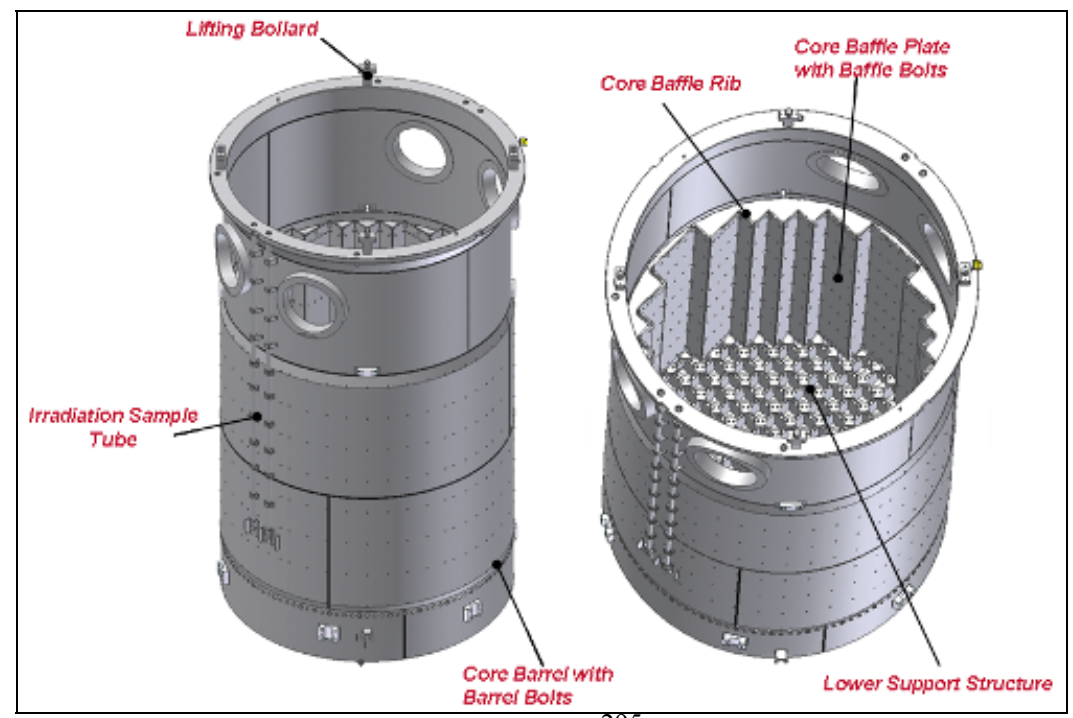

Figure 10: $\quad$ Lower Core Internal ${ }^{295}$

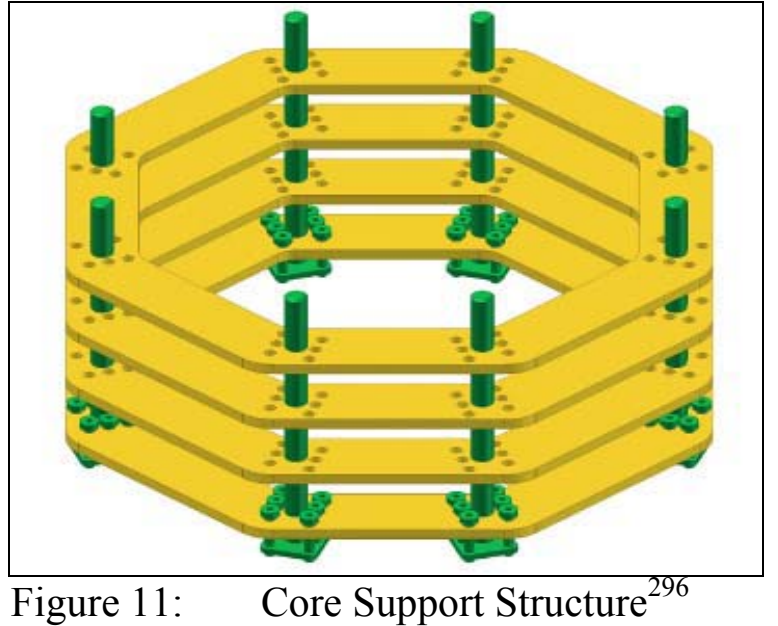

The total weight of the internals was 85 tons $^{297}$.

\subsubsection{Reactor Opening Deck, Spent Fuel Pool and Reactor Cavity}

The following figures show the adjustments to the equipment in the pools ${ }^{298}$, (see figures Figure 12, Figure 13 and Figure 14) all components and masses are managed within the dismantling and decommissioning process.

295 see JCP (2009), p. 14

${ }^{296}$ see JCP (2009), p. 14

${ }^{297}$ see JCP (2009), p. 15

${ }^{298}$ see JCP (2009), p. 15 


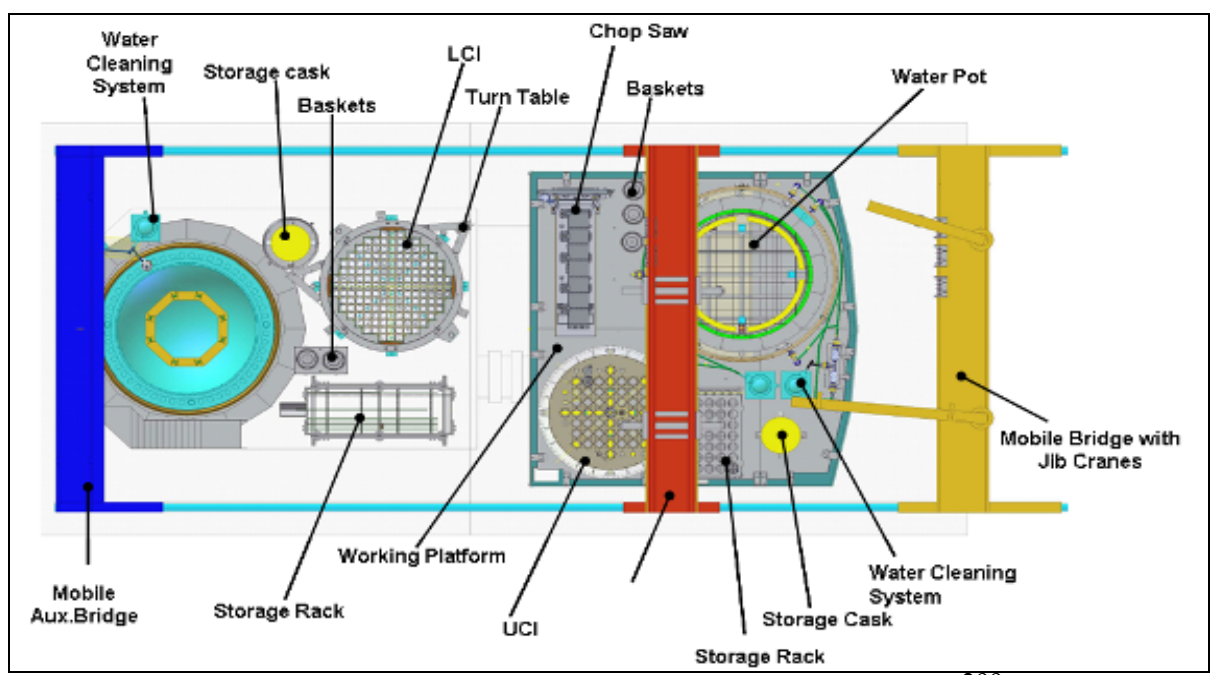

Figure 12: $\quad$ Top View on the Reactor Operating Deck ${ }^{299}$

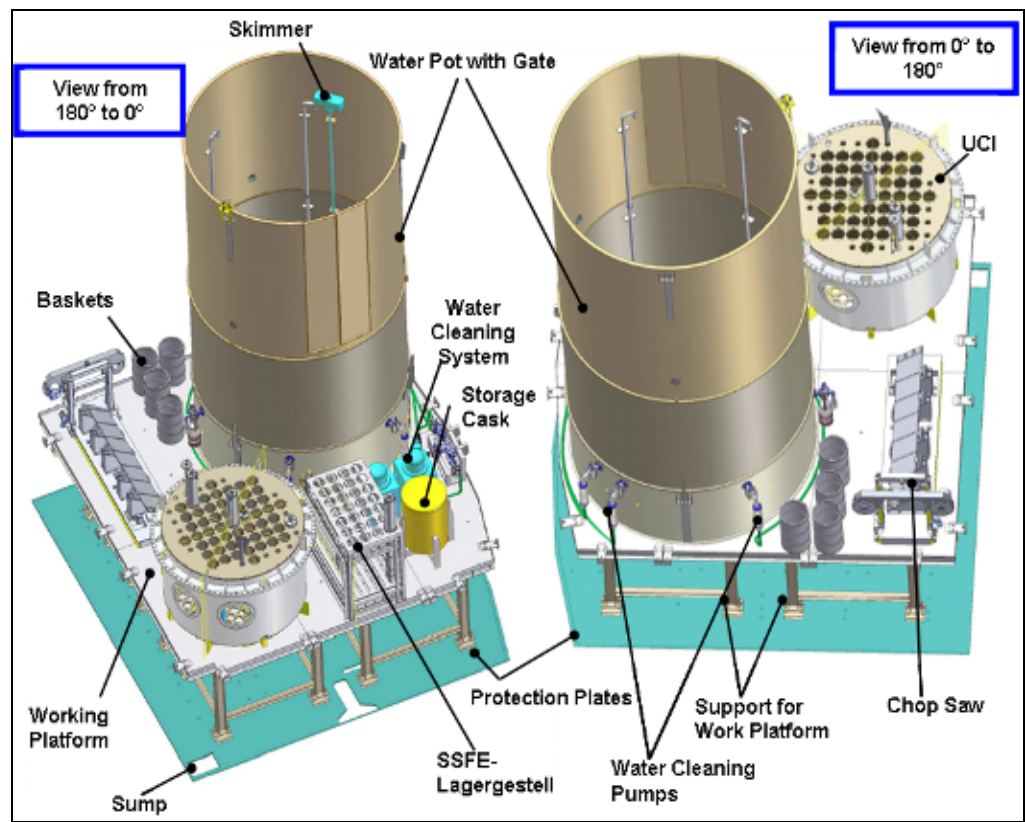

Figure 13: $\quad$ Occupation of the Spent Fuel Pool ${ }^{300}$

${ }^{299}$ see JCP (2009), p. 15

${ }^{300}$ see JCP (2009), p. 16 


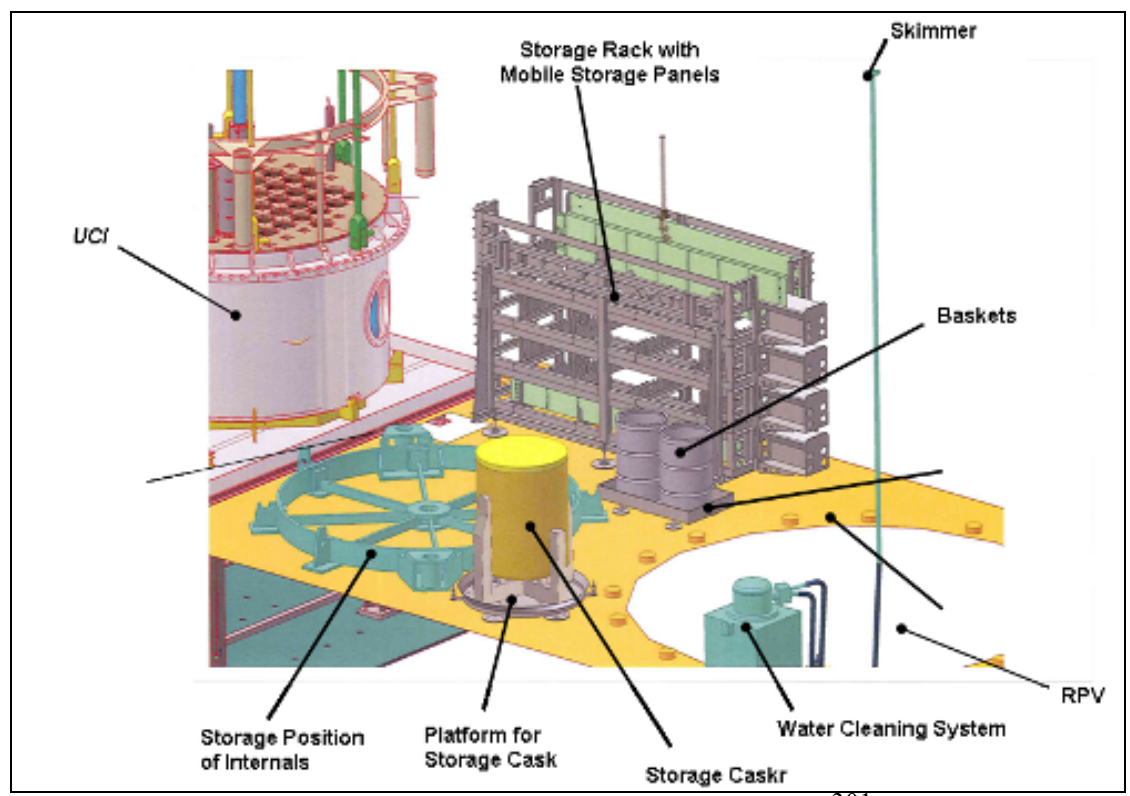

Figure 14: $\quad$ Occupation of the Reactor Cavity ${ }^{301}$

\subsubsection{Equipment for Cutting, Disassembly \& Handling of RVI Components}

The equipment was tested and an intensive personnel training was necessary. The cutting and disassembly of the components was carried out within the following processes and $\operatorname{methods}^{302}$ :

- Abrasive water jet cutting,

- $\quad$ Sawing process (chop saw, compass saw, band saw),

- Mechanical unlocking of bolt connections,

- Milling process to remove bolt heads,

- Electrical Discharge Machining (EDM) process to remove weld locks,

- Contact Arc Metal Cutting (CAMC) process to cut connections, which cannot be mechanically unlocked.

\footnotetext{
${ }^{301}$ see JCP (2009), p. 16

302 see JCP (2009), p. 17
} 
A special cutting tank was built to minimize the pollution of the pool water and related objects. They were put inside this tank and then cut. The Water Abrasive Suspension Cutting was used to cut $^{303}$ :

- $\quad \mathrm{UCI}$ - Top Plate

- UCI - Shell

- UCI - Upper Grid

- UCI - Upper Grid Plate

- UCI - CRDM Guide Pins

- $\quad$ LCI - Lower Grid Plate

- $\quad$ LCI - Flow Distribution Plate

- $\quad$ LCI - Lower Core Grid

- Core Support Structure

The Compass Saw was used to $\mathrm{cut}^{304}$

- Core instrumentation columns

- Irradiation sample tubes

- Neutron flux measurement columns

The Chop Saw was used to cut ${ }^{305}$

- Control Rod Drive Mechanism (CRDM) - assemblies

- Lever detector tubes

- Support columns

\footnotetext{
303 see JCP (2009), p. 18

${ }^{304}$ see JCP (2009), p. 19

305 see JCP (2009), p. 19ff.
} 
- Former ribs

- Baffle plates

The Band Saw was used to cut $^{306}$

- Core barrel

The Mast System was used to remove $\mathrm{e}^{307}$

- Core barrel bolts

- Core baffle bolts

The Milling Machine was used to remove $\mathrm{e}^{308}$

- Bolt heads

And the EDM / CAMC - Tool was used for ${ }^{309}$

- Removal of weld locks

- Preparation of holes in the core barrel for lifting

\subsubsection{Packaging of Cut Segments}

The conditioning and packaging of the primary waste has to be done in accordance to the storage rules of the federal deposit KONRAD ${ }^{310}$, which will start its operation in 2013 $(\text { expected })^{311}$.

Only two different types of storage casks were allowed ${ }^{312}$ :

- Storage cask I: Container with or without concrete shielding

- Storage cask II: Cask (MOSAIK ${ }^{313}$ ) with or without lead inlay

\footnotetext{
${ }^{306}$ see JCP (2009), p. 20

${ }^{307}$ see JCP (2009), p. $20 \mathrm{ff}$.

${ }^{308}$ see JCP (2009), p. 21

${ }^{309}$ see JCP (2009), p. 21

${ }^{310}$ see KONRAD (Schacht Konrad, proposed radioactive waste repository in Germany)

${ }^{311}$ see JCP (2009), p. 24

312 see JCP (2009), p. 24

${ }^{313}$ see MOSAIK ${ }^{\circledR}$ Casks (Mobile Collecting Containers in Nuclear Power Plants)
} 
For packaging the reactor internal at Stade NPP the following were used ${ }^{314}$

- 10 Containers

- 58 Drums (12 of these were filled with abrasive)

\subsection{Feedback and Lessons Learned}

The lessons learned from previous projects, especially from the dismantling and decommissioning projects performed at the NPP Stade and Wuergassen, are recounted in shorthand ${ }^{315}$ :

- "Radiological characterization especially before the dismantling and decommissioning is a key element for a reliable dismantling concept as well as for an efficient waste management.

- The packaging strategy (type of container and cask) and the requirements for the storage conditions have to be defined in advance so that optimized packaging is possible.

- An open and permanent communication with the customer and the authorities helps to improve the workflow.

- The early involvement of the authority is important to reduce discussions during the performance.

- Avoid adaptation of equipment on site.

- Extended mock-up testing is necessary to have the opportunity to make adjustments before the equipment is transported into the controlled area.

- Staff training in advance helps to improve the workflow on-site

- According to auxiliary systems and facilities the use of modular and mobile facilities (as much as possible) helps to reduce secondary waste as well as costs

\footnotetext{
${ }^{314}$ see JCP (2009), p. 24

${ }^{315}$ see JCP (2009), p. $52 \mathrm{ff}$.
} 
- The use of designs with flexibility to accommodate possible changes is very important, especially if construction drawings of the plant are limited

- For a reliable schedule, the use of proven and experienced methods and technologies are very important

- Use of multifunctional grippers instead of many single ones will help to reduce interfaces on site and reduce the costs

- Avoid equipment with long delivery time

- Avoid sophisticated equipment in order to limit the susceptibility to faults

- Limit the use of equipment inside controlled area in order to reduce the secondary waste

- If different casks and containers with variable shielding is used, a definition of dose limits for the packaging instead of exact packaging plans, allow higher flexibility on site

- Use half shells to build up the cutting tank instead of ring-segments for better handling and transportation

- Use of additional service bridges with jib cranes was very useful and relieved the use of polar Crane"

\subsection{Preliminary Estimates for Quantities and Physical}

The estimated quantities for secondary, induced and technological waste, as generated during onsite performance, are as follows ${ }^{316}$ :

- "Combustible waste such as rags, gloves and protective mask one way filter cartridges in constrained condition: $7.5 \mathrm{~m}^{3}$

- Combustible waste from WPS tubes: $0.5 \mathrm{~m}^{3}$

${ }^{316}$ see JCP (2009), p. 113 
- Incombustible waste such as saw blades, milling cutters and WASS tubes: $0.3 \mathrm{~m}^{3}$

- 2201- drums with baskets containing fine filter cartridges filled with suspended solids from the segmentation process: $15 \mathrm{pcs}$.

- Sawdust from post segmentation activities inside the SFP: $0.1 \mathrm{~m}^{3}$

- 2201- drums with baskets containing abrasive and kerfs' material from WASS cutting activities: 43 pcs. +8 pcs. for performing ZIRP (based on assumed 2201drum basket inlay containing 1351)

- Technological waste from cutting devices and auxiliary components: approx. 35 Metallic Transport Container (CMT) boxes"

Furthermore, the following facilities will be required during onsite performance ${ }^{317}$ :

- "Changing rooms

- Laundry service

- Office cleaning service

- Possibility of using the mechanical workshop, hot and cold in case of necessity"

${ }^{317}$ see JCP (2009), p. 118 


\section{APPLICATION AND DISCUSSION OF RESULTS}

\subsection{Application of the model using AIMMS, MATLAB, R, SPSS (Overview)}

The application of the framework is realized using the software tools introduced in chapter 3.5 - AIMMS (see chapter 6.3), MATLAB (see chapter 6.4), R (see chapter 6.5) and SPSS (see chapter 6.6).

While the implementation of the framework in $\mathrm{R}$ is shown in detail (see chapter 6.5), the implementation in MATLAB, AIMMS and SPSS is just an example due to the goal defined in item $\mathrm{C}$ (see chapter 1.2).

The implementation of the framework - shown in detail in chapter 6.3 - is valid and practicable also for the use of MATLAB, R and SPSS.

The steps of the implementation are the declaration of the model (see chapter 6.3.1), specification of the minimization of the risk of storage (see chapter 6.3.2), specification of the constraints for the minimization of the risk of storage (see chapter 6.3.3), attributes of sets, variables, parameters, constraints and mathematical programs (see chapter 6.3.4), creating a database table (see chapter 6.3.5) and the execution, initialization and termination of the model (see chapter 6.3.6).

\subsection{Application of the model using MS Project}

\section{MS Project - Timeline, Calendar View, Network Diagram and Resource Sheet}

The application of the framework is represented through the example of a project duration of 15 months (Wed 1/1/14 - Thu 3/26/15). The timeline shows the main phases of the project (see Figure 15 and 15a). A detailed listing of the tasks is given in this chapter. 
Further MS Projects offers several other views of the task plan in order to increase the organization and communication level, transparency, usability, connectivity and visibility of the underlying tasks and processes. Some examples and excerpts of those views are shown in the appendix 1, 2 and 3.

The calendar view is helpful, to have a diary vision based on a breakdown by months, weeks and days. All tasks are listed on a daily basis (see appendix 2).

Excerpts of the network diagram show various zoom levels for the connectivity between tasks - helpful in visualizing the procedure flow between the tasks and the dependencies between tasks (see appendix 3).

The resource sheet depicts the costs of the participating human resources and the rates associated with these costs. This view enables the project manager to link the resources with rates and costs e. g. per hour (see appendix 1).

The primary function of MS project is to reduce complexity. All varying concepts, methods and tools are summarized in a road map and are communicated in a comprehensive manner. All knowledge derived from the evaluation of empirical data concerning the definition of the tasks is aggregated in a view. Through the use of a project management tool the organizational efficiency is increased and a minimization of the project costs and duration is ensured in the area of management. The minimization of OR-sided issues will be focused upon in chapter 6.3. In the MS Project task view (see Table 6 to 6e) all approaches, such as lean management, simultaneous engineering and software tools are included. These concepts and methods are integrated in the specific tasks (for example tasks 5-11, see Table 6) implicitly. These approaches emerge in the iterative and linked task structure as listed in the project schedule, as follows: 


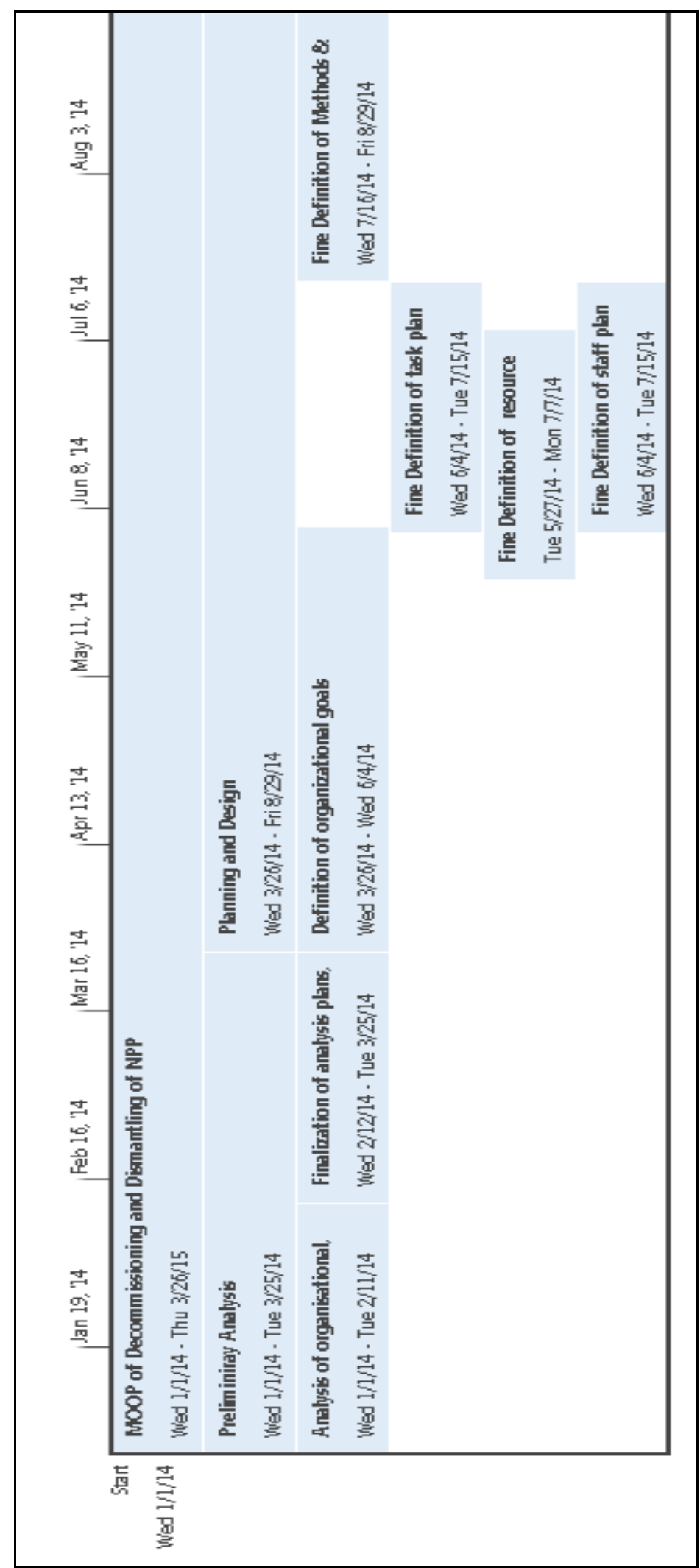

Figure 15: Timeline of the Project (1/1/14 - 08/31/14) 


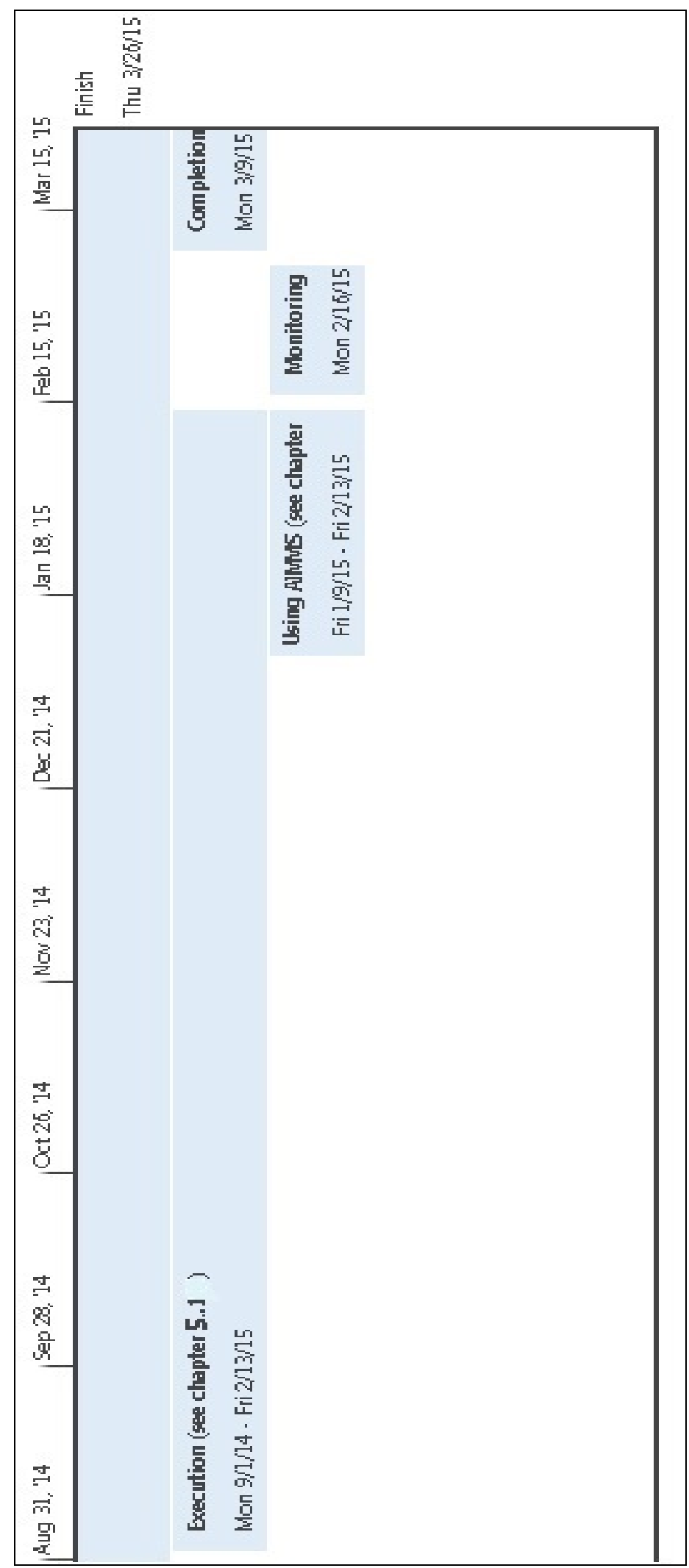

Figure 15a: Timeline of the Project (9/1/14 - 3/26/15) 


\section{MS Project - Aided Application of the framework}

Below is a detailed listing of the tasks defined for the application of the framework (see tables Table $6-6 e$ ).

Table 6: Tasks $1-11$

\begin{tabular}{|c|c|c|c|c|c|c|c|}
\hline & ( & $\begin{array}{l}\text { Task } \\
\text { Mode . }\end{array}$ & Task Name & Duration. & Start & Finish & Pre \\
\hline 0 & & -4 & $\begin{array}{l}\text { MOOP of } \\
\text { Decommissioning } \\
\text { and Dismantling of } \\
\text { NPP }\end{array}$ & 323 days & Wed 1/1/14 & $\begin{array}{l}\text { Thu } \\
3 / 26 / 15\end{array}$ & \\
\hline 1 & & $\pi$ & $\begin{array}{l}\text { Preliminary } \\
\text { Analysis }\end{array}$ & 60 days & Wed $1 / 1 / 14$ & Tue $3 / 25 / 14$ & \\
\hline 2 & & $\overline{6}$ & $\begin{array}{l}\text { Analysis of } \\
\text { organisational, tasks, } \\
\text { staff and } \\
\text { technological } \\
\text { structures }\end{array}$ & 30 days & Wed $1 / 1 / 14$ & Tue $2 / 11 / 14$ & \\
\hline 3 & & $=$ & $\begin{array}{l}\text { Finalization of } \\
\text { analysis plans, expert } \\
\text { estimations and } \\
\text { contracts }\end{array}$ & 30 days & Wed $2 / 12 / 14$ & Tue $3 / 25 / 14$ & 2 \\
\hline 4 & & $\star x$ & $\begin{array}{l}\text { Planning and } \\
\text { Design }\end{array}$ & 114 days & Wed $3 / 26 / 14$ & Fri $8 / 29 / 14$ & \\
\hline 5 & & $\pi$ & $\begin{array}{l}\Delta \text { Definition of } \\
\text { organizational goals }\end{array}$ & 52 days & Wed $3 / 26 / 14$ & Wed $6 / 4 / 14$ & \\
\hline 6 & & - & Define Project Tean & 6 days & Wed $3 / 26 / 14$ & Wed $4 / 2 / 14$ & \\
\hline 7 & 围 & - & Define Quality Stan & 6 days & Tue $4 / 1 / 14$ & Tue $4 / 8 / 14$ & \\
\hline 8 & & $\Rightarrow$ & $\begin{array}{l}\text { Define Task } \\
\text { Structure }\end{array}$ & 6 days & Wed $4 / 9 / 14$ & Wed $4 / 16 / 14$ & 7 \\
\hline 9 & 四 & -5 & $\begin{array}{l}\text { Define Tools and } \\
\text { Methods }\end{array}$ & 6 days & Wed $4 / 16 / 14$ & Wed $4 / 23 / 14$ & \\
\hline 10 & 四 & -4 & $\begin{array}{l}\text { Define Project } \\
\text { Controlling } \\
\text { Standards }\end{array}$ & 6 days & Wed 4/16/14 & Wed $4 / 23 / 14$ & \\
\hline 11 & & - & $\begin{array}{l}\text { Define Risk Analysis } \\
\text { Standards }\end{array}$ & 6 days & Thu $4 / 24 / 14$ & Thu 5/1/14 & 10 \\
\hline
\end{tabular}


As shown, the tasks are sorted in a hierarchical order, since they're divided into phases and (sub-) categories. In the case of this project there are the main phases and categories "Preliminary Analysis", "Planning and Design", "Execution", "Monitoring and Controlling" and "Completion, Finalization and Delivery". Those are subdivided into sub phases or subcategories and elementary tasks (see tables Table $6-6 \mathrm{e}$ ).

All phases, categories and elementary tasks are described in different parts of this dissertation.

Table 6a: Tasks $12-26$

\begin{tabular}{|c|c|c|c|c|c|c|c|}
\hline 12 & & 4 & Define Budget Plan & 6 days & Fri $5 / 2 / 14$ & Fri $5 / 9 / 14$ & 11 \\
\hline 13 & & $=$ & $\begin{array}{l}\text { Create Resource } \\
\text { Map }\end{array}$ & 6 days & Mon 5/12/14 & Mon 5/19/14 & 12 \\
\hline 14 & & $=$ & $\begin{array}{l}\text { Refine Organisation } \\
\text { Plan }\end{array}$ & 6 days & Tue 5/20/14 & Mon 5/26/14 & 13 \\
\hline 15 & & -5 & $\begin{array}{l}\text { Create } \\
\text { Organisation Charts }\end{array}$ & 6 days & Tue 5/27/14 & Tue $6 / 3 / 14$ & 14 \\
\hline 16 & & $\pi$ & $\begin{array}{l}\triangle \text { Fine Definition of } \\
\text { task plan }\end{array}$ & 30 days & Wed 6/4/14 & Tue $7 / 15 / 14$ & 15 \\
\hline 17 & 柬 & -5 & $\begin{array}{l}\text { Analysis of team } \\
\text { structure }\end{array}$ & 5 days & Wed $6 / 4 / 14$ & Tue $6 / 10 / 14$ & \\
\hline 18 & & $\Rightarrow$ & $\begin{array}{l}\text { Fine estimation of } \\
\text { work activities }\end{array}$ & 5 days & Wed $6 / 11 / 14$ & Tue $6 / 17 / 14$ & 17 \\
\hline 19 & & -4 & $\begin{array}{l}\text { Risk analysis of } \\
\text { activities }\end{array}$ & 5 days & Wed $6 / 18 / 14$ & Tue $6 / 24 / 14$ & 18 \\
\hline 20 & & $=$ & $\begin{array}{l}\text { Optimization of } \\
\text { tasks to team } \\
\text { members I }\end{array}$ & 5 days & Wed $6 / 25 / 14$ & Tue $7 / 1 / 14$ & 19 \\
\hline 21 & & - & $\begin{array}{l}\text { Adaptation of } \\
\text { controlling } \\
\text { methods and tools }\end{array}$ & 5 days & Wed $7 / 2 / 14$ & Tue $7 / 8 / 14$ & 20 \\
\hline 22 & & -5 & Create Task Charts & 5 days & Wed $7 / 9 / 14$ & Tue $7 / 15 / 14$ & 21 \\
\hline 23 & & $\star$ & $\begin{array}{l}\text { Fine Definition of } \\
\text { staff plan }\end{array}$ & 30 days & Wed $6 / 4 / 14$ & Tue $7 / 15 / 14$ & \\
\hline 24 & & -4 & Build Skill Plan & 3 days & Wed $6 / 4 / 14$ & Fri $6 / 6 / 14$ & \\
\hline 25 & & $\overline{4}$ & $\begin{array}{l}\text { Delegation of } \\
\text { Responsibilities }\end{array}$ & 16 days & Mon $6 / 9 / 14$ & Mon 6/30/14 & 24 \\
\hline 26 & & -5 & $\begin{array}{l}\text { Optimization of } \\
\text { tasks to team } \\
\text { members II }\end{array}$ & 16 days & Mon $6 / 9 / 14$ & Mon 6/30/14 & 24 \\
\hline
\end{tabular}


Table 6b: Tasks $27-40$

\begin{tabular}{|c|c|c|c|c|c|c|c|}
\hline 27 & 国 & $\Rightarrow$ & $\begin{array}{l}\text { Definition of } \\
\text { communication } \\
\text { techniques }\end{array}$ & 18 days & Wed $6 / 4 / 14$ & Fri $6 / 27 / 14$ & \\
\hline 28 & 柬 & $\Rightarrow$ & $\begin{array}{l}\text { Time Management } \\
\text { Strategies }\end{array}$ & 5 days & Wed $7 / 9 / 14$ & Tue $7 / 15 / 14$ & 27 \\
\hline 29 & 柬 & $\Rightarrow$ & $\begin{array}{l}\text { Methods for } \\
\text { Monitoring of } \\
\text { Activities }\end{array}$ & 30 days & Wed $6 / 4 / 14$ & Tue $7 / 15 / 14$ & \\
\hline 30 & & $\star$ & $\begin{array}{l}\text { Fine Definition of } \\
\text { resource plan }\end{array}$ & 30 days & Tue 5/27/14 & Mon $7 / 7 / 14$ & \\
\hline 31 & & $\Rightarrow$ & $\begin{array}{l}\text { Specification of } \\
\text { organizational } \\
\text { resources }\end{array}$ & 30 days & Tue 5/27/14 & Mon $7 / 7 / 14$ & \\
\hline 32 & & $\Rightarrow$ & $\begin{array}{l}\text { Specification of } \\
\text { human resources }\end{array}$ & 22 days & Tue 5/27/14 & Wed $6 / 25 / 14$ & \\
\hline 33 & & G & $\begin{array}{l}\text { Specification of } \\
\text { tool resources }\end{array}$ & 20 days & Tue 5/27/14 & Mon $6 / 23 / 14$ & \\
\hline 34 & & $\pi$ & $\begin{array}{l}\triangle \text { Fine Definition of } \\
\text { Methods \& Tools }\end{array}$ & 33 days & Wed $7 / 16 / 14$ & Fri $8 / 29 / 14$ & 29 \\
\hline 35 & 国 & 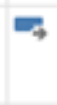 & $\begin{array}{l}\text { Status Analysis } \\
\text { Methods\&Tools }\end{array}$ & 33 days & Wed $7 / 16 / 14$ & Fri $8 / 29 / 14$ & \\
\hline 36 & 国 & -5 & $\begin{array}{l}\text { Variance Analysis } \\
\text { Methods\&Tools }\end{array}$ & 33 days & Wed $7 / 16 / 14$ & Fri $8 / 29 / 14$ & \\
\hline 37 & 四 & 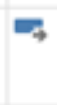 & $\begin{array}{l}\text { Quality Analysis } \\
\text { Methods\&Tools }\end{array}$ & 33 days & Wed $7 / 16 / 14$ & Fri $8 / 29 / 14$ & \\
\hline 38 & 丑 & 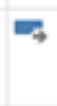 & $\begin{array}{l}\text { Risk Analysis } \\
\text { Methods\&Tools }\end{array}$ & 33 days & Wed $7 / 16 / 14$ & Fri $8 / 29 / 14$ & \\
\hline 39 & 国 & $\Rightarrow$ & $\begin{array}{l}\text { Iterative adaptive } \\
\text { actions }\end{array}$ & 33 days & Wed $7 / 16 / 14$ & Fri $8 / 29 / 14$ & \\
\hline 40 & 囲 & $\Rightarrow$ & $\begin{array}{l}\text { Reporting } \\
\text { Methods\&Tools }\end{array}$ & 33 days & Wed $7 / 16 / 14$ & Fri $8 / 29 / 14$ & \\
\hline
\end{tabular}

The first column shows the task number, the second "I" shows indications and information with detailed documentation about the task accessible on a one-click-basis. In the column "task mode" several options such as grouping, sorting, filtering and scheduling (manually and automatically) can be applied, in order to calculate the given durations (see $5^{\text {th }}$ column) automatically. 
Table 6c: Tasks $41-53$

\begin{tabular}{|c|c|c|c|c|c|c|c|}
\hline & i & $\begin{array}{l}\text { Task } \\
\text { Mode }\end{array}$ & Task Name & Duration & Start & Finish & Pres \\
\hline 41 & & 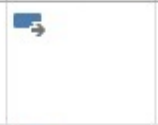 & $\begin{array}{l}\text { Execution (see } \\
\text { chapter } 5.1 \text { ) }\end{array}$ & 120 days & Mon $9 / 1 / 14$ & Fri $2 / 13 / 15$ & 40 \\
\hline 42 & & 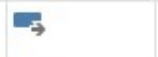 & Visual Inspection & 7 days & Mon $9 / 1 / 14$ & Tue $9 / 9 / 14$ & \\
\hline 43 & & $\Rightarrow$ & $\begin{array}{l}\text { Positioning } \\
\text { equipment for } \\
\text { measurements }\end{array}$ & 7 days & Mon $9 / 1 / 14$ & Tue $9 / 9 / 14$ & \\
\hline 44 & & $\Rightarrow$ & $\begin{array}{l}\text { Final Segmentation } \\
\text { and Packaging Plan }\end{array}$ & 3 days & Mon $9 / 1 / 14$ & Wed $9 / 3 / 14$ & 40 \\
\hline 45 & & -5 & $\begin{array}{l}\text { Mockup Tests and } \\
\text { Process Qualification }\end{array}$ & 7 days & Thu $9 / 4 / 14$ & Fri $9 / 12 / 14$ & 44 \\
\hline 46 & & -3 & $\begin{array}{l}\text { Performance of Plant } \\
\text { Modifications }\end{array}$ & 8 days & Mon $9 / 15 / 14$ & Wed $9 / 24 / 14$ & 45 \\
\hline 47 & & 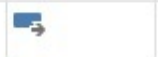 & Removals & 7 days & Thu $9 / 25 / 14$ & Fri $10 / 3 / 14$ & 46 \\
\hline 48 & & 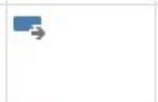 & $\begin{array}{l}\text { Advanced } \\
\text { Measurements }\end{array}$ & 7 days & Mon $10 / 6 / 14$ & Tue $10 / 14 / 14$ & 47 \\
\hline 49 & & $\Rightarrow$ & Extraction of bolts & 7 days & Wed $10 / 15 / 14$ & Thu $10 / 23 / 14$ & 48 \\
\hline 50 & & $\Rightarrow$ & $\begin{array}{l}\text { Positioning of } \\
\text { equipment for the } \\
\text { extraction of samples }\end{array}$ & 7 days & Fri $10 / 24 / 14$ & Mon $11 / 3 / 14$ & 49 \\
\hline 51 & & 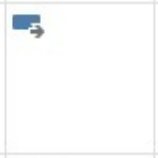 & $\begin{array}{l}\text { Identification, } \\
\text { marking and cutting } \\
\text { of components }\end{array}$ & 8 days & Tue $11 / 4 / 14$ & Thu $11 / 13 / 14$ & 50 \\
\hline 52 & & 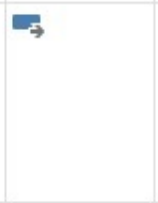 & $\begin{array}{l}\text { Supply, Installation } \\
\text { and Preoperational } \\
\text { Tests of Contractors } \\
\text { Equipment }\end{array}$ & 8 days & Fri $11 / 14 / 14$ & Tue $11 / 25 / 14$ & 51 \\
\hline 53 & & $\Rightarrow$ & $\begin{array}{l}\text { RVI Segmentation } \\
\text { and Packaging }\end{array}$ & 8 days & $\begin{array}{l}\text { Wed } \\
11 / 26 / 14\end{array}$ & Fri $12 / 5 / 14$ & 52 \\
\hline
\end{tabular}

MS-Project enables the project manager to link the tasks based on the specified time data with specific tasks, defined in the Predecessor-Column of the task table (see $8^{\text {th }}$ column). This way it is granted that a task can only start when the proceeding task is completed. For example, task 64, 65 (Monitoring and Controlling - Implementation of performance standards) can only begin when the execution of the model in AIMMS is successfully finalized (task 63). 
Table 6d: Tasks 54-63

\begin{tabular}{|c|c|c|c|c|c|c|c|}
\hline 54 & & $\sigma$ & $\begin{array}{l}\text { Final Demobilization, } \\
\text { Clean-Up and } \\
\text { Decontamination }\end{array}$ & 8 days & Mon 12/8/14 & $\begin{array}{l}\text { Wed } \\
12 / 17 / 14\end{array}$ & 53 \\
\hline 55 & & 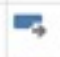 & Transfer & 8 days & Thu $12 / 18 / 14$ & Mon $12 / 29 / 1$ & 54 \\
\hline 56 & & $=$ & $\begin{array}{l}\text { Final - iterative } \\
\text { optimized - Report }\end{array}$ & 8 days & Tue $12 / 30 / 14$ & Thu $1 / 8 / 15$ & 55 \\
\hline 57 & i & $\Rightarrow$ & $\begin{array}{l}\text { Using AIMMS (see } \\
\text { chapter } 6.3 \text { ) }\end{array}$ & 26 days & Frì $1 / 9 / 15$ & Fri $2 / 13 / 15$ & 56 \\
\hline 58 & i & $=$ & $\begin{array}{l}\text { Declaration of the } \\
\text { model }\end{array}$ & 12 days & Fri $1 / 9 / 15$ & Mon $1 / 26 / 15$ & \\
\hline 59 & & -5 & $\begin{array}{l}\text { Specification of the } \\
\text { Minimization of the } \\
\text { risk of storage }\end{array}$ & 7 days & Tue $1 / 27 / 15$ & Wed $2 / 4 / 15$ & 58 \\
\hline 60 & i & $\Rightarrow$ & $\begin{array}{l}\text { Specification of the } \\
\text { Constraint for the } \\
\text { Minimization of the } \\
\text { risk of storage }\end{array}$ & 2 days & Thu $2 / 5 / 15$ & Fri $2 / 6 / 15$ & 59 \\
\hline 61 & i & $\Rightarrow$ & $\begin{array}{l}\text { Attributes of sets, } \\
\text { variables, } \\
\text { parameters, } \\
\text { constraints and } \\
\text { mathematical } \\
\text { programs in AIMMS }\end{array}$ & 2 days & Mon 2/9/15 & Tue $2 / 10 / 15$ & 60 \\
\hline 62 & & -5 & $\begin{array}{l}\text { Creating a } \\
\text { Database Table }\end{array}$ & 1 day & Wed $2 / 11 / 15$ & Wed $2 / 11 / 15$ & 61, \\
\hline 63 & & $\Rightarrow$ & $\begin{array}{l}\text { Executing the } \\
\text { Model, } \\
\text { Initialization, } \\
\text { Termination and } \\
\text { the AIMMS Math } \\
\text { Program Inspector }\end{array}$ & 2 days & Thu $2 / 12 / 15$ & Fri $2 / 13 / 15$ & 62 \\
\hline
\end{tabular}


Table 6e: Tasks $64-75$

\begin{tabular}{|c|c|c|c|c|c|c|c|}
\hline 64 & & $\pi$ & $\begin{array}{l}\text { Monitoring and } \\
\text { Controlling }\end{array}$ & 15 days & Mon 2/16/15 & Fri $3 / 6 / 15$ & \\
\hline 65 & & $=$ & $\begin{array}{l}\text { Implementation of } \\
\text { performance } \\
\text { standards }\end{array}$ & 2 days & Mon 2/16/15 & Tue $2 / 17 / 15$ & 63 \\
\hline 66 & & $=$ & $\begin{array}{l}\text { Measurement of } \\
\text { categories of } \\
\text { performances }\end{array}$ & 2 days & Wed $2 / 18 / 15$ & Thu 2/19/15 & 65 \\
\hline 67 & & -4 & $\begin{array}{l}\text { Comparing of } \\
\text { performances with } \\
\text { standards }\end{array}$ & 4 days & Fri $2 / 20 / 15$ & Wed $2 / 25 / 15$ & 66 \\
\hline 68 & & 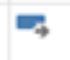 & Analysing variances & 1 day & Thu $2 / 26 / 15$ & Thu $2 / 26 / 15$ & 67 \\
\hline 69 & & $=$ & Correcting & 2 days & Fri $2 / 27 / 15$ & Mon 3/2/15 & 68 \\
\hline 70 & & $=$ & Iterative Reporting & 4 days & Tue $3 / 3 / 15$ & Fri $3 / 6 / 15$ & 69 \\
\hline 71 & & $\star$ & - Completion/Finalizi & 14 days & Mon $3 / 9 / 15$ & Thu $3 / 26 / 15$ & \\
\hline 72 & & -4 & $\begin{array}{l}\text { Review\&Inspect Task } \\
\text { Lists }\end{array}$ & 3 days & Mon 3/9/15 & Wed $3 / 11 / 15$ & 70 \\
\hline 73 & & $=$ & $\begin{array}{l}\text { Obtain approvals and } \\
\text { certifications \& Audit }\end{array}$ & 4 days & Thu $3 / 12 / 15$ & Tue $3 / 17 / 15$ & 72 \\
\hline 74 & & $=$ & $\begin{array}{l}\text { Commit final reports } \\
\text { \& Documentations }\end{array}$ & 4 days & Wed $3 / 18 / 15$ & Mon 3/23/15 & 73 \\
\hline 75 & 囲 & $=$ & $\begin{array}{l}\text { Organize final } \\
\text { meeting }\end{array}$ & 3 days & Tue $3 / 24 / 15$ & Thu $3 / 26 / 15$ & 74 \\
\hline
\end{tabular}

These dependencies between tasks and their chronological order, given by parallelism and serialism and specified by their proceeding tasks are visualized with a Gantt chart. These are visible to the project manager in the same view with the task plan (see figureFigure 16 and Figure 17). 


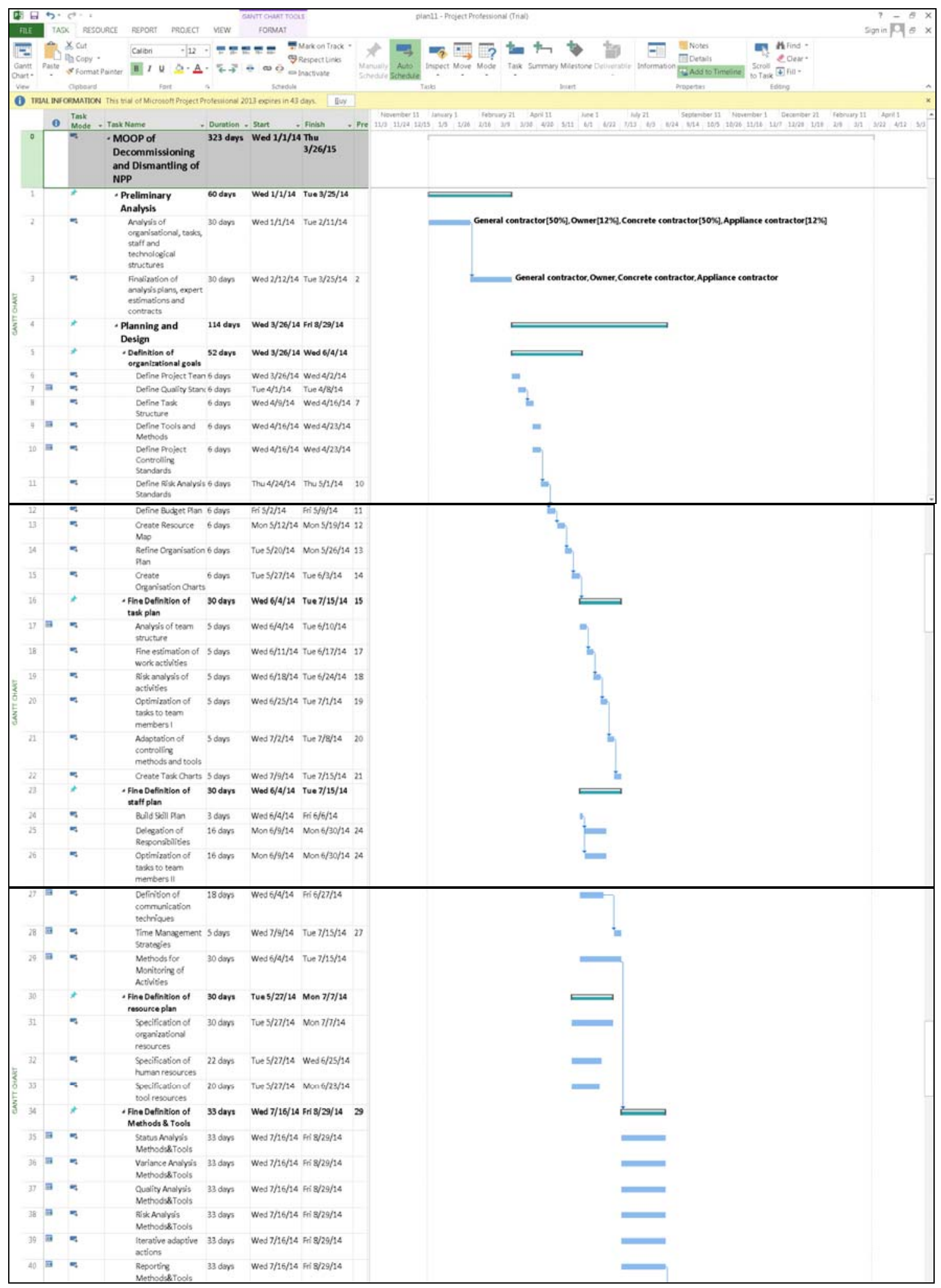

Figure 16: MS Project - Phases "Preliminary Analysis" and "Planning and Design" 


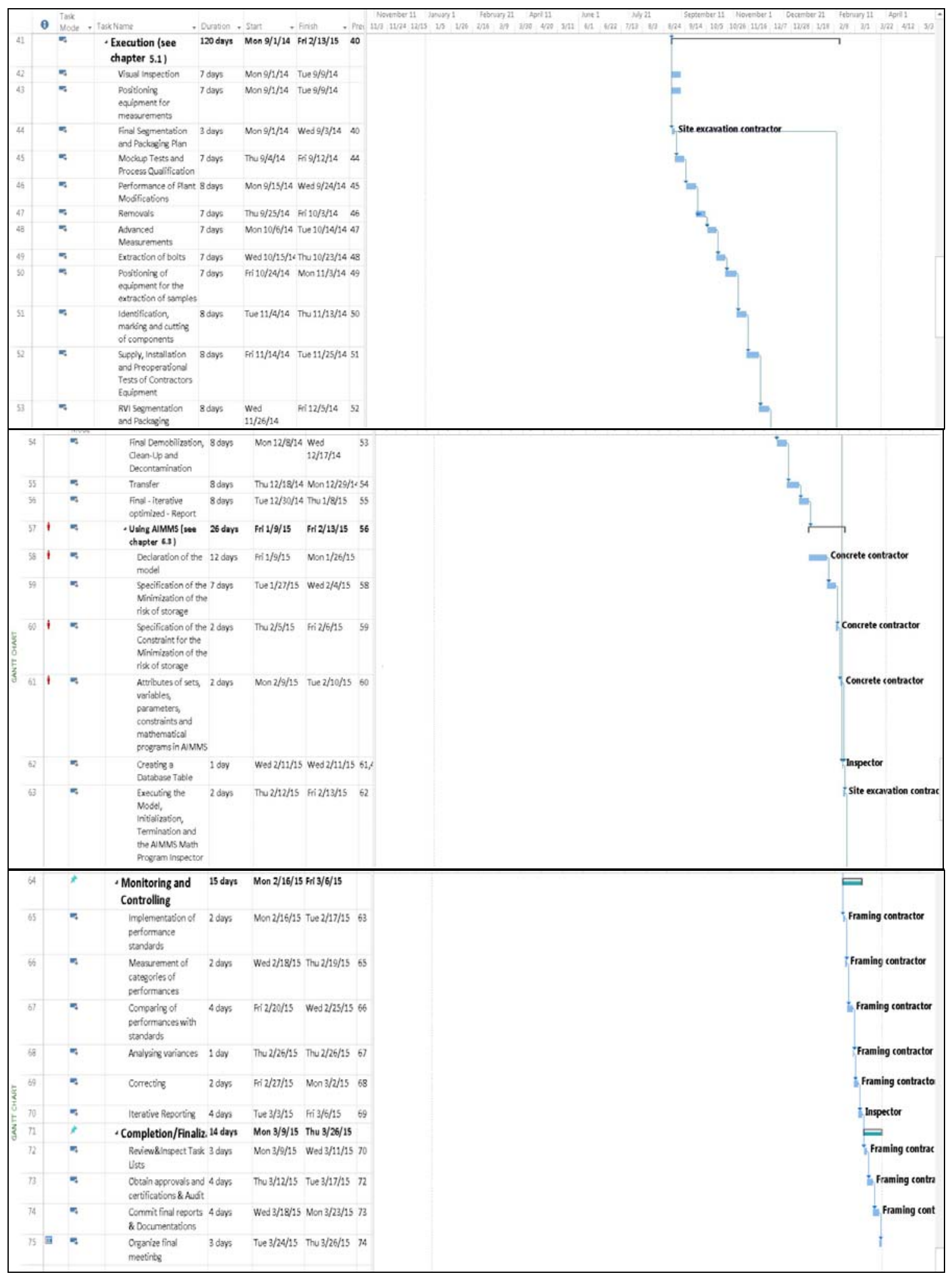

Figure 17: MS Project - Phases "Execution" and "Monitoring and Controlling" 


\subsection{Application of the model in AIMMS}

\subsubsection{Declaration of the model}

Two types of files are necessary in order to work with AIMMS ${ }^{318}$ :

- Project file - Contains all data built up within an AIMMS project and is instantiated first

- Model file - Contains the model data with an AIMMS project. There are two formats: ASCII (.AIM) and binary (.AMB).

The declaration of the model is used to implement the identifiers in the model tree visible in the Model Explorer as leaf nodes (see Figure 18). There are several identifier types supported by AIMMS:

Table 7: $\quad$ Identifiers in AIMMS ${ }^{319}$

\begin{tabular}{|l|l|}
\hline Set & convention \\
varameter & arc \\
constraint & complementarity variable \\
mathematical program & node \\
element parameter & assertion \\
string parameter & file \\
index & database table \\
quantity & horizon \\
unit parameter & \\
\hline
\end{tabular}

The insertion of the identifiers in AIMMS is shown in the next figure:

\footnotetext{
318 see AIMMS-Help (2013)

319 see AIMMS-Help (2013)
} 


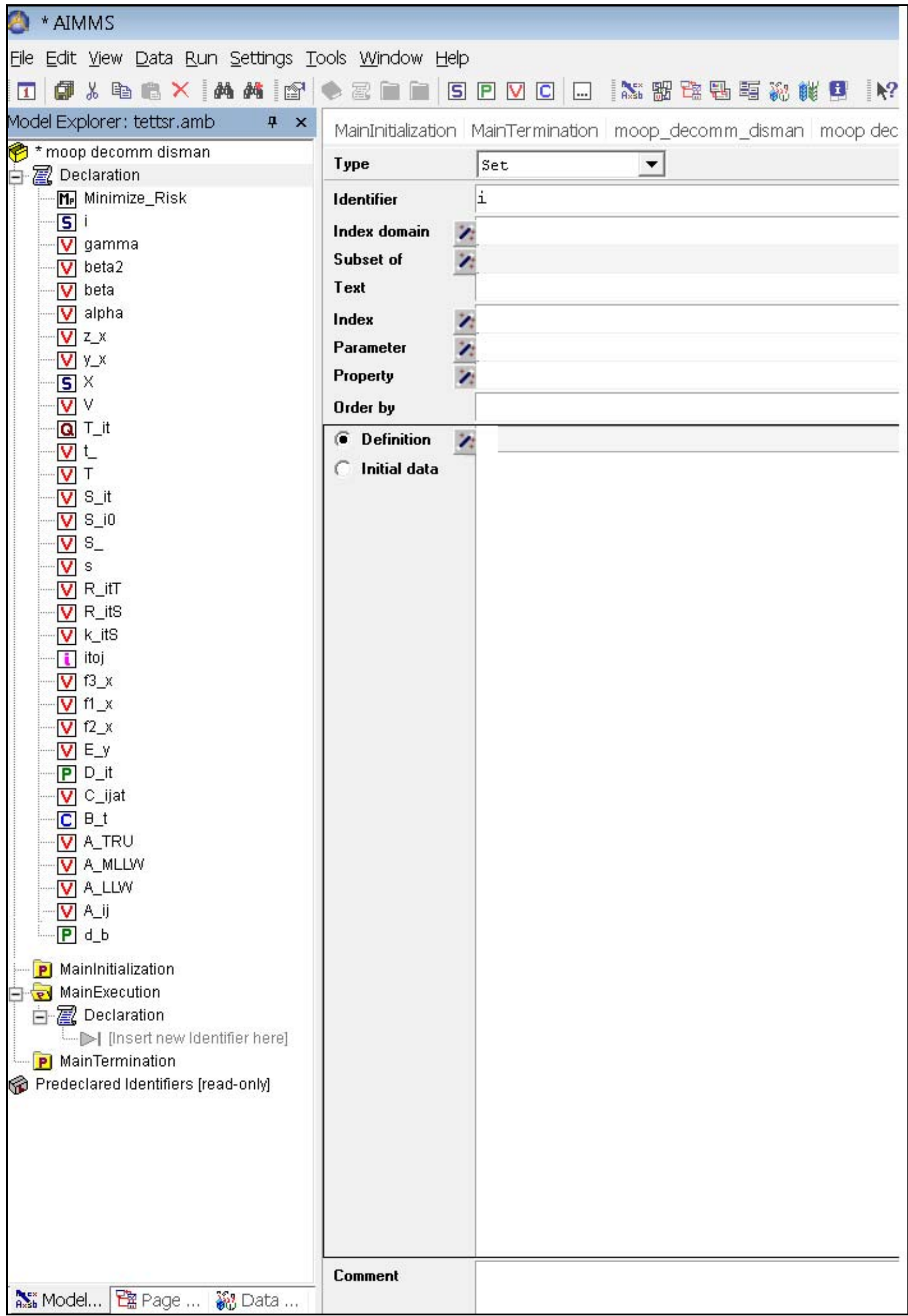

Figure 18: Adding the identifiers to the model 


\subsubsection{Specification of the Minimization of the risk of storage}

The Minimization function given in

$\operatorname{Minimize}_{\left\{T_{i j t}\right\}} \overline{R_{10}}=\sum_{i} \sum_{j \neq S, D} R_{i j 10}$

is implemented in AIMMS as shown in the Figure 18 example and is conditional on restrictions on the maximum allowable risk per unit volume for each waste type in

$\lambda_{i j t}\left(R_{i s 0} / S_{i 0}\right) \geq(R / V)_{i j t,} \quad \forall i, j, t$

Regarding the MOOP to SOOP strategy, $f_{1}(X)$ and $f_{3}(X)$ are under the bounding value $d_{b}$ and must be repeated through several iterations, in an attempt to identify a convergent solution (see also chapter 6.5.4.7) ${ }^{320}$.

$\overline{C_{10}} \leq d_{b}$

$\overline{C_{10}} * \overline{R_{t}} \leq d_{b}$

The constraint is also implemented in AIMMS as shown in Figure 19. The main identifiers used in the minimization function are listed below:

- waste type $i$ is defined as a set (of waste types),

- the minimization function Minimize_Risk is defined as a mathematical program and

- $\mathrm{j}$ and $\mathrm{R}$ as variables and

- D_is defined as a parameter

- $\mathrm{d}_{\mathrm{b}}$ is defined as a parameter

${ }^{320}$ see Miettinen (1999), p. 5ff. / Hwang; Masud (1979) / Wikipedia (2013) 


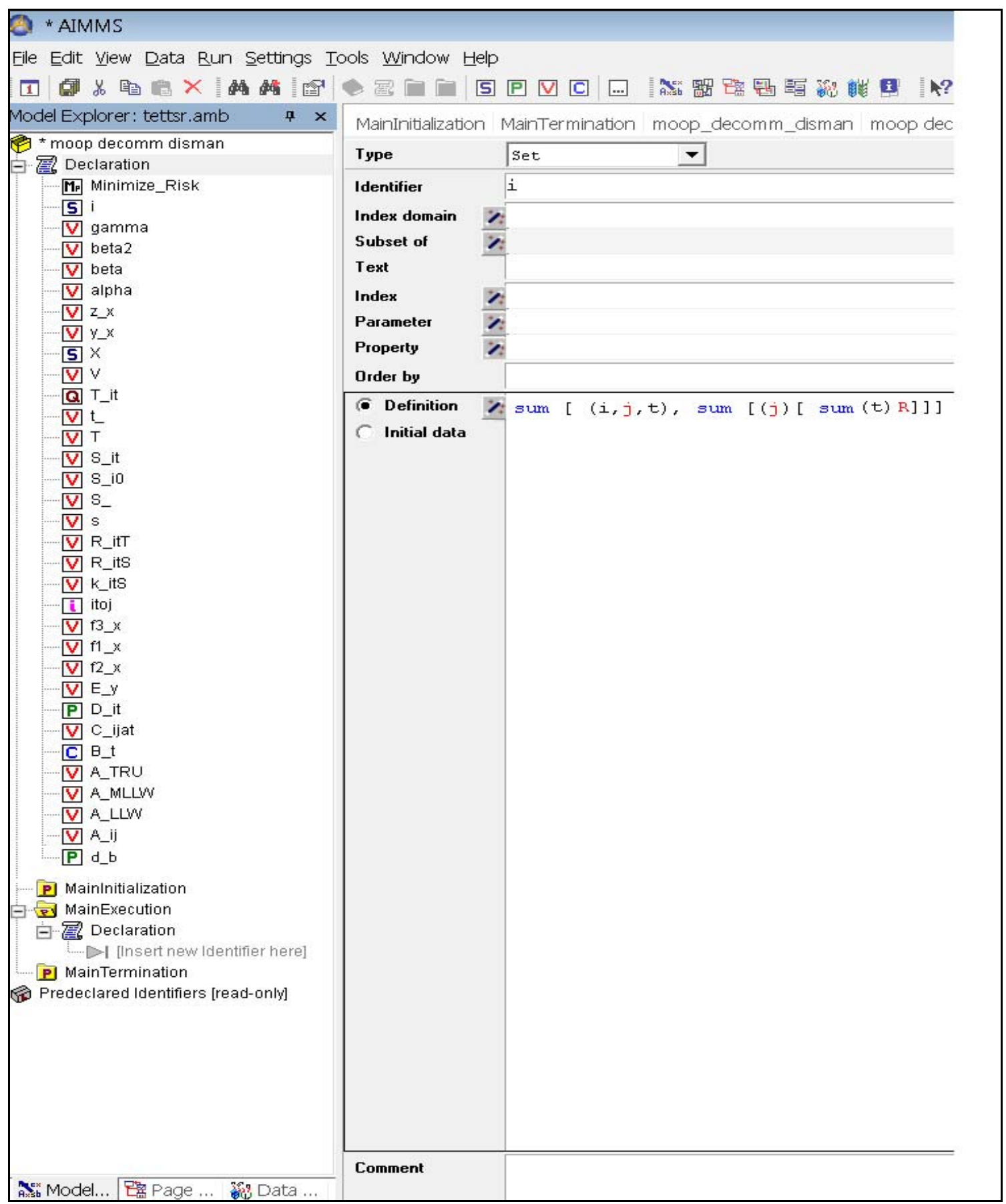

Figure 19: Specification of the minimization 


\subsubsection{Specification of the Constraint for Minimization of the risk of storage}

As shown in the next Figure 20 a constraint Min_Risk_Constraint is defined in the next step.

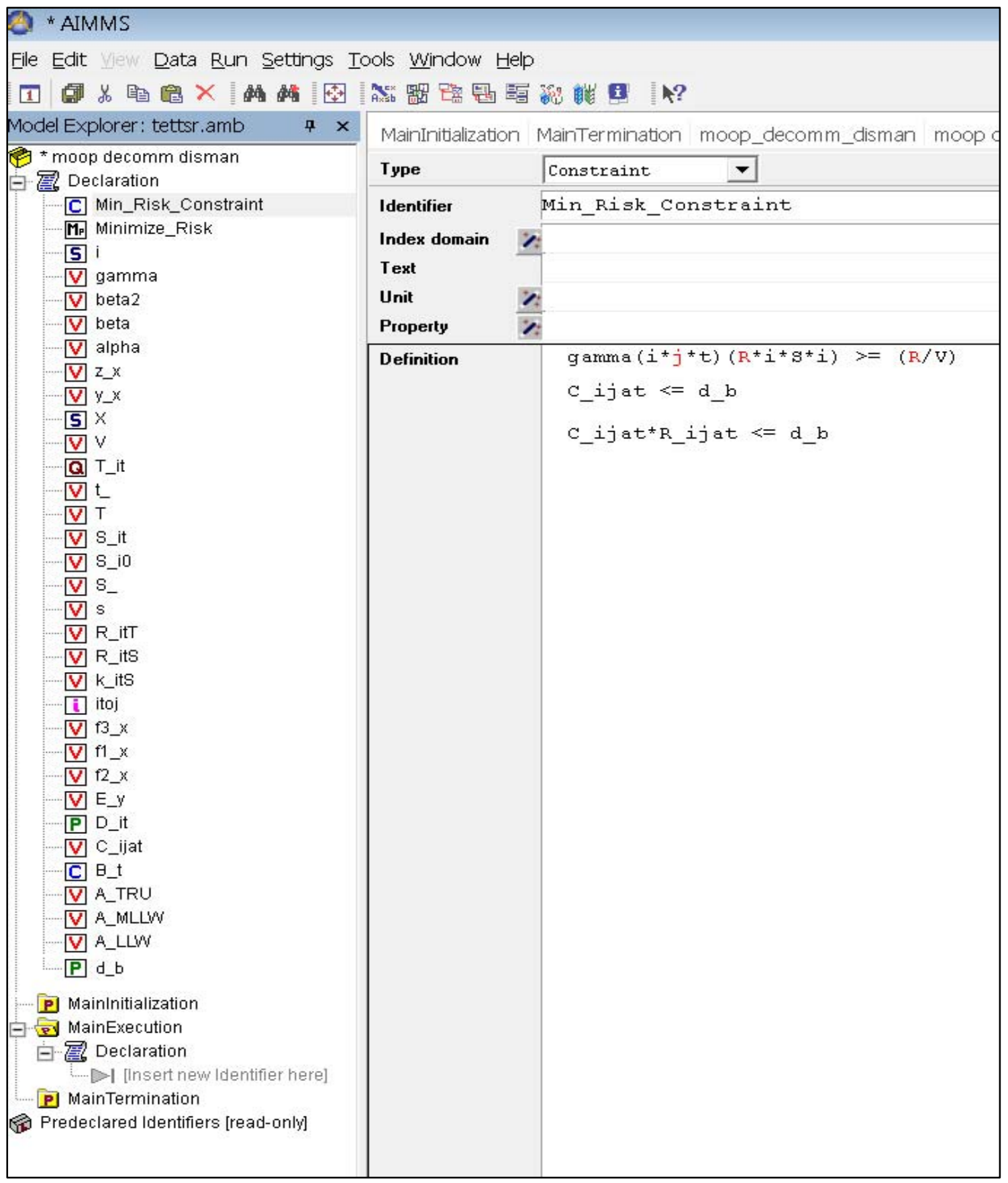

Figure 20: Specification of the constraint 


\subsubsection{Attributes of sets, variables, parameters, constraints and mathematical programs in AIMMS}

There are also attributes that need to be specified for each identifier. The most commonly

used attributes for variables and parameters are given below ${ }^{321}$

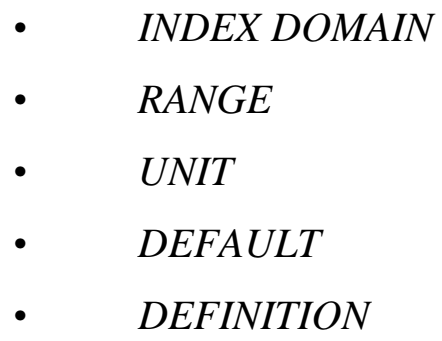

Attributes for constraints are ${ }^{322}$

- INDEX DOMAIN

- UNIT

- PROPERTY

- DEFINITION

Attributes for mathematical programs are ${ }^{323}$

- OBJECTIVE

- DIRECTION

- VARIABLES

- CONSTRAINTS

- TYPE

- VIOLATION PENALTY

321 see AIMMS-Help (2013)
${ }^{322}$ see AIMMS-Help (2013)
${ }^{323}$ see AIMMS-Help (2013) 
The attributes of a database table identifier are listed here ${ }^{324}$ :

- INDEX DOMAIN

- DATA SOURCE

- TABLE NAME

- $\quad$ MAPPING

The DATA SOURCE attribute is used to define the data source in order to communicate with the data provider (e.g. database) and contains information about how to connect to the data provider (e.g. Open Database Connectivity data source). The DATA SOURCE attribute specifies the data table name that is being connected with. A data source is usually made up of multiple data tables. The MAPPING attribute specifies the relationships between the data base columns and the AIMMS model identifiers ${ }^{325}$.

In the specification section of a database table those options should be set depending on the underlying data structures (see Figure 21). The basis for the data used in the optimization model is extractable from the specific domain which is given by the dismantling and decommissioning project (see chapter 5).

\subsubsection{Creating a Database Table}

A database table can be selected from the declaration option within the model tree. Further specifications such as DATA SOURCE, DATA SOURCE and MAPPING can be specified in the same declaration window.

${ }_{325}^{324}$ see AIMMS-Help (2013)

${ }^{325}$ see AIMMS-Help (2013) 


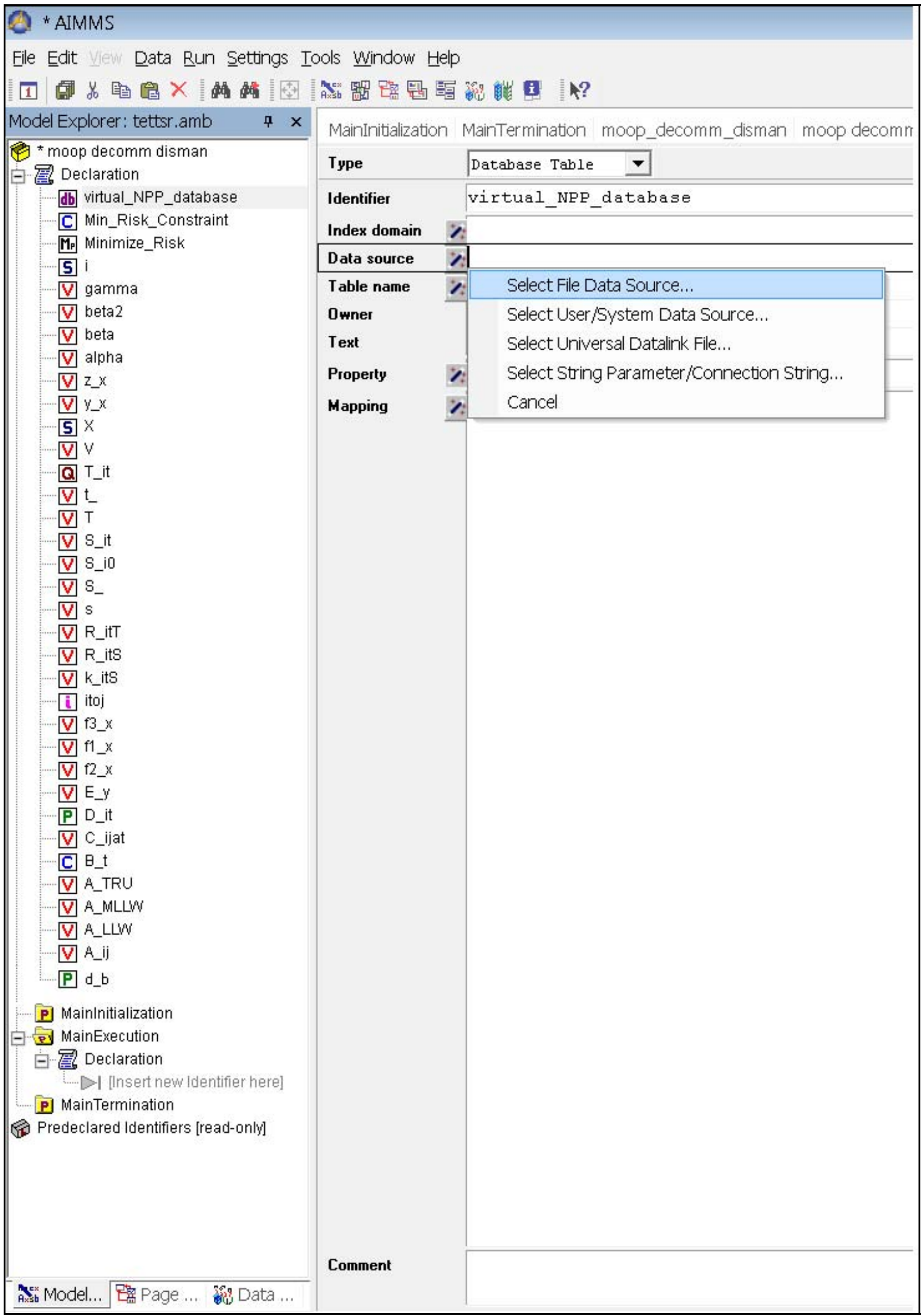

Figure 21: Creating a Database Table in AIMMS 
The design of the virtual database table used for the implementation in AIMMS (see tables Table 8 and $8 \mathrm{a}$ ) is used in the case study discussed in chapter 5.

Table 8: Virtual Database Table (Template) I

\begin{tabular}{|c|c|c|c|c|c|c|c|c|c|c|c|c|c|c|c|c|}
\hline 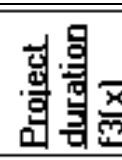 & & & & & & & & & & & & & & & & \\
\hline 氧骨荺 & & & & & & & & & & & & & & & & \\
\hline 氮商圈 & & & & & & & & & & & & & & & & \\
\hline 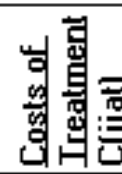 & & & & & & & & & & & & & & & & \\
\hline 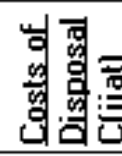 & & & & & & & & & & & & & & & & \\
\hline 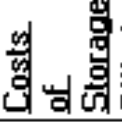 & & & & & & & & & & & & & & & & \\
\hline 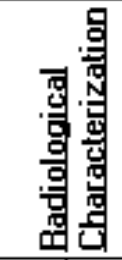 & & & & & & & & & & & & & & & & \\
\hline 兽 & & & & & & & & & & & $-\frac{6}{50}$ & & & & & \\
\hline 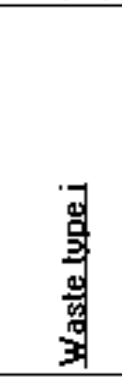 & 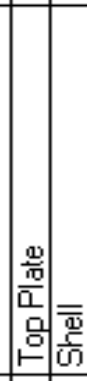 & 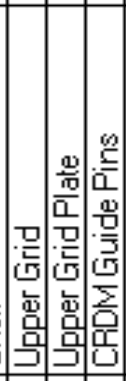 & 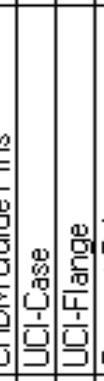 & 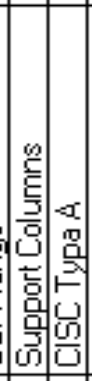 & : & | & 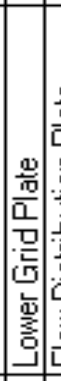 & 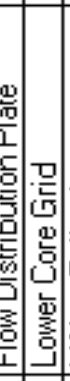 & 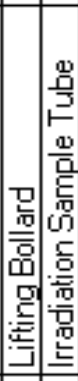 & 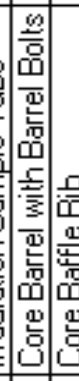 & 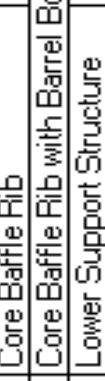 & & 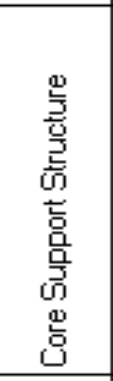 & 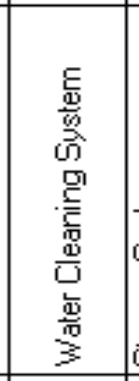 & 商 & 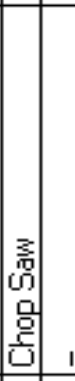 \\
\hline 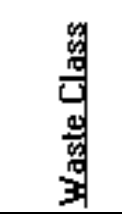 & $\overline{\mathrm{g}}$ & & & & & & $\bar{\Xi}$ & & & & & & 壳 & 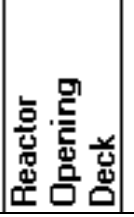 & 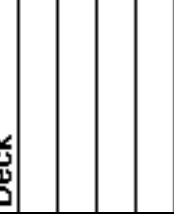 & 1 \\
\hline
\end{tabular}


Table 8a: Virtual Database Table (Template) II

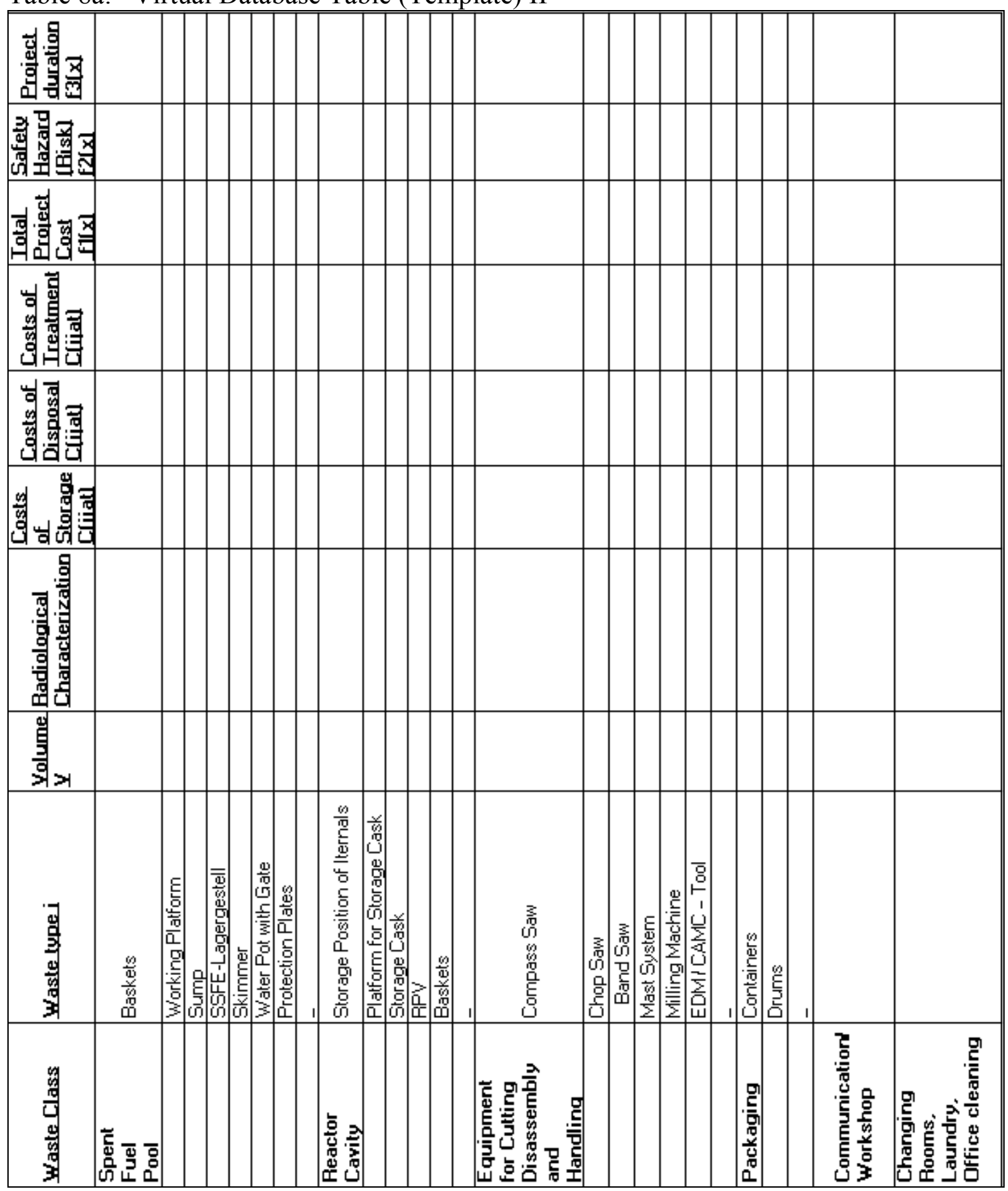

The empty cells in these tables can be filled with real values given by any NPP and its properties, to be gathered in the context of the requirement analysis. These values have to be entered with the AIMMS-Data-Management-Interface (see Figure 22) into the database (see 6.3.7, Table 10, task 62). 


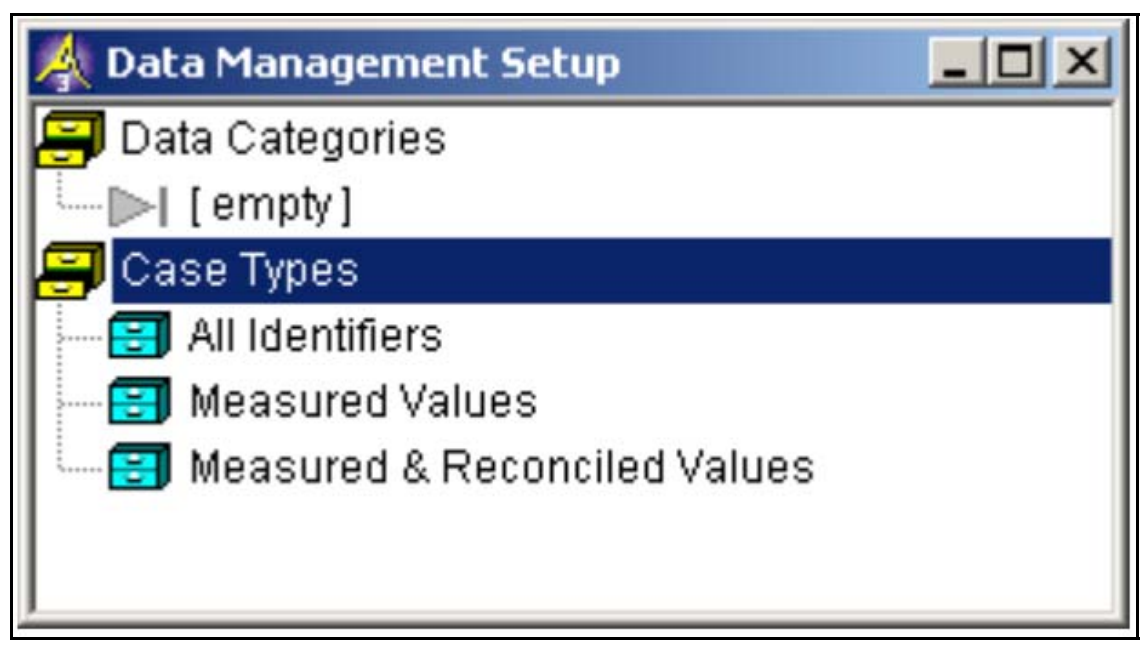

Figure 22: $\quad$ AIMMS-Data Management Setup

The data shown in table (see Table 9) are generated in a simplified version. The values in this table are based on the preliminary estimates (see chapter 5.7) and the package plans ("Verpackungspläne") ${ }^{326}$ given in appendix 4. These values are simulated for exemplarily purposes only and are of limited representational value. This table will be used as basis for the implementation of the Pareto-optimum in $\mathrm{R}$ (see chapter 6.5).

Table 9: Virtual data for the database

\begin{tabular}{|c|c|c|c|c|}
\hline Waste type i & Cost in $\$$ & $\frac{\text { Volume v }}{\underline{\text { in I }}}$ & $\frac{\text { Radiation } \mathbf{r}}{\underline{\text { in } \mathbf{m b q}}}$ & $\underline{\text { Risk factor } \mathrm{rf}}$ \\
\hline Top Plate & 613 & 29 & 115 & High \\
\hline Shell & 848 & 128 & 170 & very high \\
\hline Upper Grid & 337 & 168 & 283 & Low \\
\hline Upper Grid Plate & 933 & 37 & 170 & very low \\
\hline CRDM Guide Pins & 152 & 43 & 169 & Average \\
\hline UCI-Case & 222 & 108 & 105 & High \\
\hline UCI-Flange & 395 & 175 & 265 & Low \\
\hline Support Columns & 619 & 184 & 203 & very low \\
\hline CISC Typa A & 505 & 78 & 147 & Average \\
\hline CISC Typa B & 602 & 220 & 213 & very high \\
\hline $\begin{array}{l}\text { Level Detector Guide } \\
\text { Tubes }\end{array}$ & 734 & 130 & 130 & Low \\
\hline ... & 686 & 78 & 278 & very low \\
\hline Lower Grid Plate & 186 & 99 & 299 & Average \\
\hline Flow Distribution Plate & 188 & 46 & 113 & High \\
\hline Lower Core Grid & 358 & 99 & 274 & Low \\
\hline
\end{tabular}

${ }^{326}$ see AREVA NP GmbH (2008) 


\begin{tabular}{|c|c|c|c|c|}
\hline Lifting Bollard & 184 & 110 & 120 & very low \\
\hline Irradiation Sample Tube & 960 & 233 & 206 & Average \\
\hline $\begin{array}{l}\text { Core Barrel with Barrel } \\
\text { Bolts }\end{array}$ & 446 & 80 & 243 & High \\
\hline Core Baffle Rib & 347 & 244 & 280 & very high \\
\hline $\begin{array}{l}\text { Core Baffle Rib with } \\
\text { Barrel Bolts }\end{array}$ & 559 & 212 & 296 & Low \\
\hline Lower Support Structure & 597 & 130 & 103 & very low \\
\hline Storage Cask I & 545 & 200 & 146 & Average \\
\hline Core Support Structure & 381 & 202 & 289 & High \\
\hline Water Cleaning System & 209 & 106 & 157 & Low \\
\hline Storage Cask II & 291 & 141 & 197 & very low \\
\hline Baskets & 320 & 207 & 298 & Average \\
\hline Turn Table & 453 & 163 & 266 & very high \\
\hline Chop Saw & 791 & 202 & 215 & Low \\
\hline Chop Saw 2 & 235 & 103 & 158 & very low \\
\hline Chop Saw 3 & 313 & 173 & 299 & Average \\
\hline Baskets & 397 & 201 & 251 & High \\
\hline Working Platform & 995 & 169 & 174 & very low \\
\hline Sump & 975 & 200 & 193 & Average \\
\hline SSFE-rack & 130 & 58 & 207 & High \\
\hline Skimmer & 734 & 100 & 167 & Low \\
\hline Water Pot with Gate & 362 & 172 & 265 & very low \\
\hline Protection Plates & 956 & 76 & 219 & Average \\
\hline 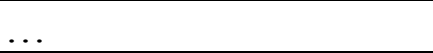 & 911 & 183 & 265 & very high \\
\hline $\begin{array}{l}\text { Storage Position of } \\
\text { Internals }\end{array}$ & 783 & 111 & 287 & Low \\
\hline $\begin{array}{l}\text { Platform for Storage } \\
\text { Cask }\end{array}$ & 615 & 209 & 212 & very low \\
\hline Storage Cask & 225 & 148 & 170 & average \\
\hline RPV & 271 & 72 & 151 & High \\
\hline Baskets & 379 & 248 & 125 & Low \\
\hline & 484 & 186 & 248 & very low \\
\hline Compass Saw & 918 & 238 & 170 & average \\
\hline Chop Saw 4 & 357 & 211 & 106 & High \\
\hline Band Saw & 400 & 172 & 119 & very high \\
\hline Mast System & 921 & 250 & 262 & Low \\
\hline Milling Machine & 880 & 140 & 254 & very low \\
\hline EDM / CAMC - Tool & 773 & 98 & 212 & average \\
\hline & 975 & 169 & 116 & High \\
\hline Containers & 135 & 84 & 232 & Low \\
\hline Drums & 263 & 107 & 144 & very low \\
\hline
\end{tabular}




\subsubsection{Executing, Initializing, Terminating the Model and AIMMS Math Program Inspector}

Executing the main model in AIMMS 3 means running a special procedure called MainExecution. The model of the minimization function has one major execution sequence. The MainInitialization is the second of the three standard procedures in the model tree of AIMMS and is initializing the model data, specified in the database table. MainInitialization is executed automatically after the model is compiled. The third standard procedure is MainTermination and is called prior to closing the project. As default the procedure contains this AIMMS code ${ }^{327}$ :

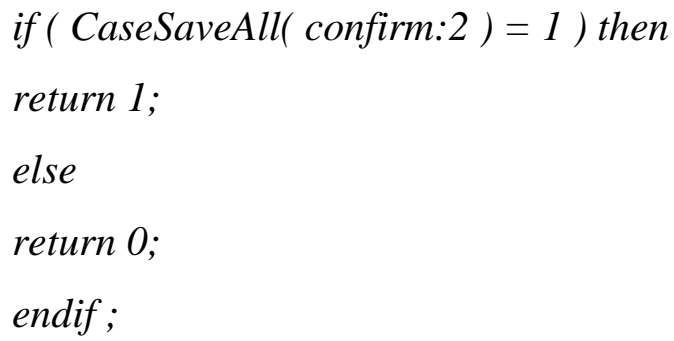

The AIMMS Math Program Inspector helps to check the feasibility and alerts if there are unboundedness and unrealistic solutions of the optimization model, analyzing both the input and output of the generated optimization model. Also the custom selections of constraints and variables, in order to inspect statistics of the corresponding matrix and solution are possible ${ }^{328}$.

${ }^{327}$ see AIMMS-Help (2013)

${ }^{328}$ see AIMMS-Help (2013) 


\subsubsection{MS-Project - Aided Application of the framework (Item C)}

The list of tasks of the implementation of the framework in AIMMS in MS Project 2013 is given (see Table 10).

Table 10: List of tasks in AIMMS in MS Project 2013

\begin{tabular}{|c|c|c|c|c|c|c|c|}
\hline 57 & i & $=$ & $\begin{array}{l}\text { Using AlMMS (see } \\
\text { chapter } 6.3 \text { ) }\end{array}$ & 26 days & Fri $1 / 9 / 15$ & Fri $2 / 13 / 15$ & 56 \\
\hline 58 & $\mathbf{i}$ & 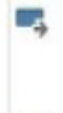 & $\begin{array}{l}\text { Declaration of the } \\
\text { model }\end{array}$ & 12 days & Fri $1 / 9 / 15$ & Mon $1 / 26 / 15$ & \\
\hline 59 & & 5 & $\begin{array}{l}\text { Specification of the } \\
\text { Minimization of the } \\
\text { risk of storage }\end{array}$ & 7 days & Tue $1 / 27 / 15$ & Wed $2 / 4 / 15$ & 58 \\
\hline 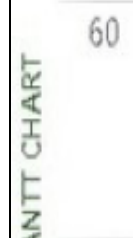 & i & 5 & $\begin{array}{l}\text { Specification of the } \\
\text { Constraint for the } \\
\text { Minimization of the } \\
\text { risk of storage }\end{array}$ & 2 days & Thu $2 / 5 / 15$ & Fri $2 / 6 / 15$ & 59 \\
\hline 5 61 & $\mathbf{i}$ & $\overline{4}$ & $\begin{array}{l}\text { Attributes of sets, } \\
\text { variables, } \\
\text { parameters, } \\
\text { constraints and } \\
\text { mathematical } \\
\text { programs in AlMMS }\end{array}$ & 2 days & Mon 2/9/15 & Tue 2/10/15 & 60 \\
\hline 62 & & 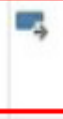 & $\begin{array}{l}\text { Creating a } \\
\text { Database Table }\end{array}$ & 1 day & Wed 2/11/15 & Wed $2 / 11 / 15$ & 61,2 \\
\hline 63 & & $=$ & $\begin{array}{l}\text { Executing the } \\
\text { Model, } \\
\text { Initialization, } \\
\text { Termination and } \\
\text { the AlMMS Math } \\
\text { Program Inspector }\end{array}$ & 2 days & Thu $2 / 12 / 15$ & Fri $2 / 13 / 15$ & 62 \\
\hline
\end{tabular}




\subsection{Application of the model in MATLAB}

The model implementation in MATLAB can be realized in 3 steps - as a round-up ${ }^{329}$ :

Step 1: Write a file min_npp_func.m for the objective function:

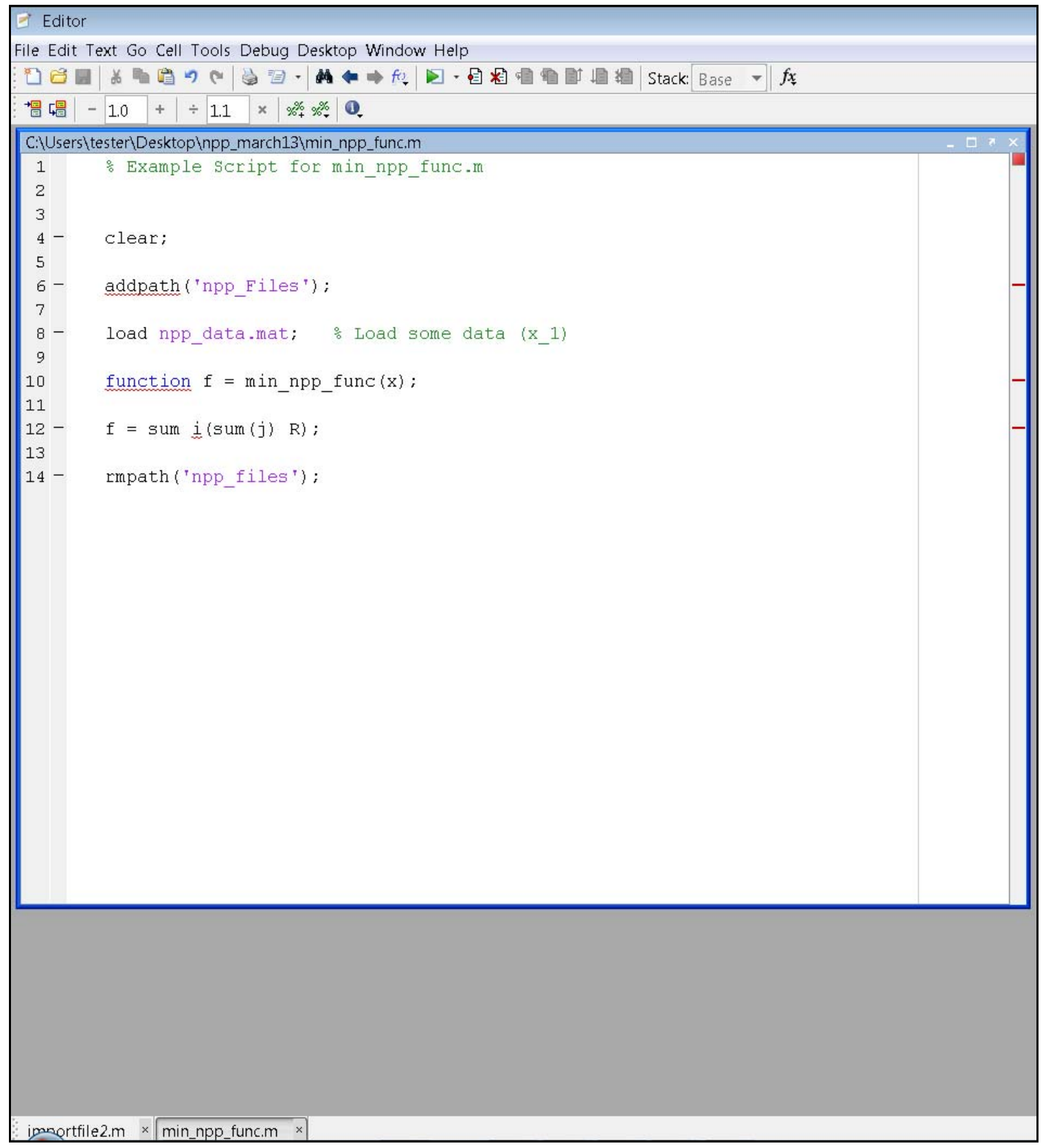

Figure 23: Write a file min_npp_func.m for the objective function

${ }^{329}$ see Mathworks (2013) 
Step 2: Write a file constraint_npp.m for the constraints:

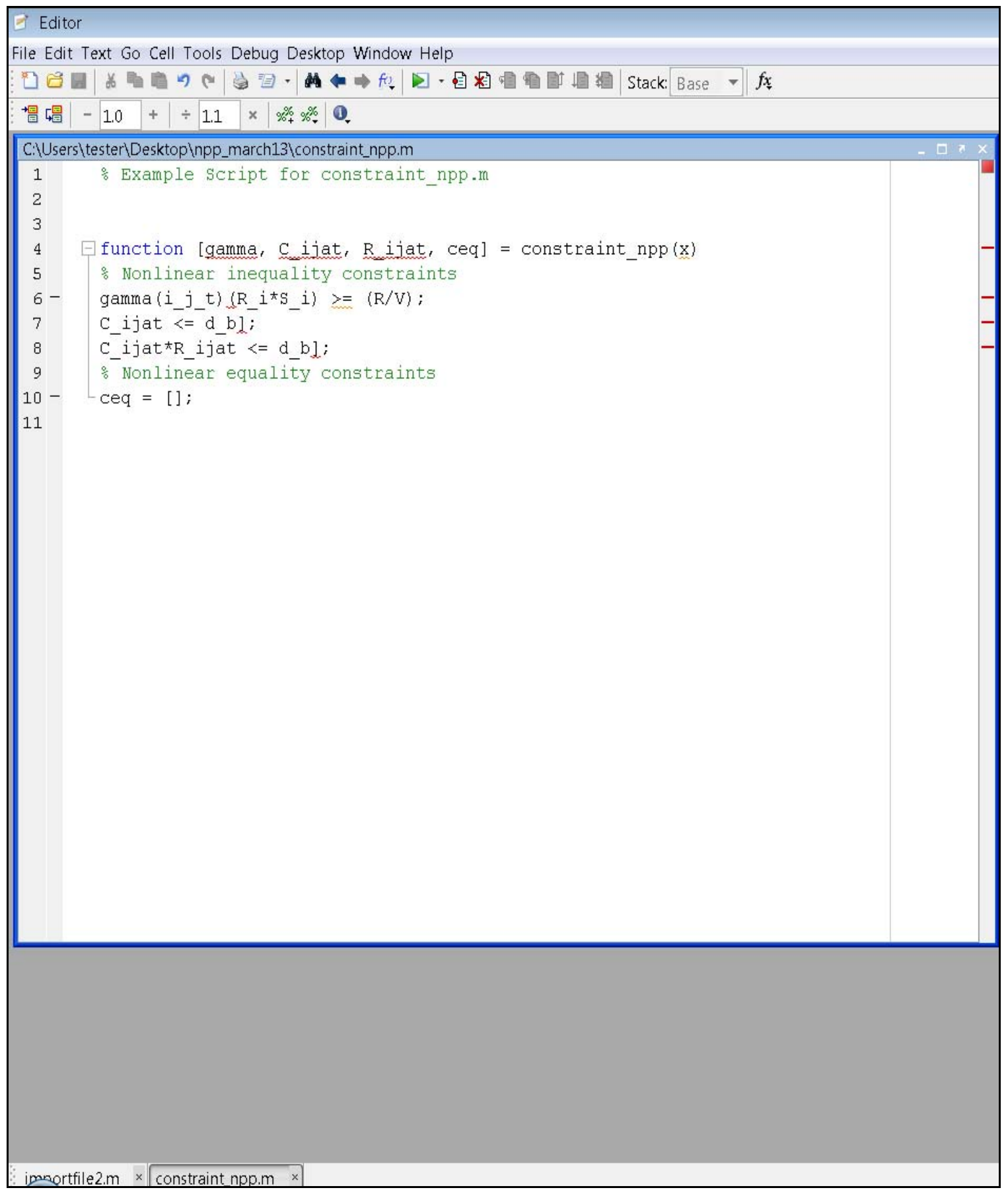

Figure 24: Write a file constraint_npp.m for the constraints 
Step 3: Invoke constrained optimization routine:

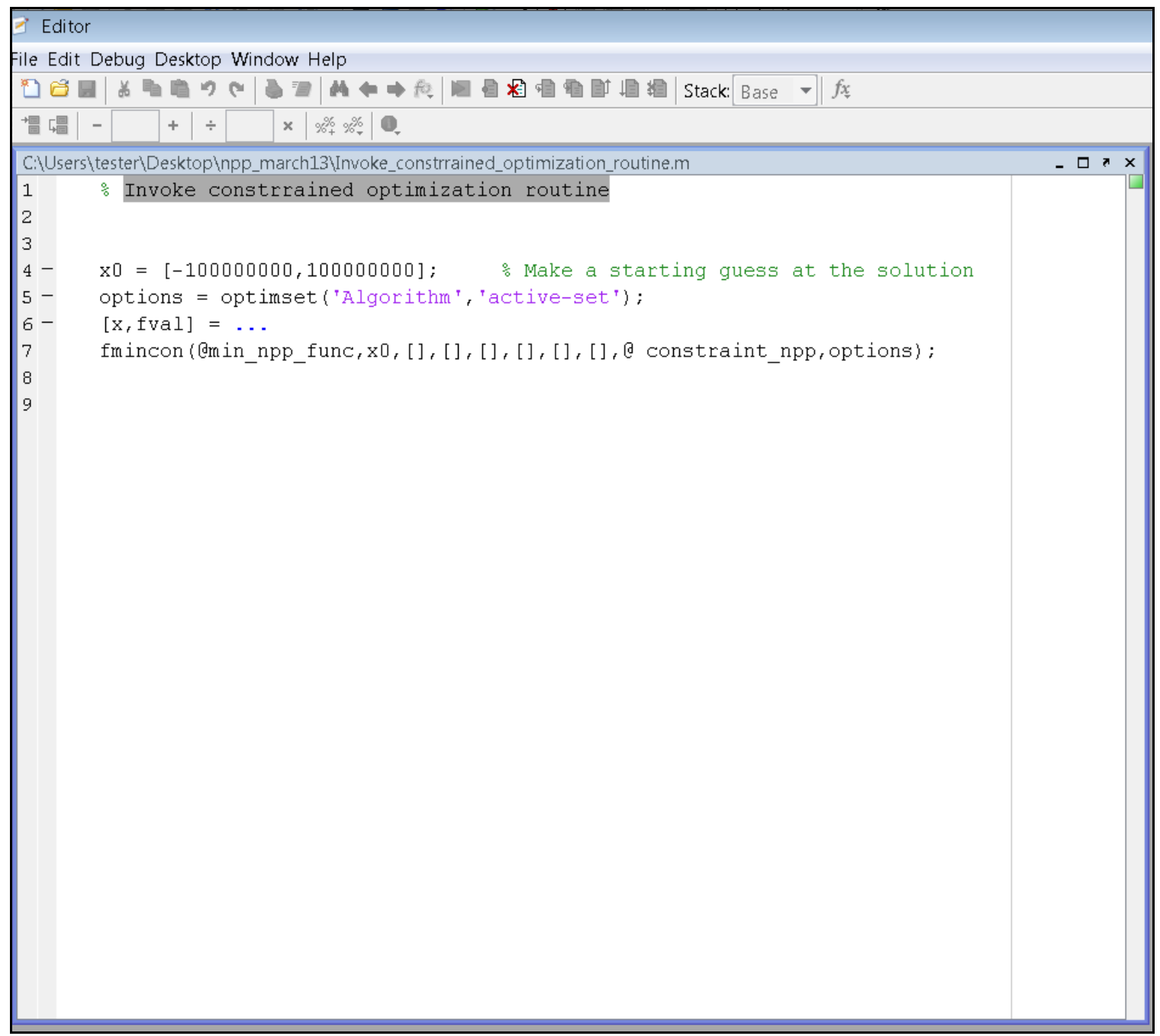

Figure 25: Invoke constrained optimization routine

\subsection{Application of the model in $\mathbf{R}$}

The language $\mathrm{R}$ is the tool with the best documented solutions for the mathematical implementation of optimization problems, since a countless number of open-source examples for implementation solutions are provided on the internet. 


\subsubsection{Introduction of the function constrOptim()}

A detailed explanation of how to implement a constrained minimization problem is given in the R-manual. For the minimization of a function in subject to linear inequality constraints the following function is usable 330331332 :

“constrOptim(theta, f, grad, ui, ci, mu $=1 \mathrm{e}-04$, control $=$ list $($ ), method $=$ if(is.null(grad))
"Nelder-Mead" else "BFGS", outer.iterations = 100, outer.eps = 1e-05, $\ldots$, hessian = FALSE)"

These arguments are specified as follows ${ }^{333}$ :

\begin{tabular}{|c|c|}
\hline “theta & $\begin{array}{l}\text { numeric (vector) starting value (of length } p \text { ): must } \\
\text { be in the feasible region }\end{array}$ \\
\hline$f$ & function to minimize (see below) \\
\hline $\operatorname{grad}$ & $\begin{array}{l}\text { gradient of } f \text { (a function as well), or NULL } \\
\text { (see below) }\end{array}$ \\
\hline ui & constraint matrix $(k X p)$, see below \\
\hline ci & constraint vector of length $k$ (see below) \\
\hline mu & (Small) tuning parameter \\
\hline control, method, hessian & passed to optim \\
\hline outer.iterations & iterations of the barrier algorithm \\
\hline
\end{tabular}

\footnotetext{
${ }^{330}$ see R-manual (2013)

${ }^{331}$ see Nelder-Mead method or downhill simplex method or amoeba method is a nonlinear optimization technique

${ }^{332}$ see Broyden-Fletcher-Goldfarb-Shanno (BFGS) method is a method for solving unconstrained nonlinear optimization problems.

${ }^{333}$ see R-manual (2013)
} 
outer.eps

$\cdots$ non-negative number; the relative convergence tolerance of the barrier algorithm

Other named arguments to be passed to $f$ and grad: need to be passed through optim and therefore should not match its argument names

\subsubsection{Applying the function constrOptim() to the model}

The arguments when applying constrOptim() on the constrained minimization model in this dissertation are as follows ${ }^{334}$ :

$\operatorname{Minimize}_{\left\{T_{i j t}\right\}} \overline{R_{10}}=\sum_{i} \sum_{j \neq S, D} R_{i j 10}$

The values of $i$ and $j$ are assigned to theta.

$f$ equals $\sum_{i} \sum_{j \neq S, D} R_{i j 10}$

ui correspond to

$\lambda_{i j t}\left(R_{i S 0} / S_{i 0}\right) \geq(R / V)_{i j t,} \quad \forall i, j, t$

ci correspond to ${ }^{335}$

$\overline{C_{10}} \leq d_{b}$

and

$\overline{C_{10}} * \overline{R_{t}} \leq d_{b}$

\footnotetext{
${ }^{334}$ see Jones et al. (1998), p. 12

335 see Miettinen (1999). p. 5ff. / Hwang; Masud (1979) / Wikipedia (2013)
} 


\subsubsection{Usage of the TunePareto-Package}

A simplified implementation and application of the model-based framework (see chapter 4) using the virtual database and the virtual data (see chapter 6.3.5) is presented by leveraging upon the TunePareto-package of $\mathrm{R}^{336}$. Applying this package it's possible to read the virtual data from the database and to calculate the Pareto-optimum by a code implemented using the values in the database (see appendix 5-7 and TuneParetoForMOOP.r):

Figure 33 (see appendix 5) shows the output of the application of TuneParetoForMOOP.r. The figures Figure 34 and Figure 35 show screenshots of the RStudio interface with a plotted graph depicting the values of the variable $r$, containing representations of the values in the virtual table col37.csv. The following line is generating the graphic on the figures Figure 34 and Figure 35:

${ }^{336}$ see CRAN (2013) 


\section{plotDominationGraph(r, legend.x="topright")}

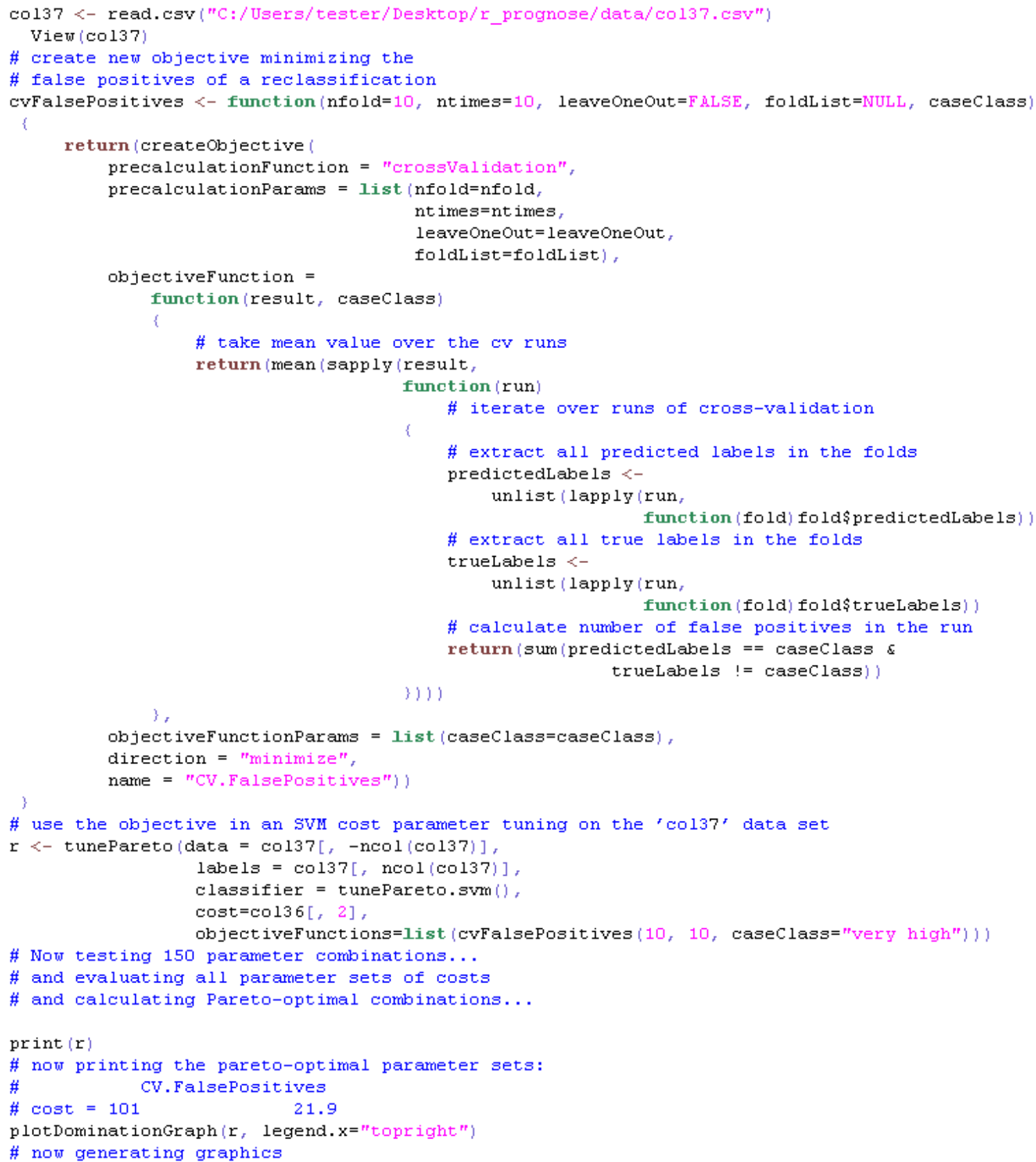

This program routine, based on the tunePareto-package shows an implemented solution to another optimization problem - the calculation of the pareto optimum. After some modifications in the source code given by CRAN, it is possible to use the virtual database for optimization purposes. The figure Figure 33 shows the test result of 150 parameter combinations based on the virtual table col37, figures Figure 34 and Figure 35 show the 
graphical representation of the test result. Since the source code of TuneParetoForMOOP.r is based on a source code given by CRAN, the next program routine is a proprietary development, as a solution for the MOOP, based on the optimize()-function.

The implementation of the TunePareto presented here was very easy to realize. TunePareto is a matter of a flexible and time efficient reimplementation of an existing Rroutine for the pareto optimization as referred to. TunePareto is another optimization method in the context of operations research. The goal of the implementation was to demonstrate how easy it is to adapt a given R-program routine for optimization purposes regarding a given case. Five advantages and positive effects could be extracted from the TunePareto optimization:

1. Only less effort was necessary to re-implement an existing R-optimizationroutine.

2. It was possible to demonstrate how to read the virtual (database) table developed in this work.

3. The table, where the routine read from is representing any input dimension for the optimization.

4. It was possible to generate an output dimension out of the input data.

5. The output dimension was visualized graphically.

\subsubsection{Usage of the optimize()-Function}

The optimize()-function is a simplified version of the constrOptim()-function mentioned earlier (see chapter 6.5.2). With the optimize()-function it is possible to affordably demonstrate the functionality of the model developed in chapter 4. This implementation of the MOOP functionality contains the logical structure of the requirements on a small scale and focuses on a limited part of the dismantling and decommissioning of a virtual NPP. 


\subsubsection{Introduction of the function optimize()}

"The optimized function searches within the lower and upper limits of the interval for a minimum or maximum of the function $\mathrm{f}$ with respect to its first argument." ${ }^{, 337}$ The implementation is shown as follows ${ }^{338}$ :

$$
\begin{gathered}
\text { “optimize }(f=, \text { interval }=, \text {..., lower }=\min (\text { interval }), \\
\text { upper }=\max (\text { interval }), \text { maximum }=\text { FALSE, } \\
\text { tol } \left.=. \text { Machine } \$ d \text { double.eps }{ }^{\wedge} 0.25\right) \\
\text { optimise }(f=, \text { interval }=, \text {..., lower }=\min (\text { interval }), \\
\text { upper }=\max (\text { interval }), \text { maximum }=\text { FALSE, } \\
\text { tol } \left.=. \text { Machine\$double.eps }{ }^{\wedge} 0.25\right) "
\end{gathered}
$$

The arguments of the optimized-function are listed below:

“f

the function to be optimized. The function is either minimized or maximized over its first argument depending on the maximum value.

\section{interval}

a vector containing the end-points of the interval to be optimized for the minimum value.

$\cdots$

additional named or unnamed arguments to be passed to $f$.

lower

the lower end point of the interval to be optimized.

\footnotetext{
${ }^{337}$ see R-manual (2013)

338 see R-manual (2013)
} 


\section{upper}

the upper end point of the interval to be optimized.

\section{maximum}

logical.variable: maximize or minimize (as default)

tol

the desired accuracy".

\subsubsection{Introduction to the R-Routine MOOP}

While the program routine based on the TunePareto-package of $\mathrm{R}$ (see chapter 6.5.3) illustrates an implementation that "calculates the Pareto front of optimal parameter configurations" ${ }^{\prime 39}$ the R-routine with the MOOP implementation based on the optimize() function shows a fully self-programmed alternative.

The goal is to implement the model described in chapter 4 with R-code. The implementation is described in the next chapters. The underlying data is represented by the table content given in the virtual database table. The matrix view of the virtual database table offers a graphical overview of the interdependencies between each variable listed in the columns (waste_type_i, volume_in_kg, storing_costs_per_year_per_g, Treatment_costs_per_year_per_g, disposal_costs_per_g, mbq_per_g) (see Figure 26). As next the used parameters, variables and functions of the MOOP R-Routine are introduced in the following chapters, the source code is shown with comments in blue followed by the "\#"-sign. Finally the output of the program routine with the table data as inputs is discussed.

\footnotetext{
339 see CRAN (2013)
} 


\subsubsection{Virtual database table with sample values}

The data in this table is dependent on the results of the research derived from the OMEGA model, the model by Jones et al. 1998 and the empirical data shown in chapter 5. In the OMEGA model several waste types are listed (see chapter 4.2, appendix $8 \mathrm{I}$ ). Each waste type $\boldsymbol{i}$ represents a different class of waste, such as metal waste, non-metalic waste, special materials (graphite), waste from the dismantling of building structures, liquid waste etc. (see appendix 8 I). The classification of storing costs, treatment costs, disposal costs and the amount of radioactivity in $\mathbf{m b q}$ is derived from the model described by Jones et al. 1998 (see chapter 4). The amounts of volume in $\mathrm{kg}$, of costs and radioactivity in $\mathbf{m b q}$ (see Table 11) are based on the findings in the empirical research

(see chapter 5, appendix 4 "Verpackungspläne") ${ }^{340}$. In order to generate random numbers in the given dimensions the webservice random.org was used ${ }^{341}$.

The mathematical notation of the model is leant on Jones et al. 1998. The costs for the time period of 10 years were limited by the maximum limit $d_{b}$ in formula (4.24). The function for the minimization of the costs $\mathrm{C}$ on the exemplarily given time period (of $\mathrm{t}=10$ years) was specified in formula (4.12) and later implemented with less complexity in the R-MOOP program routine. The inequality in the formula (4.25) depicts the objectives of this work in a summarizing main inequality. $\mathrm{R}_{\mathrm{t}}$ is given by the formula (4.14). The three dimensions (costs $C$, risk $R$ and duration $t$ ) are bounded by $d_{b}$ in formula (4.25). While the fully development of the research objectives was achieved in the modeling part, it was only possible to implement a limited part of the model by the RMOOP program routine due to temporal reasons. Software development is an area with an extraordinarily high necessity of long term planning and testing. In an analogue way as the R-MOOP demonstrates and considering how the costs and the duration can be minimized, it is possible to demonstrate how to minimize the activity in total, which is the main factor of risk. The logical structure, the information technology architecture and the development environment worked out here is usable for further developments.

\footnotetext{
340 see AREVA NP GmbH (2008)

341 see Random.org (2013)
} 
In the R-MOOP routine there are processed $i$ different waste types. They can be assigned to the types for example defined in OMEGA (see appendix 8I). In the product functions (4.1), (4.2), (4.3) and (4.4) is $i$ the waste type, due to Jones et al. 1998. Based on those terms the calculation of the risk can be calculated in the formulas (4.5), (4.6) and (4.7). These terms can be used in the minimization functions given in (4.12), (4.13), (4.14) and (4.15). These terms must be calculated for each waste type $i$, listed in the virtual table (see Table 11). Hence each waste type is assigned to $i$, with each waste type associated with five properties. In our case 29 waste types or waste classes are associated with five properties. For example, in the OMEGA-model, there are 9 waste classes (see appendix 8 I) dividable in different types depending on the given business model. 
Table 11: Virtual Database Table II

\begin{tabular}{|c|c|c|c|c|c|c|}
\hline & $\begin{array}{c}\text { waste_typ } \\
\text { e_i }\end{array}$ & $\begin{array}{c}\text { volume_in } \\
\quad \text { kg }\end{array}$ & $\begin{array}{c}\text { storing_costs } \\
\text { per_year_pe } \\
\text { r_g }\end{array}$ & $\begin{array}{l}\text { Treatment_costs } \\
\text { _per_year_per_g }\end{array}$ & $\begin{array}{c}\text { disposal_cost } \\
\text { s_per_g }\end{array}$ & $\begin{array}{c}\text { mbq_per_ } \\
\text { g }\end{array}$ \\
\hline 1 & 1 & 29 & 50 & 14 & 49 & 449297 \\
\hline 2 & 2 & 128 & 34 & 62 & 74 & 143948 \\
\hline 3 & 3 & 168 & 44 & 51 & 68 & 915179 \\
\hline 4 & 4 & 37 & 56 & 32 & 21 & 401834 \\
\hline 5 & 5 & 43 & 100 & 29 & 63 & 533459 \\
\hline 6 & 6 & 108 & 77 & 84 & 24 & 853827 \\
\hline 7 & 7 & 175 & 85 & 92 & 90 & 660482 \\
\hline 8 & 8 & 184 & 12 & 25 & 21 & 252913 \\
\hline 9 & 9 & 78 & 57 & 98 & 92 & 882256 \\
\hline 10 & 10 & 220 & 15 & 91 & 32 & 204469 \\
\hline 11 & 11 & 130 & 17 & 94 & 15 & 16545 \\
\hline 12 & 12 & 78 & 65 & 13 & 48 & 269297 \\
\hline 13 & 13 & 99 & 96 & 1 & 48 & 773 \\
\hline 14 & 14 & 46 & 44 & 11 & 37 & 291714 \\
\hline 15 & 15 & 99 & 44 & 17 & 18 & 591043 \\
\hline 16 & 16 & 110 & 3 & 97 & 61 & 108942 \\
\hline 17 & 17 & 233 & 35 & 94 & 75 & 766534 \\
\hline 18 & 18 & 80 & 40 & 99 & 18 & 163178 \\
\hline 19 & 19 & 244 & 29 & 86 & 68 & 14021 \\
\hline
\end{tabular}




\begin{tabular}{|c|c|c|c|c|c|c|}
\hline & $\begin{array}{c}\text { waste_typ } \\
\text { e_i }\end{array}$ & $\begin{array}{c}\text { volume_in } \\
\text { _kg }\end{array}$ & $\begin{array}{c}\text { storing_costs } \\
\text { _per_year_pe } \\
\text { r_g }\end{array}$ & $\begin{array}{l}\text { Treatment_costs } \\
\text { _per_year_per_g }\end{array}$ & $\begin{array}{c}\text { disposal_cost } \\
\text { s_per_g }\end{array}$ & $\begin{array}{c}\text { mbq_per_ } \\
\text { g }\end{array}$ \\
\hline 20 & 20 & 212 & 3 & 45 & 87 & 614320 \\
\hline 21 & 21 & 130 & 96 & 63 & 71 & 861586 \\
\hline 22 & 22 & 200 & 61 & 77 & 89 & 321319 \\
\hline 23 & 23 & 202 & 91 & 88 & 37 & 331162 \\
\hline 24 & 24 & 106 & 77 & 85 & 8 & 782336 \\
\hline 25 & 25 & 141 & 38 & 76 & 72 & 790886 \\
\hline 26 & 26 & 207 & 46 & 67 & 9 & 44262 \\
\hline 27 & 27 & 163 & 100 & 40 & 100 & 54971 \\
\hline 28 & 28 & 202 & 82 & 45 & 75 & 614341 \\
\hline 29 & 29 & 103 & 84 & 69 & 66 & 337282 \\
\hline
\end{tabular}

As argued before, the values of the properties for each waste type are determined based on estimations. Firstly the masses are estimated based on the values given in the package plans. In appendix $4 \mathrm{~A}$, the value $73.28 \mathrm{~kg}$ is listed in the table as the activated load. Regarding the masses of the other components in the package plans, it can be ascertained that most of the components are roughly in this scale. The emphasis was on the demonstration and presentation of the feasibility of the model, on the basis of any given data. Nevertheless, these limitations in accuracy and precision have no effects on the functionality and the logical structure of the R-MOOP program routine.

\subsubsection{Matrix View of virtual database table}

The matrix view of the virtual data table shows the interdependencies between the selected variable types (see Figure 26). Based on the matrix view, it is possible to show patterns as relations between different column values of the same row or dataset. This way it is possible to detect how different properties correlate to each other. In case of the 
R-MOOP, there are no effects on the construction of the algorithm. The matrix view is a helpful instrument to discover correlations within more complex database content connected with the R-MOOP algorithm. This would be the case in a real future project scenario. This way it would be much easier to analyze millions of datasets. Instead of analyzing millions of datasets with numbers and characters, it is easier to examine images built by the matrix view describing the database content graphically, and further possible to reveal dependencies between system components, business objects, and processes etc.

The matrix view only shows one of many possibilities and functions to visualize structures of a given database content offered by the programming language $\mathrm{R}$. The source code is as follows:

$>$ virtual_table.test $<$

read. csv( "C: / Users/t est er/Deskt op/NPP_apr 13/ npp_post_1101/ col 80. csv", header $=$ TRUE)

$>$ pl ot (vi rtual_tabl e. test) 


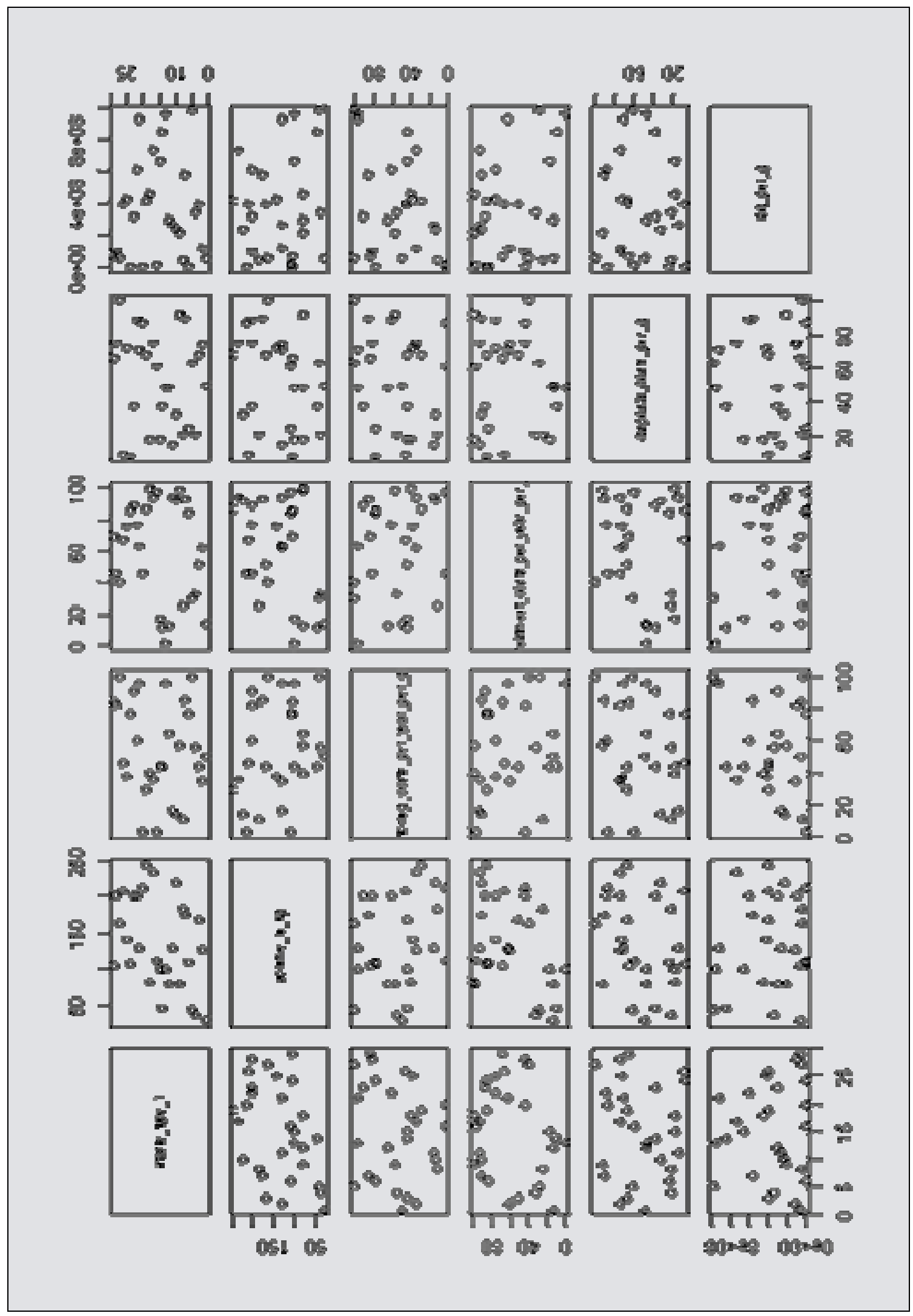

Figure 26: Matrix view of the virtual database table 
For example the coordinate system in the first cell of the second row shows the values of the variable waste_type_i on the $\mathrm{x}$-axis and the values of the variable volume_in_kg on the $y$-axis. The coordinate system in the first cell of the third row shows the values of the variable waste_type_i on the x-axis and the values of the storing_costs_per_year_per_g on the $y$-axis and so on. The advantage of the matrix view is the visualization of hidden patterns and structures in a table.

\subsubsection{Discussion of variables, parameters and functions in the MOOP program routine}

The variables, parameters and functions used in the MOOP program routine are as follows:

- Variables and parameters: wti, month, totalscosts, totaltcosts, totaldcosts, totalrad, constraintscpy, constrainttcpy, constraintrpy, vikg, scpypg, scosts, tcpypg, tcosts, dcpg, dcosts, mbqpg, radio, moopoutput, mindur

- Cost functions: scostsfunction, tcostsfunction, dcostsfunction, totalradfunction, moopfunction, minduration

- The optimization function optimize() for the minimization of the minduration function as a MOOP of scostsfunction, tcostsfunction, dcostsfunction

The next table shows the interdependencies between the parameters, variables and functions in the MOOP program routine (see Table 12). The constants for the constraints for storage costs per month (constraintscpy), for treatment costs per month (constrainttcpy) and for radio activity per month (constraintrpy) are built in orientation at the boundaries given in the formulas (4.13), (4.15), (4.20), (4.21) and (4.23) and their simplifications. The functions totalradfunction, scostfunction, tcostsfunction, dcostsfunction are built in orientation at the formulas (4.12), (4.14), (4.19) and (4.22) and their simplifications. The sum functions are implemented by the control structures within the for-loops (for $(i$ in $1: \max (w t i))\{$ ). wti corresponds to the variable $i$ for the waste type. All other variables correspond to the variables in the virtual database table. 
Table 12: Interdependencies between parameters, variables and functions in the MOOP program routine

\begin{tabular}{|c|c|c|}
\hline$\frac{\text { Variable/ }}{\text { Parameter/ }}$ & Used in Function & $\underline{\text { Task }}$ \\
\hline Wti & $\begin{array}{l}\text { scostsfunction, } \\
\text { tcostsfunction, } \\
\text { dcostsfunction, } \\
\text { totalradfunction, } \\
\text { minduration }\end{array}$ & $\begin{array}{l}\max (w t i) \text { ) equals the maximum of waste types } \\
\text { (here } 29) \text {, performing } 29 \text { runs through the } \\
\text { variables contained by the functions to the left }\end{array}$ \\
\hline Month & $\begin{array}{l}\text { scostsfunction, } \\
\text { tcostsfunction, } \\
\text { totalradfunction, } \\
\text { minduration, } \\
\text { moopfunction }\end{array}$ & $\begin{array}{l}\text { Increasing by } 1 \text { if the total constraint is reached } \\
\text { defined by } \\
\text { \# constraint for storage costs per month } \\
\text { constraintscpy }<-5000000 \\
\text { \# constraint for treatment costs per month } \\
\text { constrainttcpy }<-4000000 \\
\text { \# constraint for radio activity per month } \\
\text { constraintrpy }<-30000000000^{342}\end{array}$ \\
\hline totalscosts & $\begin{array}{l}\text { scostsfunction, } \\
\text { minduration }\end{array}$ & total storage costs \\
\hline totaltcosts & $\begin{array}{l}\text { tcostsfunction, } \\
\text { minduration }\end{array}$ & total treatment costs \\
\hline totaldcosts & $\begin{array}{l}\text { dcostsfunction, } \\
\text { minduration }\end{array}$ & total disposal costs \\
\hline Totalrad & $\begin{array}{l}\text { totalradfunction, } \\
\text { minduration }\end{array}$ & total radioactivity in $\mathrm{mbq}$ \\
\hline constraintscpy & $\begin{array}{l}\text { Scostsfunction, } \\
\text { minduration }\end{array}$ & constraint for allowed storage costs per month \\
\hline constrainttcpy & $\begin{array}{l}\text { tcostsfunction, } \\
\text { minduration }\end{array}$ & constraint for allowed treatment costs per month \\
\hline constraintrpy & $\begin{array}{l}\text { totalradfunction, } \\
\text { minduration }\end{array}$ & constraint for allowed radioactivity per month \\
\hline Vikg & $\begin{array}{l}\text { scostsfunction, } \\
\text { tcostsfunction, } \\
\text { dcostsfunction, } \\
\text { totalradfunction, } \\
\text { minduration, } \\
\text { moopfunction }\end{array}$ & volume in kilograms \\
\hline Scpypg & $\begin{array}{l}\text { scostsfunction, } \\
\text { moopfunction, } \\
\text { minduration }\end{array}$ & storage costs per month per gram \\
\hline Scosts & scostsfunction & $\begin{array}{l}\text { auxiliary variable for the calculation of } \\
\text { totalscosts }\end{array}$ \\
\hline Tсруpg & tcostsfunction, & treatment costs per month per gram \\
\hline
\end{tabular}

${ }^{342}$ see Bounds for constraintscpy, constrainttcpy and constraintrpy are set in orientation on the radio activity tables shown in AREVA NP GmbH (2008). 


\begin{tabular}{|c|c|c|}
\hline & $\begin{array}{l}\text { moopfunction, } \\
\text { minduration }\end{array}$ & \\
\hline Tcosts & tcostsfunction & $\begin{array}{l}\text { auxiliary variable for the calculation of } \\
\text { totaltcosts }\end{array}$ \\
\hline Dcpg & $\begin{array}{l}\text { dcostsfunction, } \\
\text { moopfunction }\end{array}$ & disposal costs per gram \\
\hline Dcosts & dcostsfunction & $\begin{array}{l}\text { auxiliary variable for the calculation of } \\
\text { totaldcosts }\end{array}$ \\
\hline Mbqpg & $\begin{array}{l}\text { totalradfunction, } \\
\text { moopfunction }\end{array}$ & $m b q$ per gram \\
\hline Radio & totalradfunction & auxiliary variable for the calculation of totalrad \\
\hline moopoutput & moopfunction & $\begin{array}{l}\text { return variable, that is " } 1 \text { " when the function is } \\
\text { performed }\end{array}$ \\
\hline Mindur & minduration & $\begin{array}{l}\text { Minimum costs at assigned amount of months: } \\
\text { scostsfunction(vikg,scpypg,month)/12 }+ \\
\text { tcostsfunction(vikg,tcpypg,month)/12 }+ \\
\text { dcostsfunction(vikg,dcpg) }\end{array}$ \\
\hline
\end{tabular}

The next table shows the interdependencies between functions and their tasks within the MOOP program routine (see Table 13).

Table 13: Interdependencies between functions and their tasks in the MOOP program routine

\begin{tabular}{|c|c|c|}
\hline Function & Interdependencies & Task \\
\hline scostsfunction & $\begin{array}{l}\text { minduration, } \\
\text { moopfunction }\end{array}$ & function for calculation of storage costs \\
\hline tcostsfunction & $\begin{array}{l}\text { minduration, } \\
\text { moopfunction }\end{array}$ & function for calculation of treatment costs \\
\hline dcostsfunction & $\begin{array}{l}\text { minduration, } \\
\text { moopfunction }\end{array}$ & function for calculation of disposal costs \\
\hline totalradfunction & $\begin{array}{l}\text { minduration, } \\
\text { moopfunction }\end{array}$ & function for calculation of radioactivity \\
\hline minduration & $\begin{array}{l}\text { scostsfunction, } \\
\text { tcostsfunction, } \\
\text { dcostsfunction }\end{array}$ & $\begin{array}{l}\text { calculates all possible durations of all } \\
\text { combinations of scostsfunction, } \\
\text { tcostsfunction and dcostsfunction }\end{array}$ \\
\hline moopfunction & $\begin{array}{l}\text { scostsfunction, } \\
\text { tcostsfunction, } \\
\text { dcostsfunction }\end{array}$ & $\begin{array}{l}\text { invokes scostsfunction, tcostsfunction, } \\
\text { dcostsfunction and totalradfunction }\end{array}$ \\
\hline optimize() & Minduration & minimizes minduration \\
\hline $\operatorname{sink}()$ & all functions and variables & $\begin{array}{l}\text { generates the output file "Ausgabe24.txt" } \\
\text { with all the output of the program routine, } \\
\text { based on the virtual database table data }\end{array}$ \\
\hline
\end{tabular}


The Figure 27 shows an Unified Modeling Language (UML) class diagram of the interactions between the functions in the R-MOOP program routine. Due to convenience the used functions are declared here as classes. A class is consisting of properties and methods. The properties of each class are equal to each variable or constant used in each function. The properties are listed in the upper half of each box. The methods used or called by each class/function are listed in the lower half of each box.

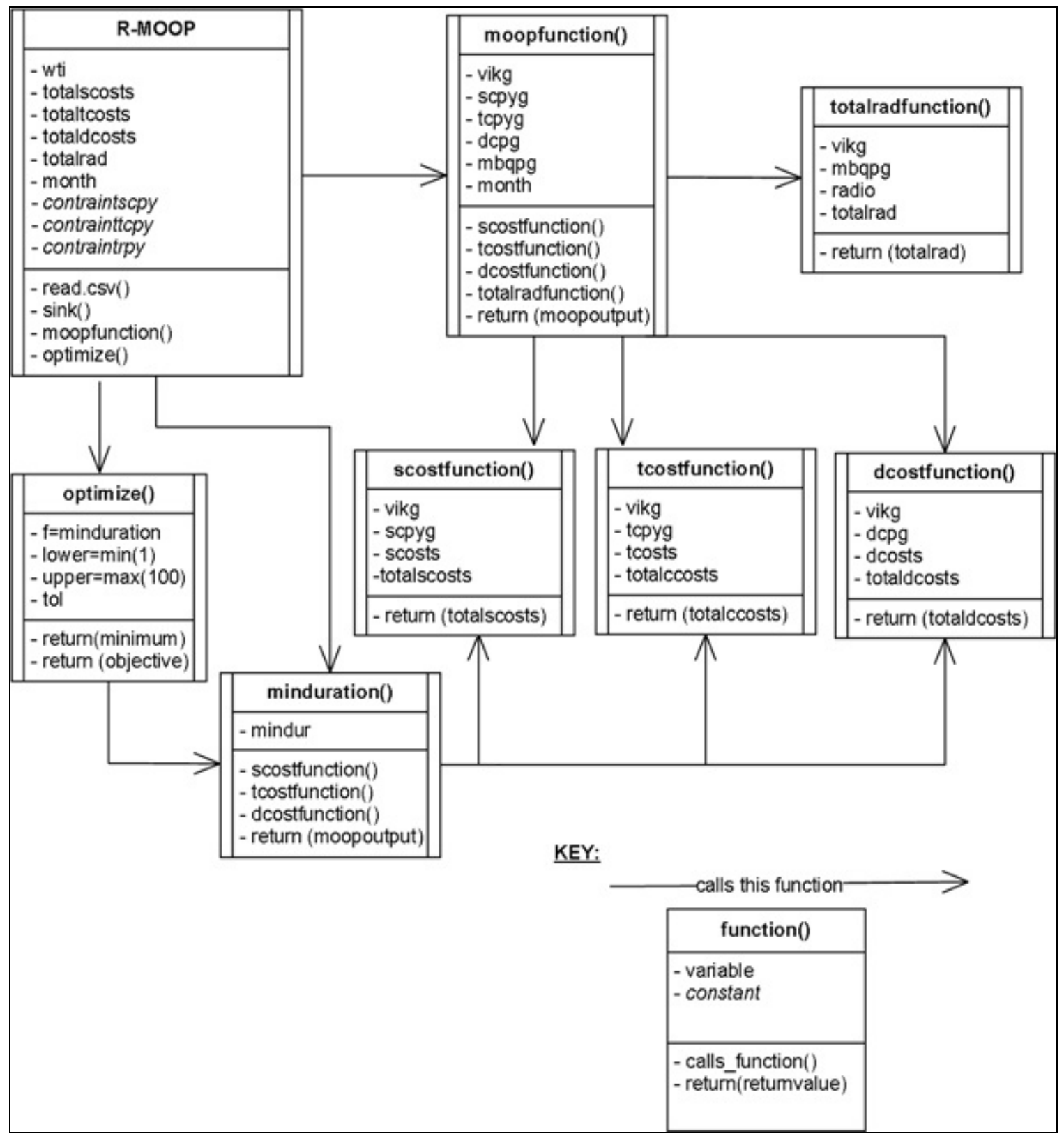

Figure 27: UML-Diagram of the R-MOOP program routine and interactions between functions 


\subsubsection{Source Code for MOOP}

The complete source code of the MOOP program routine (see appendix 9/ moop_final_R_code.r) and comments of the code in blue, followed by “\#” follow.

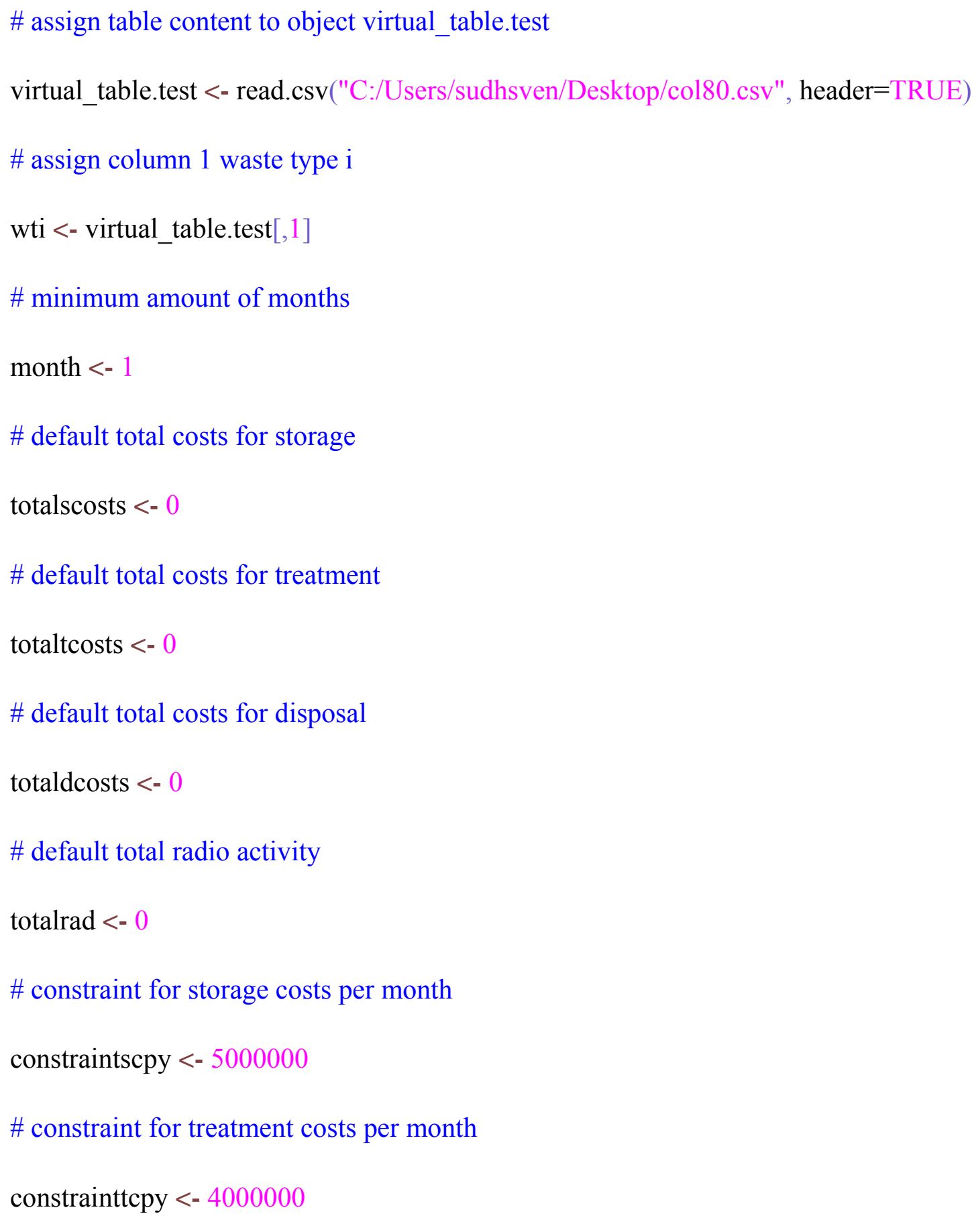




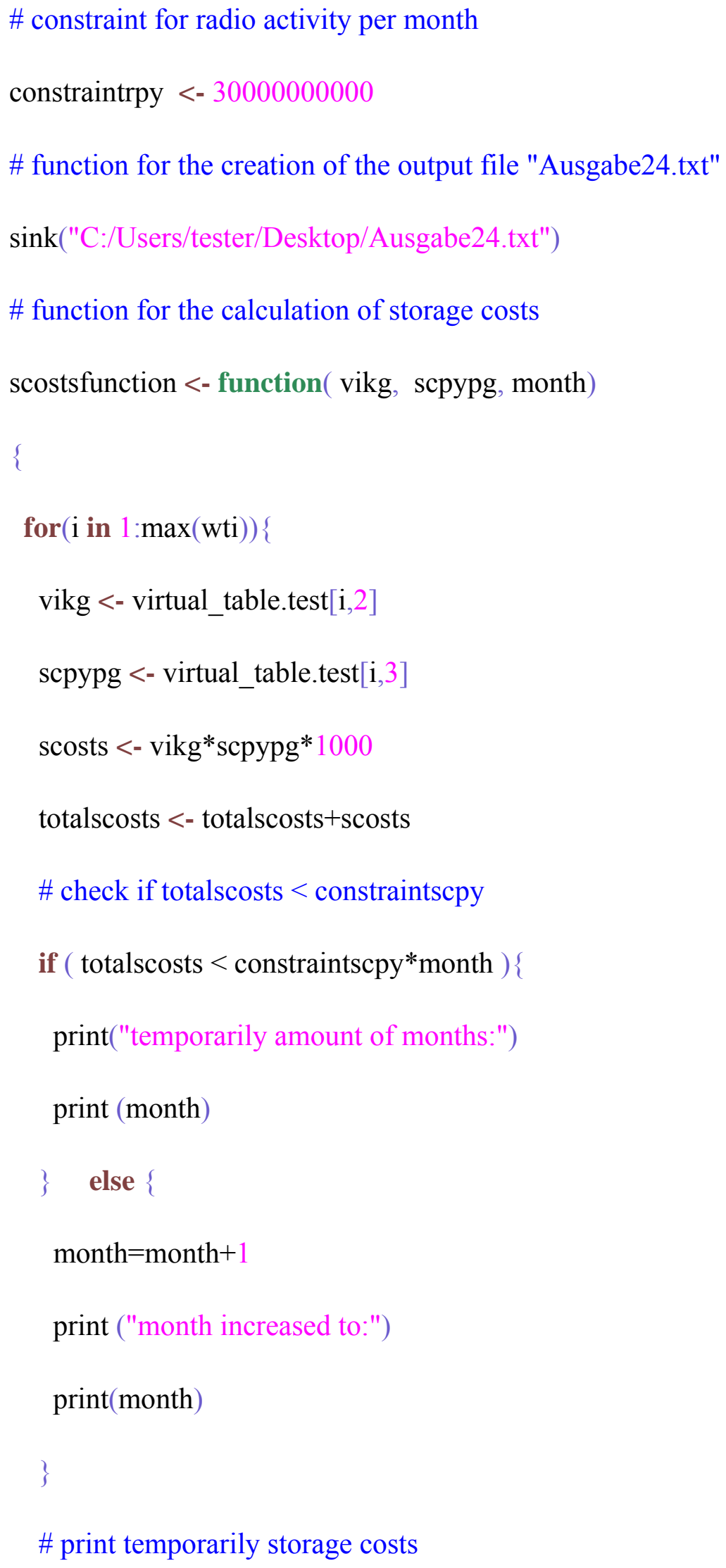




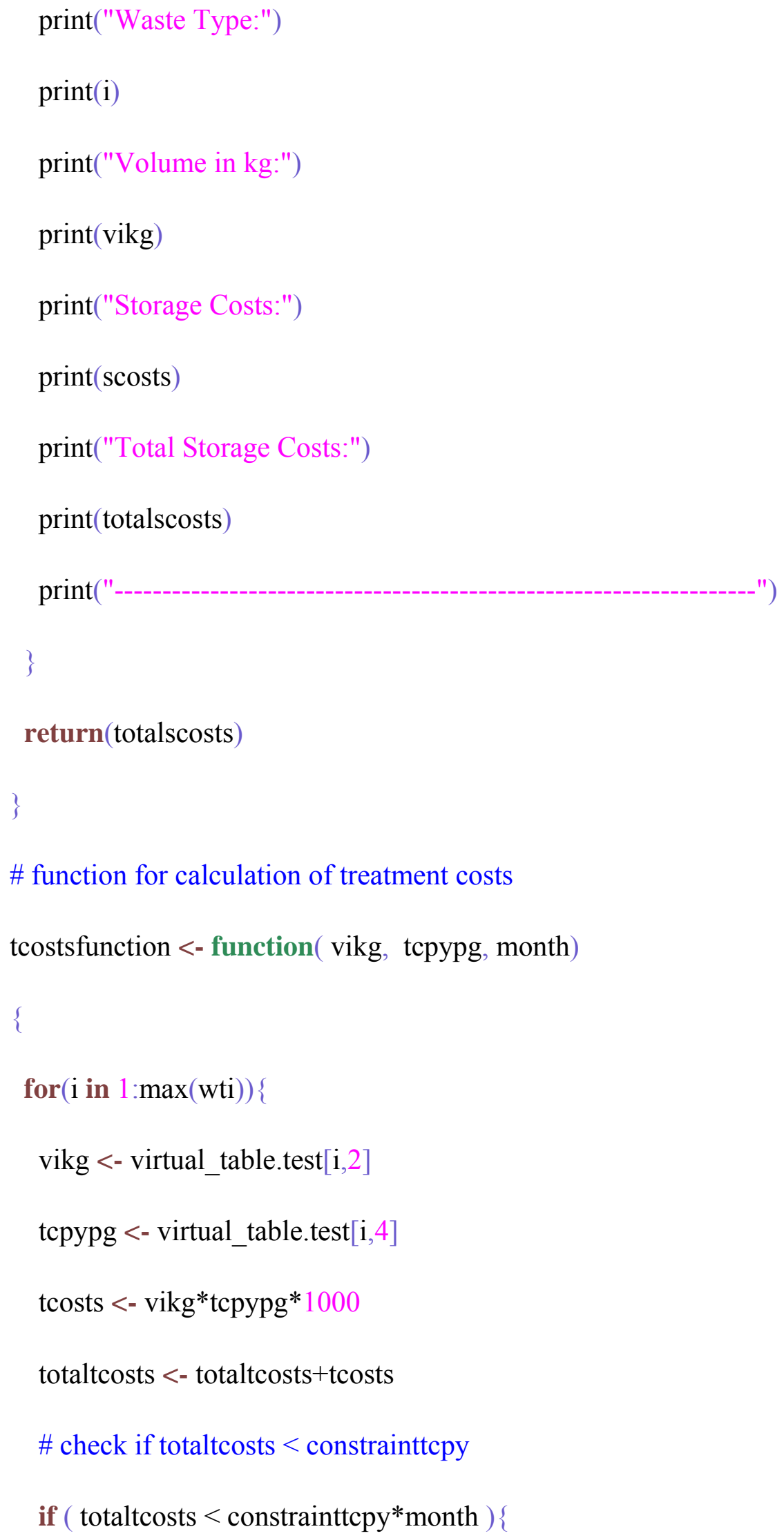




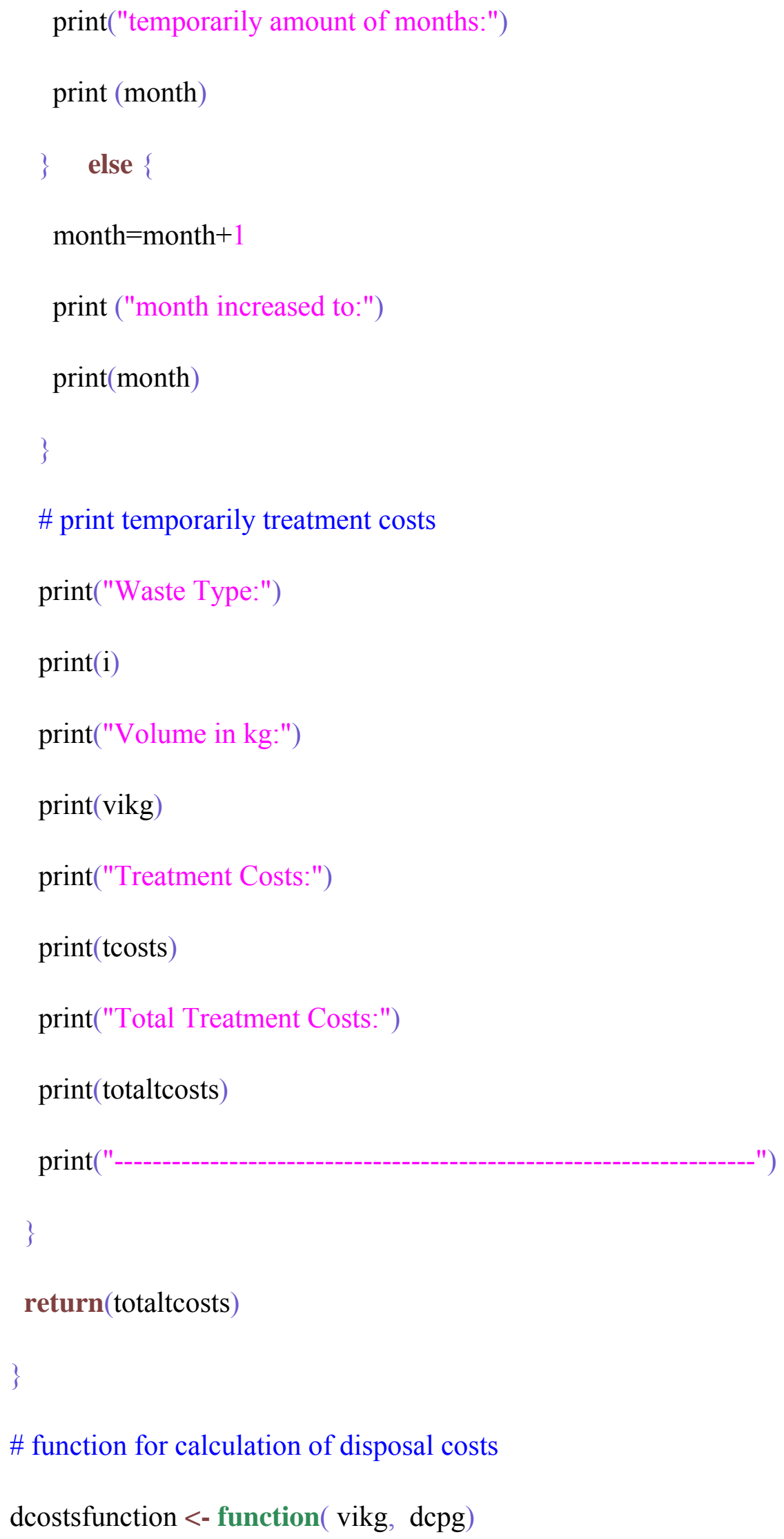




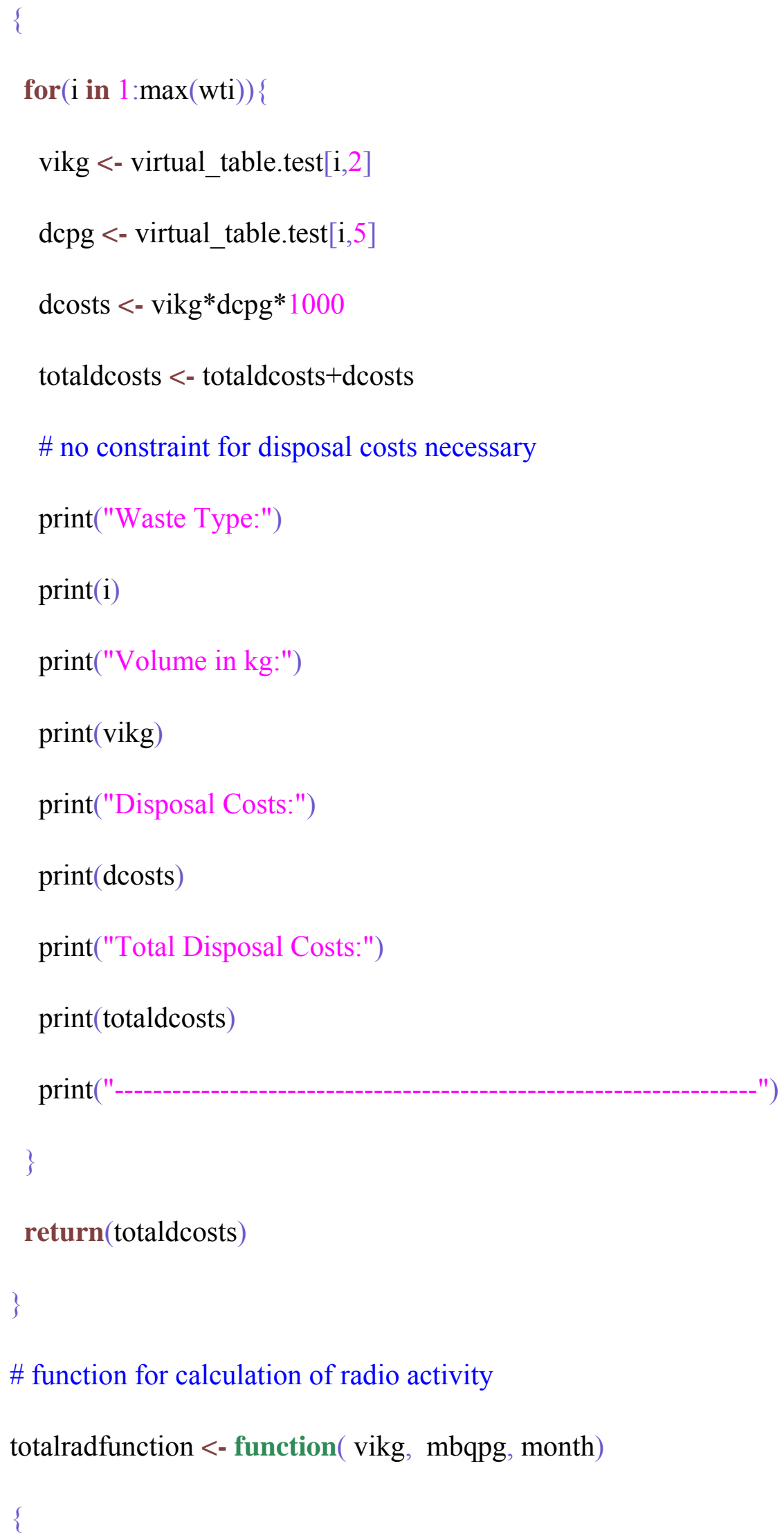




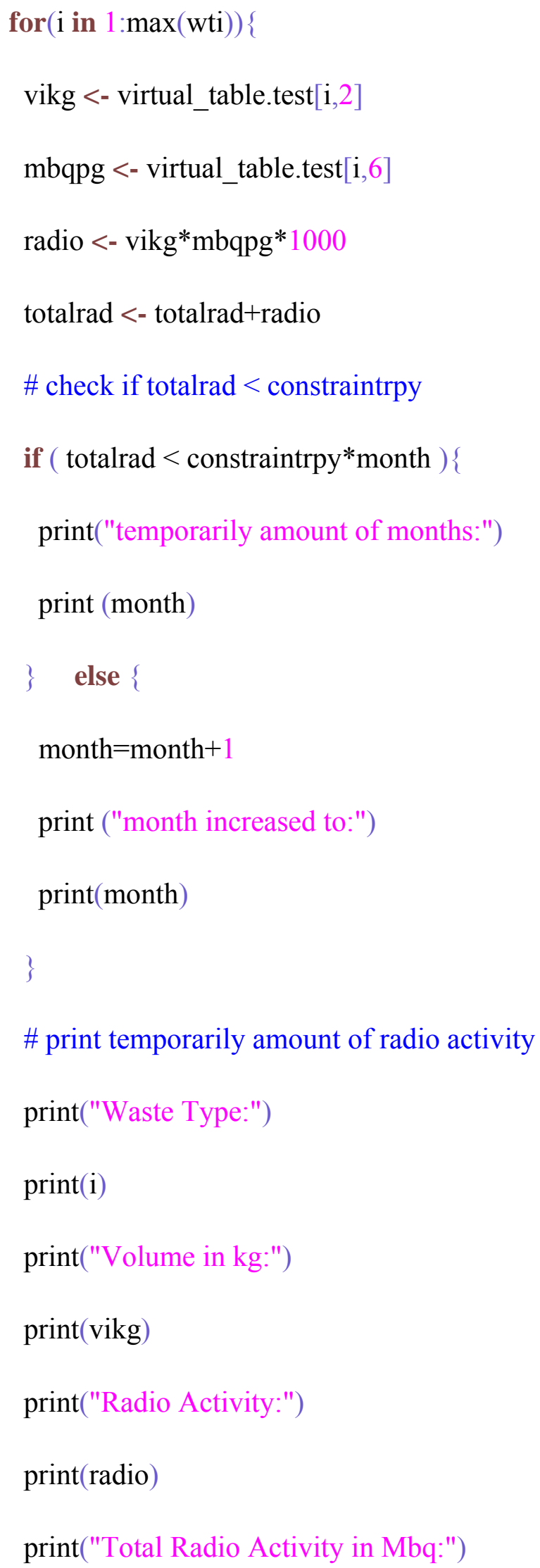




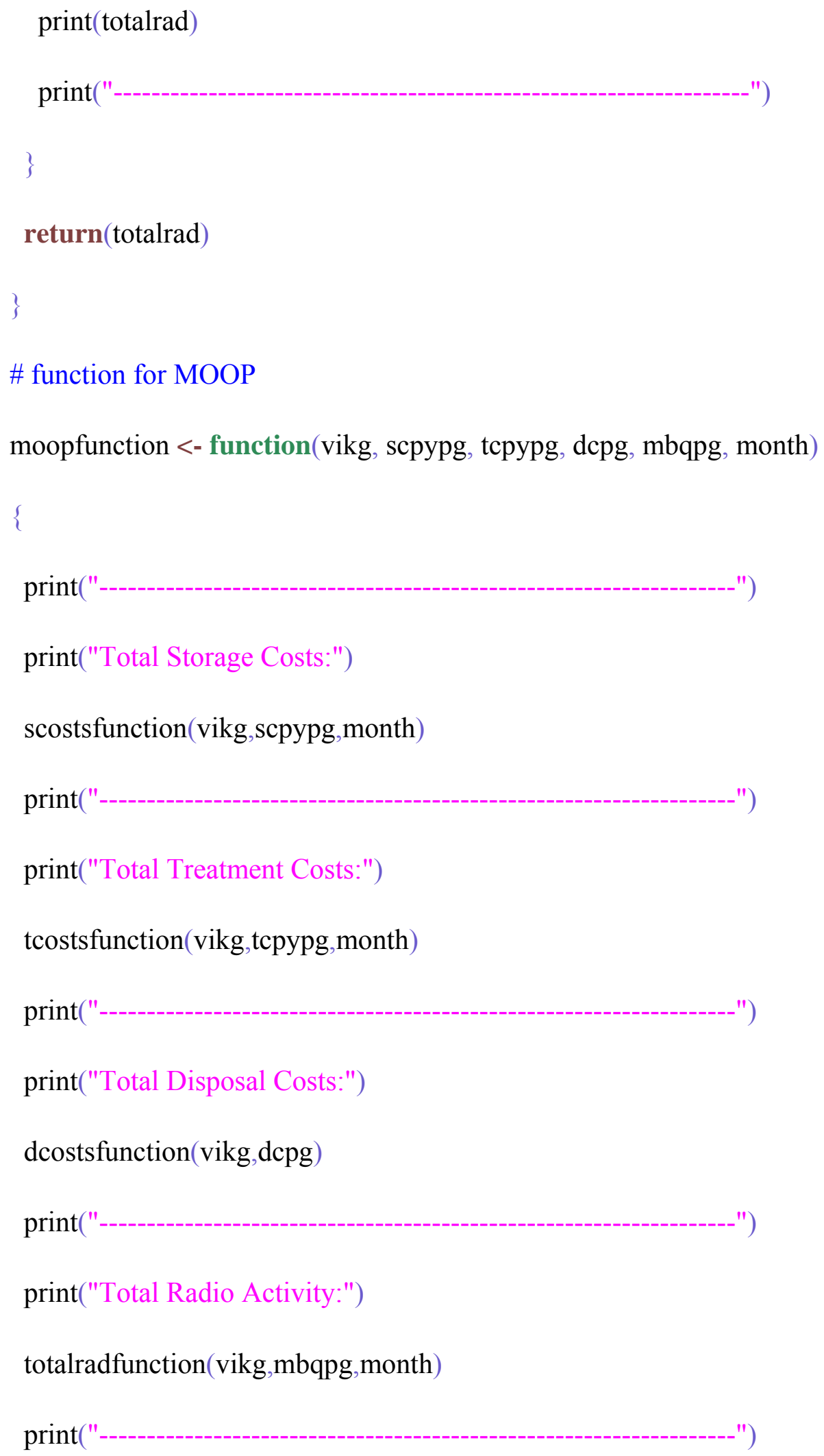




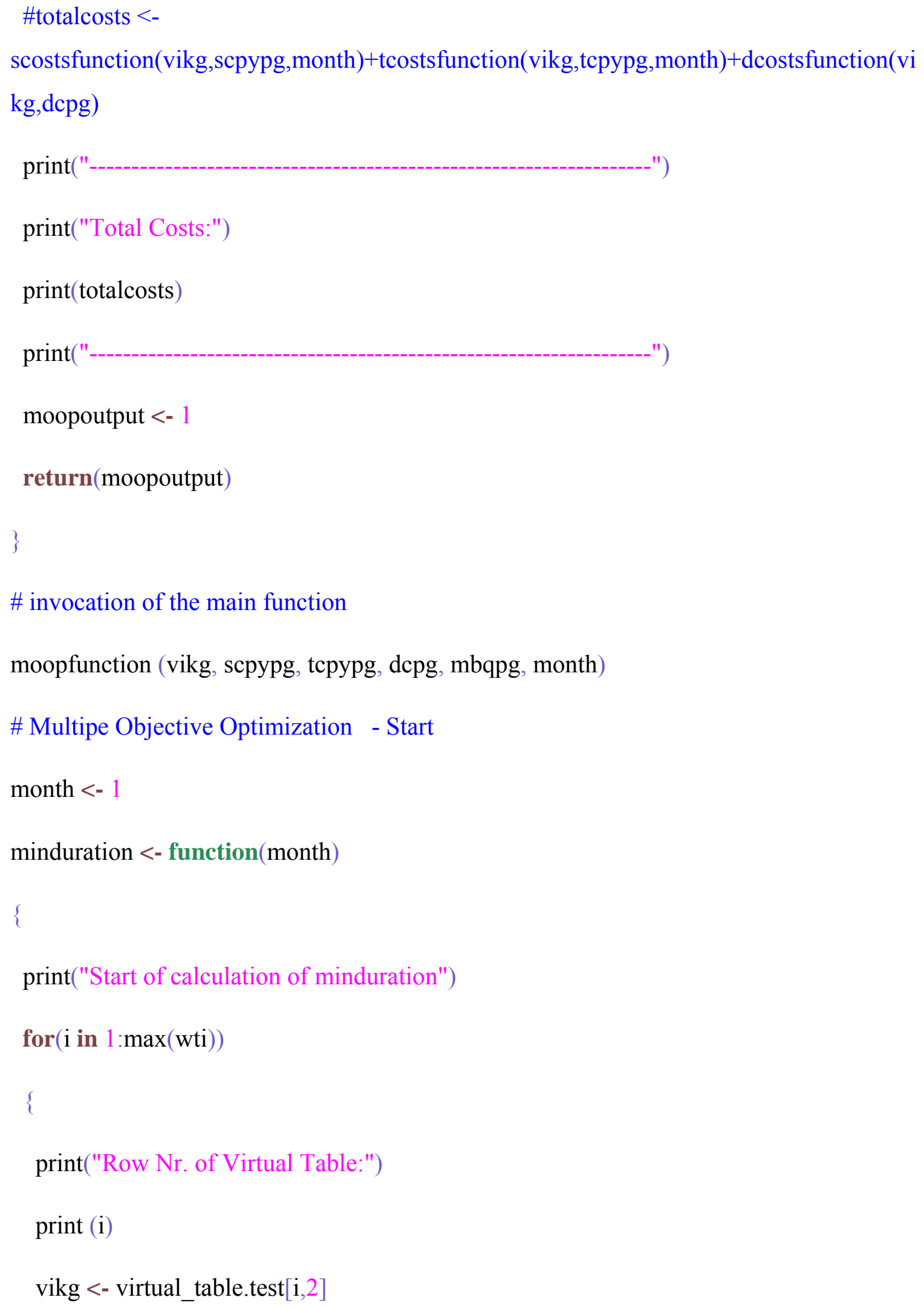




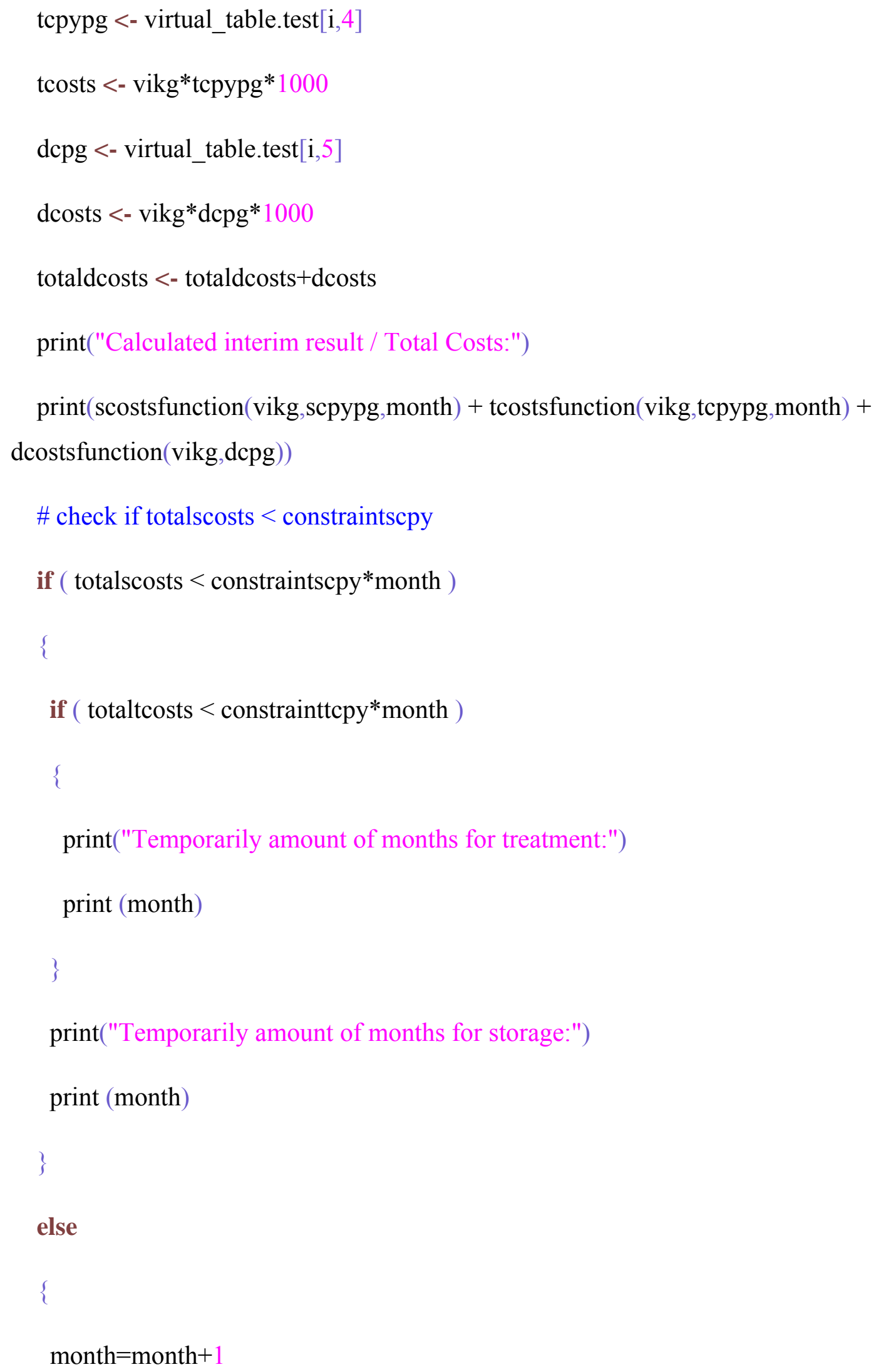




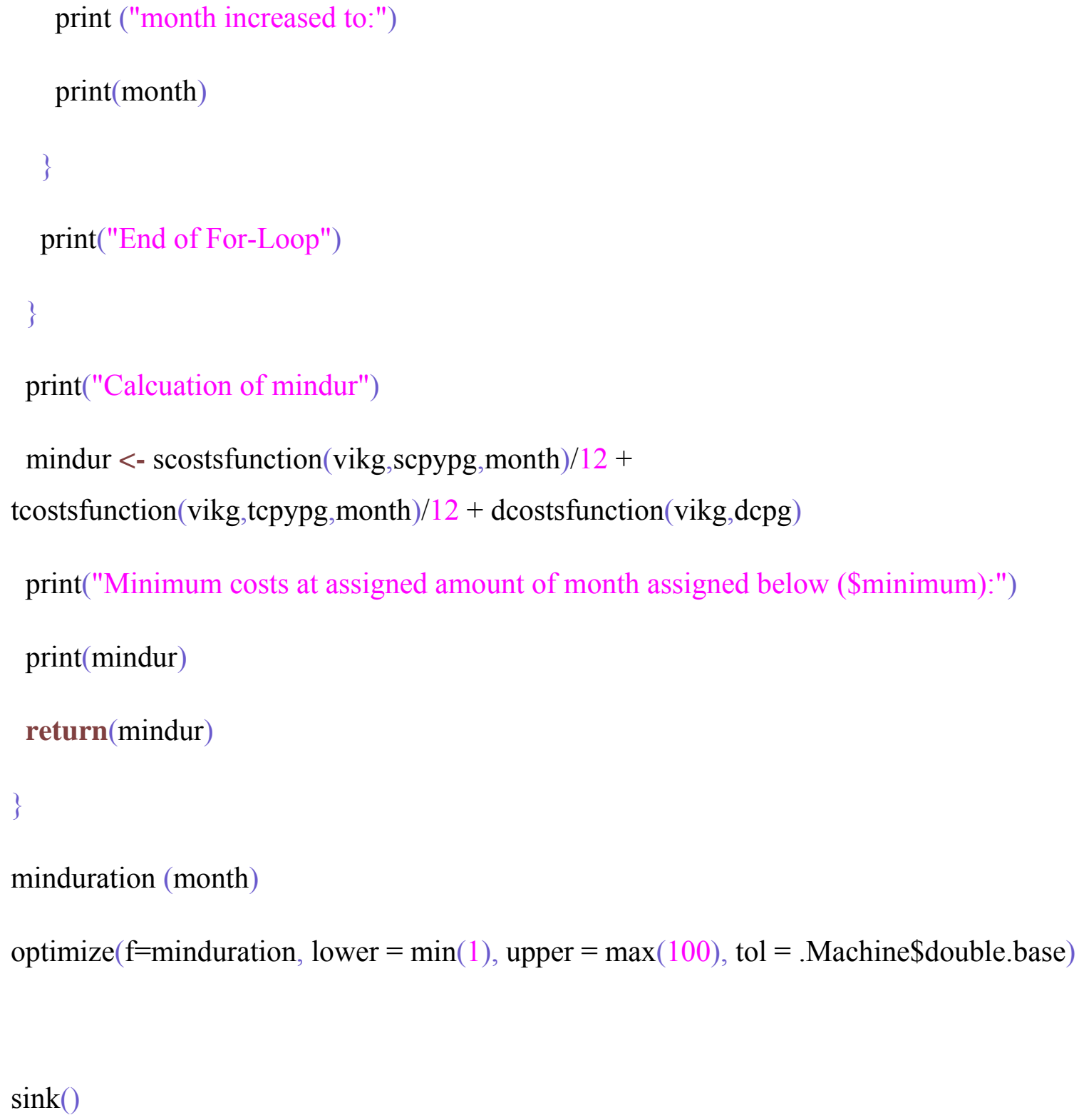




\subsubsection{MOOP R-Routine-Output}

Regarding the results, theoretically a duration of 1 to 120 months is imaginable for the processing of waste being transferred from the state $\mathrm{S}$ to $\mathrm{T}$. If there are, for example, waste in marginal amounts, a total project duration of 1 month would not be unrealistic. The higher the total amount of waste to be processed, the higher the total time needed to process the total waste will be. Depending of the given future project scenario, it is possible to adjust this issue parametrically.

As emphasized before, it is possible to optimize many details in the R-MOOP program routine. Therefore it is possible with an added control structure, to implement the following functionality: If the maximum contingent of the state treatment for a month is reached, no further waste for treatment will be transferred from the state storage to treatment before some new resources are free. This is the case after waste is being transferred from the state treatment to the state disposal. Such a more detailed implementation would require more temporal capacities. It is necessary to point out again, that the countless interdisciplinary and specialized issues, case studies, software tools and complexity of the underlying models increase the intricacy of the R-MOOP.

The results of the R-Output sequence contain both interim and final results which are documented in the output file (see appendix 9/Ausgabe24.txt) and specified in the source code of the MOOP program routine. Here are some excerpts from this output file showing the iterative structure within the output file:

The output file begins as shown next:

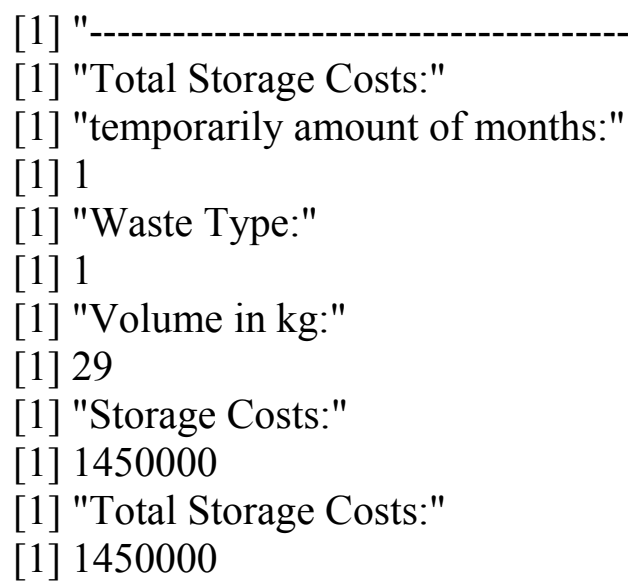




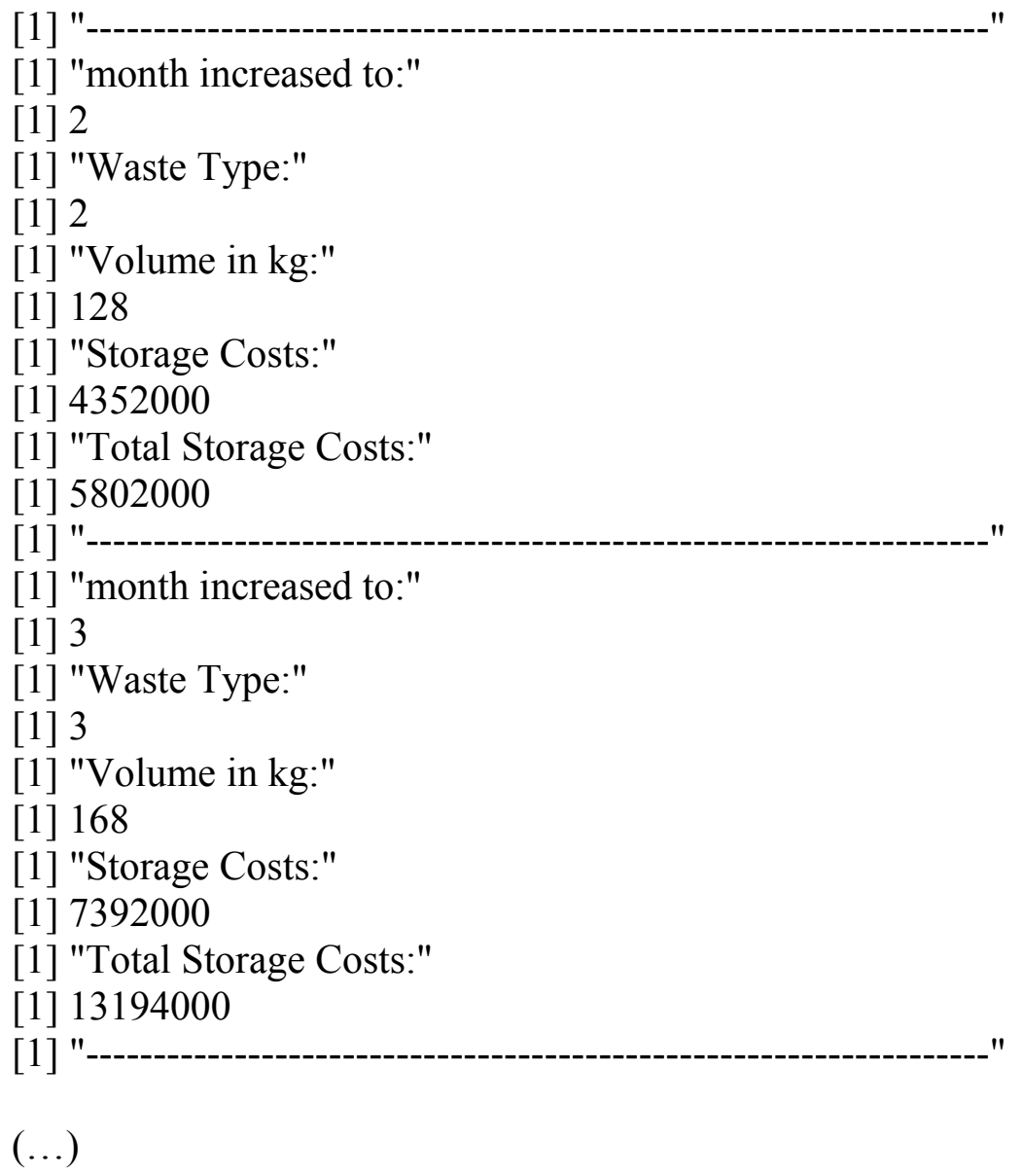

Controlled by for-loops and the amount of months and the waste type is increased by one in each loop and the costs are summed up. Representing by the sum-function in the formulas (4.12), (4.14), (4.19) and (4.22) and the output file "Ausgabe24.txt" shows each iteration by month and waste type transparently in order to track the summation of the different cost types in each step. Here the storage costs after month 3 are 13,194,000 \$. In analogy the disposal costs, storage costs and the treatment costs are calculated iteratively and step by step as shown in the next excerpts of "Ausgabe24.txt":

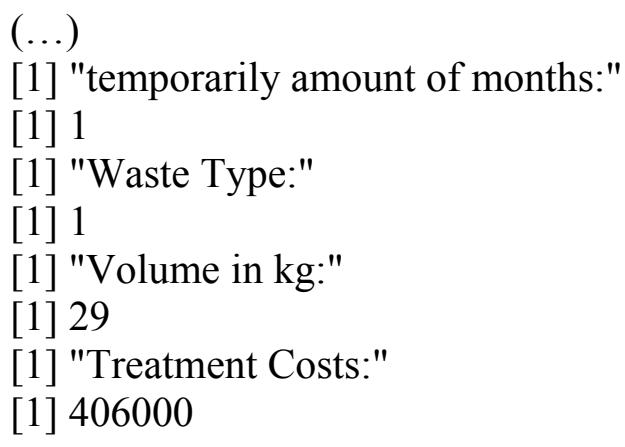


[1] "Total Treatment Costs:"

[1] 406000

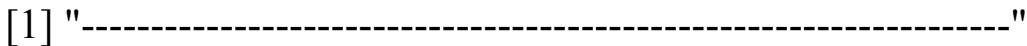

[1] "month increased to:"

[1] 2

[1] "Waste Type:"

[1] 2

[1] "Volume in kg:"

[1] 128

[1] "Treatment Costs:"

[1] 7936000

[1] "Total Treatment Costs:"

[1] 8342000

[1] "-

[1] "month increased to:"

[1] 3

[1] "Waste Type:"

[1] 3

[1] "Volume in kg:"

[1] 168

[1] "Treatment Costs:"

[1] 8568000

[1] "Total Treatment Costs:"

[1] 16910000

(...)

[1] "Waste Type:"

[1] 1

[1] "Volume in kg:"

[1] 29

[1] "Disposal Costs:"

[1] 1421000

[1] "Total Disposal Costs:"

[1] 1421000

[1] "-------------------------------------------------------------------"

[1] "Waste Type:"

[1] 2

[1] "Volume in kg:"

[1] 128

[1] "Disposal Costs:"

[1] 9472000

[1] "Total Disposal Costs:"

[1] 10893000

[1] "

[1] "Waste Type:"

[1] 3 
[1] "Volume in kg:"

[1] 168

[1] "Disposal Costs:"

[1] 11424000

[1] "Total Disposal Costs:"

[1] 22317000

(...)

As a result of the iterations and the optimization process the following output is presented - with minimum costs in a duration of 98.7 months and a total cost of 261,088,083 \$:

[1] "Minimum costs at assigned amount of month assigned below (\$minimum):"

[1] 261088083

\$minimum

[1] 98.69759

\$objective

[1] 261088083

The iteration procedure is documented completely in the file "Ausgabe24.txt" based on hundreds of lines of calculated interim results corresponding to each for-loop and function.

The value "\$minimum" relates to an ideal amount of months, the decommissioning and dismantling project runs, with the goal to keep the total costs for the project to a minimum level. This duration is 98.69759 months, which equals 8 years, 2 months and 21 days.

In the for-loops all waste types i and the costs arising - leant on the sum formula (4.12) are summed up, for the phases "storage", "treatment" and "disposal" for all constellations of the possible durations of the phases and for all waste types.

The constraints given are as follows:

- \# constraint for storage costs per month

o constraintscpy $<-5000000$

- \# constraint for treatment costs per month

o constrainttcpy $<-4000000$ 
- \# constraint for radio activity per month

$$
\text { o constraintrpy }<-30000000000
$$

Based on these constraints each constellation of costs and durations are passed through and the optimum of the minimum amount of months (\$minimum) and costs (\$objective) is given as output. In the file "Ausgabe.txt" each step of the iteration is documented step by step (e. g. see last iteration in each for-loop for total costs of storage, treatment and disposal):

\section{(...)}

[1] "temporarily amount of months:"

[1] 98.69759

[1] "Waste Type:"

[1] 29

[1] "Volume in kg:"

[1] 103

[1] "Storage Costs:"

[1] 8652000

[1] "Total Storage Costs:"

[1] 202892000

[1] "temporarily amount of months:"

[1] 98.69759

[1] "Waste Type:"

[1] 29

[1] "Volume in kg:"

[1] 103

[1] "Treatment Costs:"

[1] 7107000

[1] "Total Treatment Costs:"

[1] 260993000

[1] "Waste Type:"

[1] 29

[1] "Volume in kg:"

[1] 103

[1] "Disposal Costs:"

[1] 6798000

[1] "Total Disposal Costs:"

[1] 222431000

(...) 
In the worst-case with a maximum number of months for each of the phases "storage", "treatment" and "disposal" the costs are as follows (see last iteration in each for-loop):

Storage: $202,892,000 \$$

Treatment: 260,993,000\$

Disposal: $222,431,000 \$$

Thus the sum of costs in the worst-case-scenario is $686,316,000 \$$. This is the possible maximum level of costs.

In the output \$minimum shows the optimum number of months and \$objective shows the minimum level of costs in the best-case scenario, with $261,088,083 \$$, based on the given constraints.

The scope of the costs is roughly leant on Jones et al. $1998^{343}$. They mention costs about $203,000,000 \$$ per year for their project. Therefore the values given here should be considered just as orientation. The main goal is it to demonstrate the feasibility based on $\mathrm{R}$ and not to fulfill requirements of precision regarding the total costs.

\subsection{Application of the model in SPSS}

The implementation of the minimization problem described in this dissertation is also possible with SPSS. The IBM SPSS Statistics 19 Algorithm presents several ways to apply a minimization on a given model. Since the tools used before (AIMMS, MATLAB and R) offer a better approach, SPSS will not be used for the implementation of the model specified in this work. This decision is due to the higher applicability of the other tools compared with SPSS in regard to the objectives defined in chapter 1.2.

\footnotetext{
${ }^{343}$ see Jones et al. (1998), p. 3
} 


\section{SUMMARY, CONCLUSIONS AND RECOMMENDATIONS}

\subsection{SUMMARY}

The goals for this dissertation were defined earlier (see chapter 1.2, 1.4 and 4.1). The relevancy of these goals is illustrated in detail in chapter 1.3, as well as in the theoretical section of this work (see chapters 2 and 3 ).

The general goal given (see chapter 1.2) was to combine the tangible issues faced during the process of decommissioning NPP such as functional, economical, technical and ORbased issues like MOOP (minimizing total costs, project time and the potential for radiation exposure etc.) - with interdisciplinary knowledge and paradigms, such as

project management, lean management, simultaneous engineering, mathematics and applied informatics.

After a thorough research and investigation on these subjects, a wide range of state-ofthe-art concepts, methods and tools were deemed worthy of a more in-depth focusing upon. The theoretical sections (terminological section - chapters 2, 3 and 4 - and methodical section - chapters 5 and 6 of this work contain all relevant issues as a result of the requirement analysis, defined in the proposal in preparation for this dissertation (see also Figure 1). 


\subsubsection{Model Building}

In order to carry out items (A-C), an approved model was consulted, in order to fulfill the requirements of items A-C. After a long period of intense research, the two models described in chapter 4 were deemed highly relevant:

- OMEGA by IAEA 2008/Daniska et al. 2008 for a business process approach (see chapter 4.2) and

- Jones et al. 1998 for the mathematical approach (see chapter 4.4, 4.5, 4.6, 4.7, 4.8, 4.9 and 4.10$)$

After a detailed analysis of those two models, an approach combining both models was chosen. The specification of the requirements needed for the modeling of the three items was accomplished via a mathematically formulated framework and the underlying process model provided by OMEGA. Further empirical data was required in order to shape a virtual scenario on which a virtual data model could be run. Therefore more real data was gathered in order to leverage the framework to produce case studies.

\subsubsection{Case study}

In chapter 5 several issues of the business model were shown, based on case studies (José Cabrera Plant, NPP in Stade and Wuergassen). From this empirical basis the data model and project schedule could be broken down step by step. It was possible to shape a virtual database model, in which the elements of the dismantling process could be gathered (see chapter 6.3.5). The case study in chapter 5 was also helpful for the definition of the process model, from which the task plan was inferred (see chapter 6.2). The simulation of virtual data was possible based on the preliminary estimates (see chapter 5.7). The implementation of the model using state-of-the-art tools and also tabular and figurative results was shown in chapter 6 and in the Appendices as well.

\subsubsection{Application of software tools}

The model-based framework was transformed with software tools to an applicable pattern. Since MS Project was used to support the process organization and task 
definition, $\mathrm{R}$ and AIMMS were tested to implement the model using specific software functionality and programming techniques. Beside R and AIMMS, MATLAB and SPSS were also tested in accordance with the requirements. As a result $\mathrm{R}$ was identified as the most usable, manageable and easy to handle tool, since the functionality was easy to learn. The R-documentation was the most helpful in the realization of the model-based framework. AIMMS was the preferred tool for application in the initial phase, due to the intuitive graphic user interface. After long-term use R distinguished itself as the preferred environment to implement the model in. Since MATLAB offers a broad range of functions for the implementation of the model too, the induction was more timeconsuming and the usability - for the purpose of this work - less favorable than that found in AIMMS. Since R is a non-commercial, open-source programming language, the documentation is accessible and widespread. After an initial training in R and RStudio it was possible to implement a simplified version of the Pareto-optimum accessing the virtual database (see appendix 5,6 and 7) and to implement a self-made MOOP-program routine calculating the minimum costs of the given database table data as input. The applicability of SPSS could not be evaluated, since optimization techniques for the given purpose provided by IBM SPSS Statistics 19 Algorithm could not be tested due to lack of time. Therefore it is not possible to make any conclusions as to the pertinence of SPSS.

\subsubsection{Lean management approach}

Lean management techniques are focused on well-organized supply chain management systems, the ability of continuous improvement, the emphasis on respect for people, effective methods of team building, strategic management and leadership techniques. The understandability of structures and processes can only be achieved by the continuous improvement of suitable underlying methodologies, techniques and tools, such as the continuous upgrading of the IT structures and IT departments. The use of lean management tools and employee participation is a good guarantee of better productivity (see also chapter 3.2). Regarding these issues the tools and methods used in this dissertation, such as a modern project management tool, like MS Project 2013 represent powerful instruments in reducing the complexity of the dismantling and 
decommissioning processes, since the transparency, understandability, documentation quality, flexibility and intuitive usage is increased.

\subsubsection{Simultaneous engineering approach}

When it comes to the parallelization of tasks, project management instruments and tools are of great importance. All phases of the project's life-cycle (functionality, maintenance, assembly, disposal etc.) should be modeled with all interdependencies in an early stage of the planning process, as specified in the project schedule (see chapter 6.2). The aim is it to perform as many activities as possible in parallel/simultaneously, which is only possible when a farsighted plan with iterative structures is in place. This goal was an overriding one during the formulation of the project schedule (see chapter 6.2, p. 121123, Tasks 5-15 and 34-40).

\subsubsection{Application of operations research methods}

Qualified design methods, artificial intelligence techniques and numeric tools are also part of the functionality of the presented software tools. The application of modern OR tools is central in the analysis and iterative development, testing, evaluation and controlling of the projects needs. The mathematical model of the MOOP and the application of linear programming techniques as shown in the chapters 6.3-6.6 offer a good idea of the requirements, challenges and potential in the context of an actual dismantling and decommissioning of a NPP. 


\subsubsection{Evaluation of the numerical results}

In the chapters 4.2 .5 and 4.3 the cost estimating approaches and the calculation structures were discussed in detail. In 4.4 the cost structure presented by Jones et al. 1998 was presented and integrated into the model in the following chapters $4.5-4.10$. In chapter 6.5.4.3 the amounts of volume in $\mathrm{kg}$, of costs and radioactivity in mbq (see Table 11) were extracted out of the findings in the empirical research (see chapter 5, appendix 4 "Verpackungspläne"). Given this scenario in 6.5.4.7 the following estimations were calculated by the R-MOOP program routine.

\subsubsection{Comparison the R-MOOP with worst case and average case scenarios}

Comparing the R-MOOP with the worst case and average case scenarios the following results can be given (see Table 14):

Table 14: Comparing the R-MOOP with worst case and average case scenarios

\begin{tabular}{|l|l|l|}
\hline $\begin{array}{l}\text { Worst Case (estimation) } \\
\text { (maximum number of months } \\
\text { for each of the phases) }\end{array}$ & $\begin{array}{l}\text { Average Case (estimation) } \\
(1 / 2 \text { of the maximum number of months } \\
\text { for each of the phases) }\end{array}$ & $\begin{array}{l}\text { R-MOOP (estimation) } \\
\text { (minimum number of months } \\
\text { for each of the phases) }\end{array}$ \\
\hline $\begin{array}{l}\text { Storage: } 202,892,000 \$ \\
\text { Treatment: } 260,993,000 \$ \\
\text { Disposal: 222,431,000 \$ }\end{array}$ & $\begin{array}{l}\text { Storage: } 101,446,000 \$ \\
\text { Treatment: } 130,496,500 \$ \\
\text { Disposal: } 111,215,500 \$\end{array}$ & $\begin{array}{l}\text { Storage: 77,184,101 \$ } \\
\text { Treatment: } 99,286,862 \$ \\
\text { Disposal: 84,617,120 \$ }\end{array}$ \\
\hline Sum: 686,316,000 \$ & Sum: 343,158,000 \$ & Sum: 261,088,083 \$ \\
\hline
\end{tabular}

The costs for the worst case scenario are calculated as follows:

$$
\begin{gathered}
\begin{aligned}
& \text { worst_case_scenario }= \sum_{1}^{\mathrm{wti}}=29 \\
& \mathrm{vikg}_{\mathrm{wti}}
\end{aligned} \operatorname{scpyg}_{\mathrm{wti}} \\
\qquad \begin{array}{c}
\mathrm{wti}=29 \\
\text { average_case_scenario }
\end{array}=\left(\sum \mathrm{vikg}_{\mathrm{wti}} * \operatorname{scpyg}_{\mathrm{wti}}\right) / 2
\end{gathered}
$$

The values for wti, vikg and scpyg can be extracted from the table (see tab. 15). 
With the R-MOOP approach the savings compared with the worst case scenario amount to

$$
\begin{aligned}
& 1-(261,088,083 \$ / 686,316,000 \$) \\
& =\underline{61,959 \%}
\end{aligned}
$$

The savings compared with the average case scenario amount to

$$
\begin{aligned}
& 1-(261,088,083 \$ / 343,158,000 \$) \\
& =\underline{23,917 \%} .
\end{aligned}
$$

\begin{tabular}{|c|c|c|c|c|c|c|c|c|c|c|}
\hline 4 & A & B & C & D & $E$ & $\mathrm{~F}$ & G & $H$ & 1 & J \\
\hline 1 & & $\begin{array}{c}\text { waste_typ } \\
\text { e i }\end{array}$ & $\underset{\mathrm{kg}}{\text { volume_in }}$ & $\begin{array}{l}\text { storing_co } \\
\text { sts_per_ye } \\
\text { ar_per_g }\end{array}$ & $\begin{array}{l}\text { vol*storage_c } \\
\text { osts }\end{array}$ & $\begin{array}{c}\text { Treatment } \\
\text { costs_per } \\
\text { year_per } \\
\text { _ g }\end{array}$ & $\begin{array}{c}\text { vol }{ }^{\pi} \text { treat_cost } \\
\text { s }\end{array}$ & $\begin{array}{c}\text { disposal_c } \\
\text { osts_per_ } \\
\text { g }\end{array}$ & $\begin{array}{c}\text { rol }{ }^{x} \text { disp_cost } \\
\text { s }\end{array}$ & $\begin{array}{c}\text { mbq_per_ } \\
\text { a }\end{array}$ \\
\hline 2 & 1 & 1 & 29 & 50 & 1450 & 14 & 406 & 49 & 1421 & 449297 \\
\hline 3 & 2 & 2 & 128 & 34 & 4352 & 62 & $7 \subseteq 36$ & 74 & 9472 & 143948 \\
\hline 4 & 3 & 3 & 168 & 44 & 7392 & 51 & 8568 & 68 & 11424 & 915179 \\
\hline 5 & 4 & 4 & 37 & 56 & 2072 & 32 & 184 & 21 & 777 & 401834 \\
\hline 6 & 5 & 5 & 43 & 100 & 4300 & 29 & 1247 & 63 & 2709 & 533459 \\
\hline 7 & 6 & 6 & 108 & 77 & 8316 & 84 & 9072 & 24 & 2592 & 853827 \\
\hline 8 & 7 & 7 & 175 & 85 & 14875 & 92 & $16 \cdot 00$ & 90 & 15750 & 660482 \\
\hline 9 & 8 & 8 & 184 & 12 & 2208 & 25 & $4 E 00$ & 21 & 3854 & 252913 \\
\hline 10 & 9 & $\mathrm{~g}$ & 78 & 57 & 4446 & 98 & $7 \in 44$ & 92 & 7176 & 882256 \\
\hline 11 & 10 & 10 & 220 & 15 & 3300 & 91 & $20 c 20$ & 32 & 7040 & 204469 \\
\hline 12 & 11 & $\pi$ & 130 & 17 & 2210 & 94 & 12220 & 15 & 1950 & 16545 \\
\hline 13 & 12 & 12 & 78 & 65 & 5070 & 13 & 1014 & 48 & 3744 & 269297 \\
\hline 14 & 13 & 13 & 99 & 96 & 9504 & & 99 & 48 & 4752 & 773 \\
\hline 15 & 14 & 14 & 46 & 44 & 2024 & 11 & 506 & 37 & 1702 & 291714 \\
\hline 16 & 15 & 15 & 99 & 44 & 4356 & 17 & $1 \in 83$ & 18 & 1732 & 591043 \\
\hline 17 & 16 & 16 & 110 & 3 & 330 & 97 & 10670 & 61 & 6710 & 108942 \\
\hline 18 & 17 & 17 & 233 & 35 & 8155 & 94 & 21602 & 75 & 17475 & 766534 \\
\hline 19 & 18 & 18 & 80 & 40 & 3200 & 99 & $7 \$ 20$ & 18 & 1440 & 163178 \\
\hline 20 & 19 & 19 & 244 & 29 & 7076 & 86 & 20584 & 68 & 16592 & 14021 \\
\hline 21 & 20 & 20 & 212 & 3 & 636 & 45 & 9540 & 87 & 18444 & 614320 \\
\hline 22 & 21 & 21 & 130 & 96 & 12480 & 63 & $8 \cdot 90$ & 71 & 9230 & 861586 \\
\hline 23 & 22 & 22 & 200 & 61 & 12200 & 77 & 15400 & 89 & 17000 & 321319 \\
\hline 24 & 23 & 23 & 202 & 91 & 18382 & 88 & 17776 & 37 & 7474 & 331162 \\
\hline 25 & 24 & 24 & 106 & 77 & 8162 & 85 & 9010 & 8 & 848 & 782336 \\
\hline 26 & 25 & 25 & 141 & 38 & 5358 & 76 & 10716 & 72 & 10152 & 790886 \\
\hline 27 & 26 & 26 & 207 & 46 & 9522 & 67 & 13869 & 9 & 1853 & 44262 \\
\hline 28 & 27 & 27 & 163 & 100 & 16300 & 40 & 6520 & 100 & 16300 & 54971 \\
\hline 29 & 28 & 28 & 202 & 82 & 16564 & 45 & 9690 & 75 & 15150 & 614341 \\
\hline 30 & 29 & 29 & 103 & 84 & 8652 & 69 & 7.07 & 66 & 6798 & 337282 \\
\hline 31 & & & & & 202892000 & & 260993000 & & 222431000 & \\
\hline 32 & & & & & & & & & 686316000 & \\
\hline
\end{tabular}

Table 15: Calculation of worst case scenario

The new columns (E, $\mathrm{G}$ and $\mathrm{H}$ ) of the table show the total costs for each waste type to be processed in each of the three states (storage, treatment, disposal). The sums of all waste types for each state are given in the line 31 and in line 32 the total sum is given. In the 
worst-case scenario all costs of the scenario will be added to each other, without using the monthly constraints and the regarding control structures of the R-MOOP as implemented here:

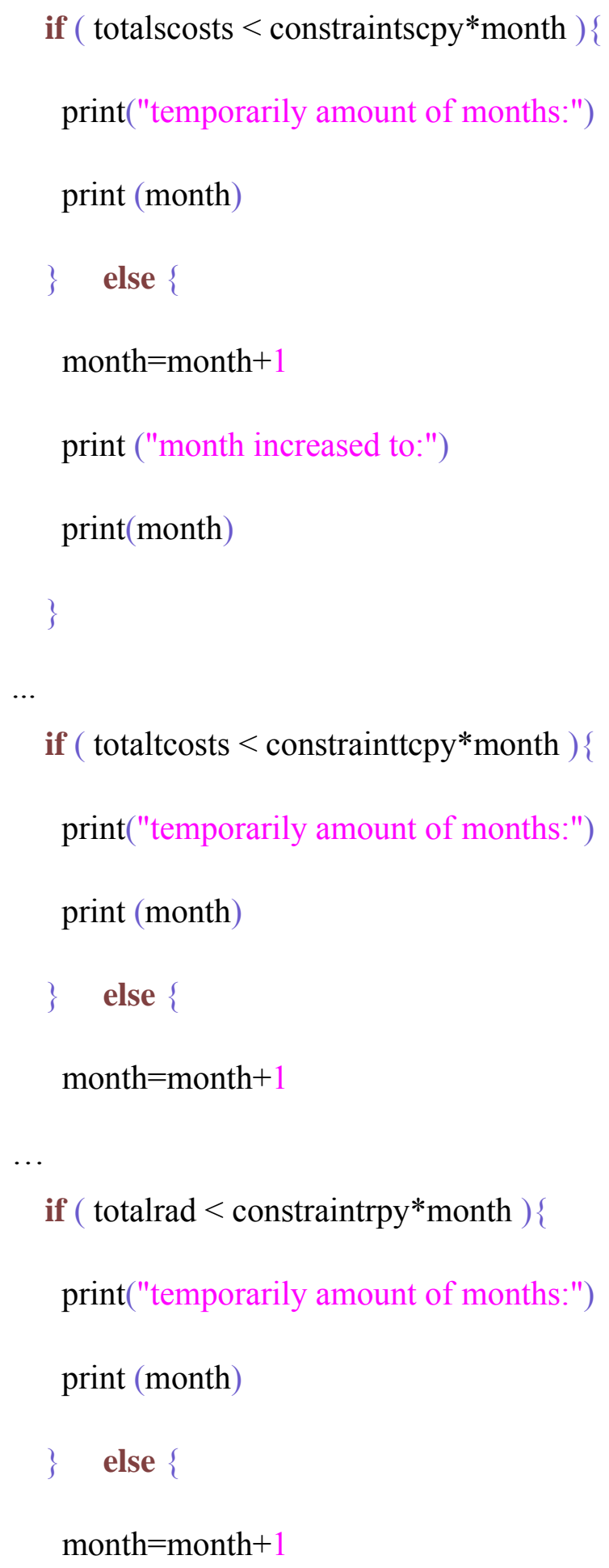




\subsubsection{Critical discussion of the constraints - Costs}

Further on Jones et al. define costs of 203 Mio \$ each year in 1997. At an averagely inflation rate of $2 \%$ it can be calculated

- 203 mio $\$ X 1.02^{16}$ or

- $203 \times 1.3727857050906122 \times 10^{6} \$=278,675,498 \$$

- say 280 mio $\$$ for today,

- on a monthly period of (280 mio \$ /12) 23,3 mio \$.

The constraints are set as follows:

\# constraint for storage costs per month

constraintscpy $<-5000000$

\# constraint for treatment costs per month

constrainttcpy $<-4000000$

5 mio $\$$ for storage costs and 4 mio $\$$ for treatment costs are roughly in this scale - in sum 9 mio $\$$ for storage and treatment and 14,30 mio $\$$ for disposal. Considering that the storage costs in the starting periods are higher in comparison to the last periods (see chapter 4.4.1) and the disposal costs are lower in the beginning periods and higher in the last periods, the constraint for the storage costs with 5 mio $\$$ for the periods in the beginning is too low. A better solution would be a dynamic setting of the constraints depending on the current period. For example if a period of 10 years and 120 month is given, a dynamic setting of the constraints regarding the costs could be as follows, with current month as the month for which the costs are calculated:

\footnotetext{
$\cdots$

if $($ current_month $<30)\{$

\# constraint for storage costs per month

constraintscpy $<-10000000$

\# constraint for treatment costs per month
} 


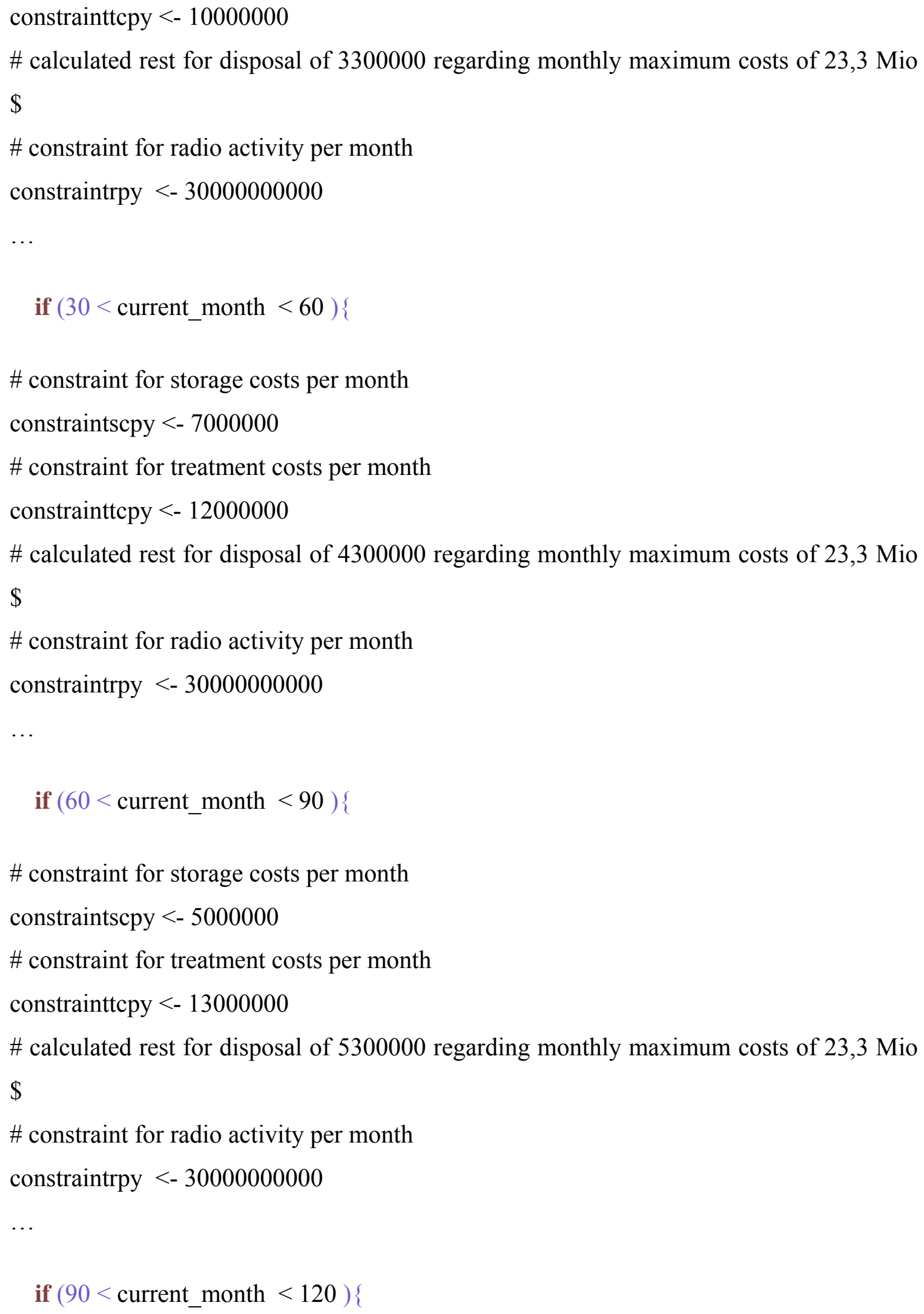


\# constraint for storage costs per month

constraintscpy $<-3000000$

\# constraint for treatment costs per month

constrainttcpy $<-8000000$

\# calculated rest for disposal of 11300000 regarding monthly maximum costs of 23,3 Mio $\$$

\# constraint for radio activity per month

constraintrpy $<-30000000000$

\subsubsection{Critical discussion of the constraints - Radio Activity}

The constraint of $30,000,000,000 \mathrm{mbq}$ or $30 \times 10^{9} \mathrm{mbq}$ was estimated - as discussed before - based on the package plans (see appendices 4 (A-I)). Considering the radio activity of the components and elements on the package plans (see appendices 4 (A-I)) it is possible to extract the following values (rounded) (see Table 16):

Table 16: Comparing the R-MOOP with the worst case and average case scenarios

\begin{tabular}{|c|c|}
\hline Appendix 4 A & Appendix 4 B \\
\hline $\mathrm{Bq} / \mathrm{g}: 1-8 \times 10$ to the power of $8-11 \mathrm{~Bq} / \mathrm{g}$ & $\mathrm{Bq} / \mathrm{g}: 1-3 \times 10$ to the power of $7-8 \mathrm{~Bq} / \mathrm{g}$ \\
\hline Appendix $4 \mathrm{C}$ & Appendix $4 \mathrm{D}$ \\
\hline $\mathrm{Bq} / \mathrm{g}: 1-3 \times 10$ to the power of $7-8 \mathrm{~Bq} / \mathrm{g}$ & $\mathrm{Bq} / \mathrm{g}: 3-9 \times 10$ to the power of $6-7 \mathrm{~Bq} / \mathrm{g}$ \\
\hline Appendix $4 \mathrm{E}$ & Appendix $4 \mathrm{~F}$ \\
\hline $\mathrm{Bq} / \mathrm{g}: 3-9 \times 10$ to the power of $6-7 \mathrm{~Bq} / \mathrm{g}$ & $\mathrm{Bq} / \mathrm{g}: 1-8 \times 10$ to the power of $2 \mathrm{~Bq} / \mathrm{g}$ \\
\hline Appendix 4 G & Appendix $4 \mathrm{H}$ \\
\hline $\mathrm{Bq} / \mathrm{g}: 2-8 \times 10$ to the power of $3-4 \mathrm{~Bq} / \mathrm{g}$ & $\mathrm{Bq} / \mathrm{g}: 1-4 \times 10$ to the power of $3-4 \mathrm{~Bq} / \mathrm{g}$ \\
\hline Appendix 4 I & \\
\hline $\mathrm{Bq} / \mathrm{g}: 1-4 \times 10$ to the power of $2 \mathrm{~Bq} / \mathrm{g}$ & \\
\hline
\end{tabular}


Regarding a total activity of averagely $10^{6} \mathrm{bq}$ per $\mathrm{g}$ (low estimation), the monthly constraint of $30 \times 10^{9} \mathrm{mbq}$ or $30 \times 10^{12} \mathrm{bq}$ is reached at a monthly mass of $30,000,000 \mathrm{~g}$ or $30,000 \mathrm{~kg}$.

$\Rightarrow$ Because $10^{6} \mathrm{bq} / \mathrm{g} \times 30,000,000 \mathrm{~g}$ equals $30 \times 10^{12} \mathrm{bq}=30 \times 10^{9} \mathrm{mbq}$.

Regarding a total activity of averagely $10^{7}$ bq per $\mathrm{g}$ (average estimation), the monthly constraint of $30 \times 10^{9} \mathrm{mbq}$ or $30 \times 10^{12} \mathrm{bq}$ is reached at a monthly mass of $3,000,000 \mathrm{~g}$ or $3,000 \mathrm{~kg}$.

$\Rightarrow$ Because $10^{7} \mathrm{bq} / \mathrm{g} \times 3,000,000 \mathrm{~g}$ equals $30 \times 10^{12} \mathrm{bq}=30 \times 10^{9} \mathrm{mbq}$

Regarding a total activity of averagely $10^{8}$ bq per g (high estimation), the monthly constraint of $30 \times 10^{9} \mathrm{mbq}$ or $30 \times 10^{12} \mathrm{bq}$ is reached at a monthly mass of $300,000 \mathrm{~g}$ or $300 \mathrm{~kg}$.

$\Rightarrow$ Because $10^{8} \mathrm{bq} / \mathrm{g} \times 300,000 \mathrm{~g}$ equals $30 \times 10^{12} \mathrm{bq}=30 \times 10^{9} \mathrm{mbq}$

Depending on the level of estimation different masses of waste can be processed in a period. 


\subsection{SUMMARY OF RESULTS}

Besides the feasibility of the model supported by the presented tools, the main result of this dissertation is: In order to achieve the defined goals (see chapter 1.4) an interdisciplinary approach is absolutely necessary, since knowledge from specialist fields does not accomplish the given complexity. Therefore the results especially in the application of the software tools were not tested exhaustively. This should be the task for following researches. The model-based framework and the applicability of the presented tools - especially in R, AIMMS and MS Project - offer results that other researchers could leverage upon.

Based on the model it was possible to reach the goals and work out the given objectives. The approaches for the model specification are leant on Jones et al. 1998 and the OMEGA model. Only regarding the model implementation, some reductions have to be made in the functionality and specifications.

The implemented R-MOOP program routine is a good basis for further enhancements on the application logic. The main goal of the R-MOOP routine was to transfer the sum functions of the model (formula 4.12) and implicitly (4.14) into executable code using standard software tools and methods. Also the input and output dimensions of the RMOOP routine are not strictly oriented on the results of Jones et al. 1998. Their results offer helpful insights for the conception of a virtual data scenario.

The objective functions $\mathrm{f} 1, \mathrm{f} 2$ and $\mathrm{f} 3$ were investigated and specified exactly and completely in the modeling part of the work. In the R-MOOP routine only a reduced implementation of the model was performed, due to the high complexity of a full implementation.

The next figure shows the step by step generation of the results in this dissertation (see Figure 28). 


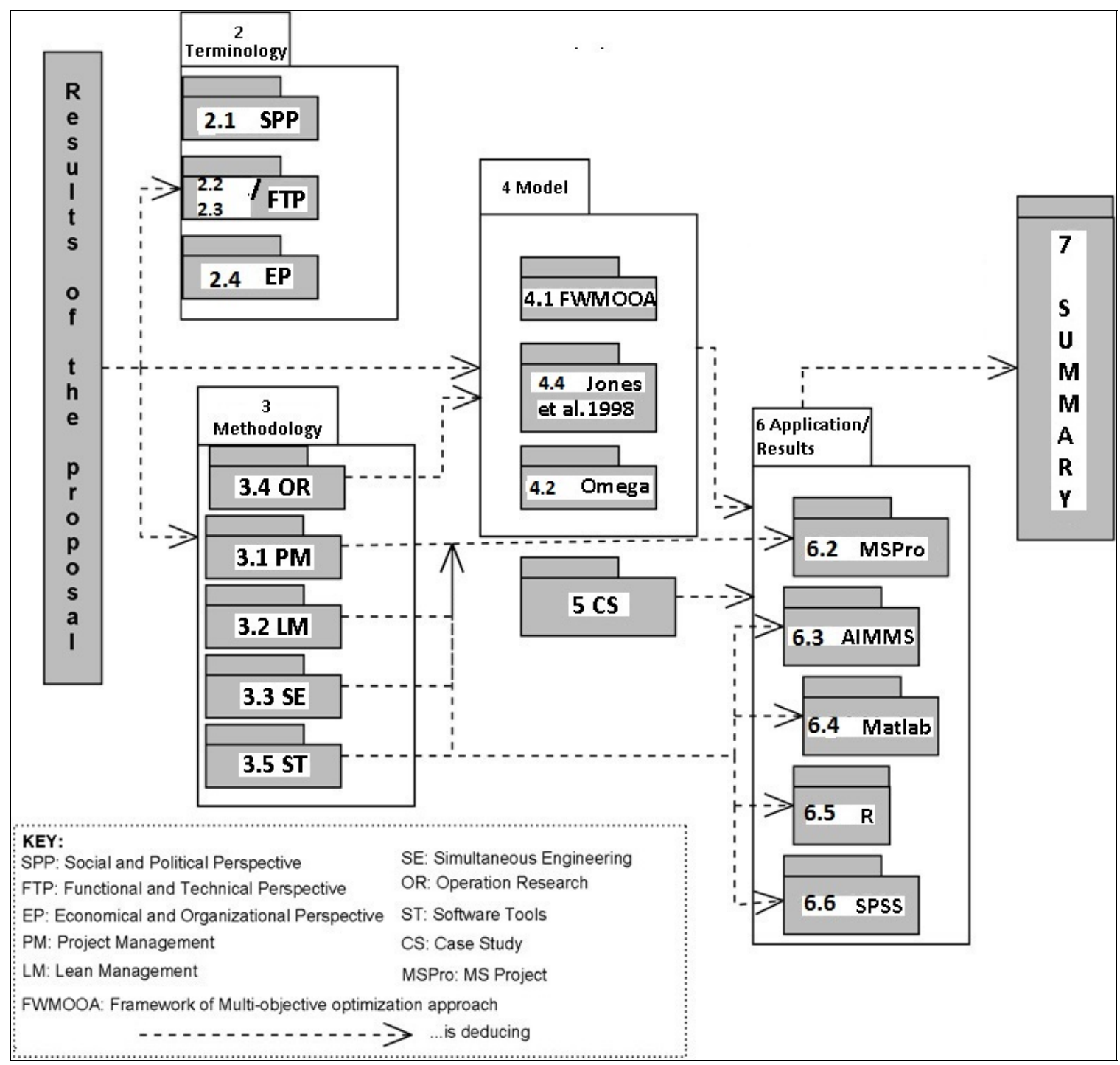

Figure 28: Generating results in the dissertation

The results of this dissertation are primarily theoretical in nature. Since the outcome of the empirical analysis (see chapter 5) was limited and no data on comparable projects and OR practices were available, emphasis was placed on the theoretical specification of the requirements.

The goals defined in 1.4 are listed below. A description follows as to how and where those goals are achieved or solved in this work:

(1) Research of up-to-date empirical data for designing a virtual NPP

$\rightarrow$ The empirical data is detailed in chapter 5. Dismantling and decommissioning is an area marked by a high degree of secrecy, confidentiality, sensitivity and safety-relevance. 
Therefore the main focus was on gaining access to sufficient quantities of data from a NPP to establish a sound empirical data set. Therefore the presented data is a conglomeration of several real sources. On this basis a virtual database structure could be created for use in R and AIMMS (see chapters 6.5 and 6.3) and also the simulation of virtual data, was performed leant on the empirical research (see chapter 5 and appendix $4)$.

(2) Description of empirical data with the framed model.

$\rightarrow$ The description of the empirical data was given in chapter 5 and appendix 4 . The extraction of the core data structures and the implementation of a virtual database table is shown in 6.3.5. The database table contains virtual values based on empirical studies of real NPP and their properties. Within the scope of the requirement analysis of a real dismantling and decommissioning project scenario these structures can be applied on a meta level.

(3) Formulation of a procedure model, based on the given NPP.

$\rightarrow$ The procedure model is described in the chapters 4.4 .1 to 4.4 .3 and 4.5 to 4.10 . Further on, the data structures are derived in orientation on the case study presented in chapter 5 in order to specify the model declaration and the modeling of the database structure and content in chapter 6 . In 6.1 the whole project time table has been depicted containing all insights from the previous chapters.

(4) The capturing of the project structure, processes and time management is assisted by a professional project management tool (e. g. MS Project).

$\rightarrow$ The project structure is presented in chapter 5.2 based on a case study. A project plan is given in 6.2 and 6.3.7.

(5) Integration of the data basis and the process structure into R and AIMMS.

$\rightarrow$ The implementation of the model-based framework is carried out in the chapters 6.5 and 6.3. 
(6) Applying state-of-the-art optimization techniques (MOOP) on the empirical data

$\rightarrow$ The definition of the MOOP based on the framework is shown in chapter 4 and implemented in 6.5.

(7) Assessment and evaluation of results and discussion

$\rightarrow$ The assessment and evaluation of the results and discussion can be found in the chapters 6 and 7.

\subsection{CONCLUSIONS AND RECOMMENDATIONS}

The main difference between the presented approach for the minimization of total costs, risk and duration in this work and current practice is the mixture of the used methods and tools. As shown before in different parts of the dissertation the management methods and underlying IT-structures are suboptimal regarding the high complexity of the decommissioning and dismantling of NPP. Lean management techniques and methods of simultaneous engineering must be integrated to the conception of the decommissioning and dismantling of NPP, as proven by several sources in different chapters of the work and demanded by many experts. The combination of the traditional requirements of the decommissioning and dismantling of NPP and the techniques provided by lean management and simultaneous engineering, require a new thinking in management and OR. The interdisciplinary thinking needed to perform this combination of these management methods and OR-techniques call for state-of-the-art methods and tools to be tested and evaluated, in order to make a point on the advantages and disadvantages of new methods and techniques of the decommissioning and dismantling of NPP. The development of the presented framework and the implementation of the R-MOOP is an attempt to discover new ground on this terrain.

New ground broken in this work is of a multidisciplinary nature. In fact there are no related works, where the subject of decommissioning and dismantling of NPP is investigated as thoroughly as here, taking such a broad spectrum of cutting edge concepts, theories, methods and tools into account. 
To accomplish such a complex endeavor as the decommissioning and dismantling of NPP it is important to evaluate a broad spectrum of possibilities. Examining all the methods and concepts from an interdisciplinary perspective is unique. The usefulness of this work for further study by researchers and responsible persons is obvious. In no other officially accessible source are all cutting edge issues of decommissioning and dismantling of NPP brought together so comprehensively.

Focus was put on the feasibility of the requirements based on cutting edge tools introduced earlier in this work. The research of the requirements aided by the analysis of empirical data (see chapter 5) was also helpful in identifying a valid model.

Since the breadth of this research, analysis and evaluation was broad, it wasn't possible to execute the models on all of the software tools at our disposition. $\mathrm{R}$ was the preferable software and an implementation of a MOOP was successfully carried out on it. In a real project environment this implementation must be advanced using additional cutting edge knowledge and insights introduced from a theoretical perspective in this dissertation.

Besides the fact, that the application of the model-based framework couldn't be tested exhaustedly, other central concepts were not discussed which could potentially be helpful in carrying out the goals specified in this work, such as system theory for a more profound project management strategy, applied informatics for an additional and professional implementation of the model and interface specification, information technology integration, procedure models and iterative testing.

The literature research and data research were extensive and up to date. All potentially relevant and cutting edge approaches on the subject were identified, discussed and integrated into the solution put forth in this thesis. A comprehensive mathematical model for the realization of the objectives was deduced and applied. Following months of queries at providers, all accessible empirical data was gathered and a database model was built upon these data sets. The most common OR tools on the market - from proprietary to open source - were evaluated and offer reference points for future research. Aided by a state-of-the-art project management tool - MS Project 2013 - the documentation of the decommissioning and dismantling of a NPP based on a MOOP was carried out. 
New ground has been broken regarding the notable constellation, topicality and relevancy of the presented concepts, methods, tools and results. A critical evaluation of this thesis leads us to conclude that the results from an empirical point of view aren't as robust as anticipated due to the narrow scope of the data gathered from providers, the sensitivity surrounding the subject and the complexity and richness of the underlying concepts, methods and tools.

The first approach to the given objectives was to work out a proposal for the work almost two years ago. A broad literature review was next performed, with the goal of determining the related works and relevant case studies. Also the research in the proposal was focused on a first analysis of the social, political, technical, functional, economical and organizational perspectives. After the acceptance of the proposal I, the first parts of this work including the terminological and methodical foundations as project management, lean management, operations research and software tools were elaborated.

After the discussion of the terminological and methodical foundations, a theoretical consolidation and synthesis of the insights followed: Two state-of-the-art-models (Jones et al. 1998 and OMEGA) were brought together and merged together mathematically and organizationally (see chapter 4 and 6).

The developed framework on this basis was enhanced by real data from several case studies. The real data was used to extrapolate and simulate virtual data, leant on the real data. This data basis was integrated into a virtual database in order to have access by algorithms as part of the R-MOOP routine, and developed I to the next step of the work.

The main challenge was to find a software tool with high usability and good documentation. In the beginning phase, AIMMS seemed to be the best tool to use. But in the working process, $\mathrm{R}$ was the better choice due to an open conception, its popularity in the web, its high usability and its great documentation.

In the next step, all necessary process requirements were put together chronologically and all dependencies between processes and milestones specified. Especially regarding the implementation, all insights from the preceding chapters was integrated into a project schedule. 
As a result, the R-MOOP-routine was implemented with access to a virtual database table using an algorithm based on the mathematical model and the optimize()-function in R.

A further development - as lessons learned - of the R-MOOP, should include the following points if enough temporal and monetary resources are given and also a rich data basis can be provided:

1. Continuation and refinement of the project schedule in MS Project 2013 (processes and tasks)

2. Build out, expansion and refinement of the database structures, not only containing waste types and the properties introduced here, but also including processes, key performance indicators, staff properties, tasks, technological coefficients, costs, etc.

3. Advancement of the source code of the R-MOOP-program routine with algorithms, in order to capture the broader data basis. The OMEGA model can be very helpful here.

4. Advancement of the R-MOOP-Source-Codes with further methods with more optimization functionality, in order to implement the objectives regarding risk and radioactivity.

5. In order to implement these advancements (1-4) a new requirement analysis should be performed on the new insights and knowledge. The current version of the R-MOOP should be considered as a rapid-prototype and not an evolutionary one. This doesn't mean that all the implementation done here was for nothing. Instead the new insights and knowledge should lead to a new approach of developing an information system for the discussed domain. Especially in order to accomplish the complexity in software development, state of the art methods such as the unified modeling language (UML) should be used in order to fulfill all needs of modeling and implementing in each phase. This includes the modeling of abstract concepts as classes, modules, processes, activities, sequences, components and their deployment in distributed networks using databases, networks, server, clients, interfaces etc. 
Abstract concepts of software development as design patterns etc. should be integrated into the approach, too.

\subsubsection{Contribution to the body of knowledge}

Regarding the totality of the techniques and methods discussed here, the contribution to the body of knowledge is it to provide a framework to reduce the total financial expenditures and minimizing operational risks at the same time. Beside of the advantages for the government, accounting, valuation and investment perspectives, establishing a tailored framework allows a comprehensive risk assessment by increasing transparency between each instances involved. Also a harmonization at the EU level is achievable by increasing the transparency of an improved information sharing and reporting across the EU, in case of a situation in which a plant has to be shut down. The contribution of an IT-based framework is, that it can potentially improve the quality of the reporting system between all these instances significantly.

In other words the contribution of this work is it to present the hard facts of the decommissioning and dismantling of NPP, such as functional, economic, technical and OR-based issues. Further the investigation of state-of-the-art-methods contribute to the reduction of complexity, such as the presentation of solutions for the integration of project management, lean management, simultaneous engineering and mathematical concepts and applied informatics as well. The presentation of detailed facts to the decontamination and dismantling of NPP, equipment and facilities, the demolition of buildings and structures, site remediation and the management of waste, extracted by widespread researches from case studies, was another contribution to increase the knowledge and the sensibility to the business logic of the regarding domain for scientifical and market-driven purposes.

The presented project OMEGA and the integration of its ideas as a source of knowledge to develop an own framework is also a benefit for the decommissioning and dismantling of NPP in general, since OMEGA is a powerful tool to build on. The conception of the framework presented in this work can be extended by the further integration of concepts developed by the OMEGA project. 
Due to the lack of storage capacity and the fact, that waste is sometimes stored in potentially unsafe storage units, waste management is a chief factor within the decommissioning and dismantling of NPP. This is one of the reasons, why this issue was focused here centrally. The goal was it to increase the available knowledge to this subject from an interdisciplinary viewpoint. Also the subsequent work phases necessary to achieve this goal were defined within the context of the project scheduling, as the procedures of project preparation (background determination, project development and strategic planning), pre-scheduling, design and approval planning, execution preparation (planning, assignment preparation and participation during the assignment), execution (project monitoring), project conclusion (project support and documentation) etc.

Another contribution of this work was it to give a sound stimulus to interdisciplinary thinking from the viewpoints of several approaches to manage the requirements of the focused subject and to show the importance and relevancy of interdisciplinary thinking. The research of up-to-date empirical data for designing a virtual NPP and its integration into the developed framework, the definition and description of a procedure model, its capturing in a project structure, processes and a professional project time management, assisted by a state-of-the-art project management tool, the integration of the data basis and the underlying control structures mapped with R and an examination of OR tools, such as AIMMS etc., the application of optimization techniques (MOOP) - leant on Jones et al. 1998 - to the given empirical data and assessment and evaluation of results and discussion, are the core issues, elaborated in this work, contributing to accelerate and support the world-wide research around the subject of the decommissioning and dismantling of NPP. Therefore the most significant and relevant concepts, methods and tools, based on an in-depth evaluation, were presented here, merged in a unique framework in order to support academic research and market developments. The efficiency of these methods presented here is especially attributed to lean methods and state-of-the-art tools. In difference to this fact, traditional plant management systems in NPP are voluminous and mostly belong from an IT point of view to another era, as many studies show. Since the IT system landscape in NPP is mainly a relict from an earlier era, also the knowledge needed to run and understand these systems is not up-to-date. 
Incompatibilities between those hardware and software systems and more efficient modern tools are difficult to handle. Since external know how must be integrated into the decommissioning and dismantling process of NPP, this external knowledge must be compatible to the structures and processes in NPP. For example the database systems and interfaces used in NPP require special know how, which is hard to elaborate for external consultants and developers, as the research for this work has shown.

Due to a high sensibility of the given branch, the technological knowledge transfer between internal and external experts is limited. The methods used in the R-MOOP belong to an open-source driven paradigm of developing information systems based on collective knowledge instead of know-how locked up in closed structures. Of course it is not necessary and also not recommended to open up the security structures of the hardware and software architecture in NPP, nevertheless the management of the businesses processes and the IT systems should be open for new and lean designs, as introduced in this work, in order to evaluate the pros and contras. Only this way the processes underlying the decommissioning and dismantling process of NPP can be optimized. 


\subsubsection{Future Research}

In the future decommissioning activities have been performed worldwide. Some of these projects are under way and some have to be projected in the future ${ }^{344}$. Different types of facilities are currently in operation, have been permanently shut down, are currently undergoing decommissioning or have already undergone decommissioning ${ }^{345}$. As discussed in this thesis the shutdown of nuclear power plants includes besides the real dismantling process the key factor of waste management and the transport of radioactive waste to the different states of storage, treatment and disposal. The transport of radioactive waste is a procedure with enormous risks (see chapter 4.9). Some highactivity types of waste require for example shielding during the transport and also other special techniques are necessary. The subject around the transport of radioactive waste is a scientifical area for its own and can't be discussed in full range, but the core concepts will be presented as next, leant on a publication of the Committee on Transportation of Radioactive Waste (CTR). The CTR (2006) published a work called "Going the Distance", discussing any health and safety risks regarding the radiological transport. In this publication they discuss core issues such as "Transportation Package Safety", "Transportation Risk" etc. Regarding the transportation package designs and regulations they recommend (CTR 2006, p. 55)

"1. Prevent an unsafe configuration (i.e., accidental criticality) of spent fuel.

2. Prevent or limit the release of radioactive contents.

3. Limit dose rates on external package surfaces to acceptable levels."

Also they present three types of packages (CTR 2006, p. 59)

- "Type A packages are designed for transport of materials of limited radioactivity - for example, uranium hexafluoride and fresh nuclear fuel.

- Type B packages are designed for transport of larger quantities of radioactive material including spent fuel, high-level waste, and mixed oxide fuel.9

\footnotetext{
${ }^{344}$ see IAEA (2004b), p.2ff.

${ }^{345}$ see IAEA (2004b), p.4ff.
} 
- Type C packages are designed for air transport of quantities of radioactive material exceeding a defined (large) threshold including, for example, plutonium and mixed oxide fuel."

Regarding the transportation risks they discuss the dimensions "Scenarios", "Probability" and "Consequences" (CTR 2006, p. 110)

- "Scenarios representing transport conditions that can lead to an exposure to ionizing radiation from either routine operations or severe accidents,

- Probability expressing quantitatively the likelihood that a scenario will actually occur during one shipment; it is expressed as a dimensionless quantity that ranges in value from 0 (impossible) to 1 (certain) - for example, a probability of 0.5 indicates that a particular scenario has a 50 percent chance of occurring, and

- Consequences describing the undesirable results if the scenario does occur: for example, undesirable health effects."

Also the CTR lists six operational issues regarding the transport of radioactive waste (CTR 2006, p. 216):

"1. Mode (road vs. rail) for transporting spent fuel and high-level waste to a federal repository

2. Route selections for transport to a federal repository

3. Use of dedicated trains for transport to a federal repository

4. Acceptance order for commercial spent fuel transport to a federal repository

5. Emergency response planning and training

6. Information sharing and openness" 
All these concepts must be considered to fulfill the requirements of the transport of waste from the NPP construction site to the facilities of storage, treatment and disposal. Further information can be extracted using this reference by the CTR and the numerous references used in this source. This work step can be performed in a real project scenario or a following scientifical work in future.

The relevancy of the chosen subject is also noticeable regarding the enormous number of NPP to be shut down in the near future, accelerated by the unhappy events in Fukushima.

Furthermore, according to Kennedy (2013) 12 NPP are on the chopping block. Due to Kennedy, Mark Cooper (a senior fellow for economic analysis at the Vermont Law School's Institute for Energy and the Environment) says

"recent changes in America's energy landscape have sent shock waves through both the nuclear industry and Wall Street (...) And he notes that 38 reactors in 23 states are at risk of being shut down before the end of their expected operational lives. These aging reactors are most at risk of an early demise as the nuclear power industry struggles to compete in America's new energy landscape.”346

In the next years in Europe and in USA a huge number of nuclear power plants focussed on PWR (pressurized water reactor) and BWR (boiling water reactors) will be shut down. In Europe in 12 different countries approximately 50 reactors of nuclear power plants have to be shut down until $2025^{347}$. In the USA in the same time period 65 reactors ${ }^{348}$. Therefore the whole process of the decommissioning and dismantling of facilities will take decades of time and generations of engineers and scientist will be involved. Especially regarding the great number of NPP to be shut down in the next years, lean management methods and therefore cost-minimized approaches for the decommissioning and dismantling of NPP are of great significance for the social welfare regarding the gain of costs, due to the large number of NPP to be shut down in the next years. The need for the research of alternatives for established project management methods and OR practices in NPP is so high, since the given budget must be provided for much more

\footnotetext{
${ }^{346}$ see Kennedy, B (2013)

${ }^{347}$ see Irrek (2007), p. VII

${ }^{348}$ see IAEA (2004b), Annex I - NUCLEAR POWER PLANTS
} 
decommissioning and dismantling projects of NPP, than expected just a few years ago, before the "Post-Fukushima-era".

In the future much more research must be done to slim down processes and structures in NPP and within the decommissioning and dismantling projects of NPP, without increasing the risks. In order to perform a cost-minimized transport between the states "storage", "treatment" and "disposal" it is necessary to calibrate the amount and type of waste to be transported, with the vehicles and transport methods that are provided.

For a detailed declaration of how to transport waste optimally between the states, it is necessary to analyze case studies and related works focusing the transport of radioactive waste. As mentioned before, the source from the CTR is a good start to elaborate the transport issue of waste management more detailed. 


\section{REFERENCES}

Ackoff, R.L. (1979). The Future of Operational Research is Past, Journal of the Operational Research Society 30, 93-104.

AIMMS (2012a). AIMMS Homepage. Paragon Decision Technology and Partners. http://www.aimms.com/aimms/

AIMMS (2012b). AIMMS Optimization modeling. Manual. Paragon Decision Technology and Partners.

http://www.aimms.com/aimms/download/manuals/aimms modeling.pdf

AIMMS-Help (2013). Help Section of the AIMMS Software Version 3.

Anderson, R.N.; Boulanger, A.; Johnson J.A.; Kressner A. (2008). Computer-Aided Lean Management for the Energy Industry, PennWell Books, Tulsa, Oklahoma.

Anonym (2010). Kosten-Nutzenanalyse der Nutzung von Atomenergie - Bachelorarbeit, Wirtschaftswissenschaftliche Fakultät Julius-Maximilians- Universität Würzburg.

AREVA NP GmbH (2008). Verpackungspläne. Beladung/Bauteile/Zerlegegut/Packhilfe/ Gebindespezifisches/Aktivitätsinventar/Einbauhreihenfolge/Maße, 2008.

AREVA NP GmbH (2011). Dismantling methods, p.147-193.

Armstrong, A. (2009). Optimization Routines Available as an R Package, I-Programmer. http://www.i-programmer.info/news/90-tools/2711-nag-optimisation-routinesavailable-as-an-r-package.html

Arnold, L., (1992). Windscale 1957 Anatomy of a Nuclear Accident, Macmillan.

Balle, M.; Balle, F. (2009). The Lean Manager, Lean Enterprise Institute, Cambridge, MA. 
Basadur, M.; Ellspermann, S.J.; Evans, G.W. (1994). A New Methodology for Formulating Ill-Structured Problems, OMEGA 22, 627-645.

Bayliss, C.; Langley, K. (2003). Nuclear Decommissioning, Waste Management, and Environmental Remediation, Elsevier Butterworth Heinemann, Burlington, MA.

BFS (Bundesamt für Strahlenschutz) (2007). Schacht Konrad - Genehmigtes Endlager für schwach-und mittelradioaktive Abfälle, Salzgitter. http://www.bfs.de/transport/endlager/Konrad/kosten/kosten:konrad.html

Bochud, F.O.; Laedermann, J.P.; Bailat, C.J.; Schuler, C. (2009). Monte Carlo Simulation of a Clearance Box Monitor used for NPP Decommissioning, Health Physics, 96 (5), 575-586. Doi: 10.1097/01.HP.0000343163.81687.86.

Bonavigo, L.; De Salve, M.; Zucchetti, M.; Annunziata, D. (2010). Contamination spread during decommissioning of a NPP, Fresenius Environmental Bulletin, 19 (10b), 2444-2448.

Bond, A.; Palerm, J.; Haigh, P. (2004). Public Participation in EIT of NPP Decommissioning Project, A Case Study Analysis, Environmental Impact Assessment Review, 24 (6), 617-641. Doi:10.1016/j.eiar.2004.02.002, 2004.

Books LLC (2010). Nuclear Power Stations: Nuclear Power, List of Nuclear reactors, Nuclear Decommissioning, List of Nuclear Power Stations, List of Power Reactors, General Books LLC.

Burger, J. (2011). Stakeholders and Scientists, Achieving Implementable Solutions to Energy and Environmental Issues, Springer, pg. 211-228, NY.

Bushart, S.P.; Kim, K.; Naughton, M. (2010). Program Change Management During NPP Decommissioning, ASME Conference Proceedings 2010, 1, 393-398. Doi: 10.1115/ICEM2010-40129, Tsukuba, Japan.

Bushart, S.P.; Kim, K.S.; Naughton, M.; Mcgrath, R. (2010). EPRI NPP Decommissioning Technology Program, ASME Conference Proceedings 2010,1, 399-401. Doi:10.1115/ICEM2010-40130, Tsukuba, Japan. 
Bylkin, B.; Pereguda, V.; Shaposhnikov, V.; Tikhonovskii, V. (2011). Composition and structure of simulation models for evaluating decommissioning costs for nuclear plant units, Atomic Energy, 110 (2), 77-81. Doi: 10.1007/s10512-011-9394-4.

Chard P.M.J., Croft S., Adams J.M.,. Bond D.S AND. Fisher J.C. (1999). Development of a residual reactivity monitoring technique, Sixth International Conference on Nuclear Criticality Safety (ICNC'99), 20-24 September, Versailles, France.

CRAN (2013). Manual of the TunePareto-Package. http://cran.r-project.org/web/packages/TunePareto/TunePareto.pdf

Cross, M.T., Mullineaux, W.C., Jennings, J.C., Ingamells, W.A., Ferris, M.L. (2005). Resolving the technical challenges in the decommissioning of an accident damaged reactor - Windscale Pile 1, WM'05, February 27 - March 3, Tucson, Arizona, USA, paper 5034.

CTR (2006). Going the Distance? The Safe Transport of Spent Nuclear Fuel and HighLevel Radioactive Waste in the United States Committee on Transportation of Radioactive Waste (CTR). Nuclear and Radiation Studies Board. Transportation Research Board. THE NATIONAL ACADEMIES PRESS http://www.nap.edu/catalog.php?record id=11538

Daniska, V.; Laraia, M. (2009). WM2009 Conference, March 1-5, 2009, Phoenix, AZ. Focus on International Co-operation in D\&D Cost Estimations for Research Reactors and the Role of the IAEA in It - 9363.

Emiliani, B. (2007). Real Lean, Understanding the Lean Management System, CLBM LLC, Wethersfield.

EnBW (2006). Annual Report

http://www.yumpu.com/en/document/view/8687265/annual-report-2006financial-report-enbw 
E.ON (2006). Annual Report - E.ON AG

http://www.eon.com/content/dam/eon-

com/en/downloads/e/EON_Annual_Report_2006.pdf

ESA (European Space Agency) (2013). What is concurrent engineering? htt://www.esa.int/SPECIALS/CDF/SEM1OF1P4HD_0.html p

Evans, G. (2012). Multiobjective Decision Making Under Risk and Uncertainty with Applications in Industrial Engineering, Business, and Medical Decision Making, University of Louisville Simulation modeling, optimization, multi-objective decision analysis, logistics and project management.

Evans, J.R. (1991). Creative Thinking in the Decision and Management Sciences, Cincinnati, OH: South-Western Publishing, Cincinnati, OH.

GAO (General Accounting Office) (2003). United States General Accounting Office (GAO): Nuclear regulation NRC needs more effective analysis to ensure accumulation of funds to decommission NPP, Diane Publishing.

Gentes, S.; Freund, C. (2009). Implementation of Lean Management to the Decommissioning of Nuclear Facilities, Institute for Technology and Management in Construction, Technology and Management for the Decommissioning of Nuclear Facilities, Karlsruhe.

Graham, S., Patel, N., Jennings, J., Simpson, K.A. AND Cross, M.T. (2006). A Study of the Thermal Behaviour of Uranium Hydride in a Windscale Pile 1 Environment, Proc. 3rd Int. Conf. on Managing Nuclear Liabilities (MNL06), Manchester, UK.

Great Britain (2008). Parliament: House of Commons: Committee of Public Accounts: Nuclear Decommissioning Authority, Taking Forward Decommissioning, The Stationary Office, Victoria, London.

Greenberg, M.R.; West, B.M.; Lowrie K.W. (2009). The Reporter's Handbook on Nuclear Materials, Energy, and Waste Management, Vanderbilt University Press, pg. 93-98, Nashville, Tennessee. 
Hennicke, P.; Irrek, W.; Küppers, C.; Timpe C.; Viefhues, D. (2000). Kernkraftwerksscharfe Analyse, Wuppertal, Wuppertal Institut.

Heyer, R. (2004). Understanding Soft Operations Research: The methods, their application and its future in the Defence setting, DSTO Information Sciences Laboratory, Australia, p. 1-2.

Higashi, T.; Hattri, T.; Iwata, T.; Minato, H. (2010). Dose Assessment for Setting of EPZ in Emergency Plan for Decommissioning of NPP, ASME Conference Proceedings, 1, 339-345. Doi:10.1115/ICEM2010-40100, Tsukuba, Japan.

Hoppenbrock, V. (2008). Finanzierung der nuklearen Entsorgung und der Stilllegung von Kernkraftwerken, Nomos, Baden Baden.

Huebner, R. E. (1982). Decommissioning of nuclear power plants: how much will it cost? AACE Transactions.

Hunger, S.G. (2007). New Ways for Lean Management, A Principle Agent Model with Respect to Human Capital, VDM Verlag Dr. Mueller e.K.

Huntzinger, J.R. (2007). Lean Cost Management, Accounting for Lean by Establishing Flow, J. Ross Publishing, Fort Lauderdale, FL.

Hwang, C.-L.; Masud, A.S.M. (1979). Multiple objective decision making, methods and applications: A state-of-the-art survey. Springer-Verlag.

IEA (2007). World Energy Outlook, China and India Insights

IAEA (1998). Radiological characterization of shut down reactor for decommissioning purposes, International Atomic Energy Agency, Vienna, Austria.

IAEA, OECD/NEA, European Commission (1999). A Proposed Standardized List of Items for Decommissioning Purposes. Interim technical document.

IAEA (2004a). Planning, managing and organizing the decommissioning of nuclear facilities: lessons learned, IAEA-TECDOC-1394, Vienna, Austria. 
IAEA (2004b). Status of the Decommissioning of Nuclear Facilities around the World. Printed by the IAEA. Vienna.

IAEA (2005a). Financial aspects of decommissioning. Report by an expert group. IAEATECDOC-1476, IAEA, November 2005.

IAEA (2005b). Selection of decommissioning strategies: Issues and factors. Report by an expert group. IAEA-TECDOC-1478, IAEA, November 2005.

IAEA (2008). Innovative and Adaptive Technologies in Decommissioning of Nuclear Facilities. Final report of coordinated research project 2004-2008, Comparative analysis of decommissioning technologies based on model calculation and multiattribute analysis of specific decommissioning cases of nuclear facilities, Daniska, V., Rehak, I., Vasko, M., Kristofova, K., Bezak, P., Ondra, F., Zachar, M., Tatransky, P., Schultz, O., Necas, V., p. 217- 249.

Iguchi, Y.; Masami K. (2009). Risk-Informed Approach for the Regulations of Decommissioning of Nuclear Facilities, Journal of Engineering for Gas Turbines and Power, 132 (10). DOI:10.1115/1.4000624, Brussels, Belgium.

International Energy Agency IEA (2007). Key World Energy Statistics, International, Paris.

Irrek, W. (2007). Wuppertal Institute for Climate, Environment and Energy, Comparison among different decommissioning funds methodologies for nuclear installations, Final Report on behalf of the European Commission Directorate-General Energy and Transport, $\mathrm{H} 2$.

Irvine, M. (2011). Nuclear Power, A Very Short Introduction, Oxford University Press, New York, NY.

Iyer, P. S. (2008). Operations Research, New Delhi, Tata McGraw-Hill Publishing Company Limited. 
Jaggi, S., Batra, P.K. (2012). SPSS: An Overview.

http://www.iasri.res.in/iasriwebsite/DESIGNOFEXPAPPLICATION/ElectronicBook/Module\%201/6SPSS-overview.pdf

JCP (2009). Technical Report of the Decommissioning of the José Cabrera Plant. Allocated.

Jones, D.W. ; Redus, K.S. ; Bjornstad, D.J. (1998). A Non -linear Programming Model of Alternative Risk-Related Goals for DOE's Weapons Complex Cleanup: A Case Study of the Oak Ridge Site. The Joint Institute for Energy and Environment

Kennedy, B. (2013). 12 nuclear plants on the chopping block. MSN Money.

Kerber, B.; Dreckshage B.J. (2011). Lean Supply Chain Management Essentials, A Framework for Materials Managers, CRC Press, Boca Raton, FL.

Kim, H.S.; Hwang T.W.; Choi Y.B. (2010). Preliminary Estimation of Radioactive Waste Volume from Decommissioning of Korean Power Plant, Transactions of the American Nuclear Society 2010,103, 51-52. Doi: 8020 B, 35400019454744.0180.

Kleijnen, J.P.C. (2008). Design and Analysis of Simulation Experiments, Springer, New York.

Koshy, R., M.R. Apte., Emeritus (2012). Waste Minimization of Construction Materials on A Bridge Site (Cement and Reinforcement Steel) - A Regression and Correlation Analysis, International Journal of Engineering and Innovative Technology (IJEIT) Volume 2, Issue 1, page 6 http://ijeit.com/vol\%202/Issue\%201/IJEIT1412201207_02.pdf

Lucas, C. (2006). Practical Multiobjective Optimization. http://www.calresco.org/lucas/pmo.htm

Luyben, W.L. (2011). Principles and Case Studies on Simultaneous Design, WileyAiche, Hoboken, New Jersey. 
Mariano, C.E.; Morales, E.F. (2000). Distributed Reinforcement Learning for Multiple Objective Optimization Problems. Instituto Mexicano de Tecnología del Agua. Morelos/Mexico.

Marler, R.T.; Arora, J.S. (2002). Survey of multi-objective optimization methods for engineering. Struct Multidisc Optim 26, 369-395 (2004). Review article. Optimal Design Laboratory, College of Engineering, The University of Iowa, Iowa City, Iowa 52242, USA.

Martin, J.W. (2006). Lean Six SIGMA for Supply Chain Management, McGraw-Hill Professional.

Maskell, B.H. (2007). Lean Accounting, A Concise Guide to Lean Management, BMA Incorporated.

Masuda, Y.; Iguchi, Y.; Kawasaki S.; Kato, M. (2010). Status of the Support Researches for the Regulation of Nuclear Facilities Decommissioning in Japan, ASME Conference Proceedings 2010, 1, 441-448. DOI:10.1115/ICEM2010-40245, Tsukuba, Japan.

Mathworks (2013). Constrained Optimization. http://www.mathworks.de/de/help/optim/constrained-optimization.html

MATLAB (2012). Overview. http://www.mathworks.com/products/matlab/index.html

Microsoft Office (2013). The Project Map: Your road map to project management. http://office.microsoft.com/en-us/project-help/the-project-map-your-road-map-toproject-management-HA010214377.aspx?CTT=1

Miettinen, K. (1999). Nonlinear Multiobjective Optimization. Kluwer Academic Publishers. Norwell, Masachusetts.

Miller, L.M. (2010). Lean Team Management, How to Create Lean Management \& Lean Organization, RJ Communications, Annapolis, Maryland. 
MONK (2012). ANSWERS Software Package, MONK8, A Monte Carlo Program for Nuclear Criticality Safety and Reactor Physics Analyses User Guide for Version 8, ANSWERS/MONK (98)6, Serco Assurance.

National Research Council (U.S.) (2001). Committee on Long-Term Research Needs for Deactivation and Decommissioning at Department of Energy Sites: Research Opportunities for Deactivating and Decommissioning Department of Energy Facilities, National Academies Press, US.

Nuclear Decommissioning Authority (2011). Nuclear Decommissioning Authority Business Plan 2011-2014, The Stationary Office Limited, London.

Nuclear Energy Agency (2003). Organization for Economic Co-operation and Development and Nuclear Energy Agency: Nuclear Development Decommissioning Nuclear Power Plants, Policies Strategies and Costs, OECD Publishing, France.

OECD/NEA, EC, IAEA (1999). A Proposed Standardized List of Costs Items for Decommissioning Purposes.

Overman, E. (2013). A MATLAB Tutorial. Retrieved from http://www.math.osu.edu/ overman.2/matlab.pdf

Petschnig, S. (2009). Effects of Lean Management on Company Value, GRIN Verlag.

Plenert, G.J. (2007). Reinventing Lean, Introducing Lean Management into the Supply Chain, Butterworth-Heinemann, Oxford.

Plenert, G.J.; Dey R.; Berji, A. (2009). Lean Management Principles for Information Technology, Taylor and Francis, Boca Raton, FL.

Random.org. (2013). Random Number Service. Random Integer Generator. http://www.random.org/integers/

Reisenweaver, D.W. and the IAE (2004). Status of the decommissioning of nuclear facilities around the world, International Atomic Energy Agency, Vienna. 
REMZA (2012). Platform for Project Management. Synoptic units 8 \& 10: Managing a multimedia project. Remza - the agile alias of David Samuel Hollands. http://www.remza.co.uk/work/u8+10/planning/schedules.html

Ribbens, J. (2000). Simultaneous Engineering for New Product Development, Manufacturing Applications, John Wiley and Sons, New York, NY.

Richmann, A. (1997). Wirtschaftswelt Energie, Essen, Verband der Industriellen Energieund Kraftwirtschaft e.V.

Rittel, H.W.J.; Webber, M.M. (1973). Dilemmas in a General Theory of Planning. Policy Science 4 (2): 155-169.

R-manual. R (2013). A Language and Environment for Statistical Computing Reference Index. The R Core Team. Version 2.15.3 (2013-03-01). http://cran.r-project.org/doc/manuals/r-release/fullrefman.pdf

Roy, U.; Usher, J.; Parsaei, H. (Eds.) (1999). Simultaneous Engineering, Methodologies and Applications, CRC Press, Amsterdam.

R-Project (2013). What is $R$ ?

http://www.r-project.org/about.html

RWE AG (2006). Annual Report http://www.rwe.com/web/cms/en/280474/rwe/investor-relations/reports/2006/

Sabri, E.H.; Shaikh, S.N. (2009). Lean and Agile Value Chain Management, A Guide to the Next Level of Improvement, J. Ross Publishing, Fort Lauderdale, FL.

Schon, D.A. (1987). Educating the Reflective Practitioner: Toward a New Design for Teaching and Learning in the Professions, Jossey-Bass, San Francisco.

Schuh G.; Wiegand B. (2007). Lean Management Summit 4, Aachener Management Tage (7.-9. November 2007), Tagungsband, Apprimus Verlag, Aachen.

Sharma, S.C. (2006). Introductionary Operations Research, New Delhi, Discovery Publishing House. 
Shinkle, G.A.; Gooding, L.H.; Smith M.L. (2004). Transforming Strategy into Success, How to implement a Lean Management System, Productivity Press, New York, NY.

Simon, H.A. (1960). The New Science of Management, Harper and Row, New York.

Sjöblom, R.; Lindskog, S. (2004). An Applied Study of the Storage for Old Intermediate Level Waste at the Studsvik Site. SKI Report.

Taboas, A.L.; LaGuardia, T.S.; Moghissi, A.A. (Eds.) (2004): Nuclear Facilities Decommissioning Handbook. ASME.

Takashima, R. (2010). Construction, Decommissioning, and Replacement of NPP under Uncertainty. http://www.intechopen.com/source/pdfs/11564/InTech-

Construction decommissioning and replacement of nuclear power plants under_uncertainty.pdf

Trent, R.J. (2008). End-to-end Lean Management, A Guide to Complete Supply Chain Improvement. Fort Lauderdale, FL: J. Ross Publishing.

Tromans, S. (2010). Nuclear Law: The Law Applying to Nuclear Instillation and Radioactive Substances in Its Historic Context $\left(2^{\text {nd }} E d\right)$, Hart Publishing Ltd., Oxford, UK.

United States Department of Energy (2004). Study of Construction Technologies and Schedules, O\&M Staffing and Cost, Decommissioning Costs and Funding Requirements for Advanced Reactor Designs, Dominion Energy, Inc., Bechtel Power Corporation, and TLG Services. http://pbadupws.nrc.gov/docs/ML1018/ML101820632.pdf

Vasko, M. (2012). 2012:08. Deterministic Assessment of Future Costs for Dismantling (FA). Swedish Radiation Safety Authority.

Vattenfall Europe (2006). Annual Report http://www.vattenfall.com/en/file/Annual-Report-2006 8459912.pdf 
Watanabe, S.; Sakakibara, K. (2005). Multi-objective approaches in a single-objective optimization environment. College of Information Science \& Engineering. Ritsumeikan Univ. Kusatsu. Japan.

Weßelmann, Ch. (2007). Key World Energy Statistics, Paris, International Energy Agency (IEA)

White, M.G.; Thomas, R.G.; Ranellone, R. (1997). Decommissioning, decontamination and reutilization, worldwide experience - DD\&R, what does it mean, American Nuclear Society, Illinois.

Wickham, A.J., AND Rahmani, L. (2007). Graphite dust explosibility in decommissioning: a demonstration of minimal risk in Proc. Conf., 'Solutions for Graphite Waste: a Contribution to the Accelerated Decommissioning of GraphiteModerated Reactors', University of Manchester UK/IAEA, 21-23 March.

Wikipedia (2013): Multi-objective optimization. http://en.wikipedia.org/wiki/Multi.objective_optimization

Wincel, J.P. (2003). Lean Supply Chain Management. A Handbook for Strategic Procurement, Productivity Press, New York NY.

Yang, Y.Y.; Xu, Z.Q. (2012). JIT Quality Control System Design Based on Simultaneous Engineering Applied Mechanics and Material (110-116), 4872-4875, Trans Tech Publications, Switzerland, Doi: 10.4028/www.scientific.net/AMM.110-116.4872

Yoshino, K. (2010). Decommissioning Project, The first challenge in Japan, ASME Conference Proceedings 2010, 1, 449-453. DOI:10.1115/ICEM2010-40253, Tsukuba, Japan. 
APPENDICES

APPENDIX 1- MS PROJECT RESSOURCE PLAN

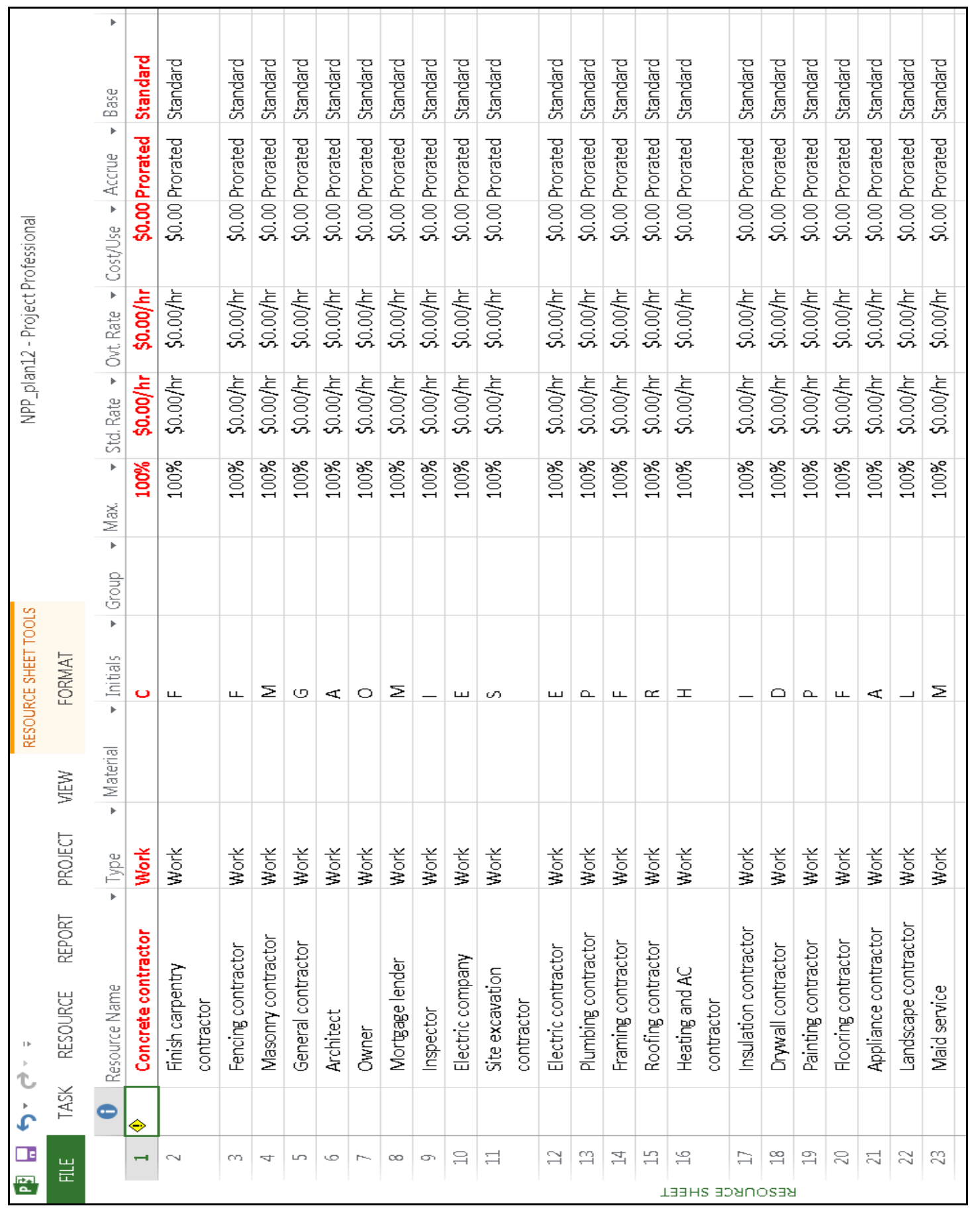

Figure 29: $\quad$ MS Project - Resource Plan 
APPENDIX 2- MS PROJECT CALENDAR VIEW - JANUARY 2014

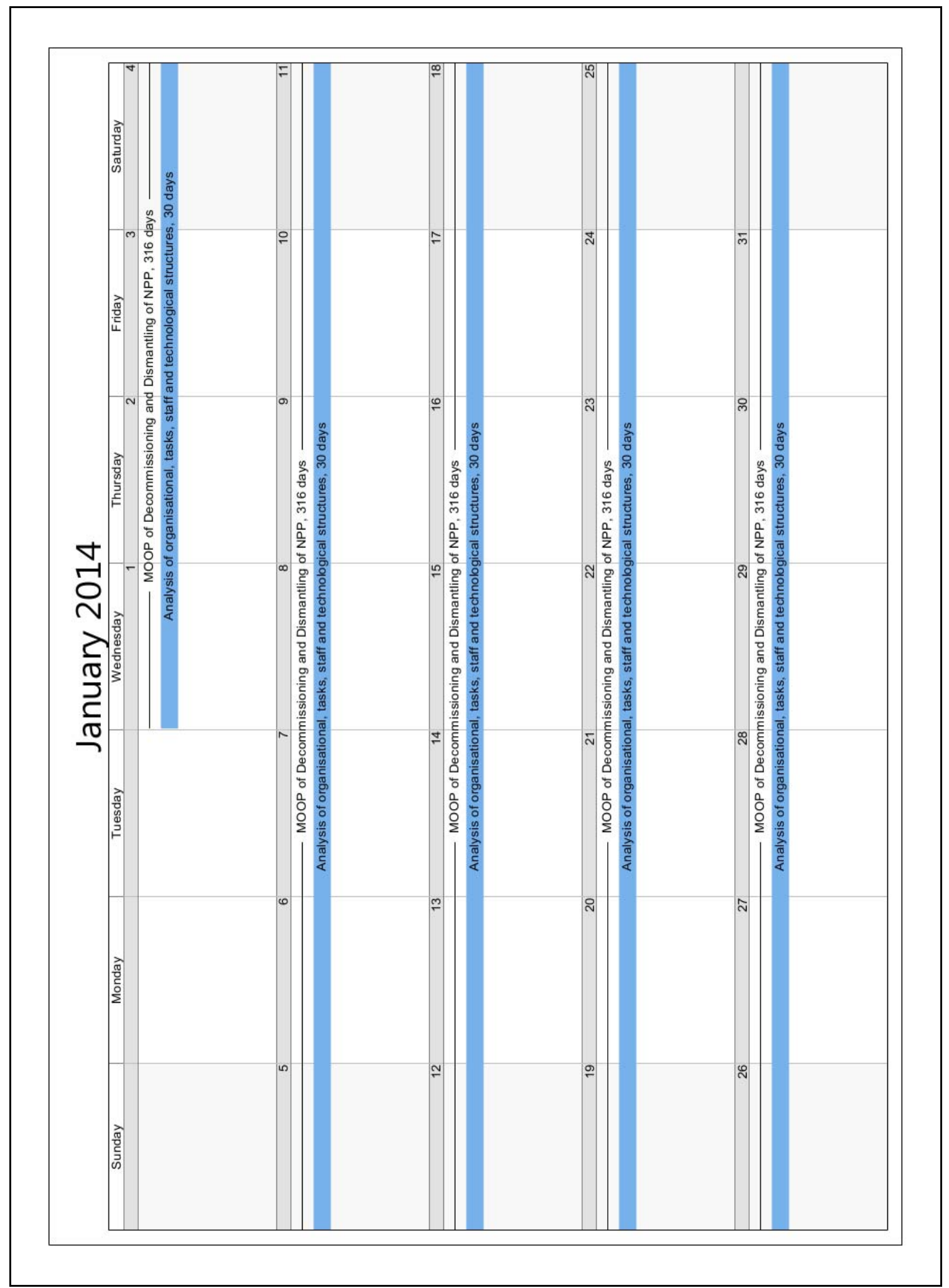

Figure 30: $\quad$ MS Project - Calendar View January 2014 
APPENDIX 2 A-MS PROJECT CALENDAR VIEW - FEBRUARY 2014

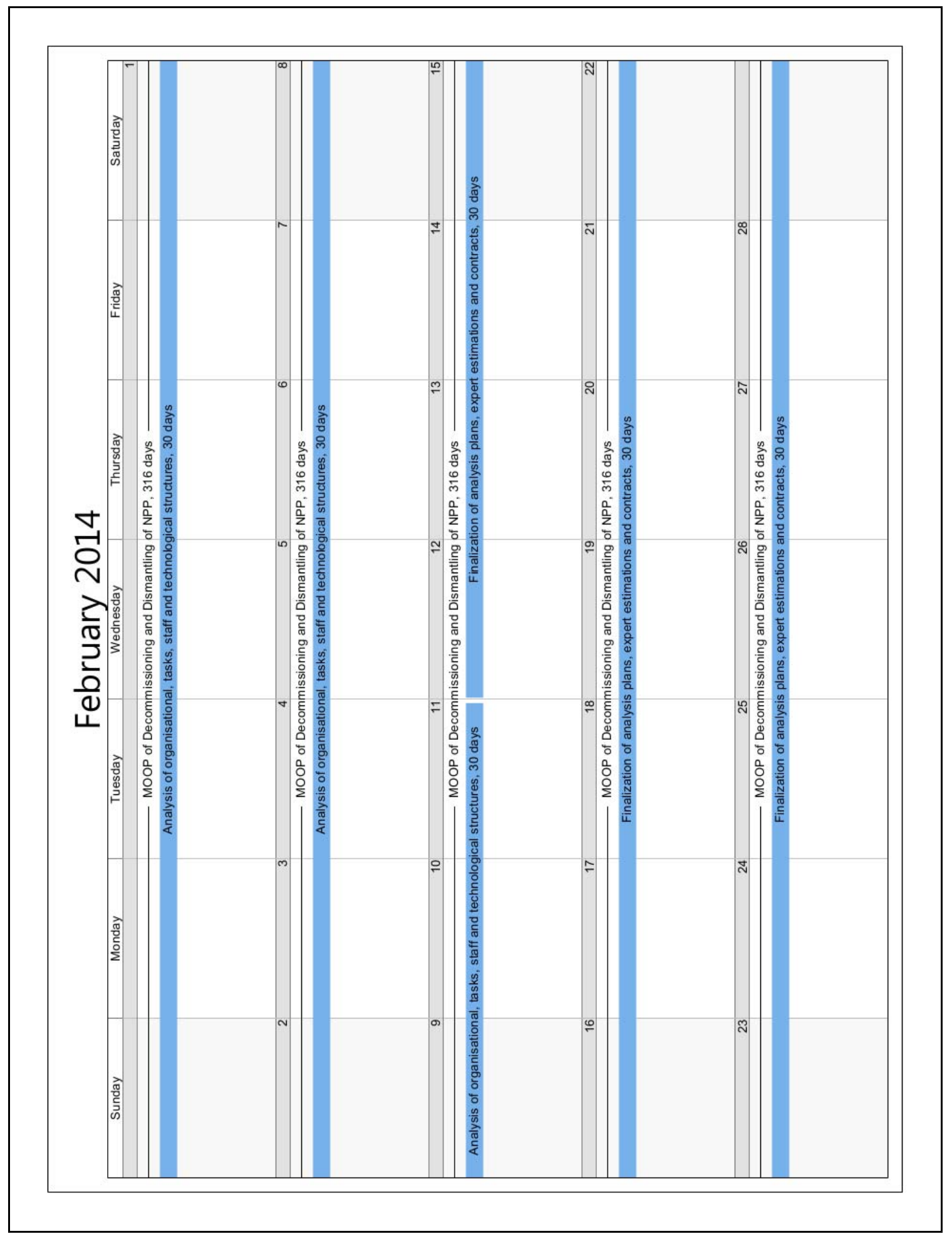

Figure 30a: MS Project - Calendar View February 2014 


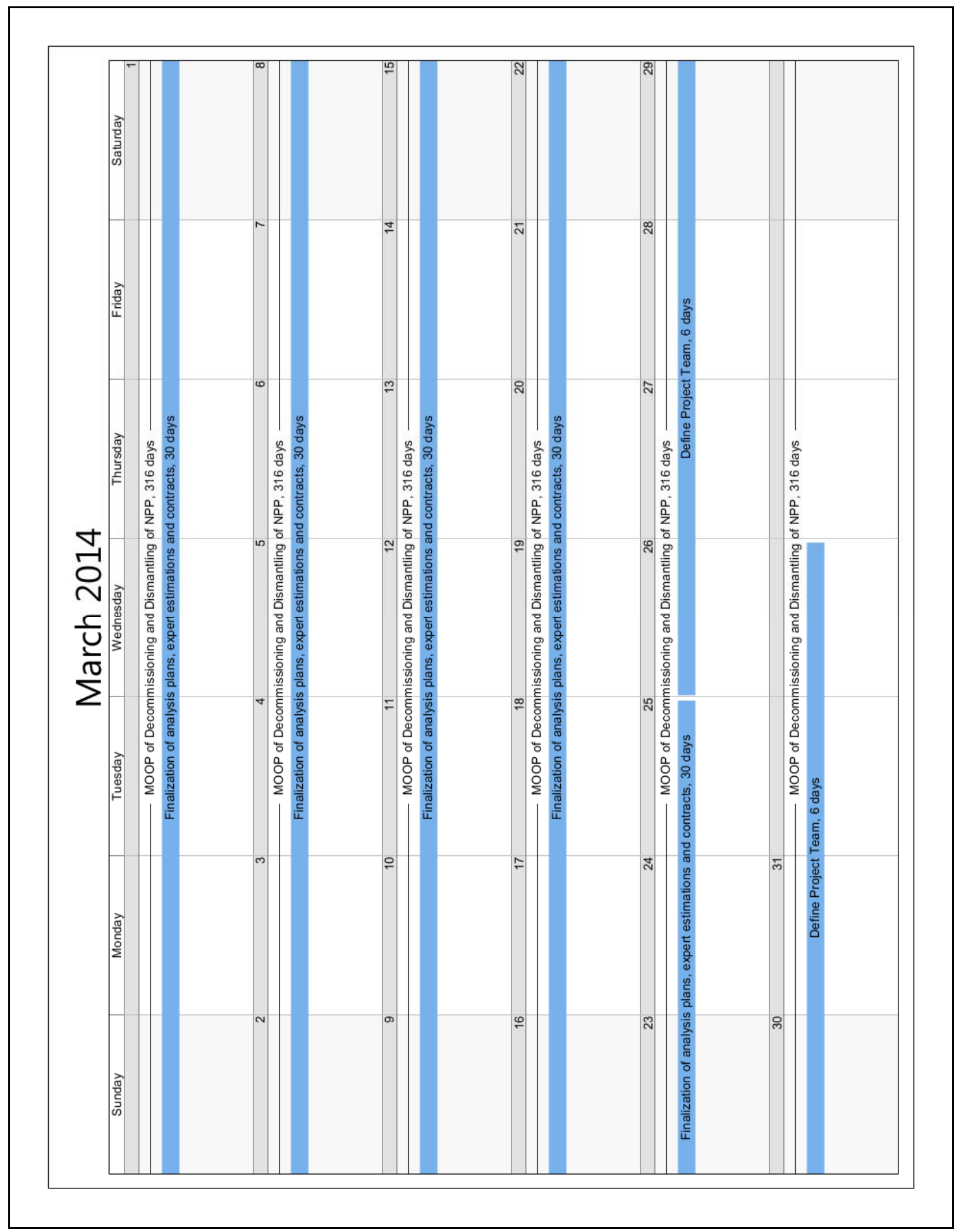

Figure 30b: $\quad$ MS Project - Calendar View March 2014 
APPENDIX 2 C - MS PROJECT - CALENDAR VIEW - APRIL 2014

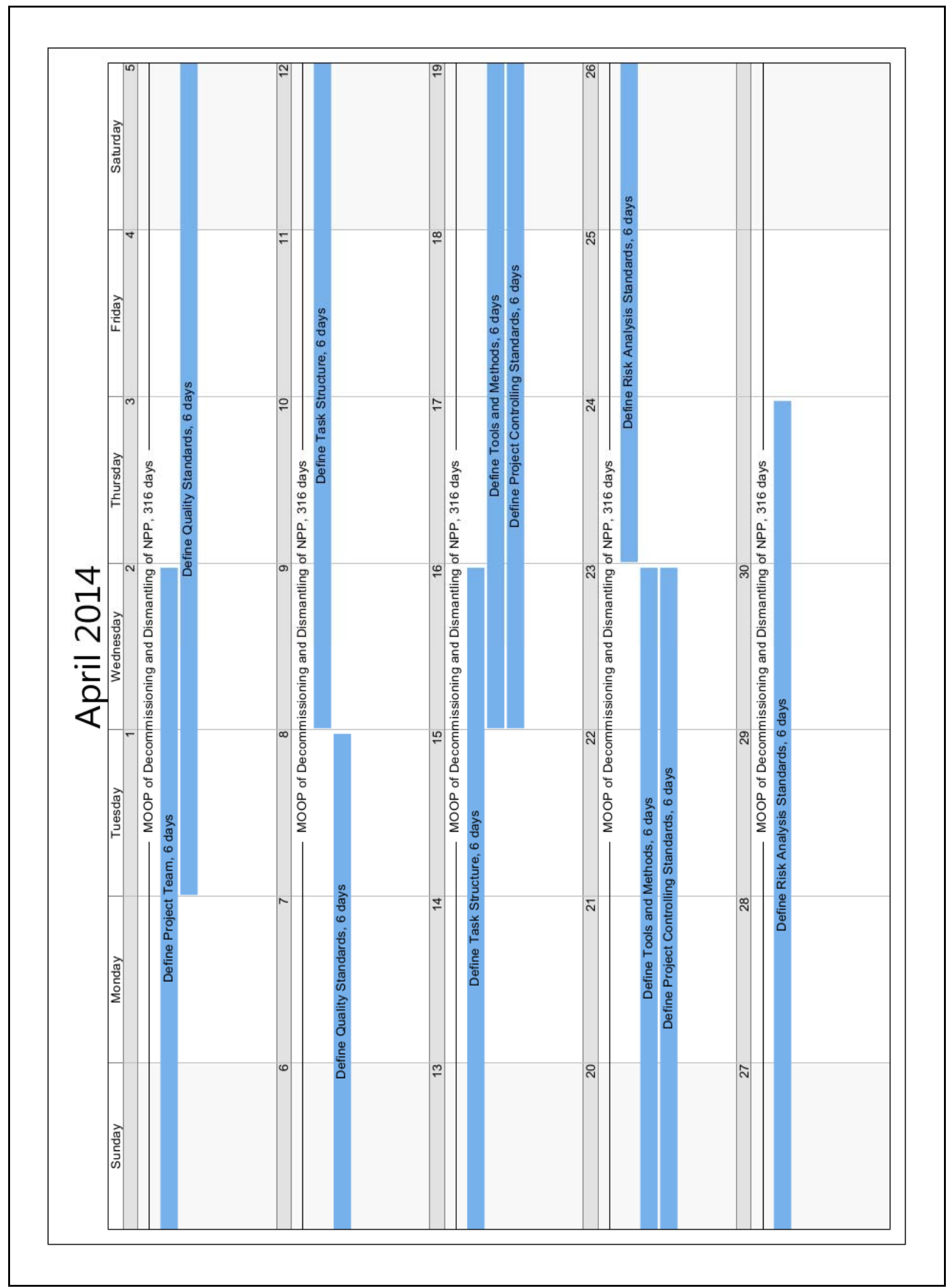

Figure 30c: $\quad$ MS Project - Calendar View April 2014 
APPENDIX 2 D- MS PROJECT - CALENDAR VIEW - MAY 2014

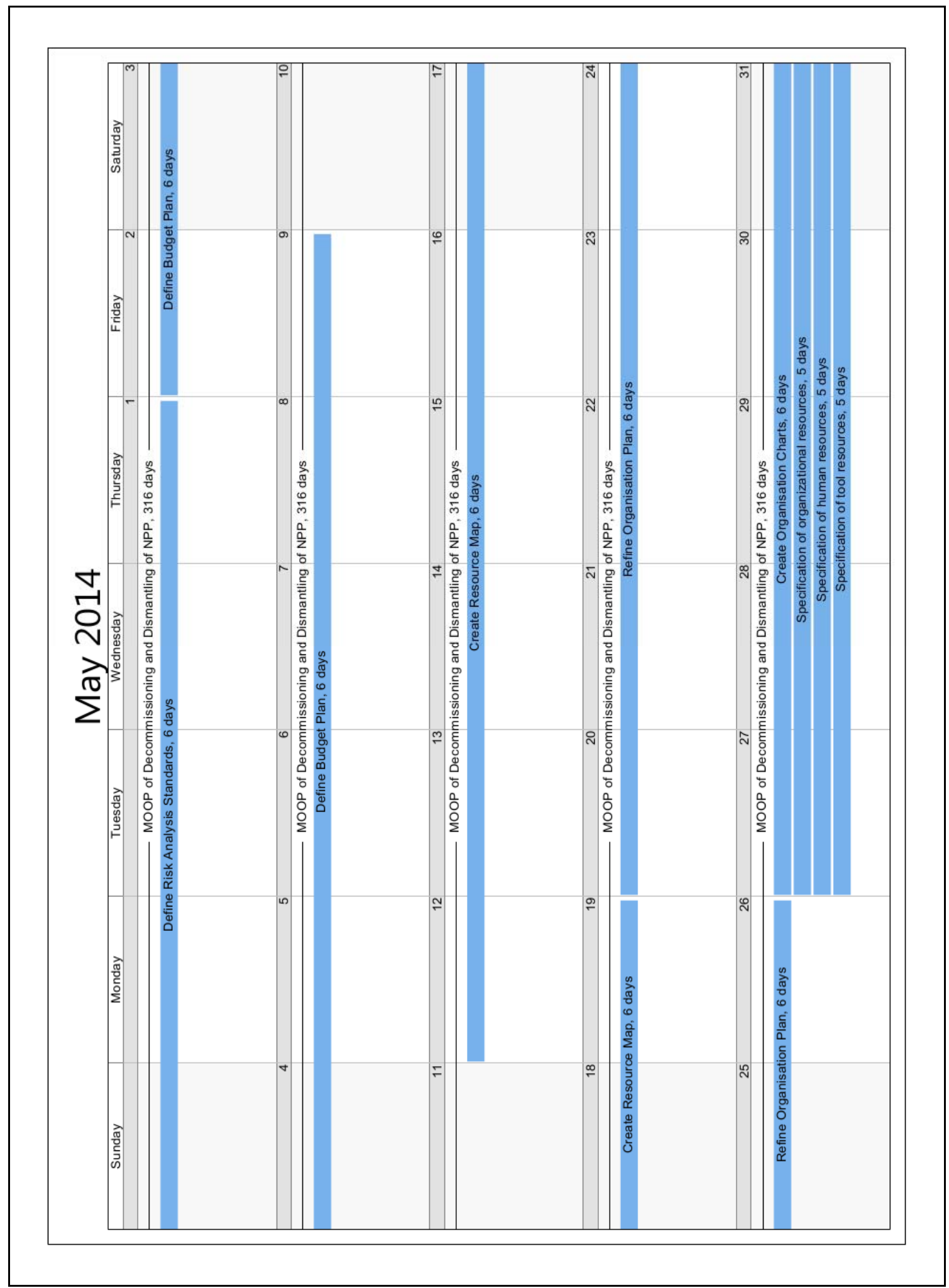

Figure 30d: $\quad$ MS Project - Calendar View May 2014 


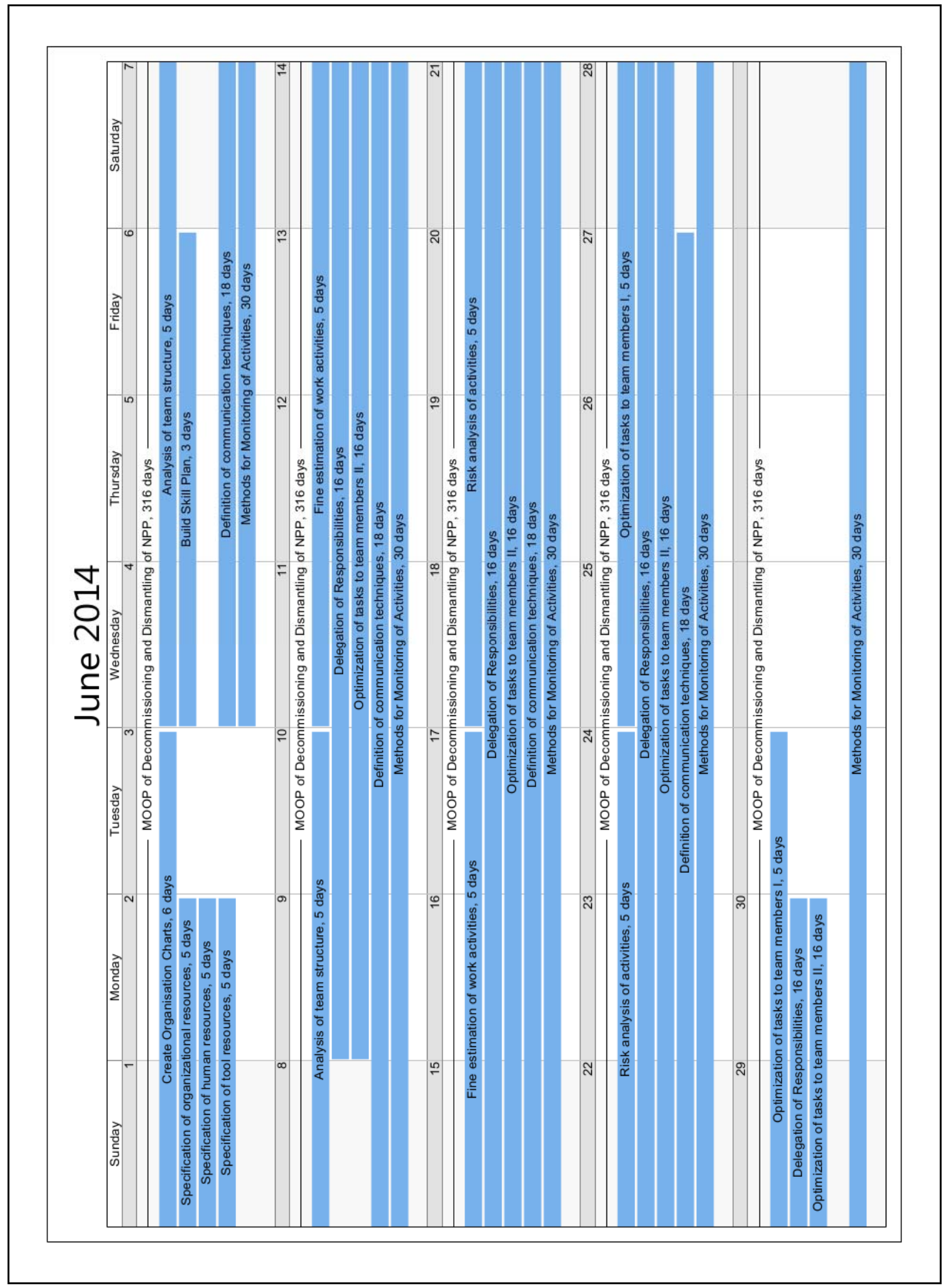

Figure 30e: $\quad$ MS Project - Calendar View June 2014 
APPENDIX 2 F - MS PROJECT - CALENDAR VIEW - JULY 2014

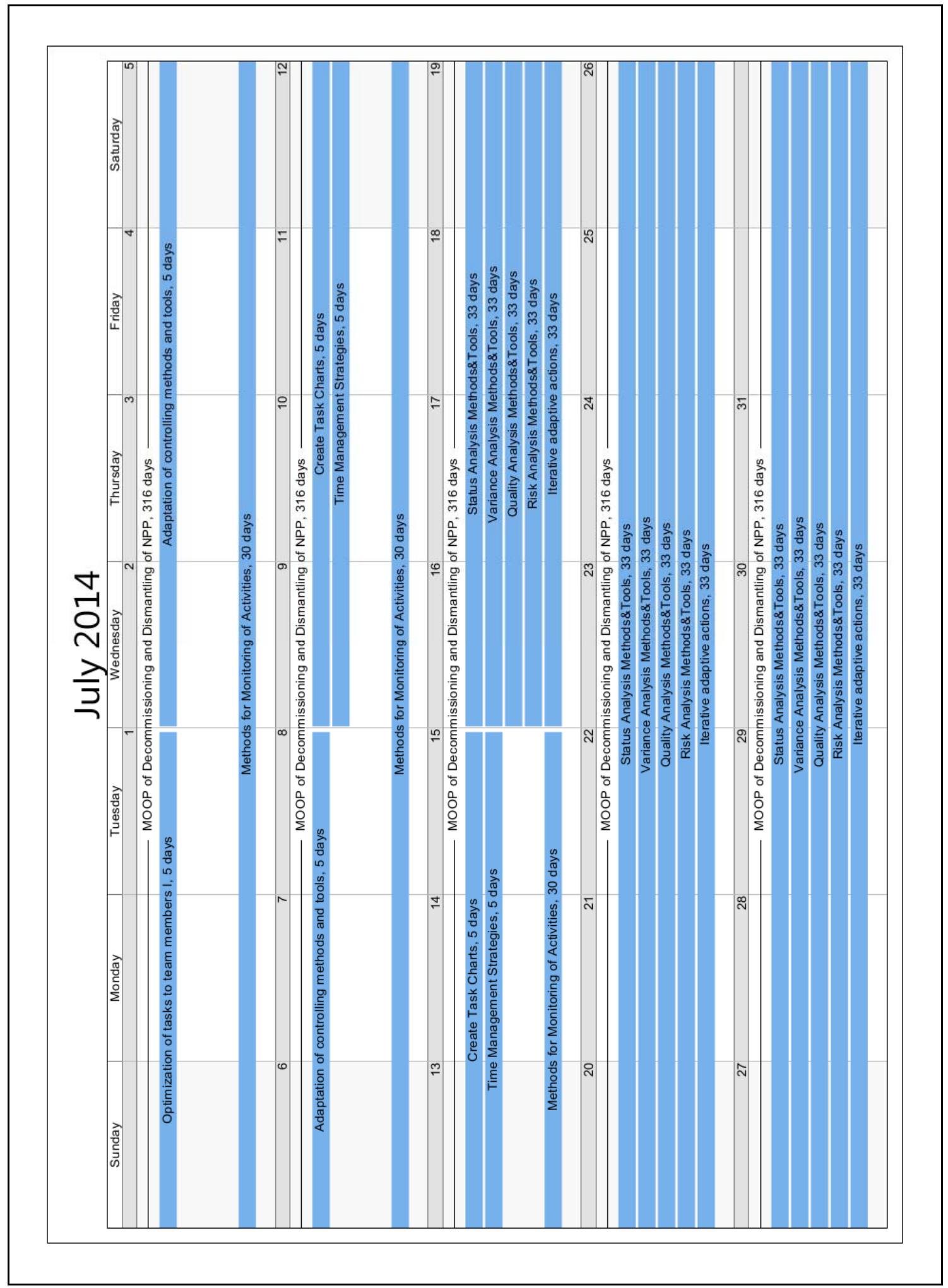

Figure 30f: $\quad$ MS Project - Calendar View July 2014 
APPENDIX 2 G-MS PROJECT - CALENDAR VIEW - AUGUST 2014

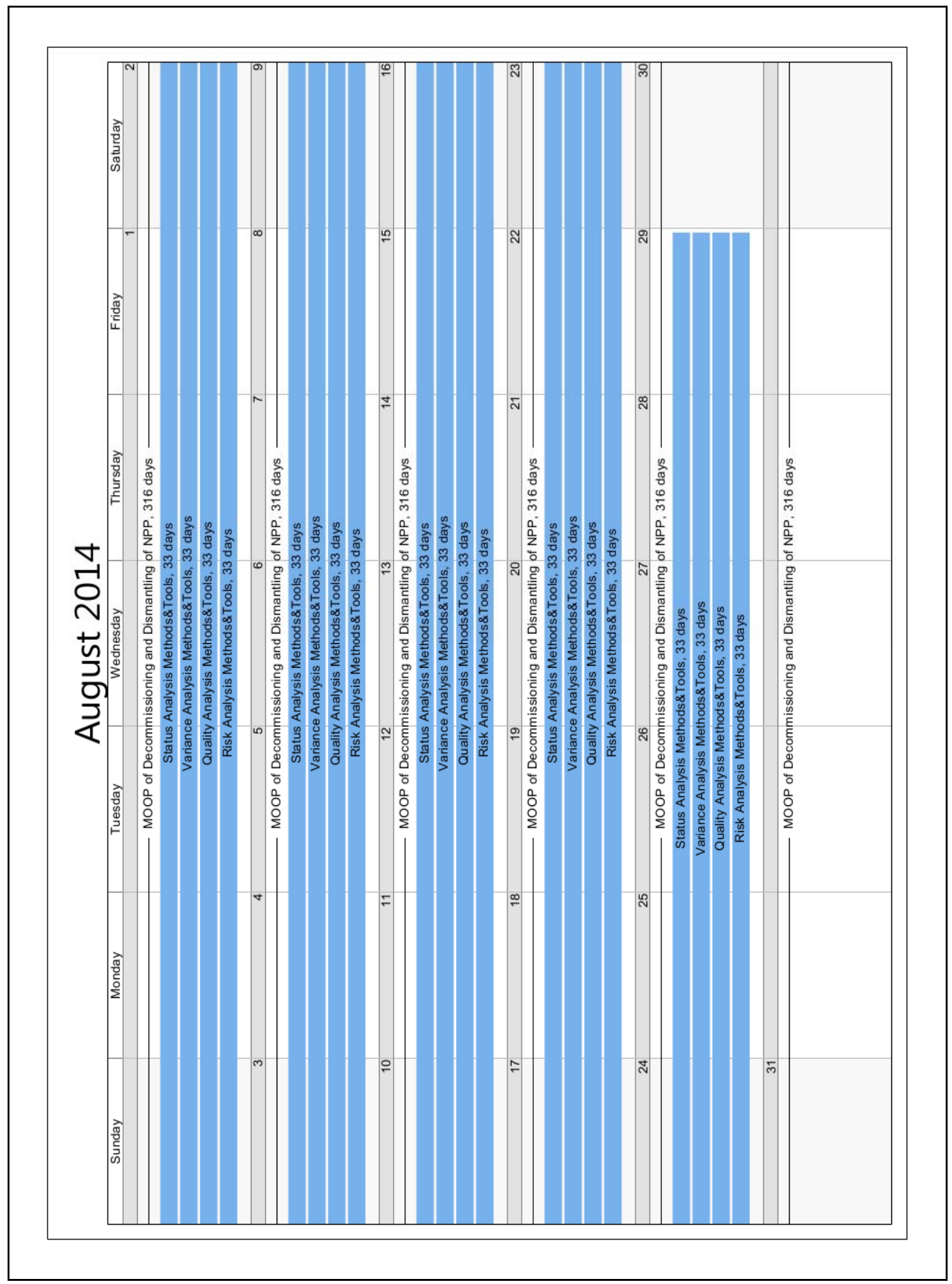

Figure 30g: $\quad$ MS Project - Calendar View August 2014 


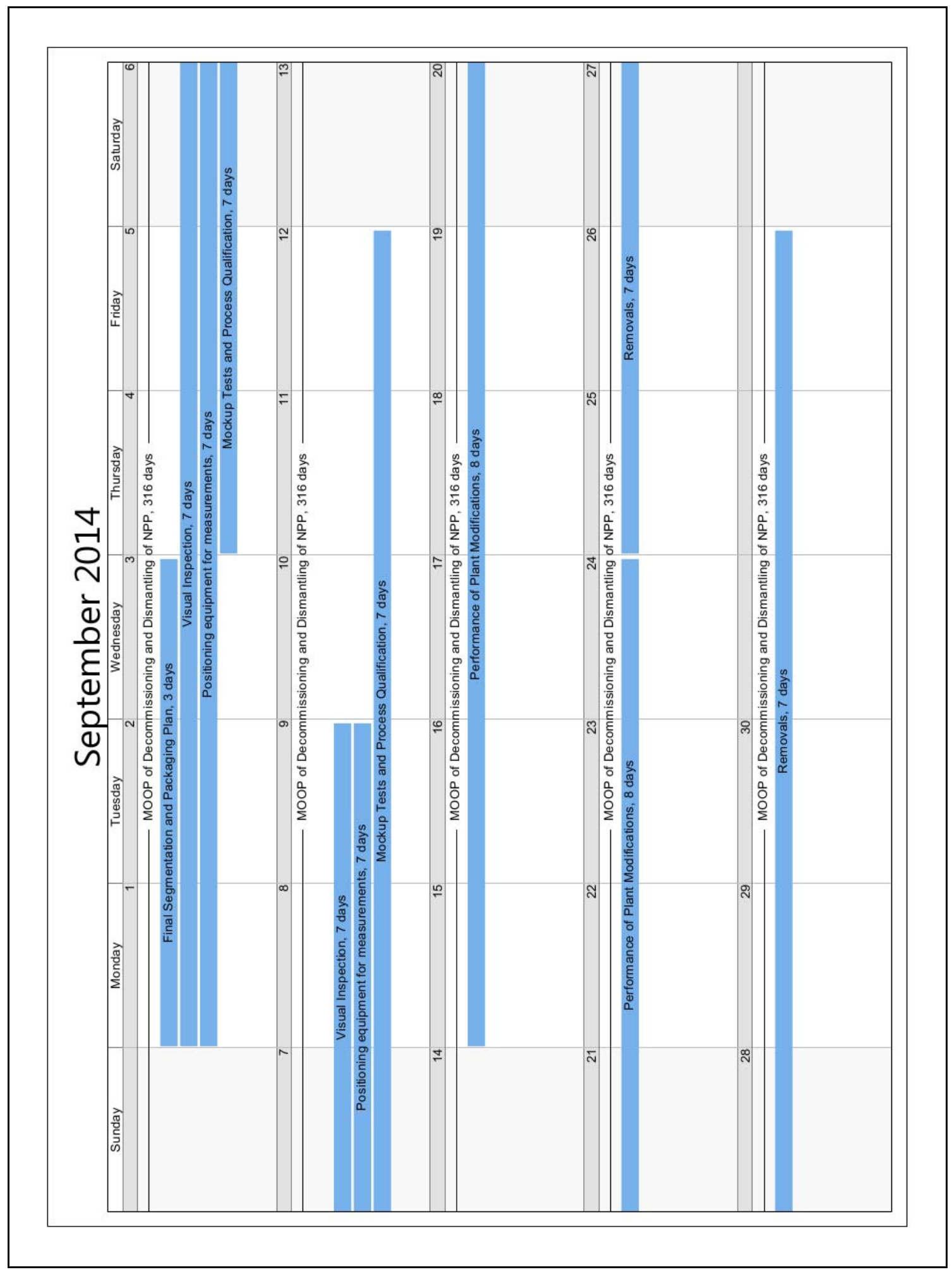

Figure 30h: $\quad$ MS Project - Calendar View September 2014 


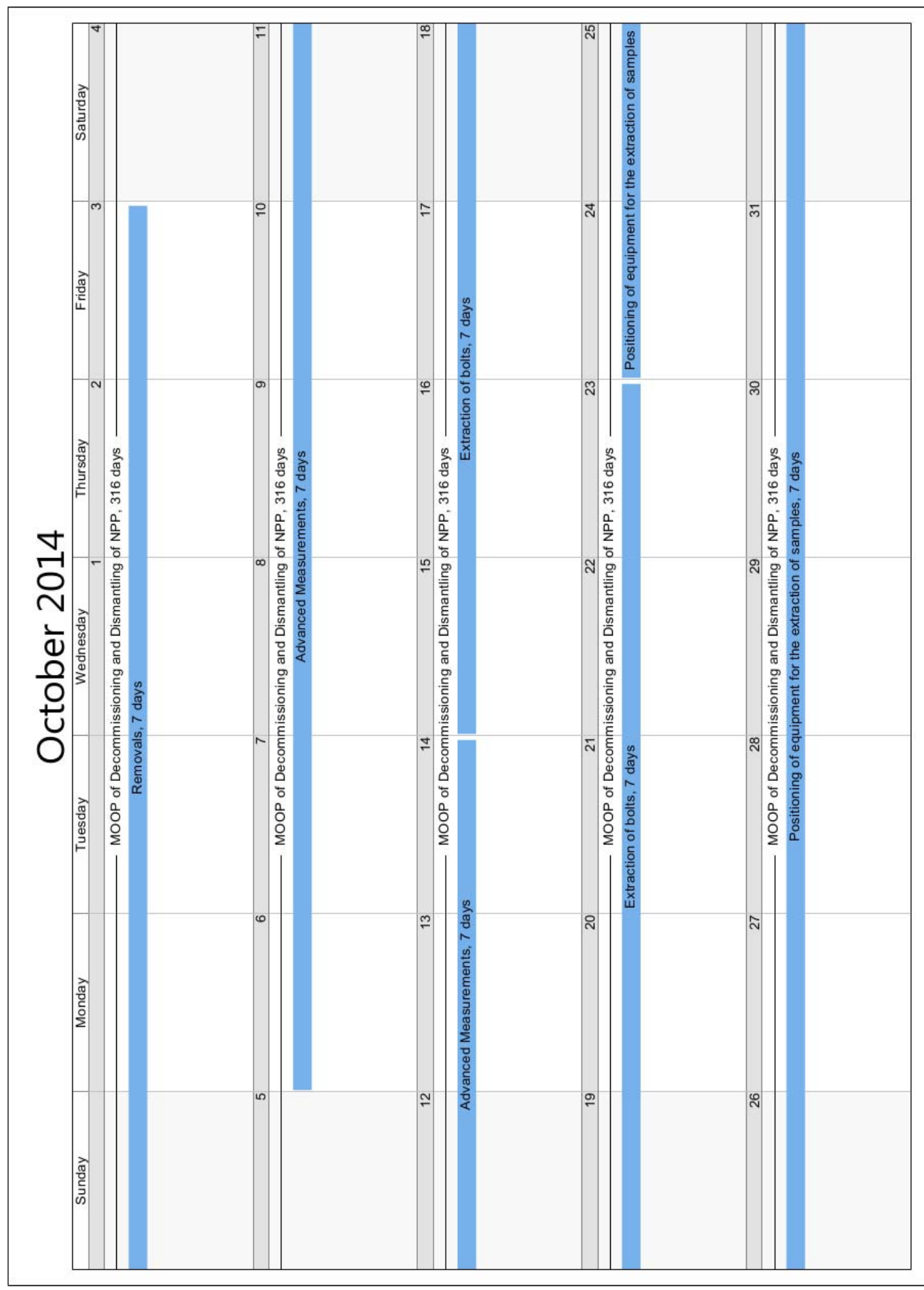

Figure 30i: $\quad$ MS Project - Calendar View October 2014 


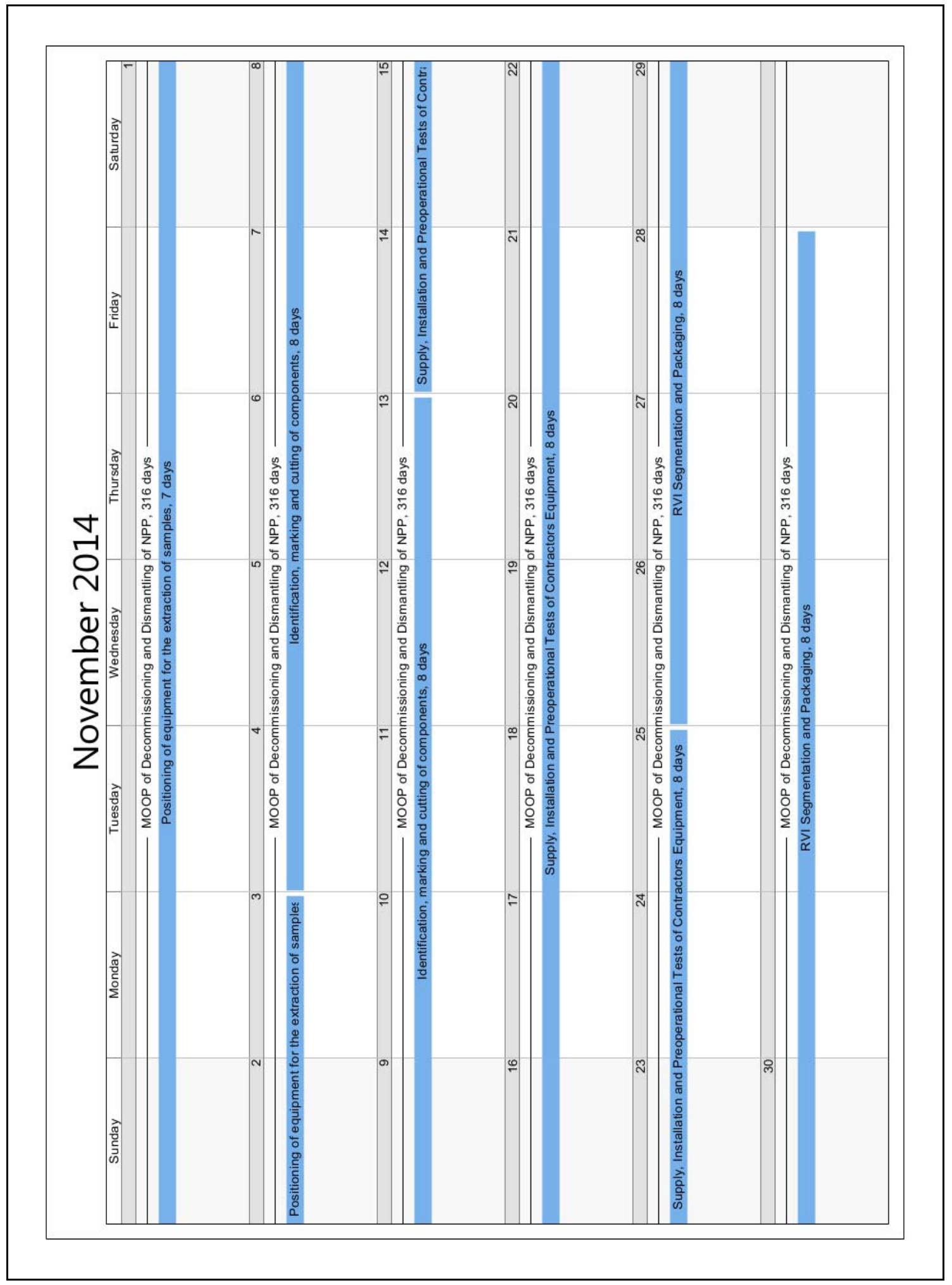

Figure 30j: $\quad$ MS Project - Calendar View November 2014 


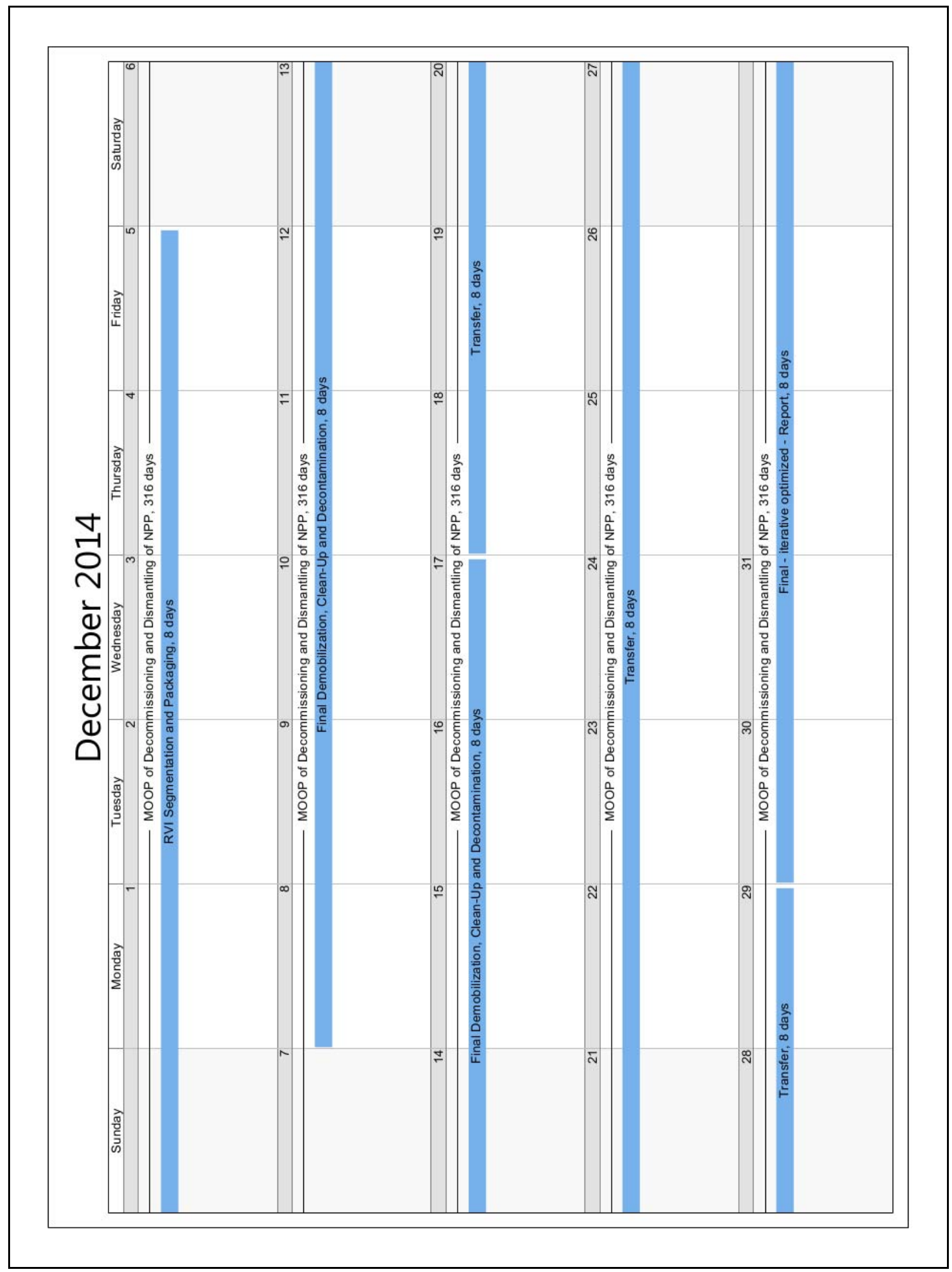

Figure 30k: $\quad$ MS Project - Calendar View December 2014 
APPENDIX 2 L - MS PROJECT - CALENDAR VIEW - JANUARY 2015

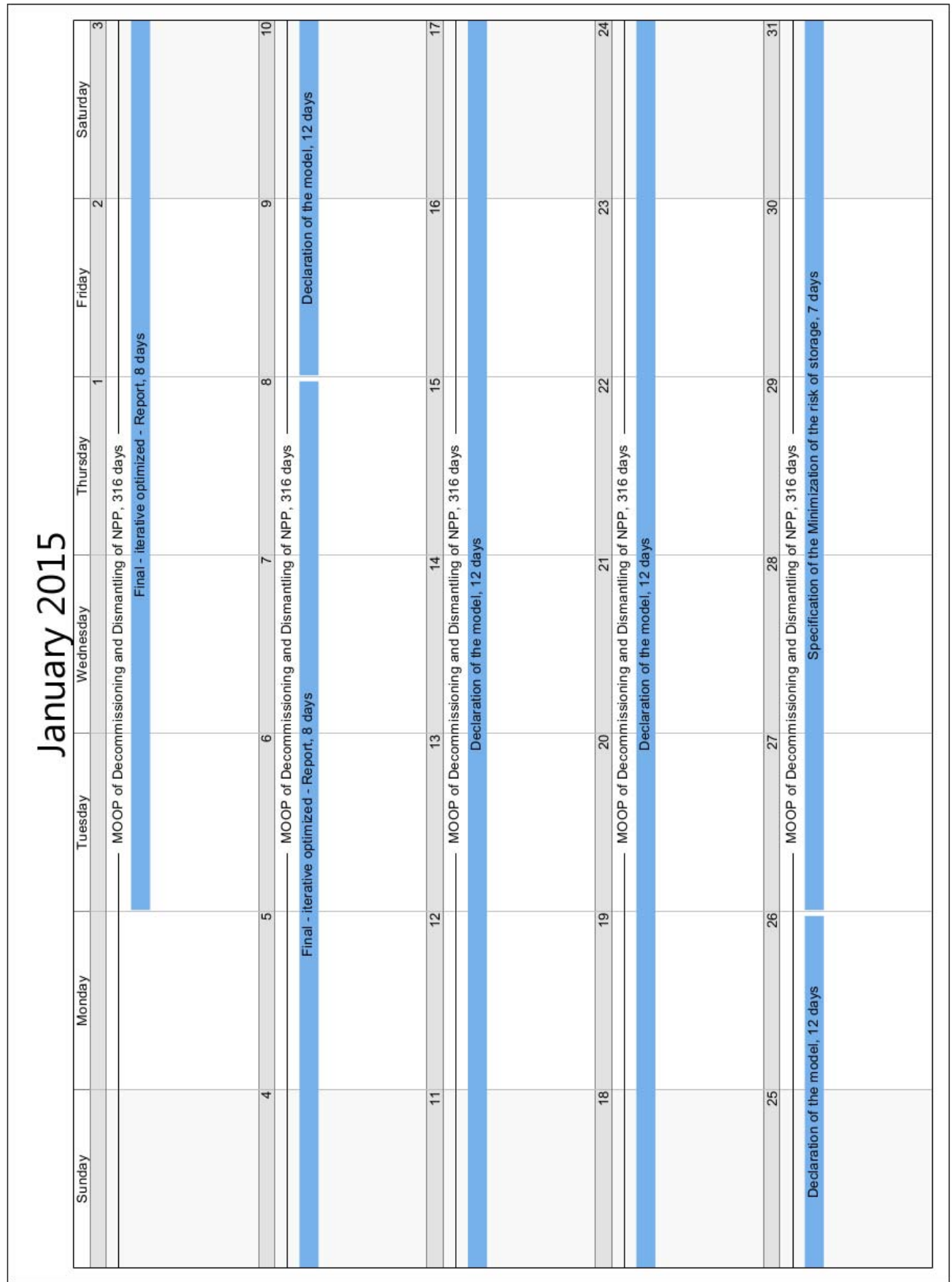

Figure 301: $\quad$ MS Project - Calendar View January 2015 


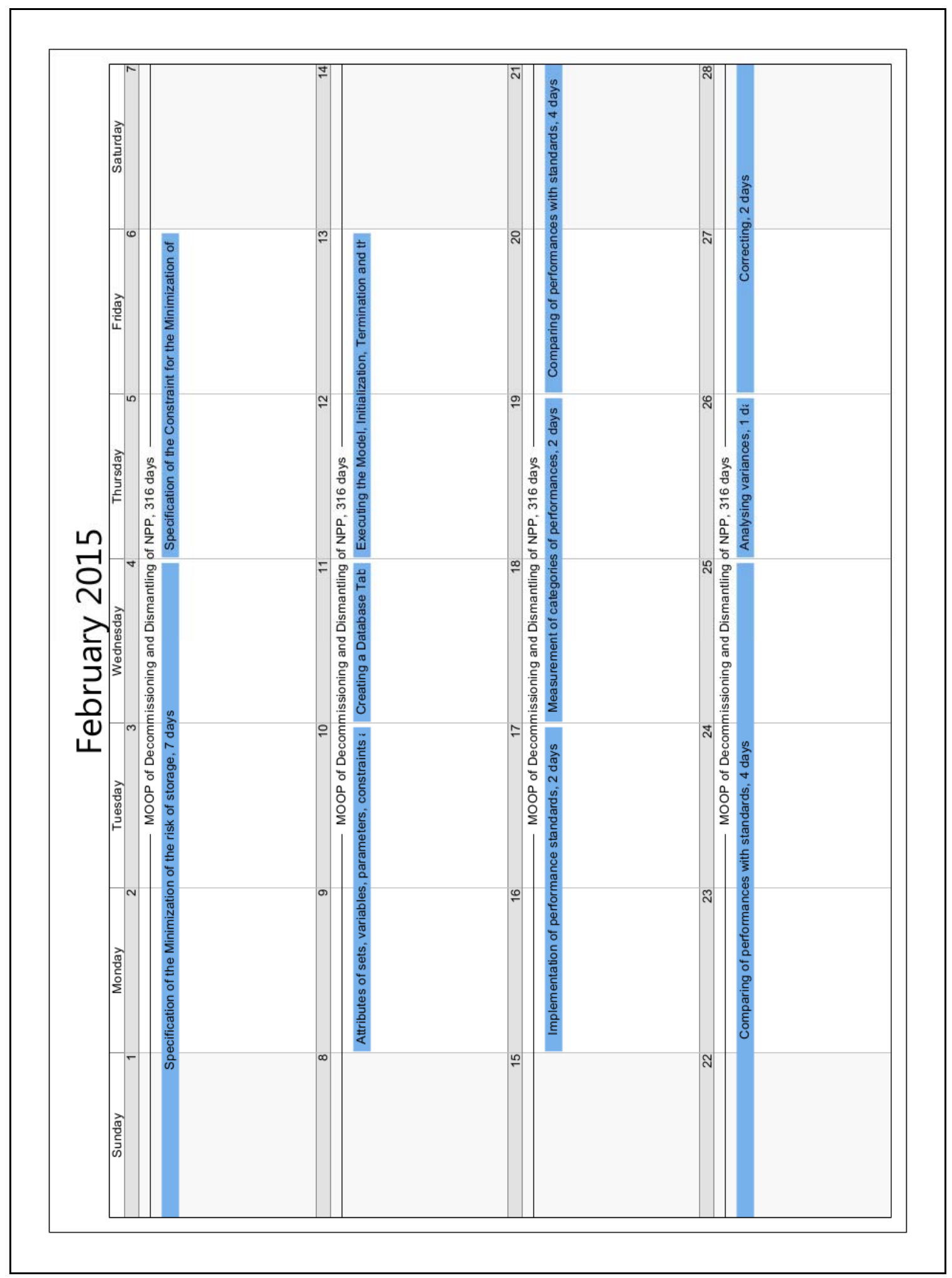

Figure 30m: MS Project - Calendar View February 2015 
APPENDIX 2 N- MS PROJECT - CALENDAR VIEW - MARCH 2015

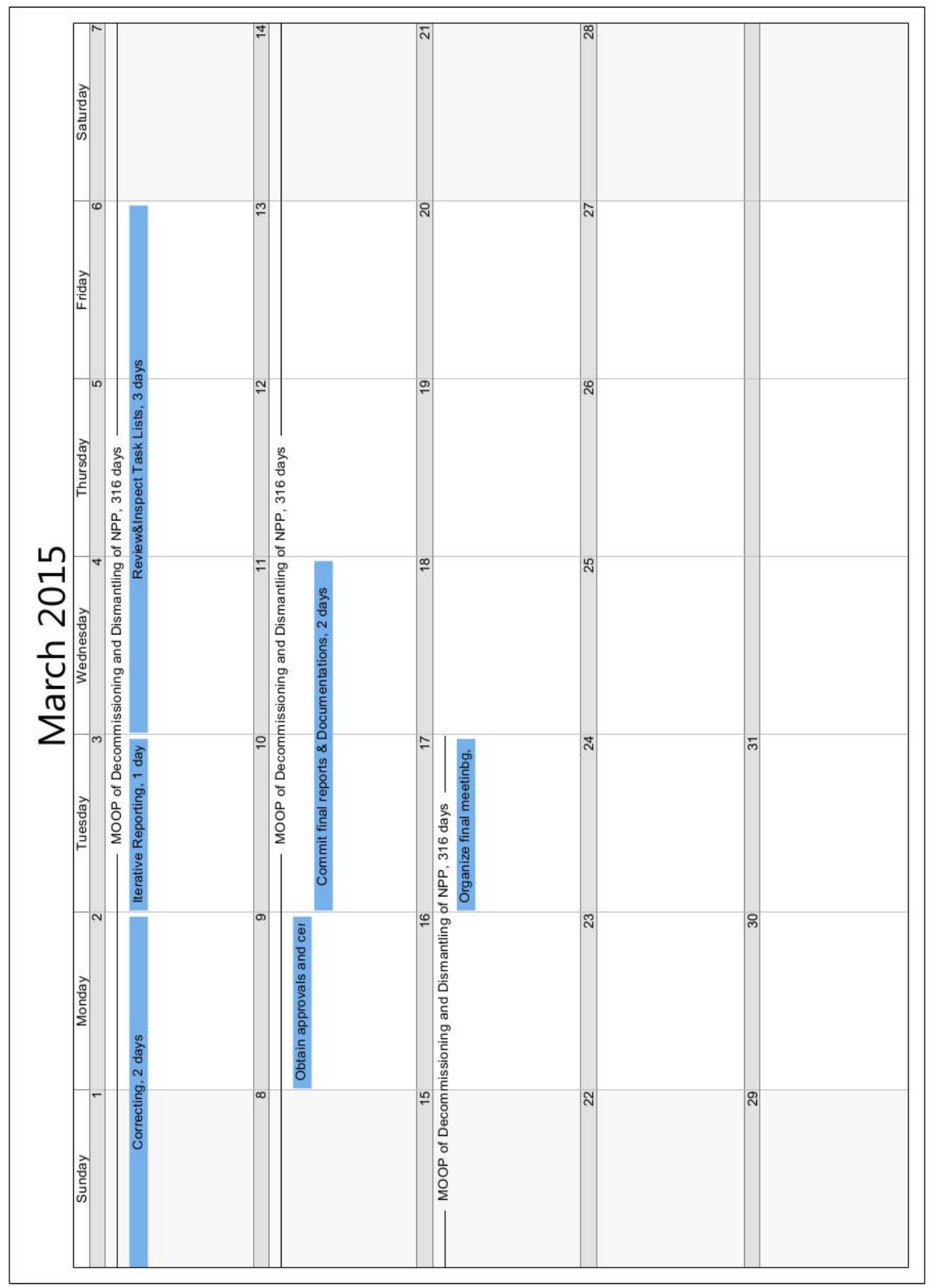

Figure 30n: $\quad$ MS Project - Calendar View March 2015 
APPENDIX 3- MS PROJECT - NETWORK DIAGRAM (EXCERPTS)

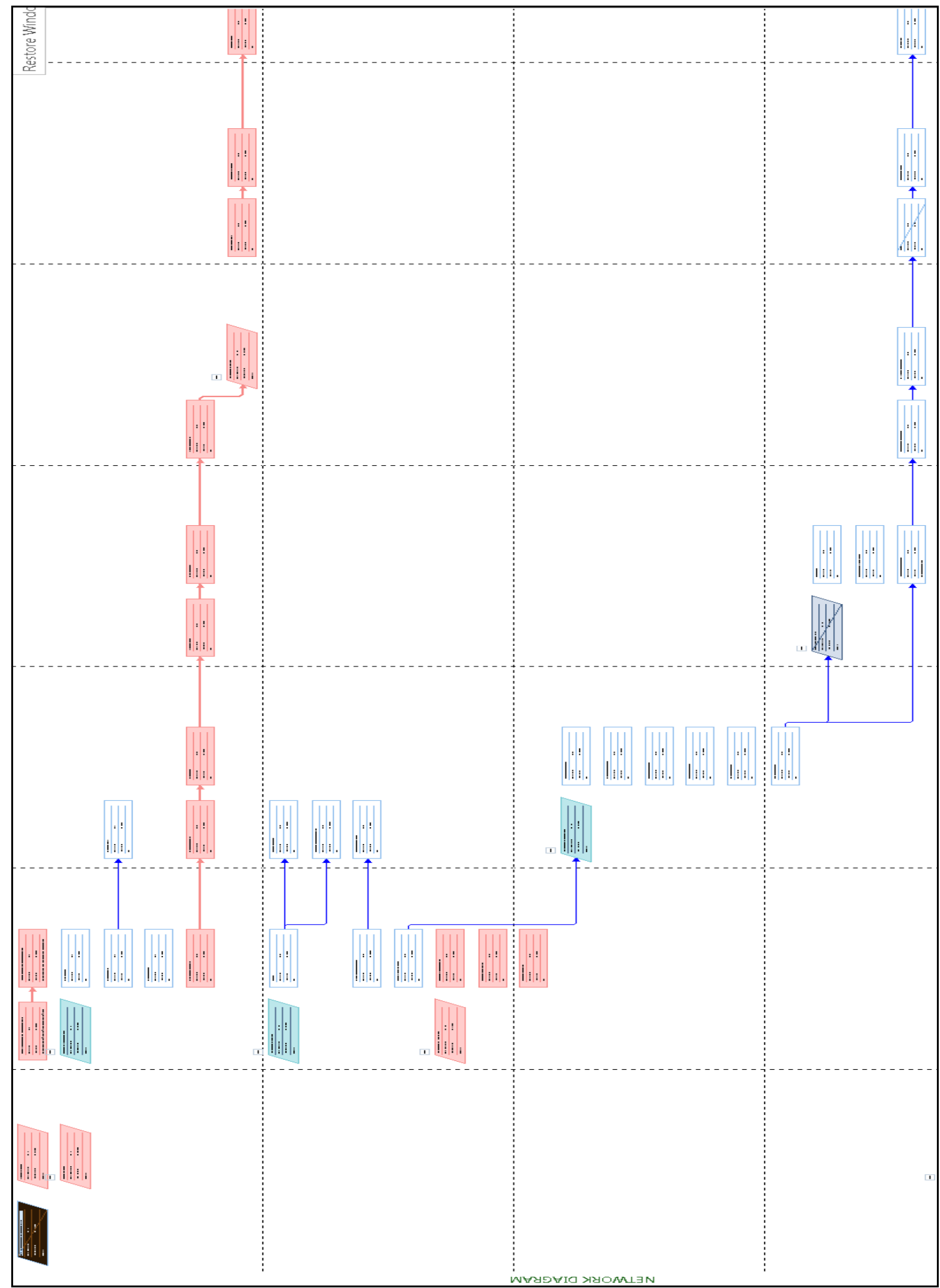

Figure 31: MS Project - Network Diagrams (Excerpts) 
APPENDIX 3 A- MS PROJECT - NETWORK DIAGRAM (EXCERPTS)

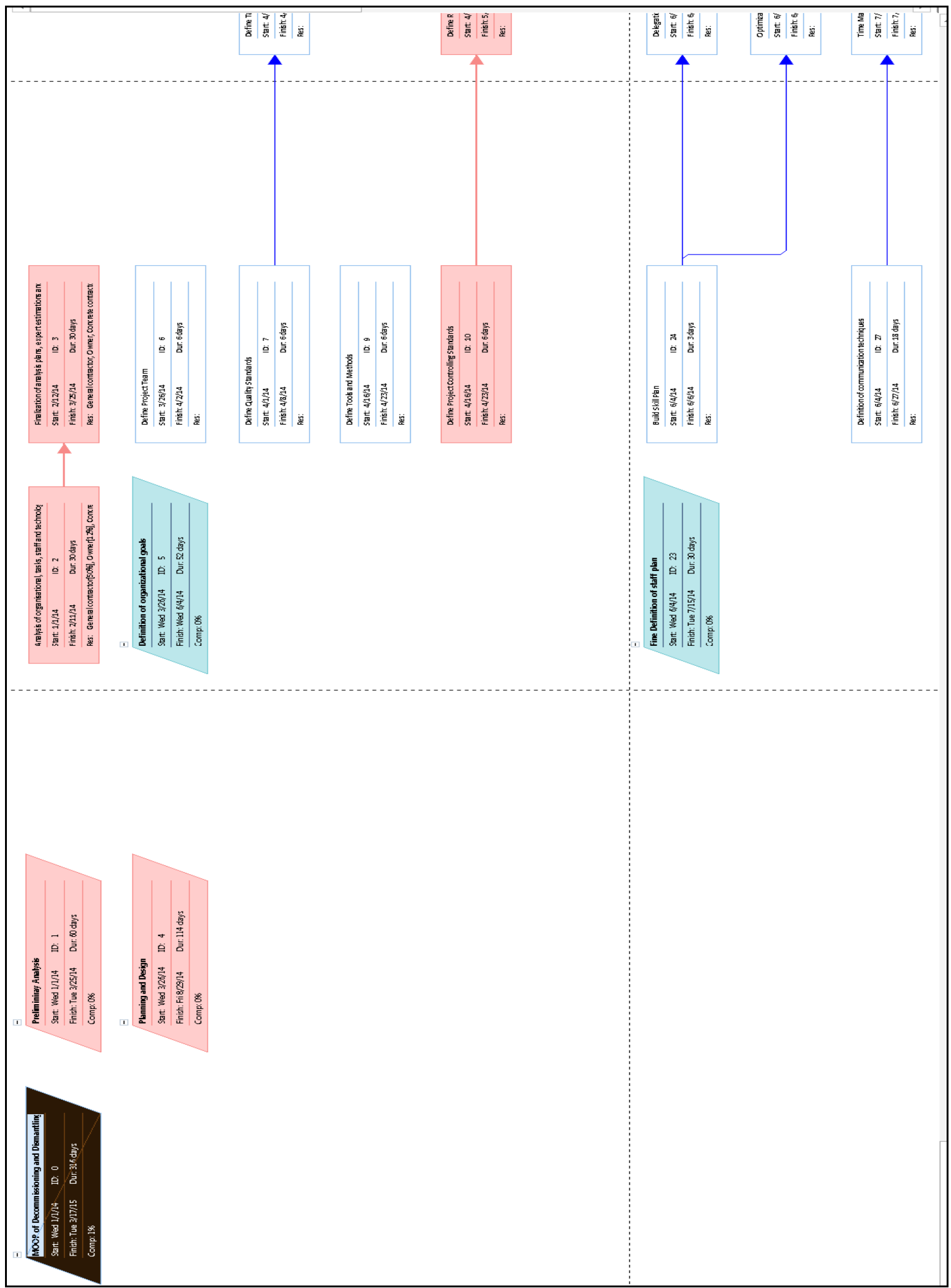

Figure 31a: $\quad$ MS Project - Network Diagrams (Excerpts) 


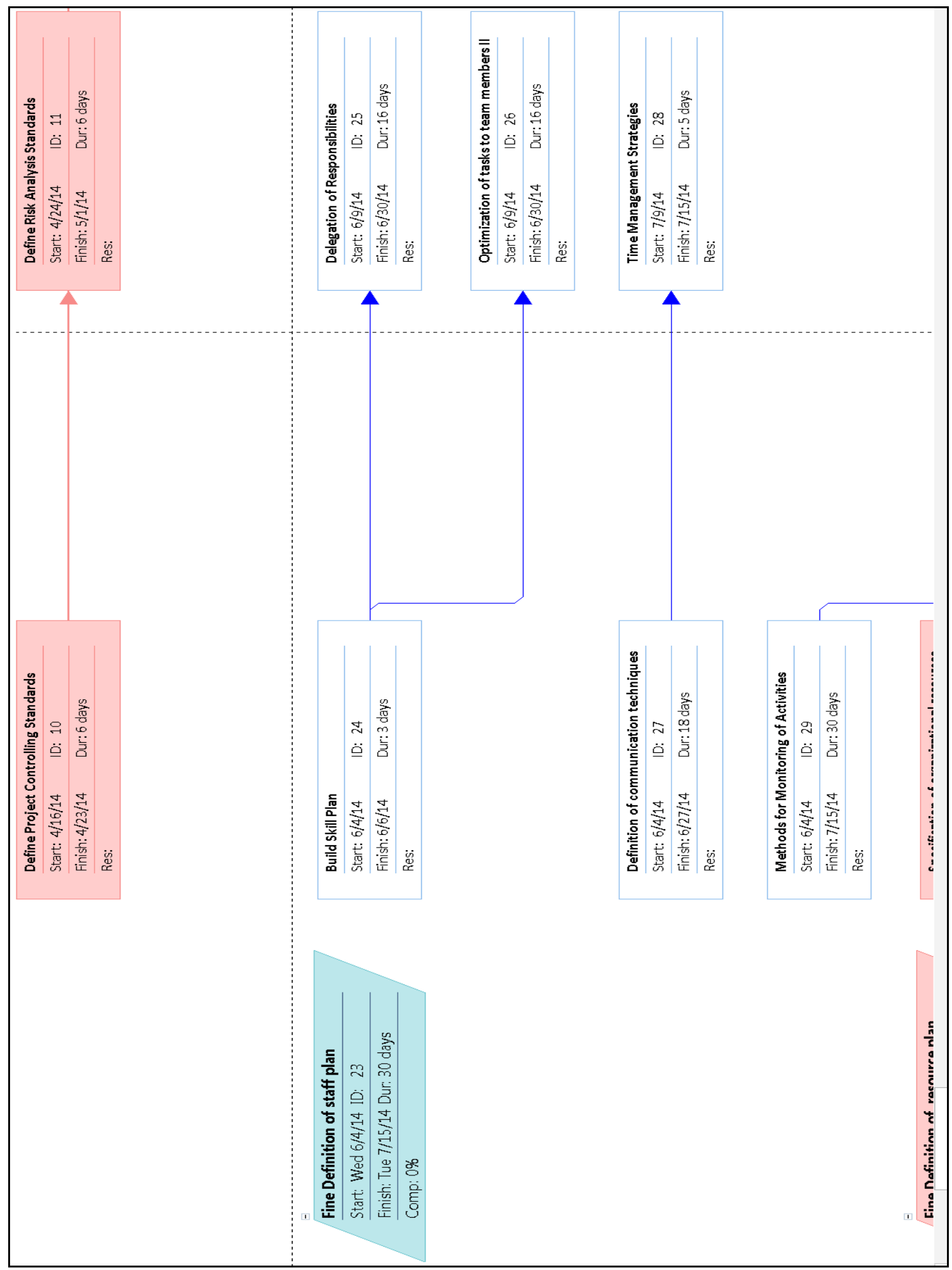

Figure 31b: MS Project - Network Diagrams (Excerpts) 


\section{APPENDIX 4- VERPACKUNGSPLÄNE (PACKAGING PLANS OF CUT SEGMENTS)}

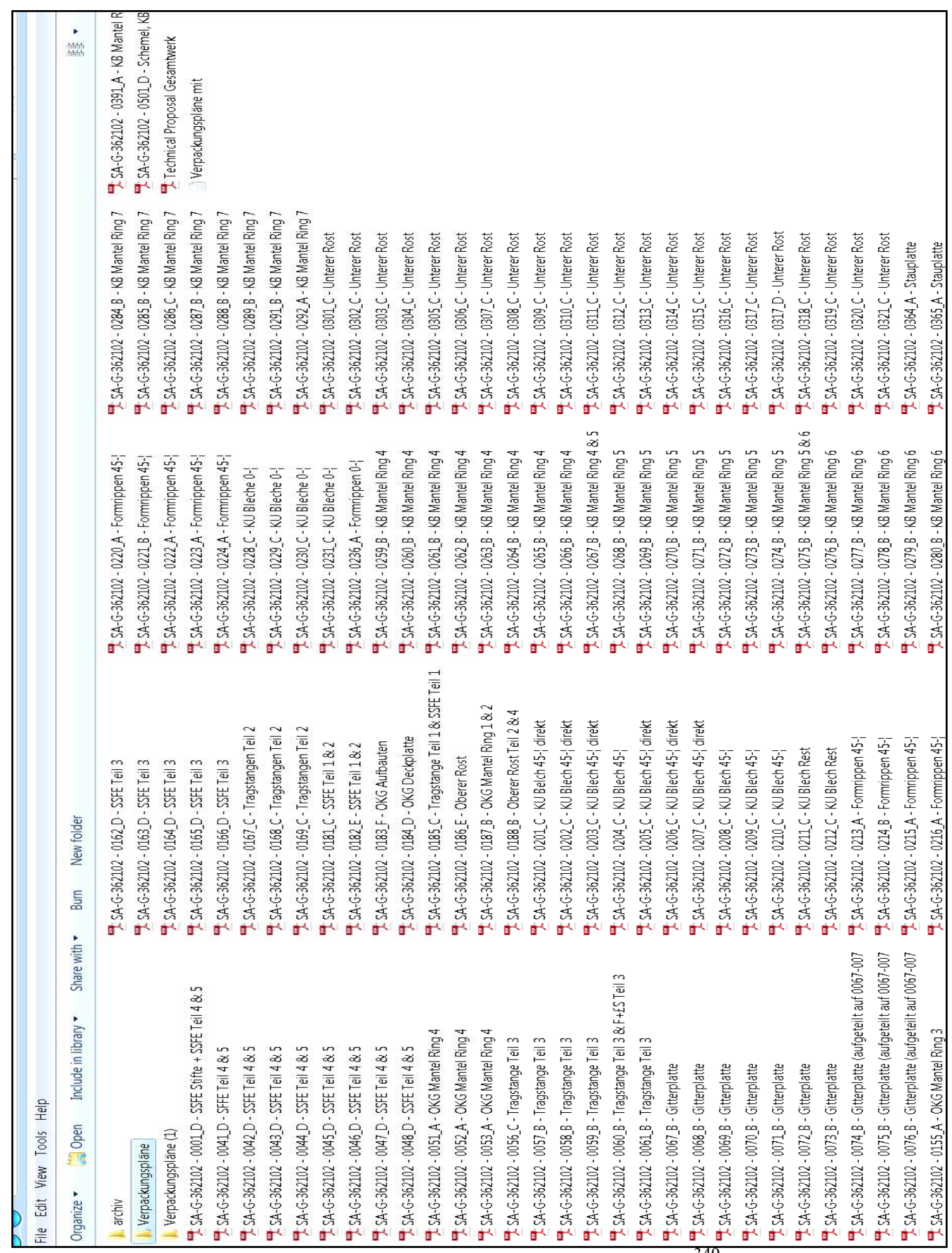

Figure 32:

${ }^{349}$ see AREVA NP GmbH (2008) 


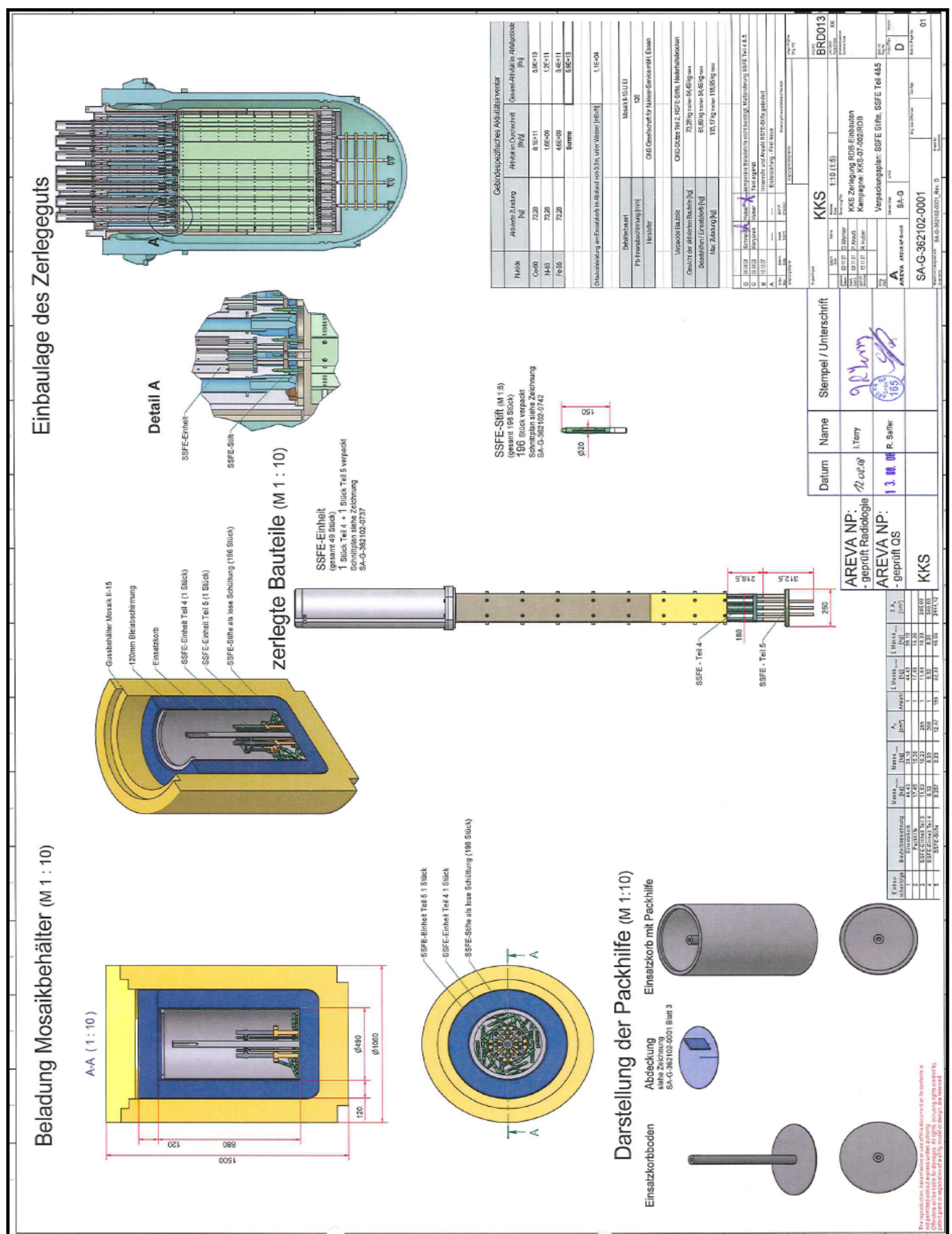

Figure 32a: Verpackungsplan - SA-G-362102 - 0001_D - SSFE Stifte + SSFE Teil 4 $\& 5^{350}$

${ }^{350}$ see AREVA NP GmbH (2008) 
APPENDIX 4 B - PACKAGING PLAN OF CUT SEGMENTS

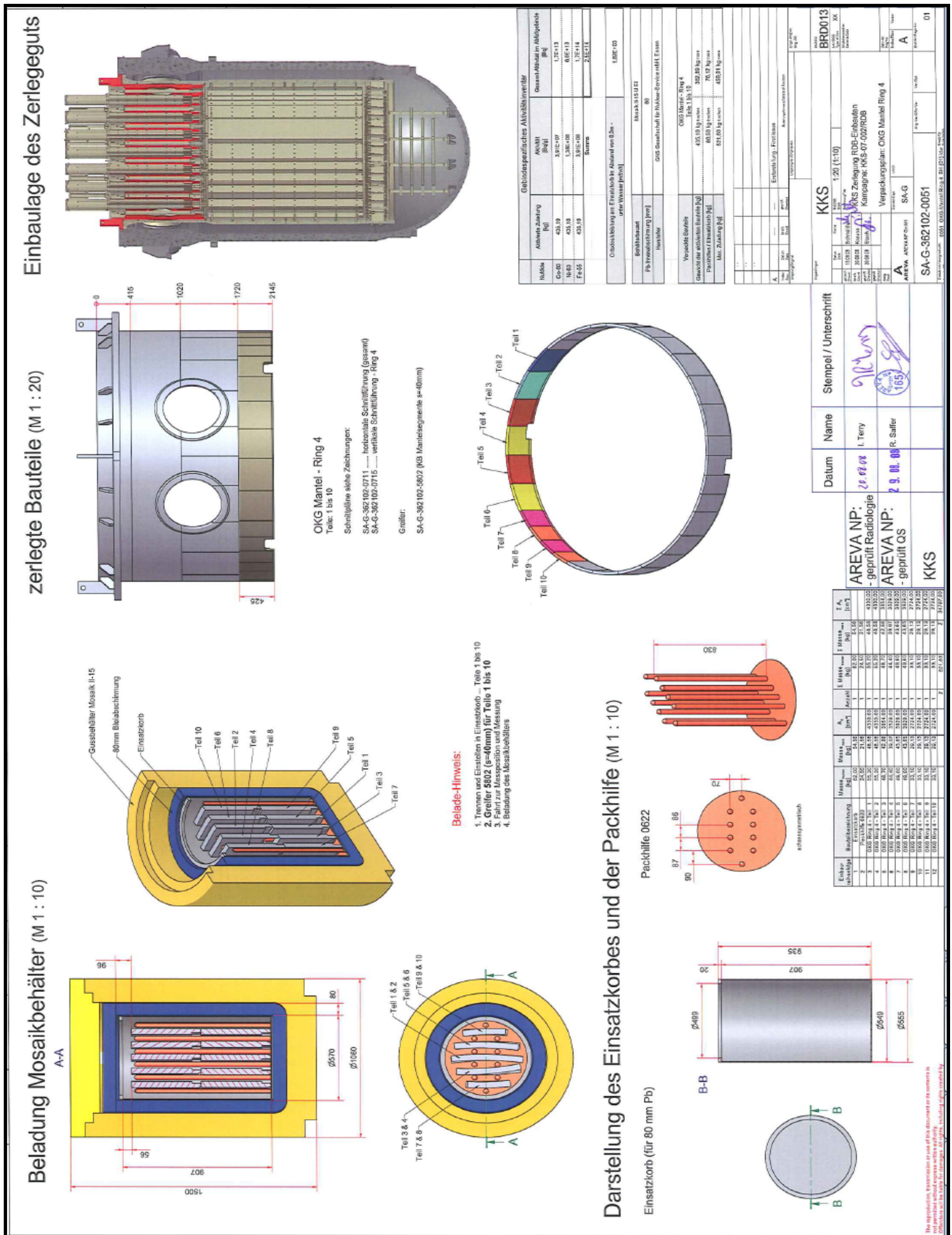

Figure 32b: Verpackungsplan - SA-G-362102 - 0051_A - OKG Mantel Ring $4^{351}$

${ }^{351}$ see AREVA NP GmbH (2008) 
APPENDIX 4 C-PACKAGING PLAN OF CUT SEGMENTS

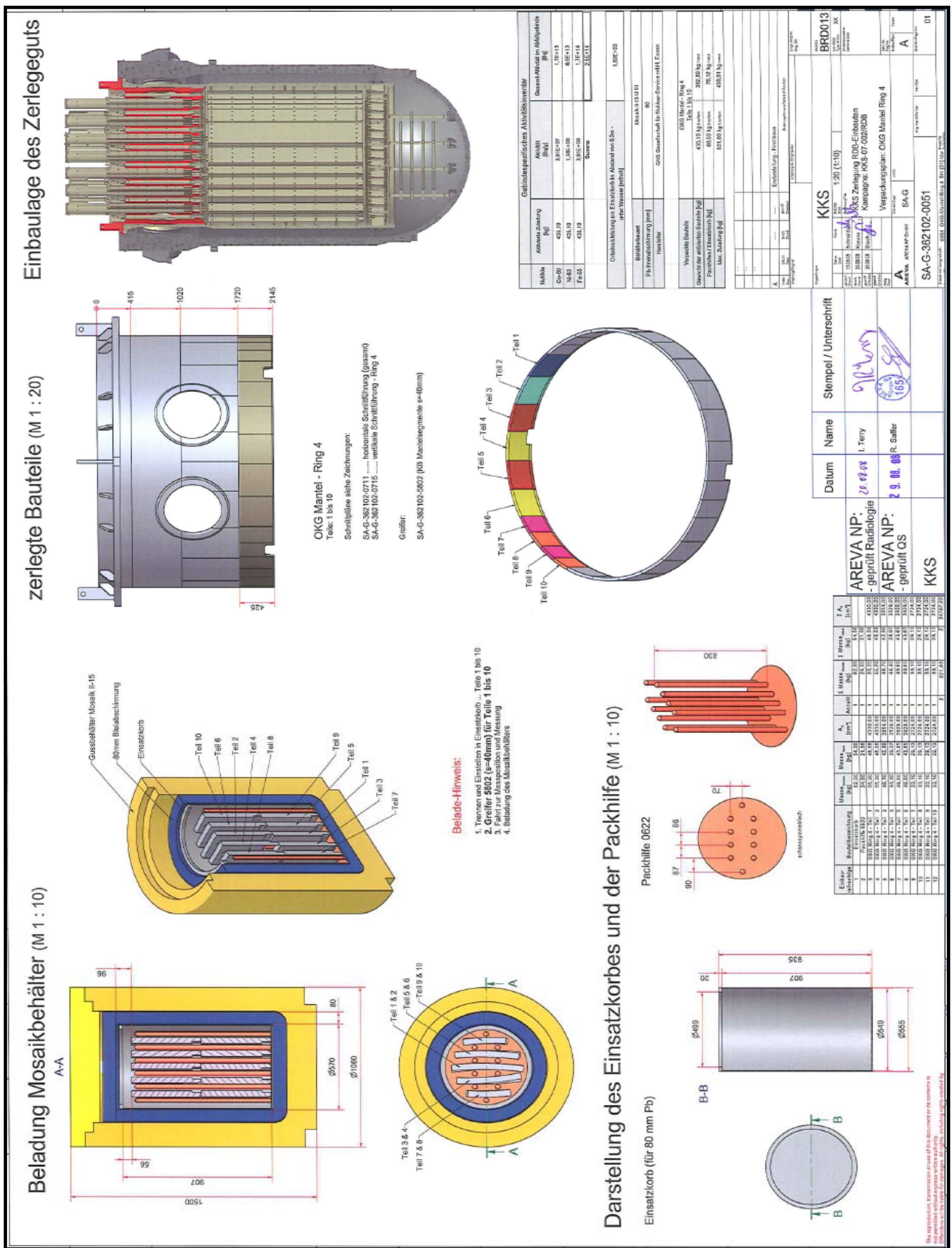

Figure 32c: Verpackungsplan - SA-G-362102 - 0056_C - Tragstange Teil $3^{352}$

${ }^{352}$ see AREVA NP GmbH (2008) 
APPENDIX 4 D-PACKAGING PLAN OF CUT SEGMENTS

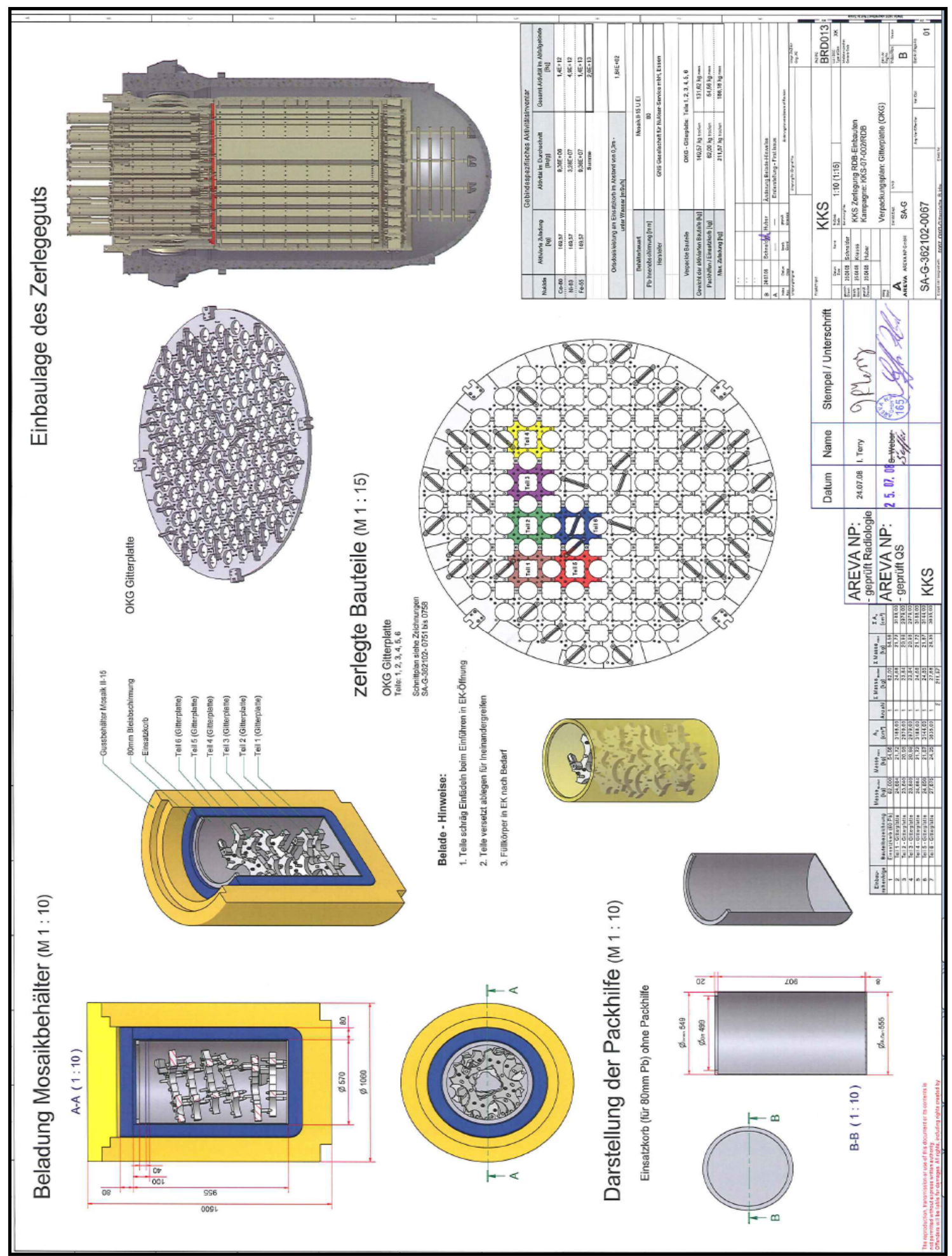

Figure 32d: Verpackungsplan - SA-G-362102 - 0067_B - Gitterplatte ${ }^{353}$

${ }^{353}$ see AREVA NP GmbH (2008) 
APPENDIX 4 E - PACKAGING PLAN OF CUT SEGMENTS

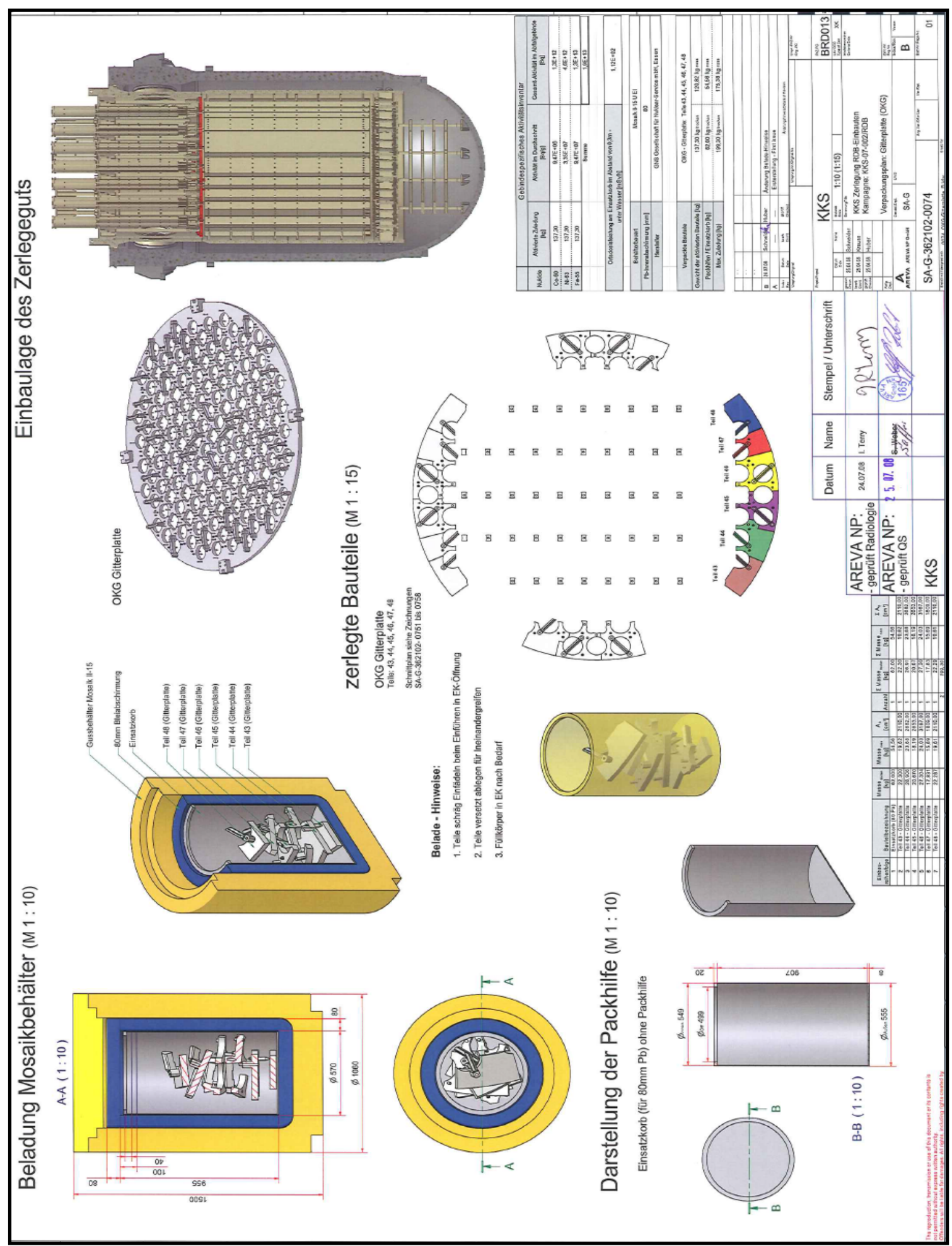

Figure 32e: Verpackungsplan - SA-G-362102 - 0074_B - Gitterplatte (aufgeteilt auf 0067-007) ) $^{354}$

${ }^{354}$ see AREVA NP GmbH (2008) 
APPENDIX 4 F - PACKAGING PLAN OF CUT SEGMENTS

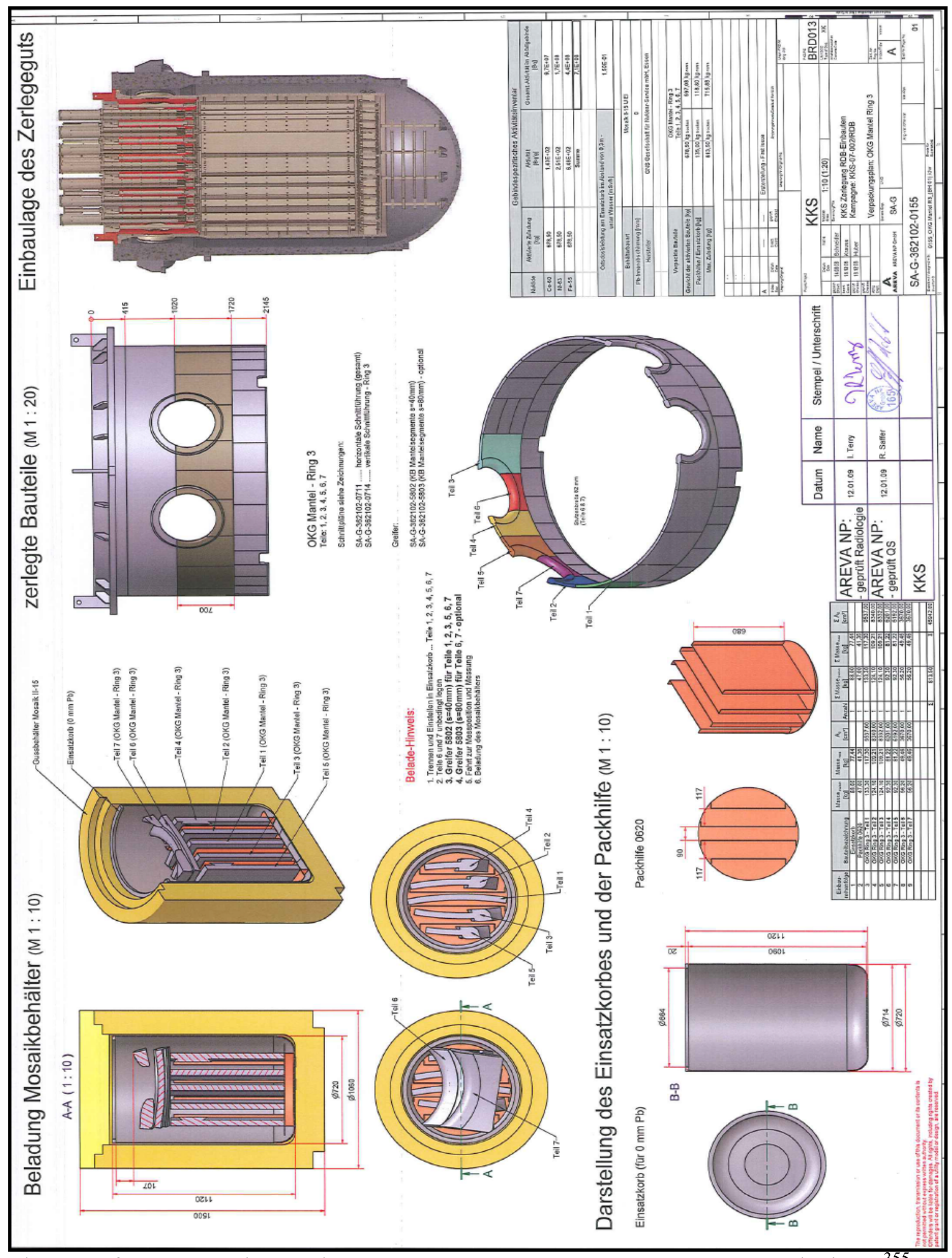

Figure 32f: Verpackungsplan - SA-G-362102 - 0155_A - OKG Mantel Ring 3 ${ }^{35}$

${ }^{355}$ see AREVA NP GmbH (2008) 


\section{APPENDIX 4 G-PACKAGING PLAN OF CUT SEGMENTS}

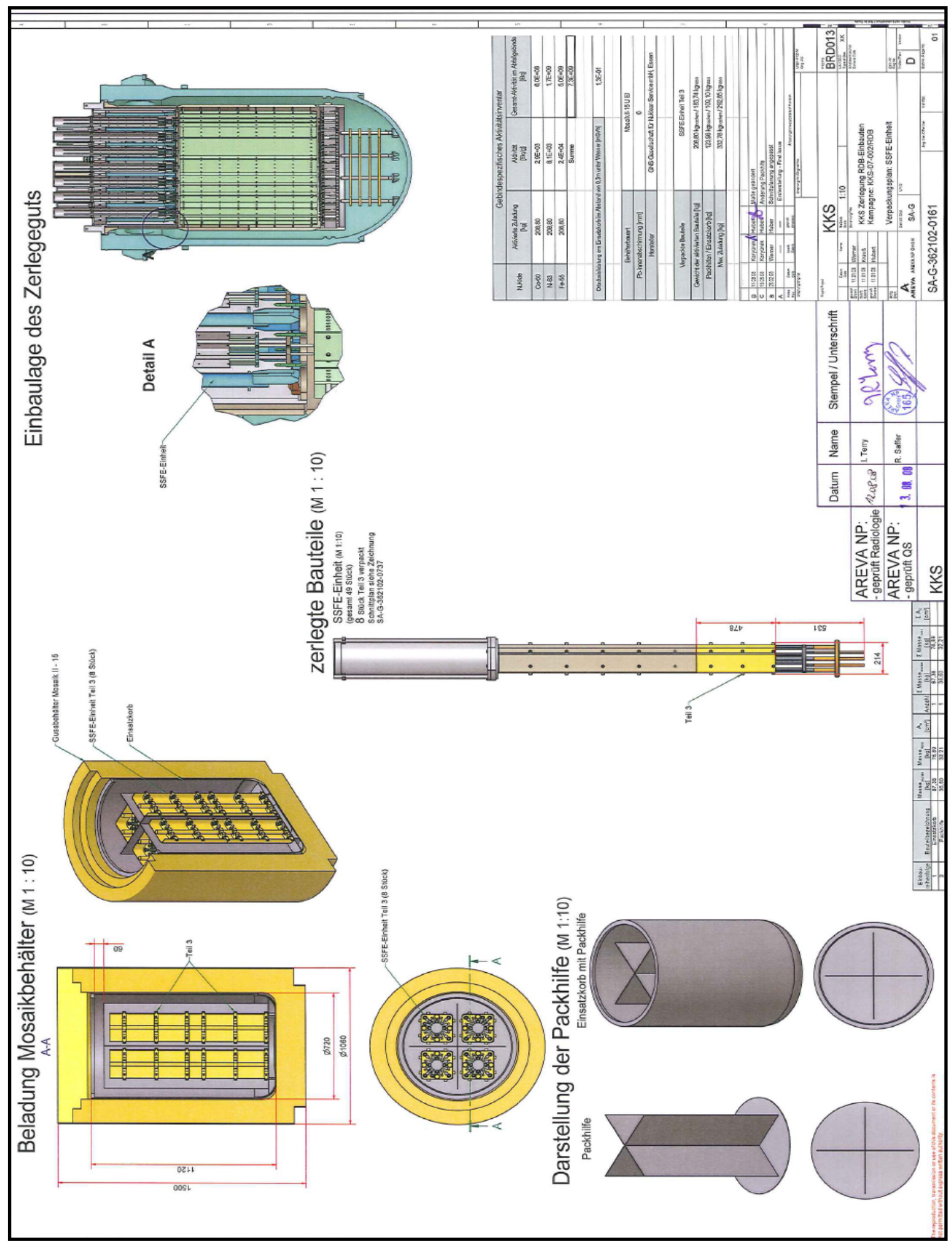

Figure 32g: Verpackungsplan - SA-G-362102 - 0161_D - SSFE Teil $3^{356}$

${ }^{356}$ see AREVA NP GmbH (2008) 


\section{APPENDIX 4 H- PACKAGING PLAN OF CUT SEGMENTS}

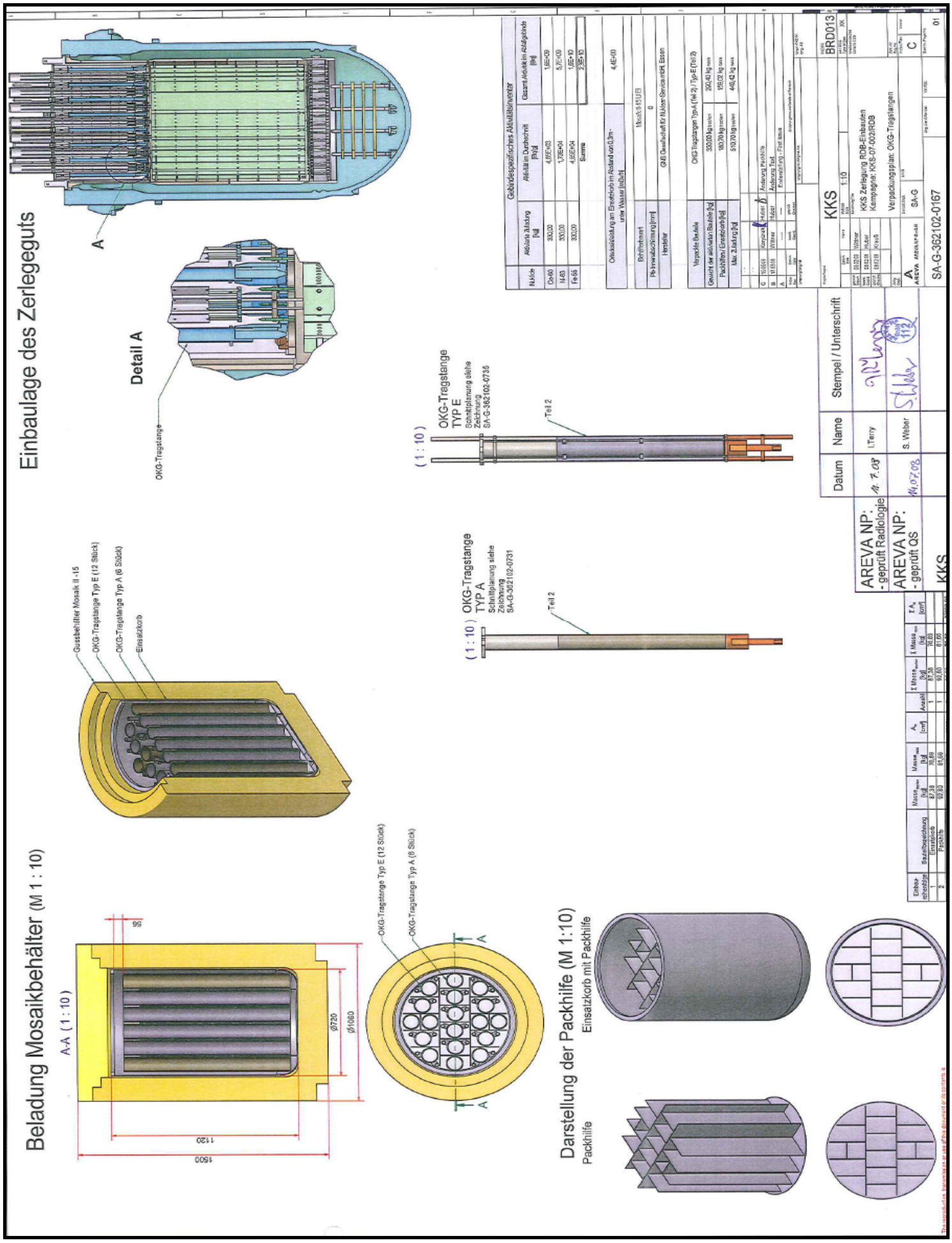

Figure 32h: Verpackungsplan - SA-G-362102 - 0167_C - Tragstangen Teil $2^{357}$

${ }^{357}$ see AREVA NP GmbH (2008) 
APPENDIX 4 I - PACKAGING PLAN OF CUT SEGMENTS

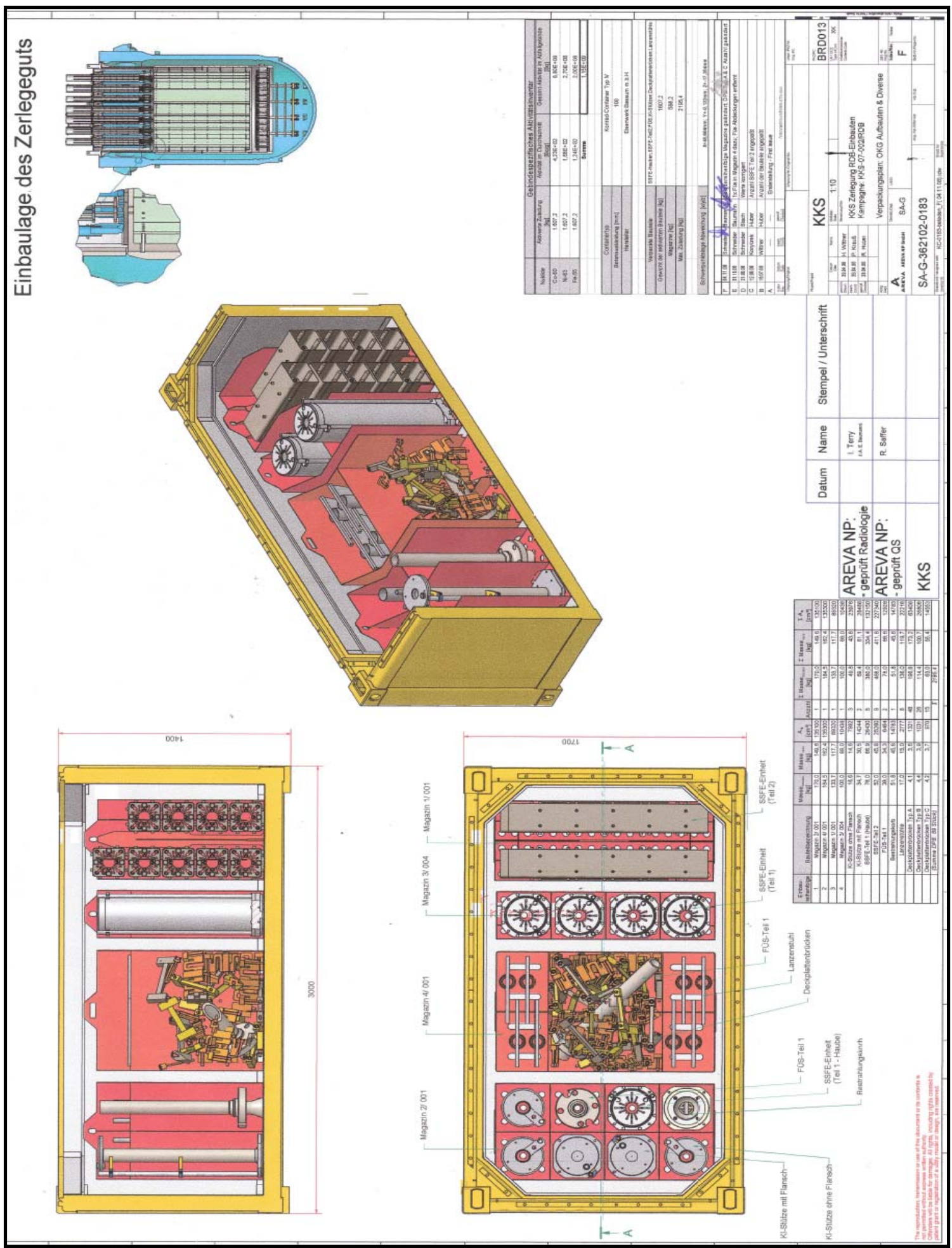

Figure 32i: Verpackungsplan - SA-G-362102 - 0183_F - OKG Aufbauten ${ }^{358}$

${ }^{358}$ see AREVA NP GmbH (2008) 


\section{APPENDIX 5- R-CODE-PARETO OPTMIZATION}

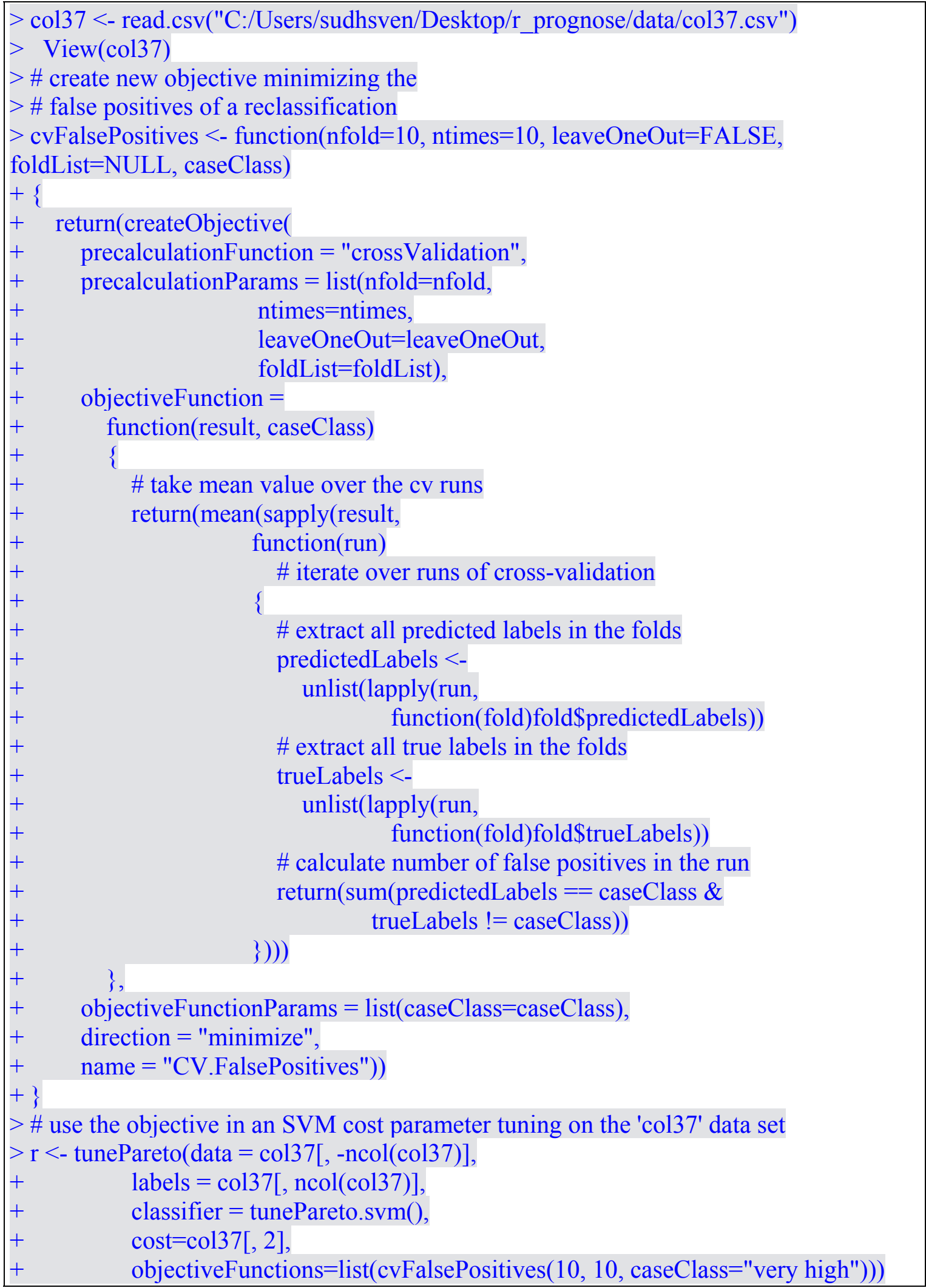


Testing 150 parameter combinations...

Evaluating parameter set: $\operatorname{cost}=613$

Evaluating parameter set: $\operatorname{cost}=848$

Evaluating parameter set: $\operatorname{cost}=337$

Evaluating parameter set: $\operatorname{cost}=933$

Evaluating parameter set: $\cos t=152$

Evaluating parameter set: $\operatorname{cost}=222$

Evaluating parameter set: $\operatorname{cost}=395$

Evaluating parameter set: $\operatorname{cost}=619$

Evaluating parameter set: $\operatorname{cost}=505$

Evaluating parameter set: $\operatorname{cost}=602$

Evaluating parameter set: $\operatorname{cost}=734$

Evaluating parameter set: $\operatorname{cost}=686$

Evaluating parameter set: $\operatorname{cost}=186$

Evaluating parameter set: $\operatorname{cost}=188$

Evaluating parameter set: $\operatorname{cost}=358$

Evaluating parameter set: $\operatorname{cost}=184$

Evaluating parameter set: $\operatorname{cost}=960$

Evaluating parameter set: $\operatorname{cost}=446$

Evaluating parameter set: $\operatorname{cost}=347$

Evaluating parameter set: $\operatorname{cost}=559$

Evaluating parameter set: $\operatorname{cost}=597$

Evaluating parameter set: $\operatorname{cost}=545$

Evaluating parameter set: $\operatorname{cost}=381$

Evaluating parameter set: $\cos t=209$

Evaluating parameter set: $\operatorname{cost}=291$

Evaluating parameter set: $\operatorname{cost}=320$

Evaluating parameter set: $\operatorname{cost}=453$

Evaluating parameter set: $\operatorname{cost}=791$

Evaluating parameter set: $\operatorname{cost}=235$

Evaluating parameter set: $\operatorname{cost}=313$

Evaluating parameter set: $\operatorname{cost}=397$

Evaluating parameter set: $\operatorname{cost}=995$

Evaluating parameter set: $\operatorname{cost}=975$

Evaluating parameter set: $\operatorname{cost}=130$

Evaluating parameter set: $\operatorname{cost}=734$

Evaluating parameter set: $\operatorname{cost}=362$

Evaluating parameter set: $\operatorname{cost}=956$

Evaluating parameter set: $\operatorname{cost}=911$

Evaluating parameter set: $\operatorname{cost}=783$

Evaluating parameter set: $\operatorname{cost}=615$

Evaluating parameter set: $\operatorname{cost}=225$

Evaluating parameter set: $\operatorname{cost}=271$

Evaluating parameter set: $\operatorname{cost}=379$

Evaluating parameter set: $\operatorname{cost}=484$

Evaluating parameter set: $\operatorname{cost}=918$ 


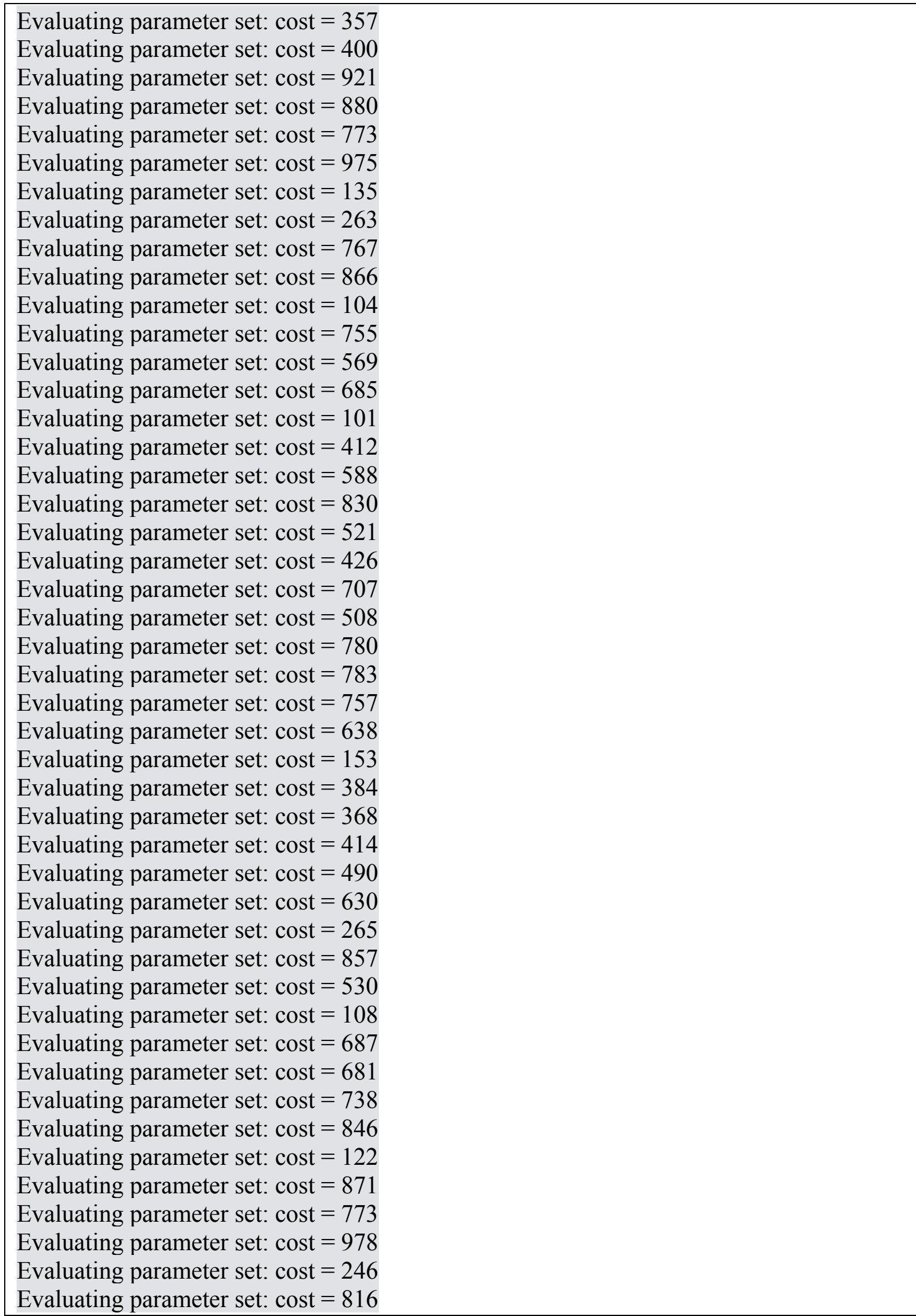




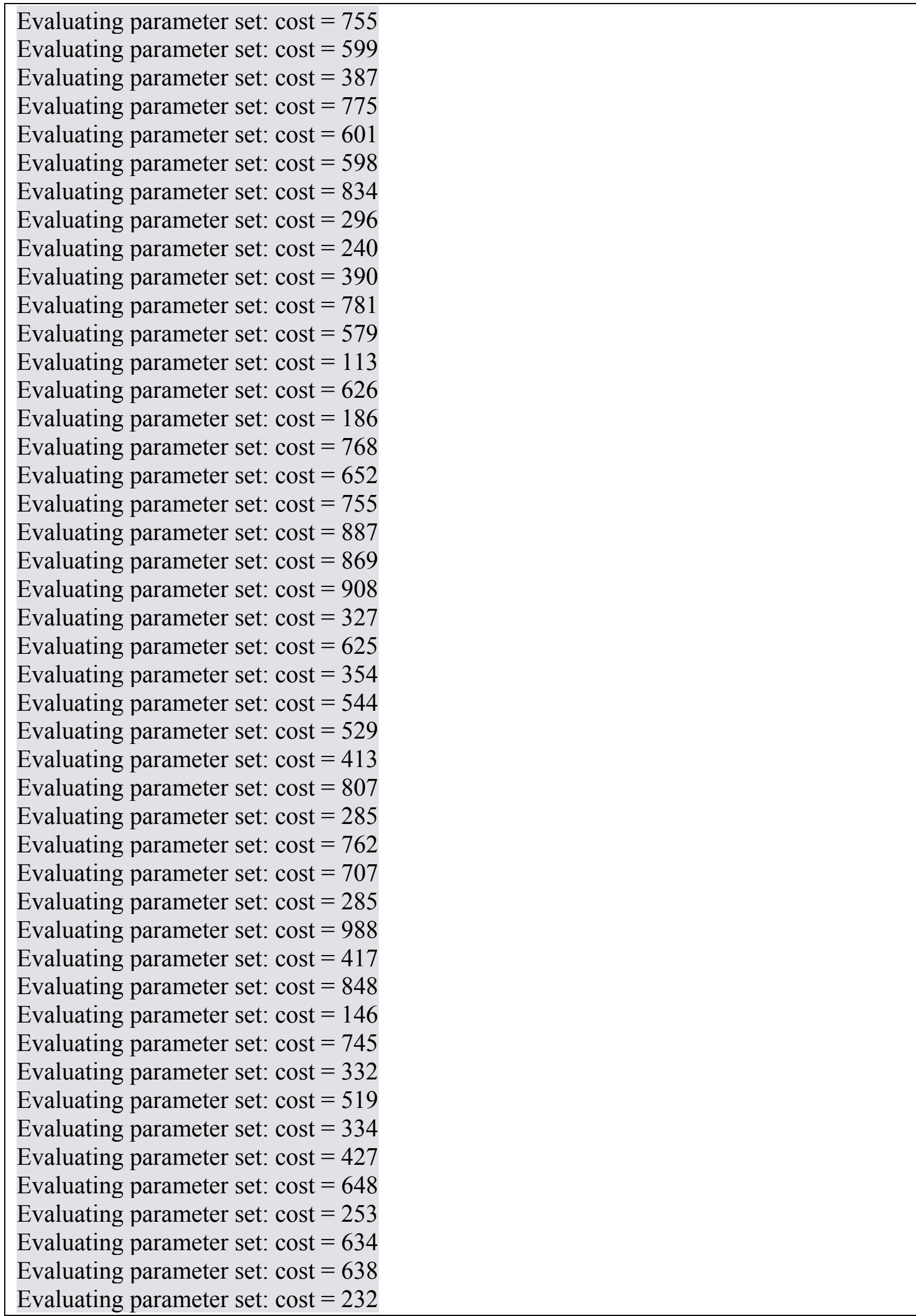


Evaluating parameter set: $\operatorname{cost}=488$

Evaluating parameter set: $\operatorname{cost}=728$

Evaluating parameter set: $\operatorname{cost}=214$

Evaluating parameter set: $\operatorname{cost}=594$

Evaluating parameter set: $\operatorname{cost}=621$

Evaluating parameter set: $\operatorname{cost}=286$

Evaluating parameter set: $\operatorname{cost}=919$

Evaluating parameter set: $\operatorname{cost}=770$

Evaluating parameter set: $\cos t=201$

Evaluating parameter set: $\operatorname{cost}=619$

Evaluating parameter set: $\cos t=311$

Evaluating parameter set: $\cos t=411$

Evaluating parameter set: $\operatorname{cost}=\mathrm{NA}$

Calculating Pareto-optimal combinations...

There were 50 or more warnings (use warnings() to see the first 50)

$>$ print(r)

Pareto-optimal parameter sets:

CV.FalsePositives

cost $=101 \quad 21.9$

$>$ plotDominationGraph(r, legend. $x=$ "topright")

Figure 33: $\quad$ R-Code - Pareto-Optimization 


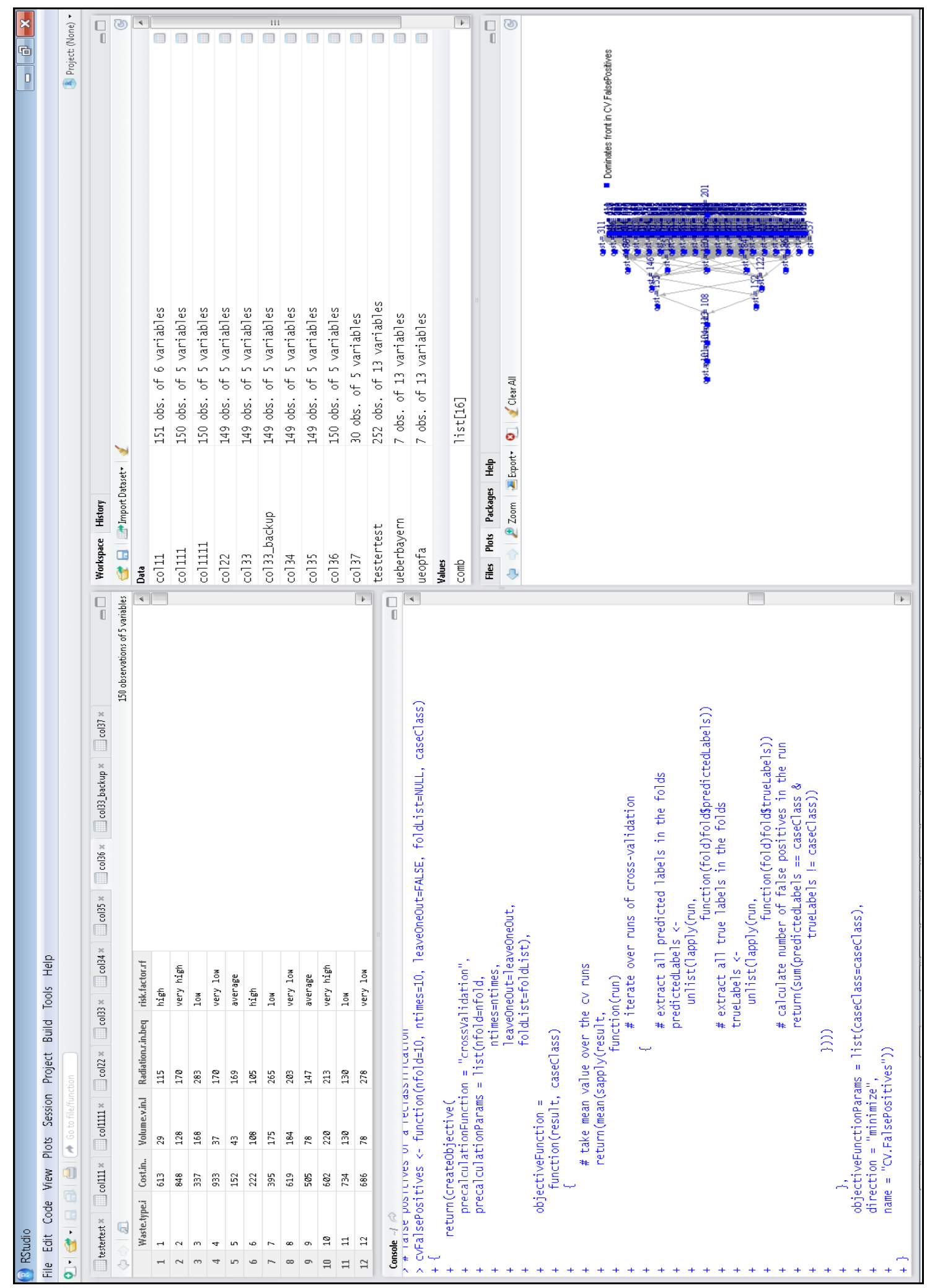

Figure 34: RStudio - Screenshot of the Workspace 


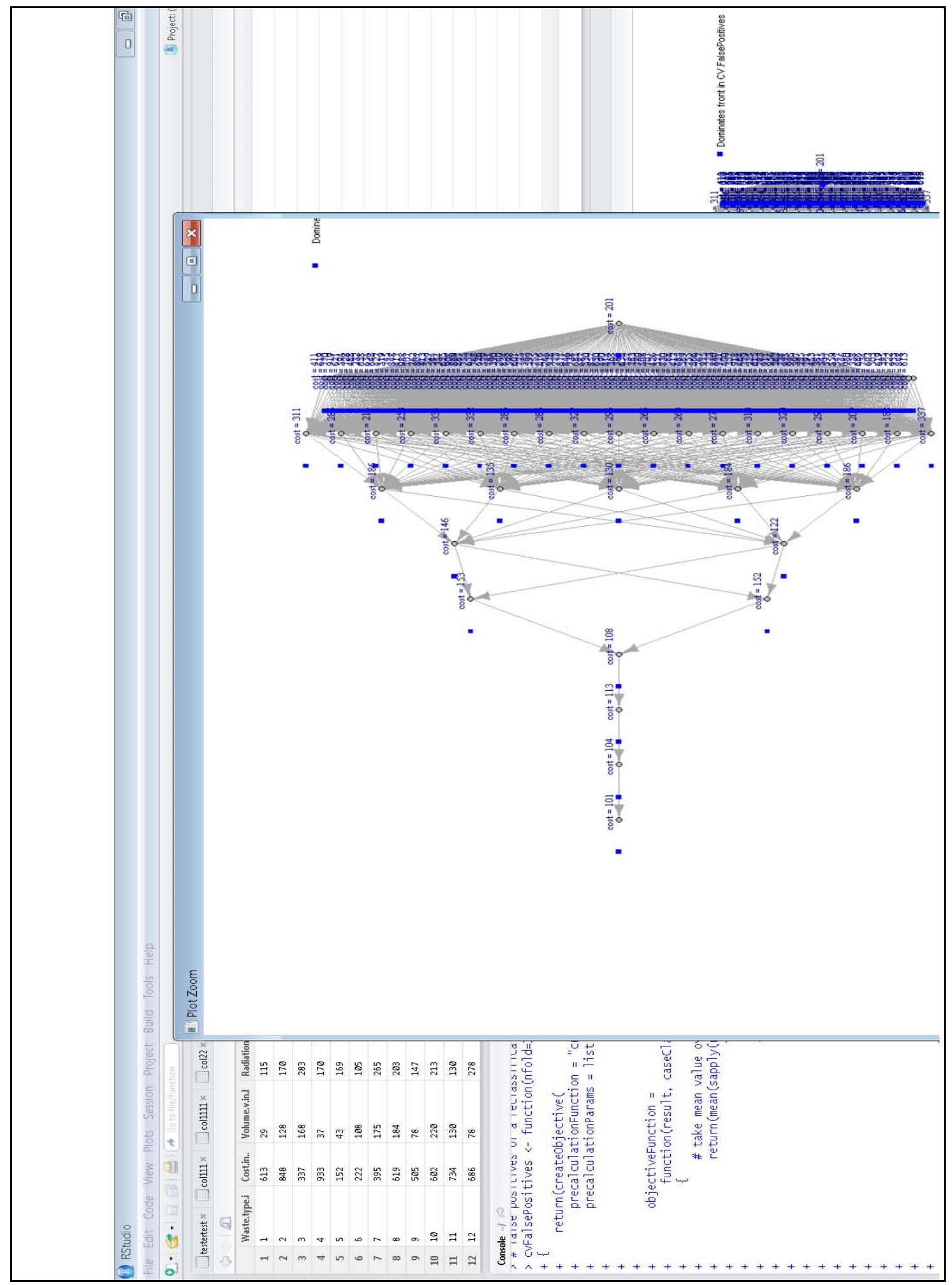

Figure 35: RStudio-Pareto-Optimum-Plot-DominationGraph 
APPENDIX 8- OMEGA CODE

APPENDIX 8 A- PRINCIPAL SCHEME OF DECOMMISSIONING CALCULATION

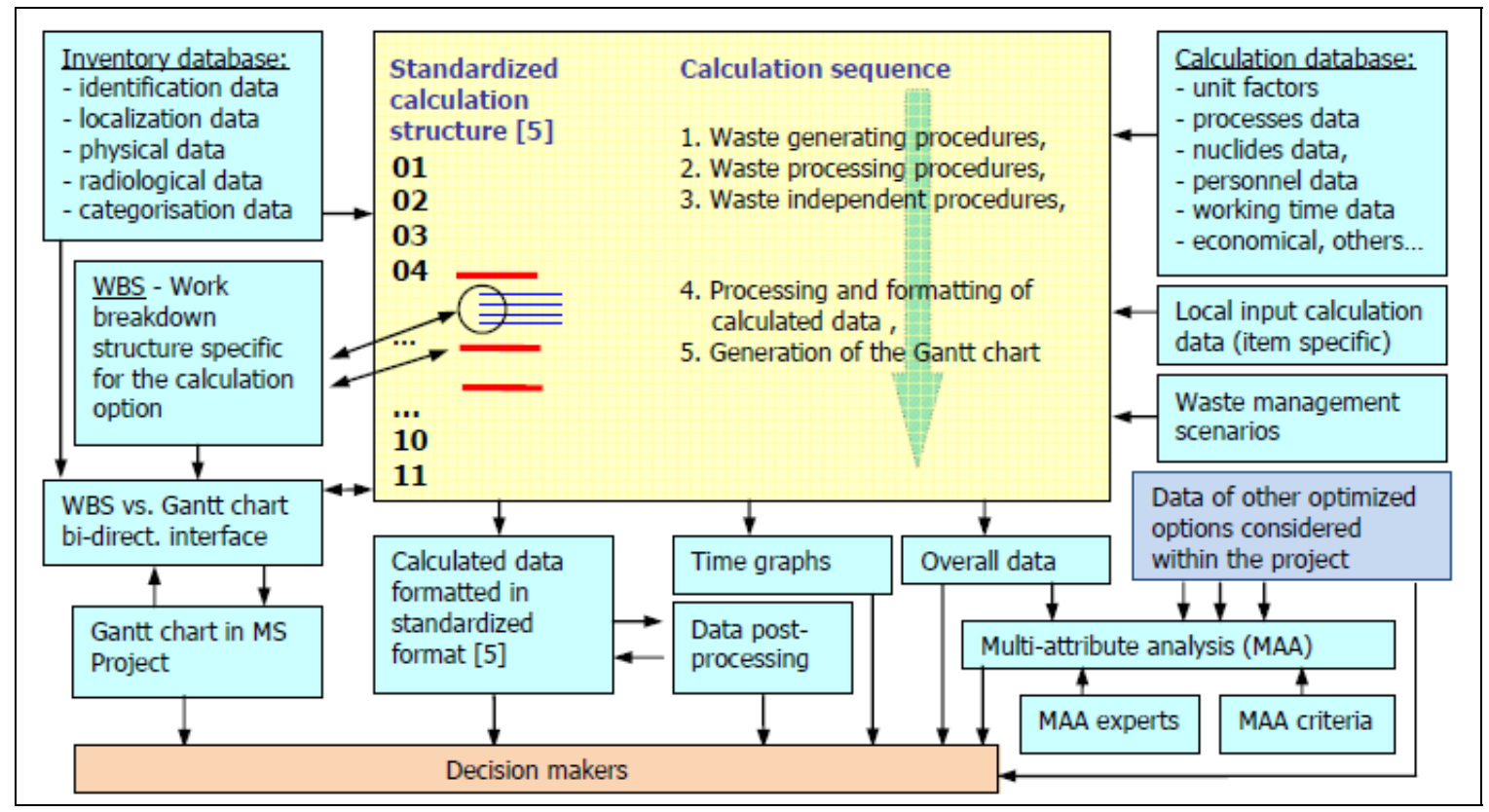

Figure 36: Principal scheme of the decommissioning calculation code OMEGA ${ }^{359}$

${ }^{359}$ see IAEA (2008), p. 221 


\title{
APPENDIX 8 B - GROUPS OF CALC. PARAMETERS
}

\author{
OMEGA generates following groups of calculated parameters ${ }^{360}$
}

- General decommissioning parameters: costs, manpower, exposure, duration, number of workers, material and technical media consumption items

- Material parameters: parameters of interim and output materials (weight, inner / outer surface, volume, etc.) including all interim waste forms, final waste form (overpacks), released materials, gaseous and liquid effluents

- Nuclide parameters: radioactivity of interim and output material. Items are evaluated for individual radio-nuclides linked to the material items

- Profession resolved parameters: manpower and exposure is resolved for individual professions and working groups

- Planning parameters: start, duration of defined decommissioning phases, individual decommissioning activities, Gantt chart, equipment needed for performing of individual decommissioning activities

\section{APPENDIX 8 C - BASIC GROUPS OF DATA}

Three basic groups of data used by OMEGA ${ }^{361}$

- Facility inventory databases - hierarchical database system of the nuclear facilities, buildings, floors, rooms and equipment in the rooms

- Database of calculation parameters - unit factors and other parameters of processes, working groups and professions, working time structure, radiation protection, radio-nuclides, general technical-economical parameters

- Input data specific to individual calculation items - general input data defined for each item of the calculation structure (e.g. increase factors, fixed costs items, number of working groups, shift work, etc.), calculation item specific data (e.g. duration, working group and working conditions for individual period-dependent activities)

\footnotetext{
${ }^{360}$ see IAEA (2008), p. $222 \mathrm{f}$.

${ }^{361}$ see IAEA (2008), p. $223 \mathrm{f}$.
} 


\section{APPENDIX 8 D- GENERAL PROCEDURES FOR EVALUATION OF DECOMMISSIONING PARAMETERS}

General procedure for evaluation of decommissioning parameters: ${ }^{362}$

(1) Definition of cost categories: defined as the activity-dependent costs, related to the extent of "hands-on" work like dismantling, the period-dependent costs, proportional to duration of individual activities/phases and the collateral costs and costs for special items which can neither be assigned to hands-on work activity nor to period-dependent activity.

(2) Identification of decommissioning activities and inventories: identification of discrete elementary activities for which unit factors are defined and completion of the list of activities within a facility buildings/equipment inventory in order to define the overall extent of activities.

(3) Definition of unit factors: unit factors are defined in accordance to the details of the items considered in the plant inventory and in the decommissioning activities listing. Unit factors are defined for ideal working conditions and correction factors are defined that reflect the specific working conditions (radiation, working height, etc.).

(4) Project scheduling and staff requirements: project time schedule is constructed based on calculated duration of individual hands-on work phases and based on the plant inventory data. This is the base for identification of the critical path for decommissioning activities. Calculated duration of decommissioning activities / phases is used as a basis for definition of duration of period-dependent activities for which the staff is defined.

(5) Definition of collateral costs and costs for special items: Definition of fixed costs like cost for heavy equipment for site support, health physics equipment and supplies, licenses and permits, costs for lighting, heating, cooling, income from sold equipment or scrap, etc.

(6) Total costs definition: Total cost estimates are obtained as a sum of the costs for three categories: activity-dependent costs, period-dependent costs, collateral costs. The cost estimates may be adjusted to include a contingency that reflects the level of uncertainty in the estimates. A separate contingency expressed in some special cost items may be applied to the total cost estimate for the processes with high uncertainty.

${ }^{362}$ see IAEA (2008), p. 224f. 


\section{APPENDIX 8 E - PRINCIPLE OF FLOW CONTROL (MATERIAL\&RADIOACTIVITY)}

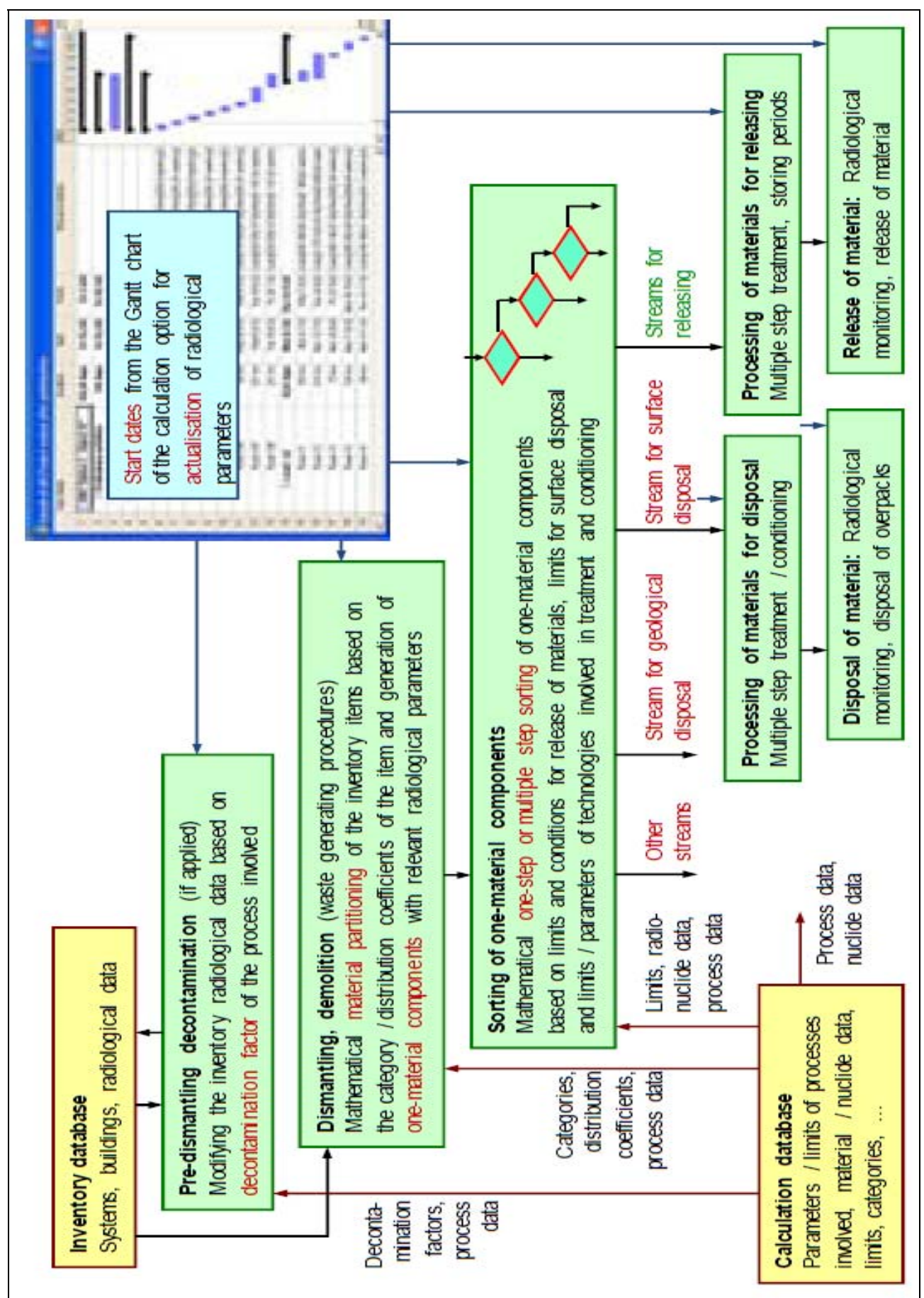

Figure 37: $\quad$ Principle of the material and radioactivity flow control as implemented in OMEGA code ${ }^{363}$

${ }^{363}$ see IAEA (2008), p. 227 


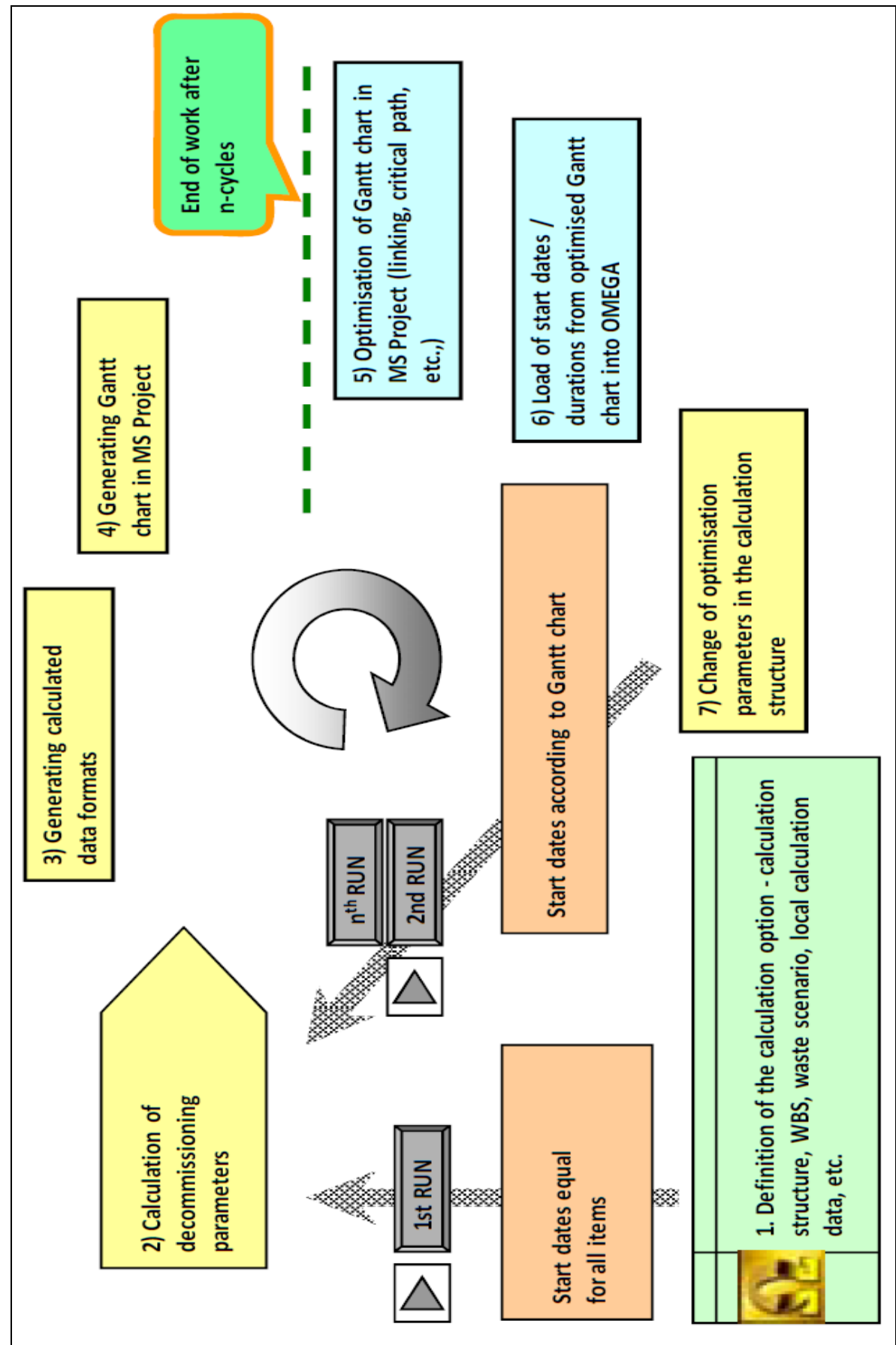

Figure 38: Graphical interpretation of main steps of the interactive work with OMEGA code ${ }^{364}$

${ }^{364}$ see IAEA (2008), p. 229 


\section{APPENDIX 8 G-PROCEDURE FOR OPTIMIZATION (GANTT CHART)}

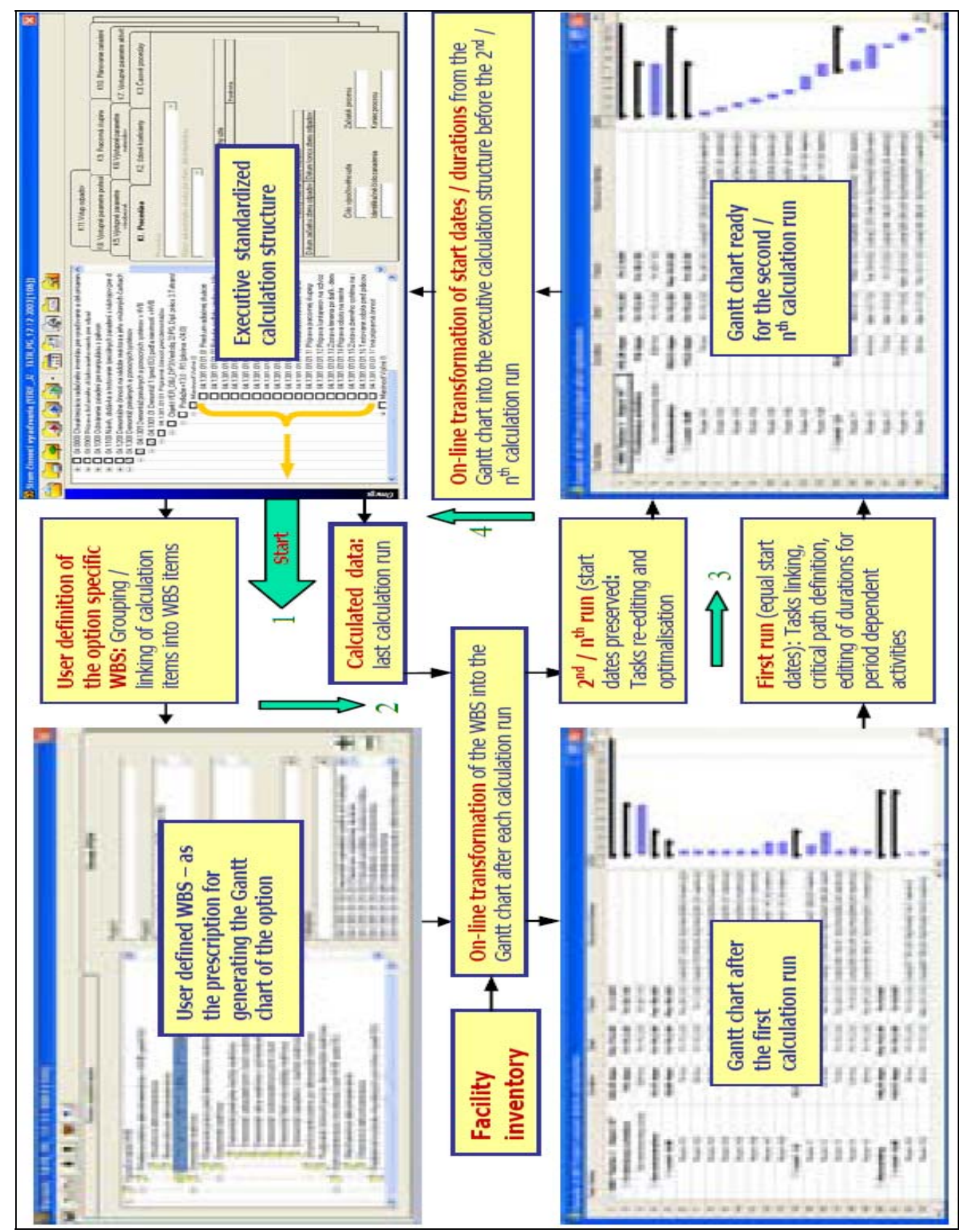

Figure 39: $\quad$ Procedure for the optimization of decommissioning options using a Gantt chart ${ }^{365}$

${ }^{365}$ see IAEA (2008), p. 228 
APPENDIX 8 H- PRINCIPLES SCHEME OF WASTE MANAGEMENT

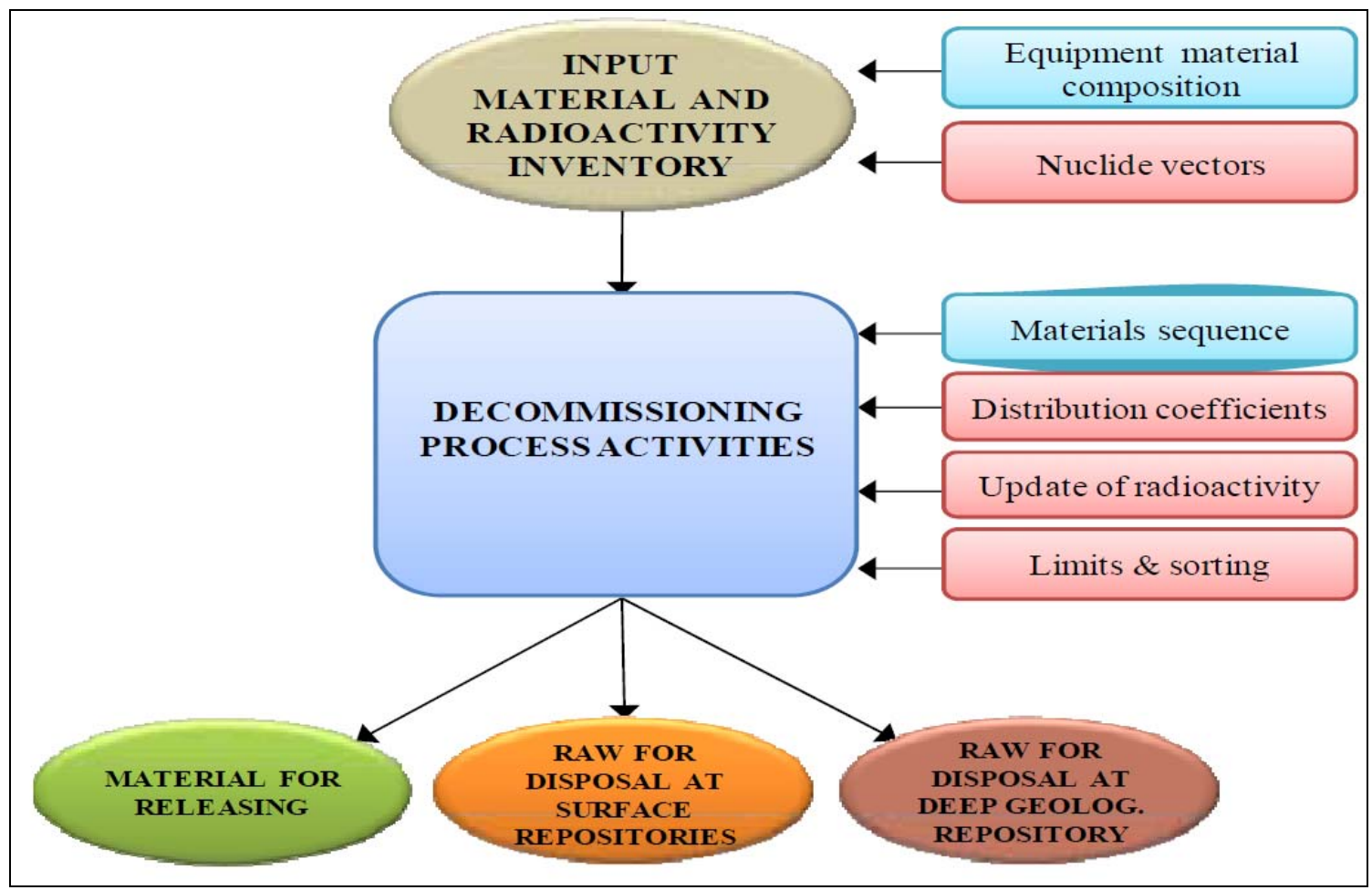

Figure 40: Principle scheme of the waste management in the OMEGA code $\mathrm{e}^{366}$

${ }^{366}$ see IAEA (2008), p. 243 


\section{APPENDIX 8 I - WASTE TYPES}

Waste-Types in $\mathrm{OMEGA}^{367}$ :

- Metal waste from dismantling - stainless / carbon steel, colour metals, electrical cables

- Non-metallic wastes from dismantling - thermal insulation materials, combustible waste, compactable waste

- Special materials (graphite)

- Waste from decontamination / dismantling of building structures

- Liquid waste from wet decontamination processes, from waste treatment, sanitary systems

- Special interim products of waste treatment

- Protective clothing and other personal protection elements

- Contaminated soils

- Non-contaminated materials from dismantling outside of the controlled area and from demolition

${ }^{367}$ see IAEA (2008), p. $243 \mathrm{f}$ 


\section{APPENDIX 8 J - REVIEW SCHEME OF WASTE MANAGEMENT}

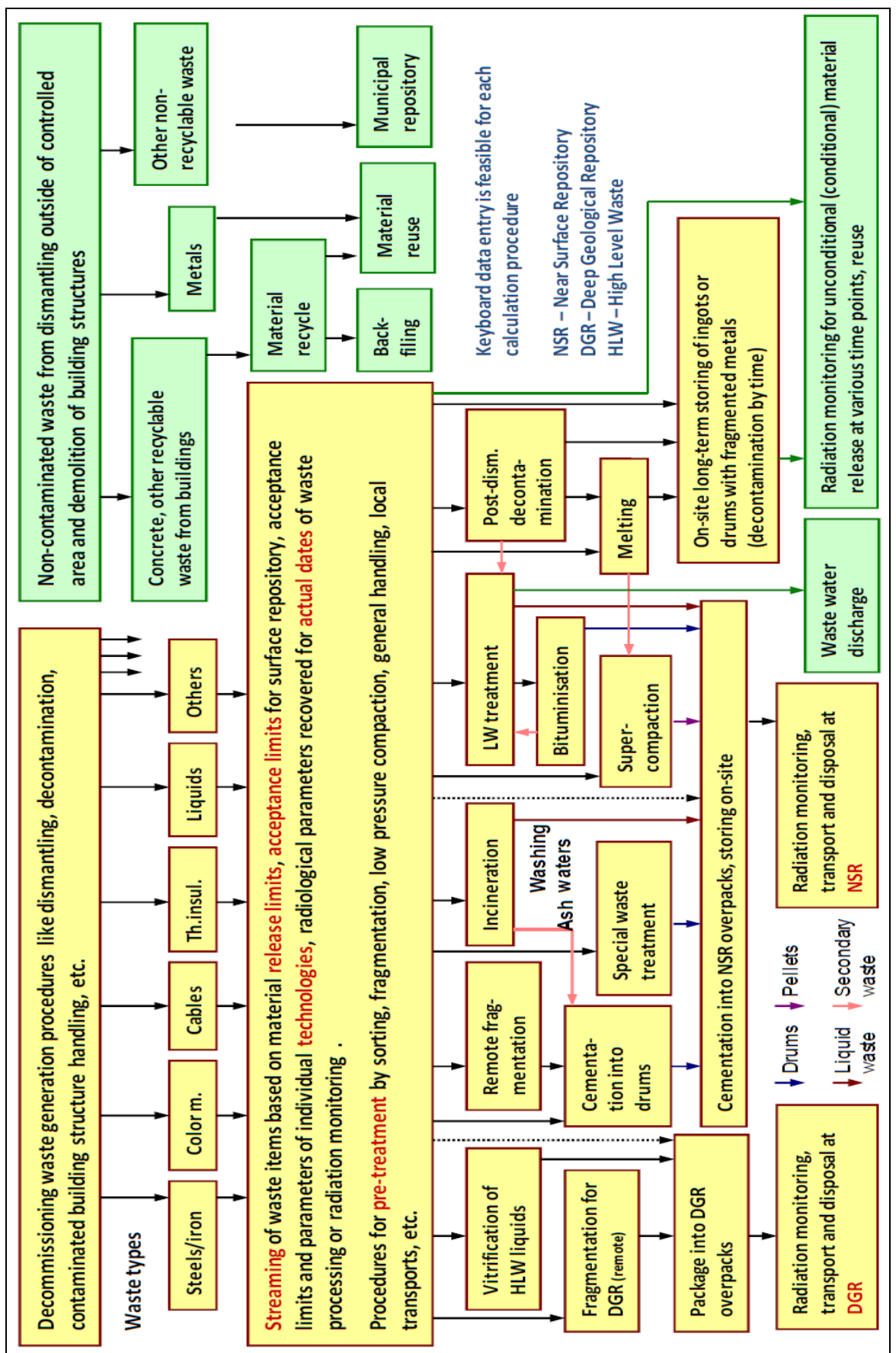

Figure 41: Review scheme of waste management in the OMEGA code ${ }^{368}$

${ }^{368}$ see IAEA (2008), p. 245 


\section{APPENDIX 9- LIST OF USED FILES}

In the following table all generated files in the workflow of the dissertation are listed:

Table 17: List of used files in the Dissertation

\begin{tabular}{|l|l|l|}
\hline Name of file & $\begin{array}{l}\text { Used in application } \\
\text { and/or function }\end{array}$ & $\begin{array}{l}\text { Reason of } \\
\text { usage }\end{array}$ \\
\hline Ausgabe24.txt.pdf & $\begin{array}{l}\text { moop_final_R_code.r } \\
\text { / RStudio }\end{array}$ & Output File \\
\hline Jones_et_al_1998 & MOOP & Model Building \\
\hline col37.csv & $\begin{array}{l}\text { TuneParetoForMOO } \\
\text { P.r }\end{array}$ & $\begin{array}{l}\text { Virtual Table } \\
\text { Data }\end{array}$ \\
\hline col80.csv & moop_final_R_code.r & $\begin{array}{l}\text { Virtual Table } \\
\text { Data }\end{array}$ \\
\hline constraint_npp.m & Matlab & Constraint \\
\hline Invoke_constrained_optimization_routine.m & Matlab & $\begin{array}{l}\text { Invocation of } \\
\text { opt. routine }\end{array}$ \\
\hline min_npp_func.m & Matlab & $\begin{array}{l}\text { Minimization } \\
\text { function }\end{array}$ \\
\hline min_npp_func.asv & Matlab (Autosave & $\begin{array}{l}\text { Minimization } \\
\text { function }\end{array}$ \\
\hline moop_final_R_code.r & File) & MOOP routine \\
\hline NPP_plan12.mpp & MSProject & $\begin{array}{l}\text { Project } \\
\text { Schedule }\end{array}$ \\
\hline OMEGA_IAEA_2008_Daniska_et_al.pdf & OMEGA IAEA & Model Building \\
\hline tettsr.amb & AIMMS & Project File \\
\hline TuneParetoForMOOP.r & RStudio & $\begin{array}{l}\text { Demonstration } \\
\text { of Pareto- } \\
\text { Optimum }\end{array}$ \\
\hline & & \\
\hline
\end{tabular}




\section{APPENDIX 10 - NOTATION}

\begin{tabular}{|c|c|}
\hline $\mathrm{A}_{\mathrm{ij}}$ & constant terms for numerical estimates \\
\hline$A_{\text {LLW }}$ & constant term for Low-Level-Waste \\
\hline $\mathrm{A}_{\mathrm{MLLW}}$, state, activity & constant term for mixed Low-Level-Waste \\
\hline $\mathrm{A}_{\mathrm{TRU}}$, state, activity & constant term for Transuranic-Waste \\
\hline $\mathrm{B}_{\mathrm{t}}$ & budget constraint in each period D disposal \\
\hline $\mathrm{C}_{\mathrm{ijat}}$ & $\begin{array}{l}\text { the costs of storage, disposal and treatment for type } \mathrm{i} \text {, in a } \\
\text { particular state, in time } \mathrm{t}\end{array}$ \\
\hline $\mathrm{D}_{\mathrm{it}}$ & $\begin{array}{l}\text { number of units } \mathrm{k} \text { devoted to the volume of waste disposal } \\
\text { for type } \mathrm{i} \text {, in time } \mathrm{t}\end{array}$ \\
\hline $\mathrm{d}_{\mathrm{b}}$ & bounding value \\
\hline$E(y)=\beta_{0}+\beta_{1} x_{1}+\ldots+\beta_{n} x_{n}$ & form of the regression metamodel \\
\hline$f_{1}(X)$ & total project cost \\
\hline $\mathrm{f}_{2}(\mathrm{X})$ & safety hazard (risk) \\
\hline$f_{3}(X)$ & project duration \\
\hline $\mathrm{i}$ & waste type \\
\hline $\mathrm{k}_{\mathrm{itS}}$ & $\begin{array}{l}\text { amount of input } \mathrm{k} \text { required to store a volume of waste for } \\
\text { type } \mathrm{i} \text {, stored in time } \mathrm{t}\end{array}$ \\
\hline j & particular state $\mathrm{R}_{\mathrm{itD}}$ risk of treated waste kept in disposal \\
\hline $\mathrm{R}_{\mathrm{itS}}$ & risk per unit of waste for type $I$, stored in time $t$ \\
\hline $\mathrm{R}_{\mathrm{itT}}$ & risk of putting a part of the stored waste through treatment \\
\hline$S$ & reorder point \\
\hline$S$ & maximum inventory level \\
\hline S & storage \\
\hline $\mathrm{S}_{\mathrm{i} 0}$ & the setting for the volume of waste of each type of storage \\
\hline $\mathrm{S}_{\mathrm{it}}$ & volume of waste for type $\mathrm{i}$, stored in time $\mathrm{t}$ \\
\hline $\mathrm{T}$ & treatment \\
\hline $\mathrm{t}$ & time \\
\hline $\mathrm{T}_{\mathrm{it}}$ & quantity of treatment for type $\mathrm{i}$, in time $\mathrm{t}$ \\
\hline $\mathrm{V}$ & volume \\
\hline$X$ & set of $n$ Treatments $t$ \\
\hline
\end{tabular}




$\begin{array}{ll}Z(x) & \text { a covariance-stationary process } \\ \alpha & \text { state Activity } \\ \beta & \text { state Activity } \\ \beta & \text { any constant } \\ \lambda & \text { coefficient values used to show maximum risk level } \\ & \text { allowed in each state }\end{array}$




\section{APPENDIX 11 - LIST OF ABBREVIATIONS}

AIMMS

ANCOVA

ANOVA

ASME

ASOR

BFGS

BFS

BSD

BWR

CALM

CAMC

CMT

CRDM

CRP

DeSa

DOE

EC

EDM

EIA

EIT
Advanced Interactive Multidimensional Modeling System

Analysis of Covariance

Analysis of Variance

American Society of Mechanical Engineers

Australian Society for Operations Research

Broyden-Fletcher-Goldfarb-Shanno

Bundesamt für Strahlenschutz

Berkeley Software Distribution

Boiling water reactor

Computer-Aided Lean Management

Contact Arc Metal Cutting

Metallic Transport Container

Control Rod Drive Mechanism

Coordinated Research Project

Demonstration of Safety for Decommissioning of Facilities

Using Radioactive Material

US Department of Energy

European Community

Electrical Discharge Machining

Environmental Impact Assessment

European Institute of Innovation and Technology 


$\begin{array}{ll}\text { EMOO } & \text { Evolutionary Multiobjective Optimization } \\ \text { EPZ } & \text { Emergency Planning Zone } \\ \text { ESA } & \text { European Space Agency } \\ \text { EU } & \text { European Union } \\ \text { EURATOM } & \text { European Atomic Energy Community } \\ \text { GAO } & \text { General Account Office } \\ \text { GNU } & \text { "Gnu-is-not-UNIX" } \\ \text { IAEA } & \text { International Atomic Energy Agency } \\ \text { IEA } & \text { International Energy Agency } \\ \text { IFRS } & \text { International Financial Reporting Standards } \\ \text { IT } & \text { Information Technology } \\ \text { JIT } & \text { Just-in-time } \\ \text { LCI } & \text { Lower core internals } \\ \text { LEAN SCM System } & \text { Lean Supply Management System } \\ \text { LLW } & \text { Now-Level-Waste } \\ \text { NDA } & \text { Muclear Decommissioning Authority } \\ \text { MOLW } & \text { Multiobjective Combinatorial Optimization } \\ \text { MOEO } & \text { Multiobjective Evolutionary Algorithms } \\ \text { MOOP } & \text { Multiple-objective-optimization-problem } \\ \text { MOPective Optimization Problems }\end{array}$




\begin{tabular}{|c|c|}
\hline NEA & Nuclear Energy Agency \\
\hline NPD & New Product Development \\
\hline NPP & Nuclear power plant \\
\hline $\mathrm{NRC}$ & Nuclear Regulatory Commission \\
\hline OECD & Organization of Economic Co-operation and Development \\
\hline OR & Operations research \\
\hline PR & Public Relation \\
\hline PSL & Proposed Standard List \\
\hline PWR & Pressurized water reactor \\
\hline SCM & Supply Chain Management \\
\hline SFP & Spent fuel pools \\
\hline SOOP & Single-objective-optimization-problem \\
\hline SPSS & Statistical Package for the Social Sciences \\
\hline TRU & Transuranic-Waste \\
\hline UCI & Upper core internals \\
\hline UKAEA & United Kingdom Atomic Energy Authority \\
\hline UML & Unified Modeling Language \\
\hline US NRC & US Nuclear Regulatory Commission TMI \\
\hline VAK & Versuchsatomkraftwerk \\
\hline VDEW & Verband der Elektrizitätswirtschaft (VDEW) \\
\hline WASS & Water Abrasive Suspension Cutting \\
\hline WBS & Work Breakdown Structure \\
\hline
\end{tabular}


WPS

WWII

ZIRP
Water purification system

World War II

Zorita Internals Retrieval Project 


\title{
CURRICULUM VITAE
}

\author{
NAME \\ Sven Sudholt \\ ADDRESS \\ Grasserstrasse 12, 80339 Munich (Germany) \\ DOB \\ April 13, 1974, Rheda-Wiedenbrück (Germany) \\ EDUCATION University of Applied Sciences Oldenburg (1998 - 2002), full time \\ Dipl.-Ing. (FH) in Civil Engineering (Construction Mgt.) \\ University of Weimar (2003 - 2005), part time \\ MSc. in Civil Engineering (Water \& Environment) \\ University of Louisville (UofL) (2009 - 2010), part time \\ MEng. in Industrial Engineering (Engineering Mgt.) \\ University of Louisville (UofL) (since 2009), part time \\ German PhD Program in Industrial Engineering \\ CAREER \\ Project Engineer METRORAPID (Magnetic Levitation System), \\ BPI-Consult (2002 - 2003) \\ Construction Manager (Civil Engineering), \\ Schnittker Tiefbau Ltd. (2004 - 2005) \\ Project Manager (Airport Logistics - India and Railway Systems - \\ Qatar), Siemens AG (2006 - 2011) \\ Project Manager (Dismantling \& Decommissioning of Reactor \\ Internals), AREVA NP \& Siemens AG (2008 - 2009) \\ Project Manager (Maintenance \& Operations, Railway Systems), \\ Siemens AG (since 2012)
}

